\title{
ARCHITECTURE AS RESPIRATORY SYSTEMS
}

\author{
by \\ Kevin Pu \\ Bachelor of Architectural Science, Ryerson Univerisity, 2013 \\ A design thesis project \\ presented to Ryerson Univeristy \\ in partial fulfillment of the \\ requirements of the degree of \\ Master of Architecture \\ in the Program of \\ The Department of Architectural Science \\ Toronto, Ontario, Canada, 2015 \\ (C) Kevin Pu, 2015
}




\section{Author's Declaration}

I hereby declare that I am the sole author of this thesis. This is a true copy of the thesis, including any required final revisions, as accepted by my examiners.

I authorize Ryerson University to lend this thesis project to other institutions or individuals for the purpose of scholarly research.

I further authorize Ryerson University to reproduce this thesis project by photocopying or by other means, in total or in part, at the request of other institutions or individuals for the purpose of scholarly research.

I understand that my thesis may be made electronically available to the public.

Kevin Pu 


\section{Architecture as Respiratory Systems}

Kevin Pu | B.Arch.Sci 2013

Ryerson University

Master of Architecture 2015

\section{Abstract}

As a hermetic divide between exterior and interior atmospheres, architecture has been sealing itself off from fluctuating environments through its reliance on artificial breathing. The ability to induce and simulate a breathable environment allows architecture to be detached from nature as a separate entity. This condition needs to be re-conceptualized in order to address the over-reliance on mechanical systems through a study of biological respiratory systems. Therefore, the urban environment must evolve, challenging the divisive barrier of buildings to transform cities into an urban respiratory system, capable of purifying the atmosphere at both micro and macro levels. Urban sustainability therefore needs to challenge the static seal of buildings and learn to breathe from nature in order to become active urban respiratory systems, capable of purifying the atmosphere and contributing positively back into the urban fabric. 


\section{Acknowledgements}

I would like to express my sincerest gratitude to Mark Gorgolewski for his wisdom, knowledge, and support throughout the course of my thesis. Mark has played a critical role as my supervisor in pushing my thesis beyond what I had imagined and it would not have been possible without his knowledge and passion for the subject. His expertise in sustainability and building science informed my approach to integrating respiration with architecture through the lens of urban sustainability.

I would also like to thank Colin Ripley, my second reader, for encouraging me to design out of my comfort zone and keeping me on track with what a thesis ought to be. Your insight and approach to a thesis helped me tremendously with conveying my ideas and concepts in presentations.

In addition, I would also like to thank Vincent Hui for his guidance and wisdom in supporting me as an architectural designer. Thank you for believing in me and giving me opportunities throughout my studies that have equipped me with a variety of skills that have been proven useful in the development of my career. Whether it was working for you as your research assistant or learning from you as your student, you have always gone above and beyond your role to push me to achieve success. Thank you for being a great mentor and for everything that you have taught me.

Lastly, I would like to thank my family, friends, and colleagues for your continual support over these past two years. Thank you for all your prayers, input, comments, and encouragements during the times that I needed it the most. A special thanks to my mentor, Chris, for your honesty, constructive criticisms, and encouragement that have inspired me to become the hard worker that I am today. 
to the glory of God, my family, and friends 


\section{Table of Contents}

i. Author's Declaration iii

ii. Abstract $\quad v$

iii. Acknowledgements vii

iv. Dedication

v. Table of Contents xi

1.0 Introduction 1

2.0 Respiration as a Discourse in Architecture 5

$\begin{array}{lll}2.1 & \text { Air } & 8 \\ 2.2 & \text { Case Studies } & 8\end{array}$

$\begin{array}{lll}3.0 & \text { How to Breathe } & 14\end{array}$

3.1 Definitions 18

3.2 Respiration 20

4.0 The Four Parameters of Respiration 26

4.1 Breathe 27

4.2 Flow 28

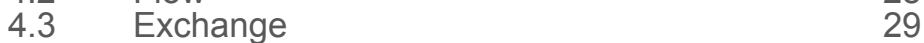

4.4 Control 31

5.0 How the City Breathes $\quad 35$

5.1 How Buildings Breathe 38

5.2 How Vehicles Breathe 43

5.3 Where to Breathe 45

5.4 Anti-Respiration 51

6.0. Learning from Nature 56

6.1 Tree 58

$\begin{array}{lll}6.2 \text { Fly } & 68\end{array}$

$\begin{array}{lll}6.3 & \text { Termite Mound } & 74\end{array}$

7.0 Driven by Respiration 83

7.1 Regenerative Architecture 94

8.0 Designing for Respiration

8.1 Responding to Users 97

8.2 Responding to Program 103

$\begin{array}{lll}9.0 & \text { The Urban Respiratory System } & 112\end{array}$

9.1 Urban Arteries 113

9.2 Extreme Urban Conditions: Toronto 115

9.3 Aspiro 118

$\begin{array}{lll}10.0 & \text { Lessons Learned } & 135\end{array}$

$\begin{array}{lll}10.1 & \text { Conclusion } & 139\end{array}$

List of Figures 141

Bibliography/References $\quad 151$

Appendix 


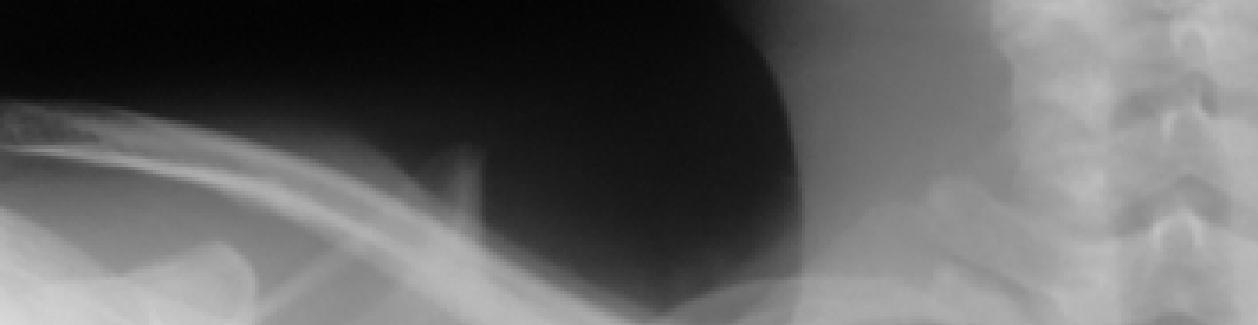




\subsection{Introduction}

As the world's population continues to increase, the idea of the home as a "machine for living" comes into conflict with the demand for adequate shelter. ${ }^{1}$ The desire (fueled by capitalism) for a private, independently owned, enclosed space leads to the commercialization of buildings and architecture. As a result, the urban fabric continues to grow at an unsustainable rate, causing significant climate change through increasing emissions of pollutants. The capitalist mentality has driven society to occupy and consume more. During the industrial revolution, the wealthy would move away from city centers in what would begin as the start to the gradual evolution of air as a commodity. Having access to clean air equated to wealth and status, whereas it should be free and accessible to all. Nancy Diniz and Benedict Anderson put it this way:

"Nevertheless, pollution from commodity production and mass consumption has made air more visible, and anything that is visible is commodified. Air is capital, and emissions can be profitable. The future of air lies not in its ability to be further capitalized but relies instead on the equalizing of labor and profits. To recapitalize air is to retrieve its purity."

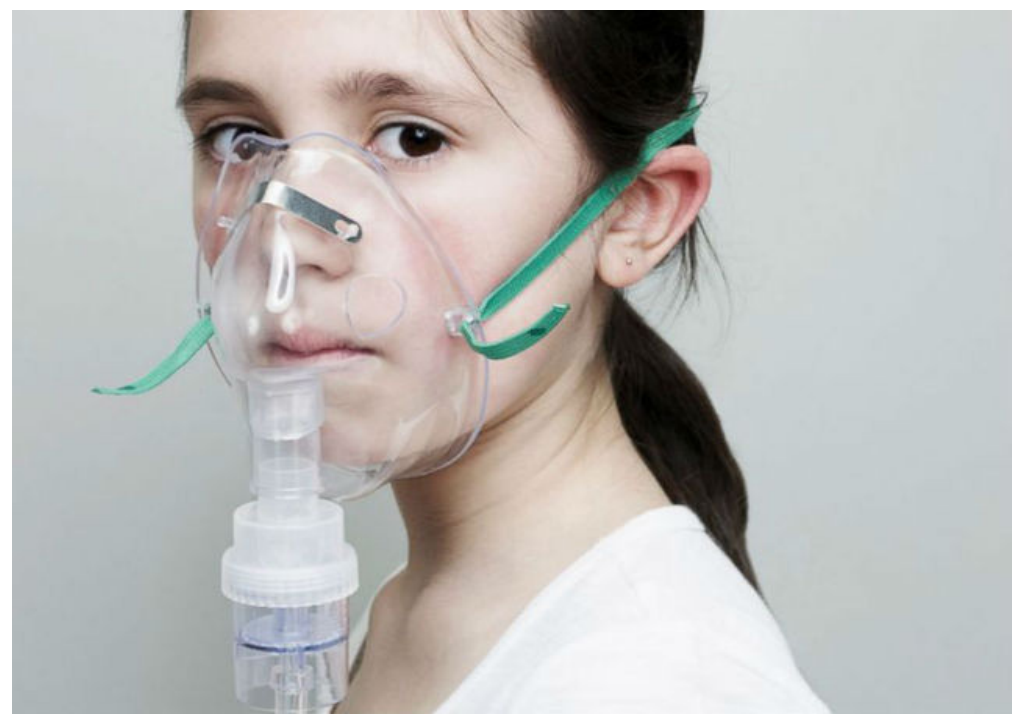

Fig 1.2 Child with assistive breathing apparatus 
On the contrary, some developing countries may actually have more access to a higher quality of air. This proves the disarray that architecture as hermetic seals has caused. The response of hermetically sealed architecture to poor atmospheric conditions has disjointed the notion of environment into separate entities. This differentiation divorces the breather from its natural environment into one that is artificially controlled. Architecture, as controlled interior environments, provided a temporary fix to the worsening conditions of the exterior air. Unbreathable architecture, as separate controlled entities, directly pollutes the precious air that is needed to sustain life. Francesco Manacorda in his short essay, There is no such thing as nature, points out that "other practitioners demonstrate that even the most artificial built environment is part of the natural world; nature, in fact, does not exist as a separate entity: we are always inside an environment with a group of other interdependent living organisms." 3 Francesco realizes that the divide in environment ceases to exist if we view architecture as a part of the natural world and by extension, the breather as a part of the architecture. So, how can we design architecture without creating both a metaphorical and literal divide in environments?

All living organisms need oxygen through breathing in order to live, but not all organisms breathe in the same way. In fact, each respiratory system has distinguishing features that set it apart from the rest. As humans, we are only familiar with our own, which often takes place in the background, without us being conscious of it during the routines of our daily lives. Despite the importance of respiration, we know little about the mechanics of breathing.

Thus, historically, many modern architects dismissed the element of breathing as it was best left to be accounted for by mechanical engineers. This approach resulted in turning architecture into the machines that Le Corbusier spoke about, reducing the breather's exposure to nature down to an artificial environment. To respond architecturally to this issue, principles need to be drawn from different respiratory systems in order to better understand how architecture could be a unified system, capable of breathing.

\section{Endnotes}

${ }^{1}$ Mohen Mostafavi, David Leatherbarrow. On Weathering: The Life of Buildings in Time. (Cambridge. The MIT Press, 1993). 16.

${ }^{2}$ Nancy Diniz and Benedict Anderson. Unconventional Computing. Wearing your air: an architecture for unstable environments. (Cambridge: ACADIA and Riverside Architectural Press, 2013). 174.

${ }^{3}$ Francesco Manacorda. There is no such thing as nature. Radical Nature. (London: Koenig Books Ltd, 2009). 15. 


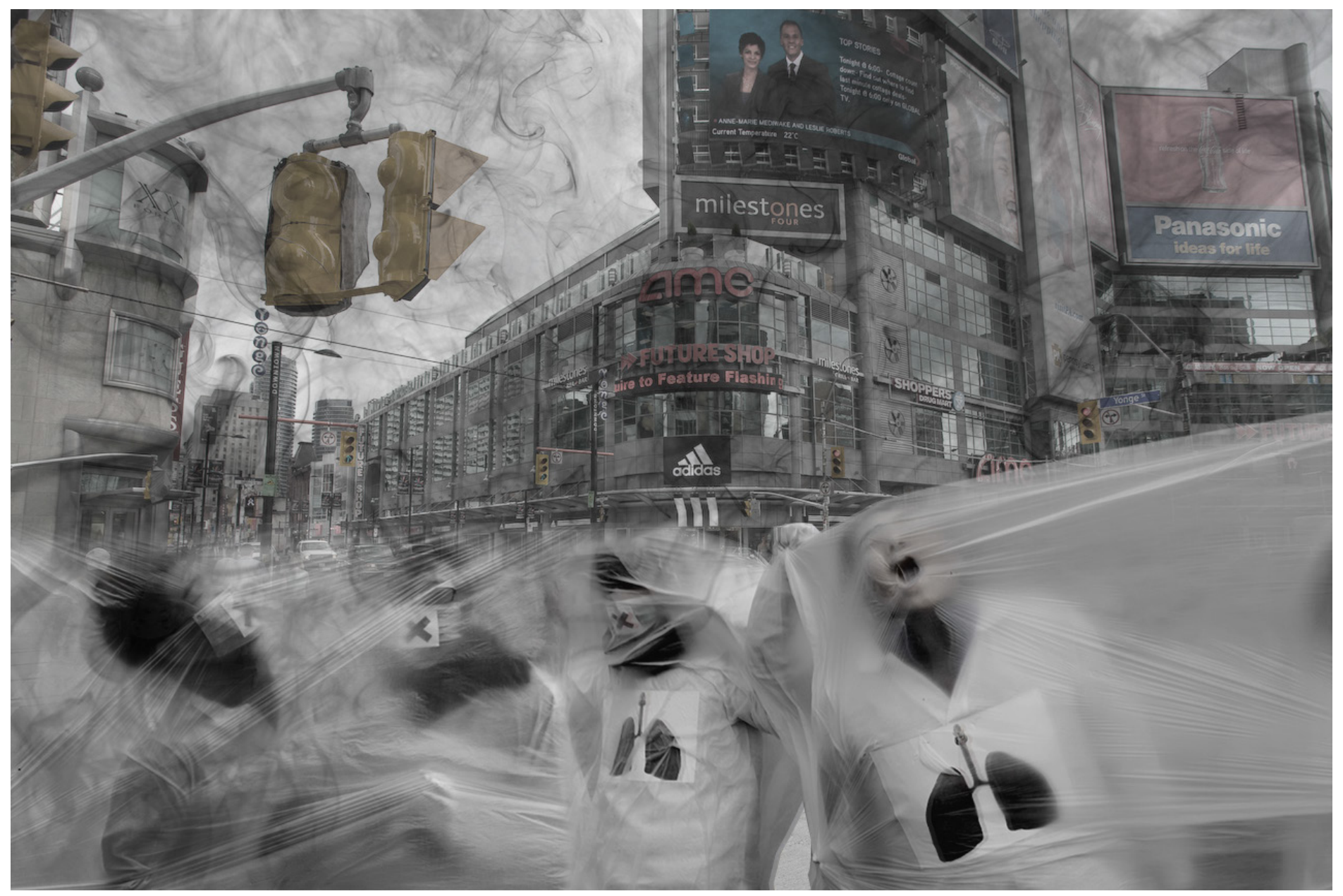

Fig 1.3 Collage of suffocating breathers in Toronto

\section{Image References}

${ }^{1} \mathrm{https}$ ://theaiexpedition.files.wordpress.com/2013/04/chestxray. jpg

2 http://www.dreamcatchersforabusedchildren.com/wpcontent/uploads/2014/09/GTY_girl_wearing_oxygen_mask_ jt_140907_16x9_992.jpg

${ }^{3}$ https://egocentrista.files.wordpress.com/2013/12/ bhjevcxcaaa1ohj.jpg

http://i.huffpost.com/gen/1914147/images/n-CHINAPERFORMANCE-ART-POLLUTION-large570.jpg

http://i1.trekearth.com/photos/85209/dundas_square_toronto.jpg 


\subsection{Respiration as a Discourse in Architecture}

While breathing is common to man, the idea of respiration is convoluted as it involves the process of how breathing is carried out. As a natural passive behavior, we pay little to no attention to the way we breathe. At times, it may even feel weird when you are told to focus on your breathing during medical examinations. It simply is not something that people notice until it is too late. Over the course of the past decade, global cities experienced an increasing amount of respiratory health cases (i.e., asthma, bronchitis, lung cancer) to which, in 2012, 7 million premature deaths were linked to air pollution in cities. ${ }^{1}$ Although there are a vast amount of non-profit organizations and pro-sustainability initiatives (ex. W.H.O) working to tackle the issue of air pollution, it seems menial compared to the consumption and demands of the average urban city dweller. The way we build, the things we eat, our methods of transportation, and the materials we waste are all contributing to the deterioration of the earth's atmosphere. Rainforests and thousands upon thousands of trees are being taken down to make way for urban developments. The consequence is a planet that is becoming more and more toxic, creating an unbreathable environment. Although architecture is not the root of the problem, reports show that the building sector is the largest contributor to carbon dioxide emissions in North America. ${ }^{2}$ This opens up opportunities in architecture to be a positive change towards the rapidly changing environment. Taking respiration as a discourse in architecture, it gives architects a refreshed lens to deal with the worsening state of the planet's atmosphere. According to Sean Lally:

\footnotetext{
"Today, in a time of climate change and environmental degradation, the public is faced with moralistic calls for sacrifice, but the resulting betterment of the world can seem imperceptible: individuals are rarely at a vantage point to witness the benefits of a carbon-neutral lifestyle or the safety of a protected species in its habitat." ${ }^{3}$
}

This approach removes the focus away from air quality and focuses on the necessities of the breather himself that can allow architecture to better address the issues that it is currently facing. 


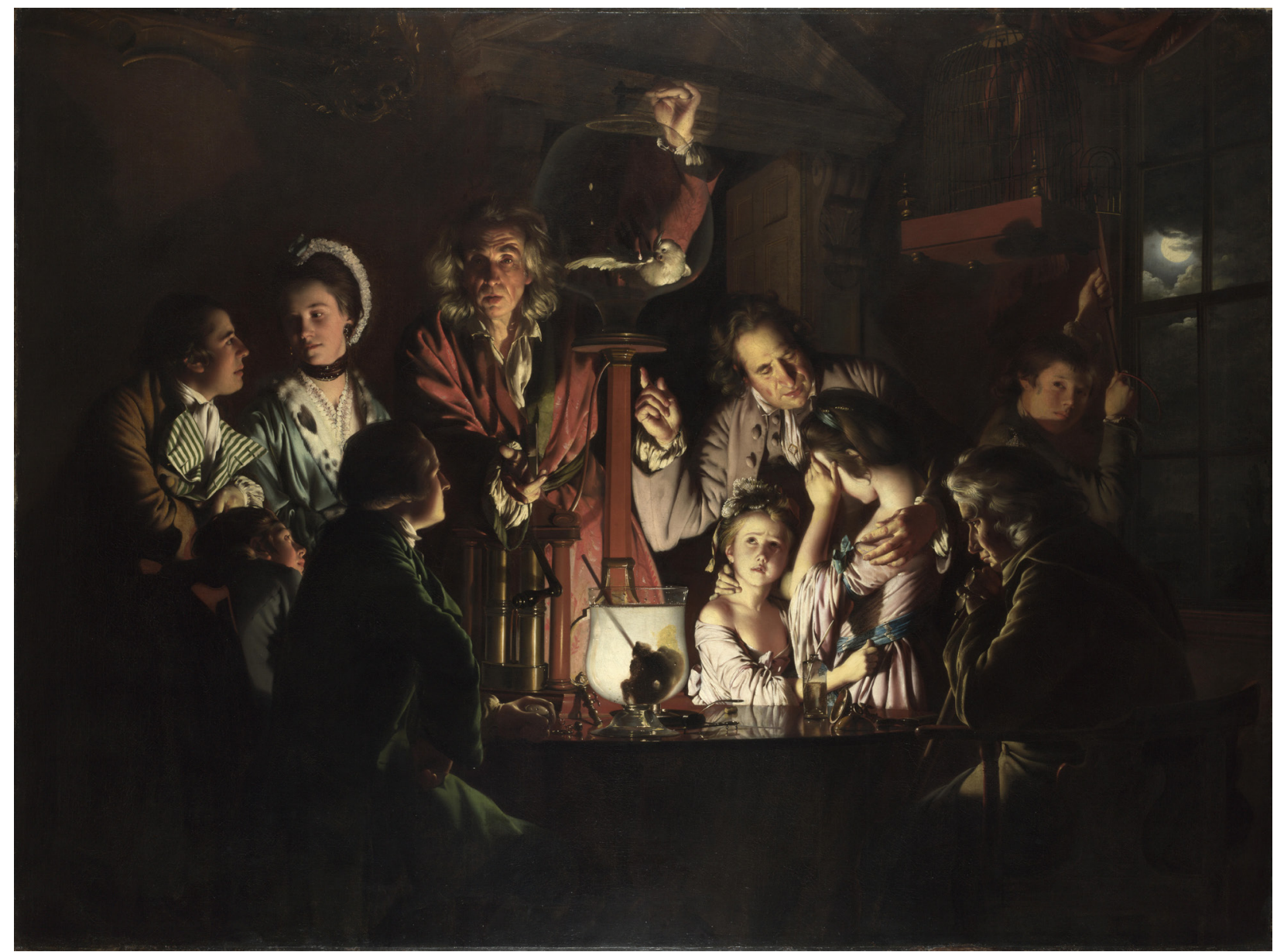

Fig 2.2 An Experiment on a Bird in an Air Pump (1768) Joseph Wright Derby. Oil on Canvas

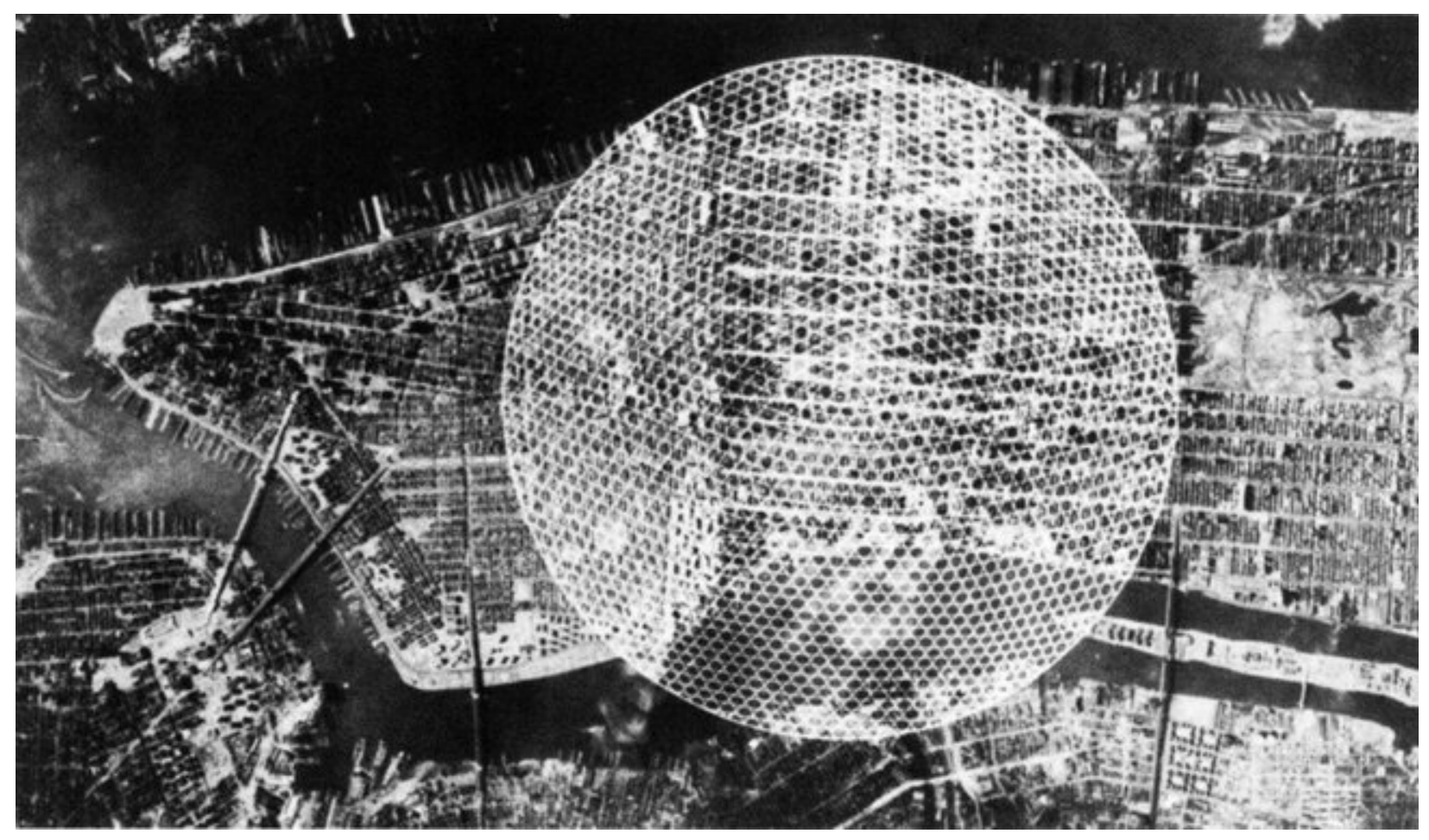

Fig 2.3 Dome over Manhattan (1960) Richard Buckminster Fuller. Plan 


\subsection{Air}

Air as a discource was not always a prominent factor in architecture until after World War I when gas attacks were first used to manipulate air as a lethal weapon, bringing immediate attention to the invisible. "The 'pestilent disease mist', as Gavin labeled the cloud of gas, reinforced existing relations between poverty and environmental degradation." ${ }^{\text {Th }}$ The degradation of air quality drew growing attention amongst designers to try to address the issue. Prior to the 1900's, artists have already been fascinated with the characteristics of air, albeit invisible. In Joseph Wright Derby's painting, An Experiment on a Bird in the Air Pump, reveals people's fear of what can be done with air. The painting depicts Boyle's ability to make birds suffocate inside his invented air pump by removing oxygen. The reaction of the children reveals the realization of air becoming a relevant proponent of life's essential even though they themselves did not suffocate. However, much of the issue was ignored as only lower social classes living in polluted cities would have to face the realities of air. But the history of World War I made air public, as people around the world witnessed the fatal effects of gas as a military weapon. Following the war, "a whole science of atmospheric manipulation had been declared."

\subsection{Case Studies}

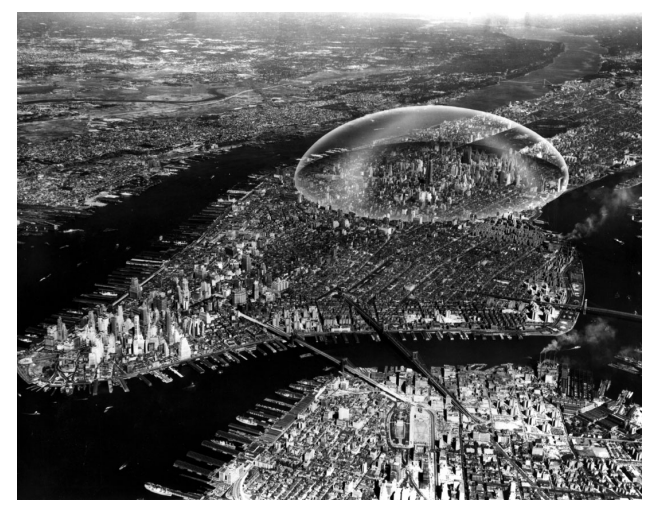

Fig 2.4 Dome over Manhattan (1960) Richard Buckminster Fuller. Aerial View
By the twentieth century, air quality became an increasingly critical issue as industrial factories continuously pumped out toxins into the atmospheres of urban cities. Ironically, German factories simultaneously initiated manufacturing gases concentrated with chemicals equipped to kill, a combined double negative with the factory's waste in process. "If the manufacture of coal gas produced horrific working conditions, the manufacture of known lethal gases lent industrialization a new inhumanity." ${ }^{\prime 6}$ Later in 1962, Rachel Carson in her book Silent Spring highlighted the effects of DDT (dichlorodiphenyltrichloroethane) toxicity in the air that was inadvertently harming the natural environment. As a biologist, Carson cataloged the environmental impacts of careless DDT spraying without understanding the lethal effects that it has on the natural environment. Her research initiated a global concern with modern chemical pollution and directed people's attention to the brittle nature of air and humanity. This renewed concern for air quality control and the ability to manipulate air inspired designers to attempt to redefine the relationship between humans and air. The success in controlling 


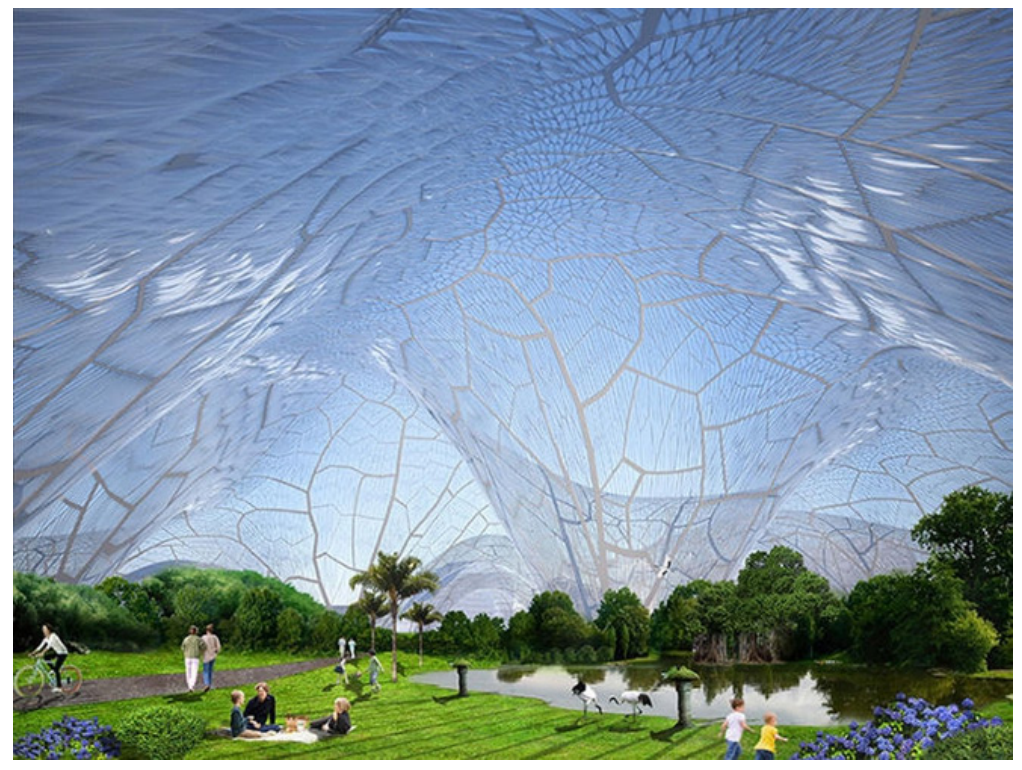

Fig 2.5 Bubbles (1960) Orproject. Interior Rendering

air equated to control over an essential element that was slowly being commodified. In 1960, Richard Buckminster Fuller proposed placing a giant geodesic dome over Manhattan in an attempt to control weather and reduce air pollution. He speculated that the dome would be able to have a payback period of 10 years simply by saving on snow removal costs. ${ }^{7}$ Although the idea sounds farfetched and insanely unlikely, it was a groundbreaking idea that pushed the thinking of air control in its time, so much that it is still pertinent amongst contemporary designers 50 years later. A London-based design firm, Orproject, explored a similar design response as Fuller's extreme idea of a Dome over Manhattan. In efforts to address the infamous air pollution faced by Beijing, Orproject proposed Bubbles, a building of "bubble-like biomes, sealed from outside pollution that would allow residents to actually breathe clean air." ${ }^{8}$ With a more comprehensive plan than Fuller, Bubbles is designed to be an enclosed botanical garden that would naturally purify and ventilate the interior atmosphere. The two theoretical projects by Fuller and Orproject reveal the endless struggle to control air.

In 1969, Reyner Banham surveyed industrial building's influence on early modernism after the World Wars. He argued that "architecture's dependence on environmental control is vastly undocumented and yet central to contemporary architecture." $\mathrm{He}$ noticed that interiors rely heavily on mechanically system to regulate interior climate conditions in his publication Architecture of the Well-tempered Environment. Instead, he points to Victory Mills, a silo made of 36 individual cylindrical bins that efficiently control its air, moisture, wind, and temperature passively. With a slightly different approach, the architectural and art collective Ant Farm sought to control the

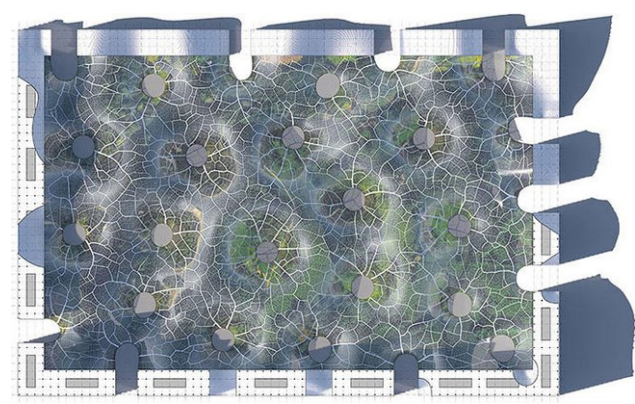

Fig 2.6 Bubbles (1960) Orproject. Plan

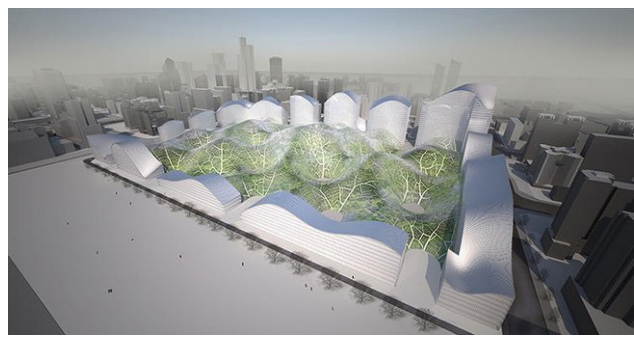

Fig 2.7 Bubbles (1960) Orproject. Aerial View

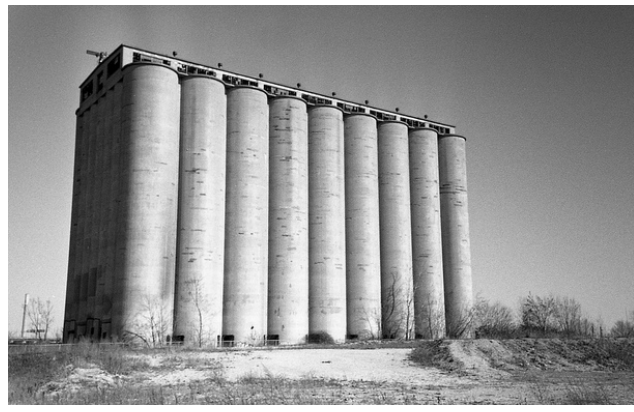

Fig 2.8 Victory Mills (1943) Toronto Harbourfront

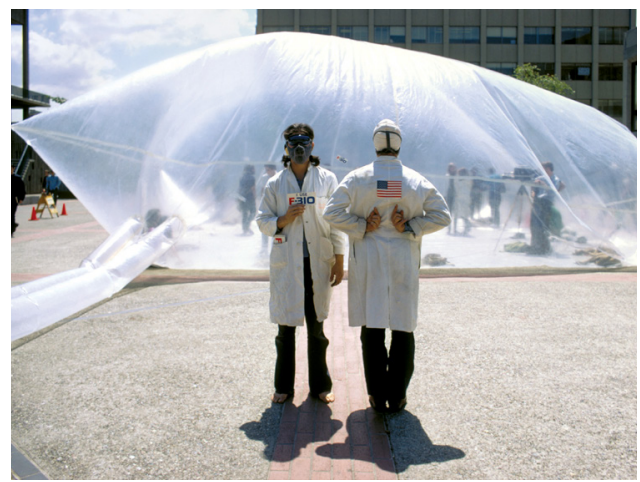

Fig 2.9 Clean Air Pod (1970) Ant Farm 

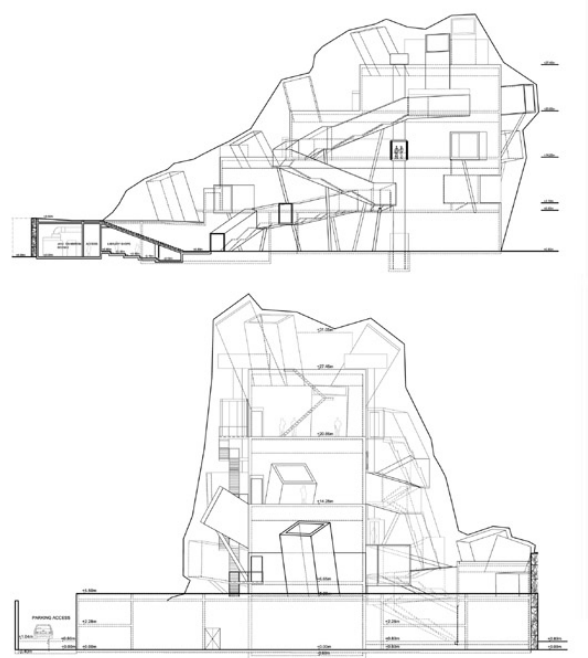

Fig 2.10 B_mu Tower (2002) R\&Sie(n). Sections

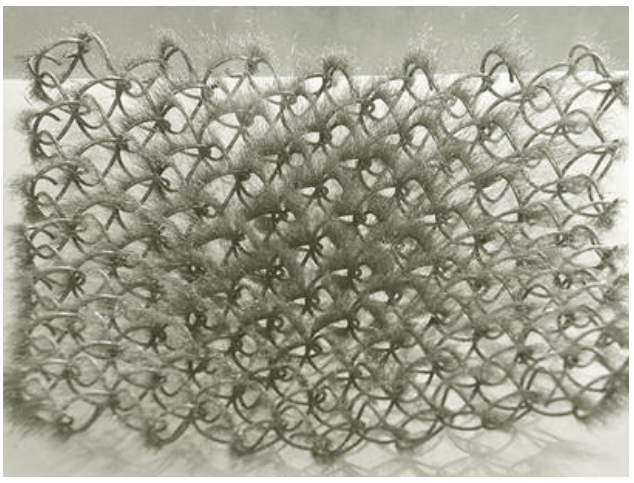

Fig 2.11 B_mu Tower (2002) R\&Sie(n). Lattice interior climate to be separate from the volatile exterior that seems to be uncontrollable due to social power. "Ant Farm was inspired by images of protesting students fired upon with clouds of tear gas by local police, as well as by environmentalist discussions of air quality."10 The result was architecture in the form of inflatable spaces that act as a refuge from gas.

In considering the discussions around air in architecture during the twentieth century, work by contemporary experimental architects such as Francois Roche of R\&Sie(n), Omar Khan, and RVTR, shift towards looking beyond air as a medium but the relationship between the breather and his environment. Within this context, Francois Roche and his firm R\&Sie(n) explores a city's exhaust of dust and smog and its relationship with the city dweller. The project $B \_m u$ Tower was a provocative theoretical building that shifted architecture's focus from protection from toxic environments to one that actively engages with these 'negative' elements. The project uses an electrically induced lattice to attract the air borne dust particles. On one hand, the collected dust acts as a thermal barrier for the building, on the other, the lattice helps filter the air within the city, actively changing architecture's approach towards changing environments.

At a smaller scale, RVTR's Stratus Project looks at "three agents and their mutually responsive relationship: the air, the envelope, and the breather."11 RVTR critiques the interior environment's inability to adapt to the comfort of breathers and its unresponsive envelope by introducing an installation that utilizes technology to alleviate the static condition of interiors. Through a responsive tessellated ceiling

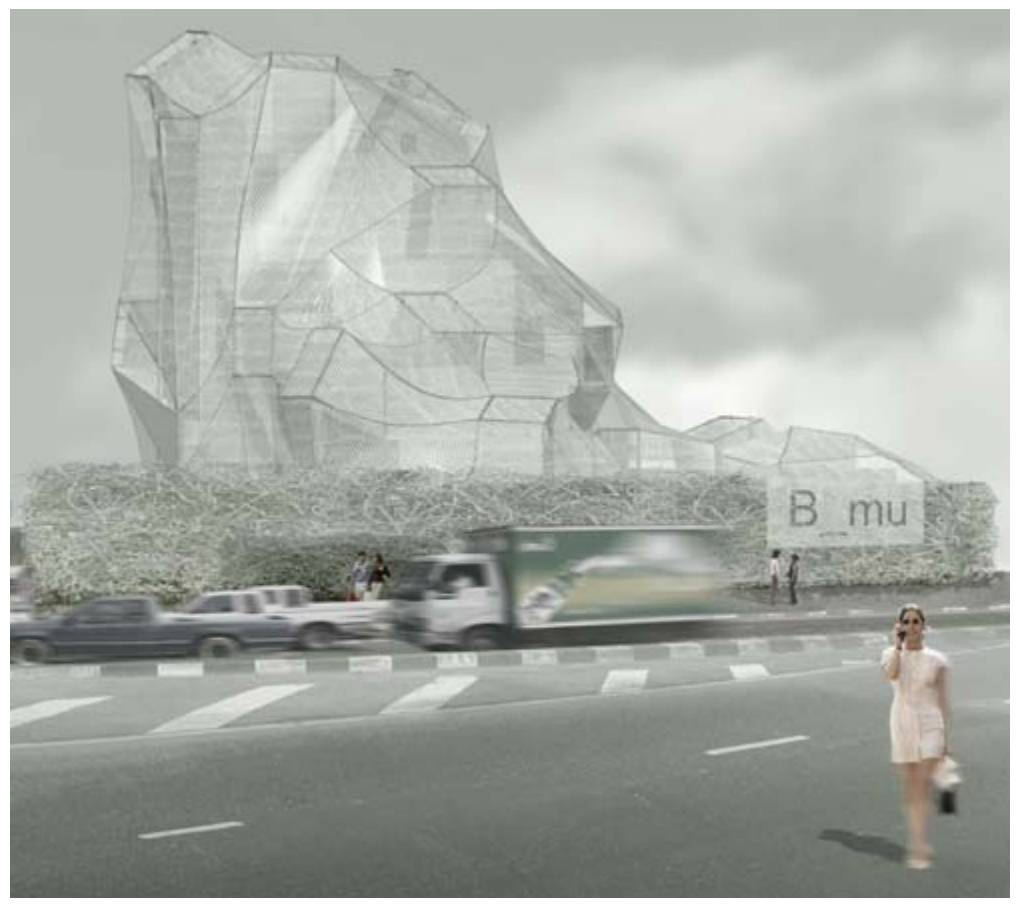

Fig 2.12 B_mu Tower (2002) R\&Sie(n). Rendering 
installation, the project begins to showcase architecture's potential in using technology to sense and respond to human comfort. ${ }^{12}$ This advances the thinking of architecture from a series of analog components to a network of digital surfaces that can process the fluctuating inputs of the environment. In a similar approach, Omar used physical computing to design a system of non-structural columns that can respond to changing interior atmospheres. Made from a composite urethane elastomer that can conform to a variety of patterns in space, Open Columns physically changes its configuration in space to bring awareness to the breather. It functions based on a simple set of rules that uses carbon dioxide sensors to sense the $\mathrm{CO}_{2}$ level as more breathers circulate through the space. When there is a high input of $\mathrm{CO}_{2}$, the columns drop down to disperse people into smaller groups. This project begins to redefine architecture's relationship with the breather and its breathing environment.

\section{Endnotes}

${ }^{1}$ http://www.who.int/mediacentre/news/releases/2014/air-pollution/ en/ (accessed November 1, 2014).

${ }^{2}$ Architecture2030.org/the_problem/problem_climage_change (accessed November 3, 2014)

${ }^{3}$ Sean Lally. The Air From Other Planets. (Lars Müller Publishers, 2013). 24.

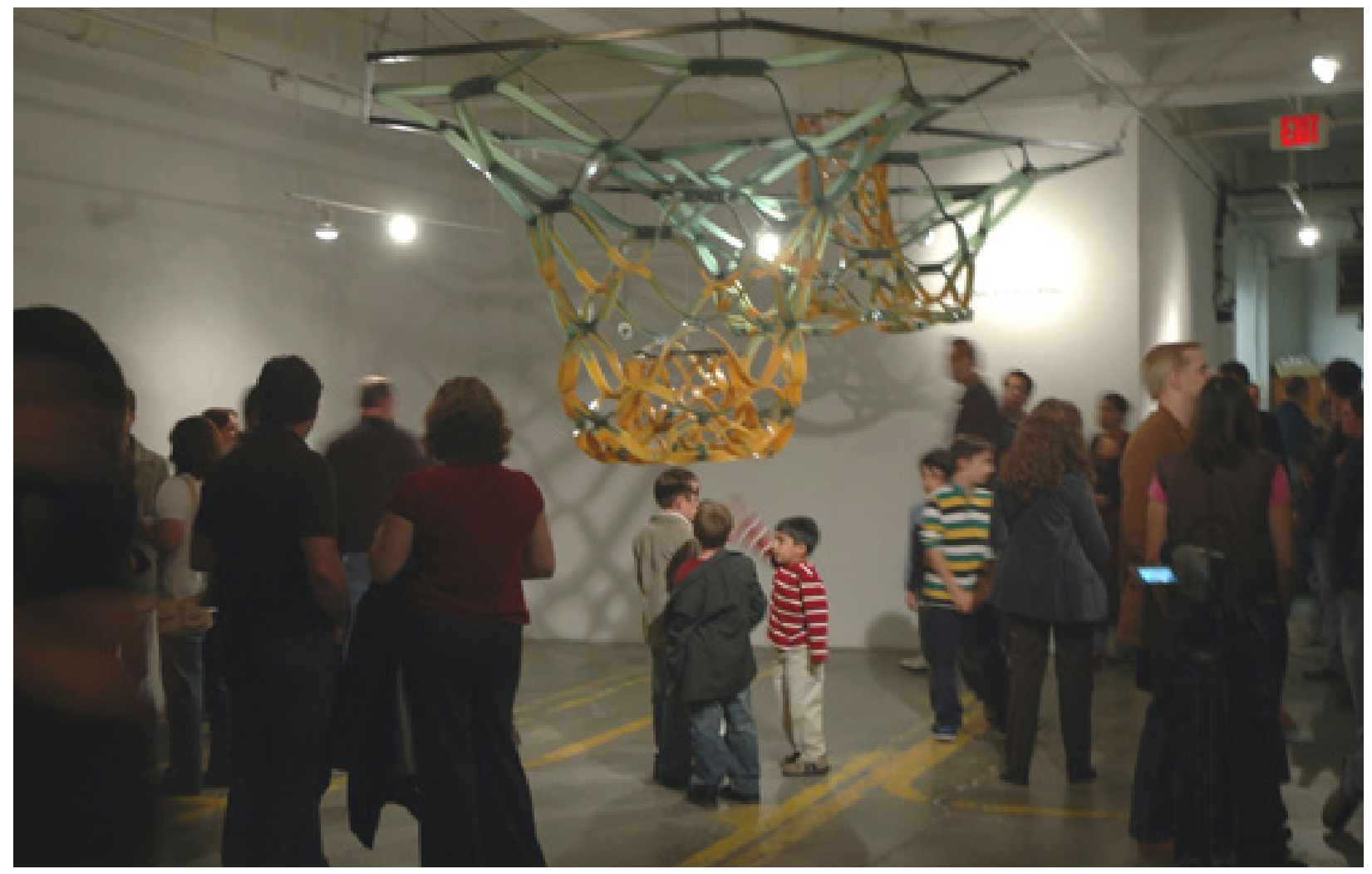

Fig 2.13 Open Columns (2007) Omar Khan 


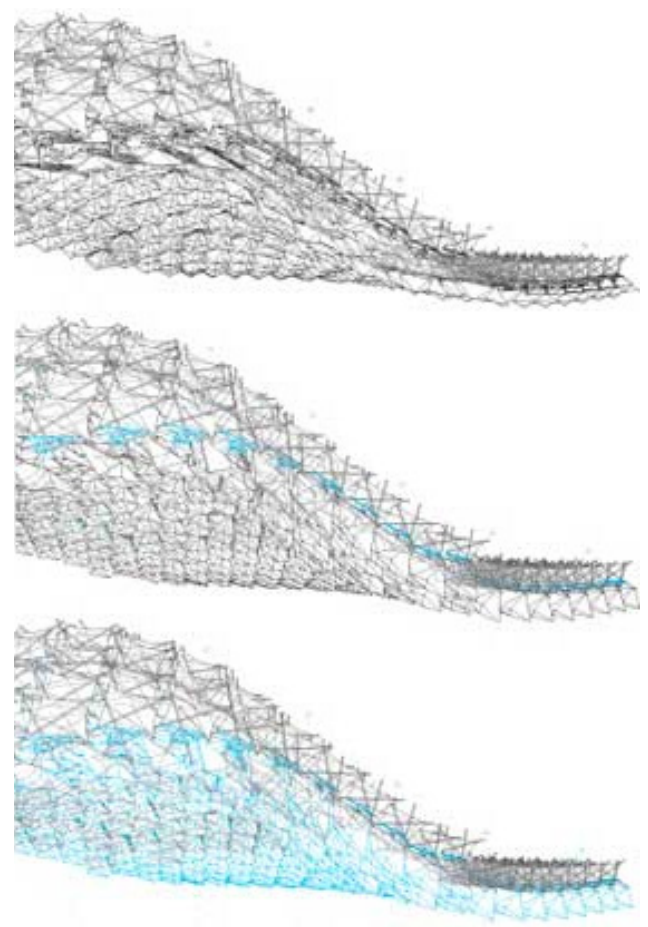

Fig 2.14 Stratus Project (2010) RVTR

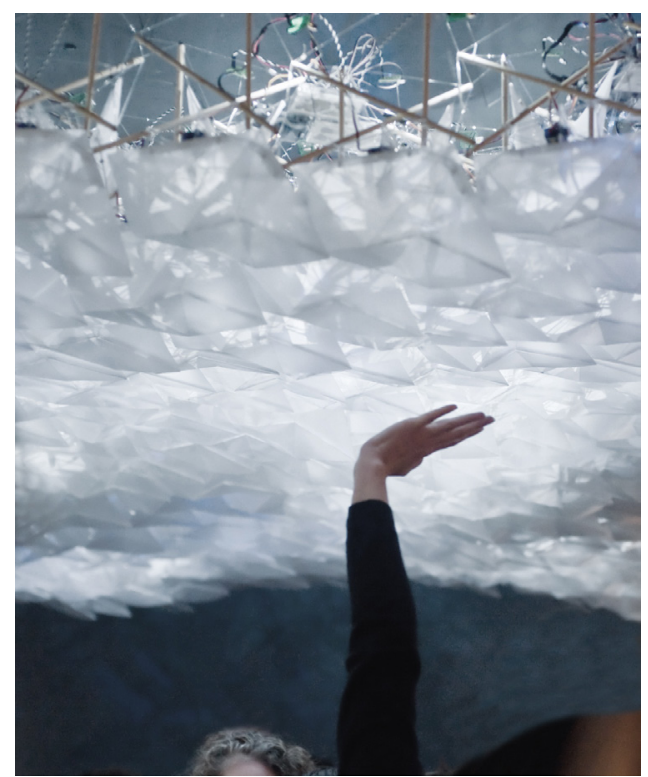

Fig 2.15 Stratus Project (2010) RVTR
${ }^{4}$ David Gissen. Subnature: Architecture's other Environments. (New York: Princeton Architectural Press, 2009). 59.

${ }^{5}$ Bruno Latour. Air. Sensorium: embodied experience, technology, and contemporary art. (Cambridge: The MIT Press, 2006). 105.

${ }^{6}$ David Gissen, Subnature: Architecture's other Environments. 61.

${ }^{7}$ http://design.designmuseum.org/design/r-buckminster-fuller (accessed November 3, 2014)

${ }^{8} \mathrm{http}: / /$ www.treehugger.com/urban-design/beijing-bubbles-biome-clean-air-orproject.html (accessed November 3, 2014)

${ }^{9}$ Mason White. Mutant Environments. -arium: Weather + Architecture. (Ostfildern: Hatje Cantz,2010). 254.

${ }^{10}$ David Gissen, Subnature: Architecture's other Environments. 62.

${ }^{11}$ Colin Ripley, Georffrey Thun, Kathy Velikov. The Stratus Project: Responsive Interior Atmospheres. Interiors. (London: Bloomsbury Publishing Plc, 2012). 45.

12 Ibid, 49.

\section{Image References}

1 http://www.trbimg.com/img-52dd9df6/turbine/la-sci-sn-china-exports-air-pollution-united-s-001/2048/2048x1273

2 http://www.nationalgallery.org.uk/upload/img/wright-experimentbird-air-pump-NG725-fm.jpg

${ }^{3} \mathrm{http}: / / 40$.media.tumblr.com/50abdb32cb191e805e9ab1c374f5bed7/tumblr_mu4pe37nwG1qgpvyjo1_500.jpg

${ }^{4} \mathrm{https}$ ://flavorwire.files.wordpress.com/2013/01/1-dome-over-midtown1.jpg

${ }^{5}$ http://www.treehugger.com/urban-design/beijing-bubbles-biome-clean-air-orproject.html

${ }^{6}$ Ibid.

${ }^{7}$ Ibid.

${ }^{8}$ https://c2.staticflickr.com/8/7122/7108328345_be30568110_b.jpg

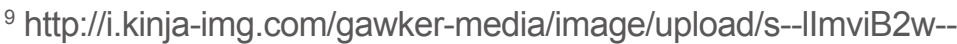
/c_fit,fl_progressive,q_80,w_636/18qmdx2a175djjpg.jpg

${ }^{10} \mathrm{http}: / /$ www.new-territories.com/roche2002bis.htm

11 lbid.

12 Ibid.

${ }^{13} \mathrm{http}: / /$ cast.b-ap.net/site/wp-content/uploads/2010/10/OC_4.jpg

14 http://acdn.architizer.com/thumbnails-PRODUC-

TION/11/31/1131ae6595196a8ee13dd22069570045.jpg

$15 \mathrm{Ibid}$. 


\subsection{How to Breathe}

The term "respiration" has multiple connotations depending on the context, e.g., in biology, ecology, or sociology. In the context of biology alone, respiration could be understood to be various different processes such as the conversion of nutrients to energy in cellular respiration or the anatomical system of organisms used to absorb oxygen. ${ }^{1}$ However, colloquially, the term "respiration" has little meaning besides relating to the act of breathing - a simple, passive activity that is often overlooked, despite apprehension regarding the state of the environment. So, why does respiration get overlooked when there exist an overwhelming number of cases of asthma, bronchitis, and lung cancer, all relating to respiration and much of it caused or exacerbated by the environment?

The act of breathing is a primary and basic necessity for human existence, as it is an essential, functional aspect of life. However, architecture, which has largely been a process of designed separate, concealed spaces, has effectively disengaged the user from the reality of surrounding atmospheres. Jane Farve puts it this way: "Much of contemporary architecture provides its users a controlled existence, disassociated from the environment and free of things that offend the senses or cause discomfort." 2 People have become ill-informed of the reality of the air they breathe because architecture has successfully masked the built environment by providing simulated conditioned spaces that convince the public there is nothing wrong with the air. Bruno Latour in his short essay, Air in the Sensorium book, points to how the world has become desensitized to the air it breathes. "Now the gentle hum of the air conditioner is heard at all times, and at all scales - including that of the global warming of planet Earth itself - even though some people don't hear it." 3 Conversely, the built environment has only covered up the fact that we are no longer able to breathe on our own. Bruno Latour describes the existing condition:

"You are on life support, it's fragile, it's technical, it's public, it's political, it could break down - it is breaking down - it's being fixed, you are not too confident of those who fix it. Our current condition merely relies on our more explicit understanding that this tentative technological system, this 'life support,' entails the whole planet - even its atmospheres." ${ }^{4}$

Fig 3.1 Breathing Architecture (2011) by WOHA 
Architecture, as a process, has infused buildings with mechanical systems that substitute the natural respiration process of breathers with machines that assist our breathing. Without notice, the breather gets put on life support that effectively controls the breathability of his environment. The city is no longer able to breathe on its own, as the air in our atmospheres has slowly become a precious commodity as seen through extremes examples in urban cities such as Beijing. Breathers in such extreme urban conditions resort to wearing masks outdoors while the interior environment appears to provide a temporary safe haven from the exterior. It seems that through artificial breathing environments, "nature" has left the exterior and moved into the confines of architecture. Philippe Rahm recognizes the conditions and questions "could architecture be reconfigured through sustainable development to become not the place of the artificial but the place of nature? A second nature, geological, chemical, where nature would not be outside the architecture but inside it."

To environmentalists, breathing and the atmosphere has become a critical cultural issue. According to Frank Kelly, director of environmental research group at King's College London, society can no longer ignore the pollution of our air. "The real problem is that wearing masks sends out the message we can live with polluted air. We need to change our way of life entirely to reduce pollution". ${ }^{6}$ As a result, breathability needs to become an architectural issue. We need to re-examine the current conditions of architectural respiration and draw inspiration from true anatomical respiratory systems. First, however, the term "respiration" needs to be defined.

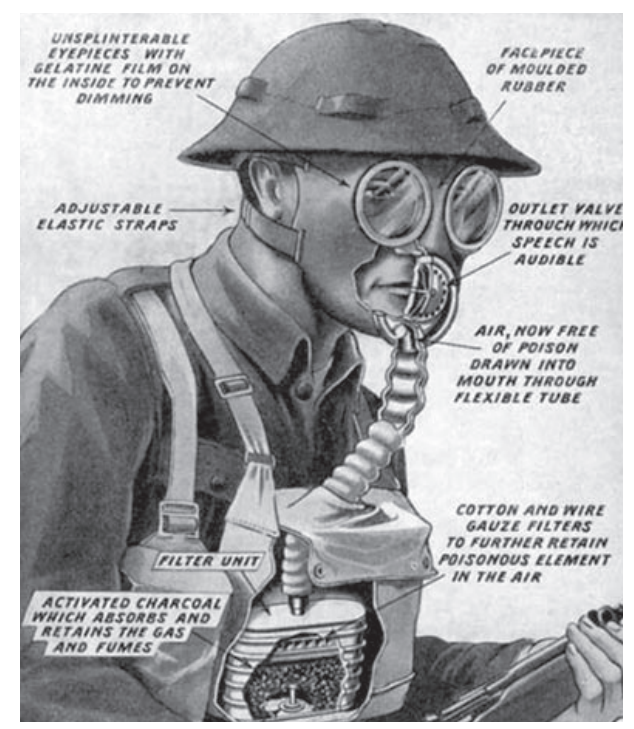

Fig 3.2 Technical Illustration of gasmask in use during WWI from Bruno Latour's short essay Air 


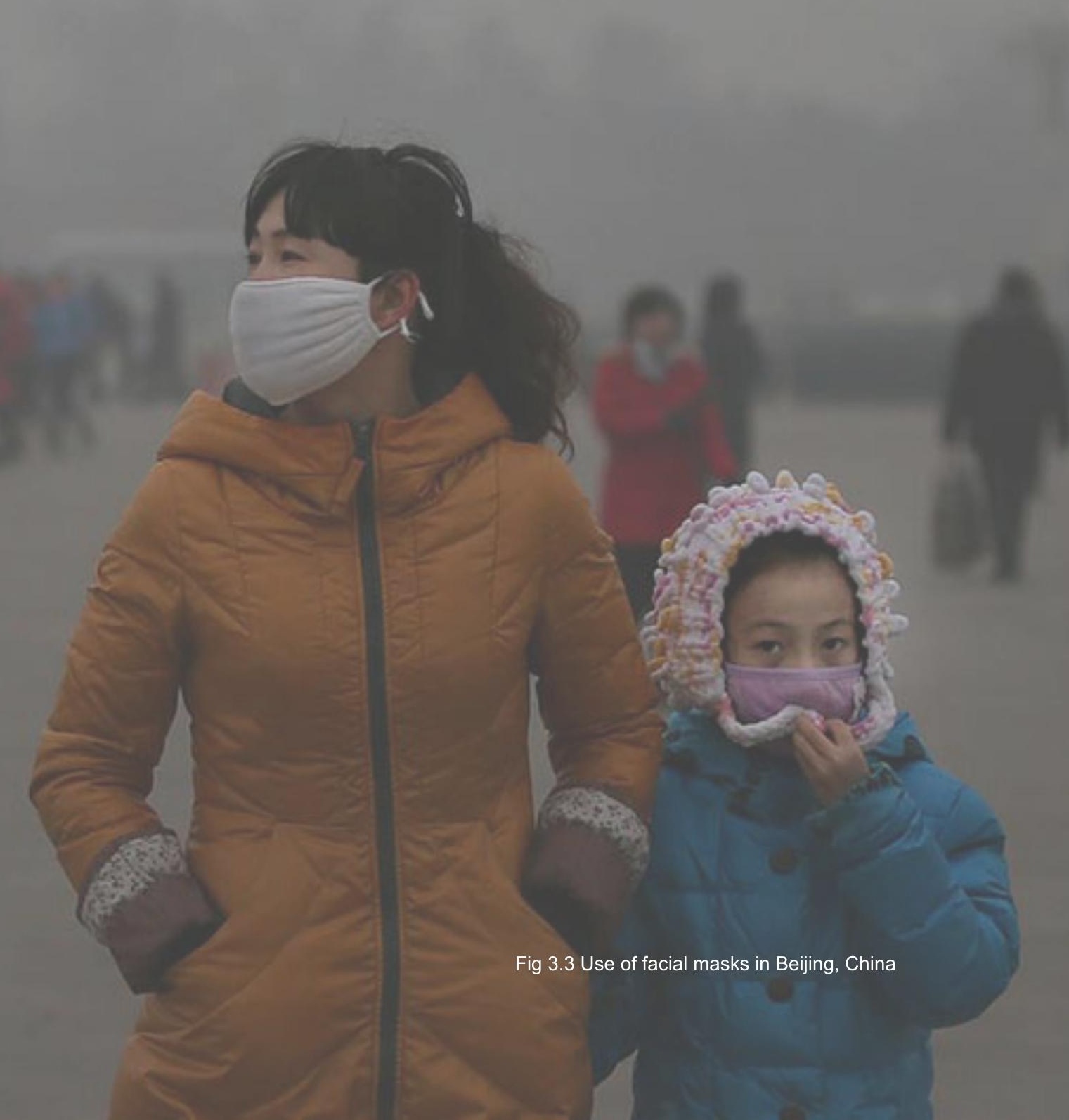




\subsection{Definitions}

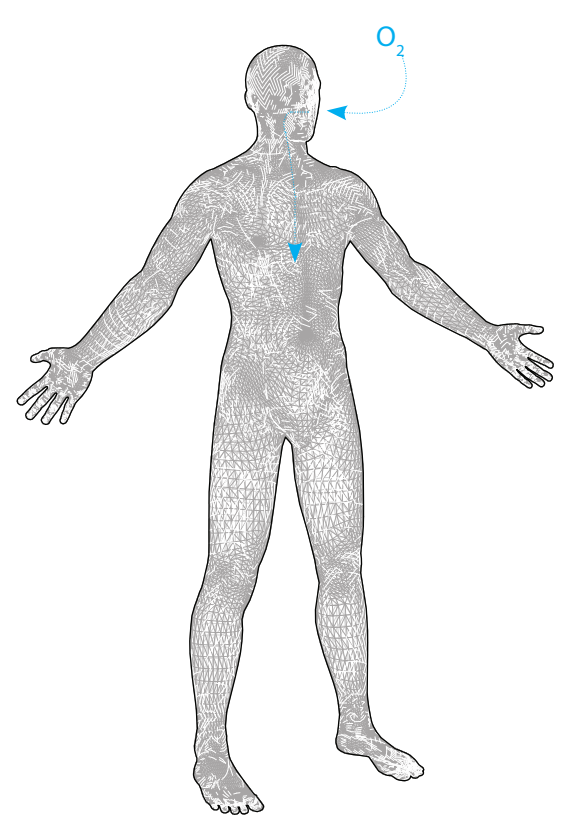

Fig 3.4 Human Flow of Oxygen

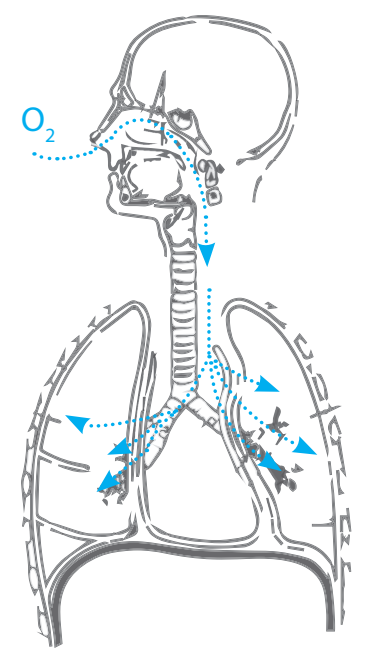

Fig 3.5 Human Respiratory System
Origin - from Latin respiration( $n$-), from respirare, "breathe out"7

\section{Cellular Respiration}

: any various energy-yielding oxidative reactions in living matter that typically involve transfer of oxygen and production of carbon dioxide and water as end products ${ }^{8}$

\section{Anaerobic Respiration}

: cellular respiration without the use of oxygen through using electron acceptors ${ }^{9}$

\section{Maintenance Respiration}

: the amount of cellular respiration required for an organism to maintain itself in a constant state ${ }^{10}$

\section{Respiration (Noun)}

: the act of breathing ${ }^{11}$

\section{Respiration (Biology)}

: a process in living organisms involving the production of energy, typically with the intake of oxygen and the release of carbon dioxide from the oxidation of complex organic substances ${ }^{12}$

\section{Respiratory System}

: a system of organs functioning in respiration and in humans consisting especially of the nose, nasal passages, pharynx, larynx, trachea, bronchi, and lungs ${ }^{13}$

\section{Artificial Respiration}

: the act of simulating respiration, which provides for the overall exchange of gases in the body by pulmonary ventilation, external respiration and internal respiration ${ }^{14}$

\section{Carbon Respiration}

: the act of measuring carbon flux occurring in the atmosphere 


\subsection{Respiration}

Respiration is often understood to be the singular act of breathing, where there is a direct exchange of oxygen and carbon dioxide. With this understanding, the importance of respiration is lost due to its perception of being passive in nature. However, with the recent rise of environmental concerns caused by human consumption, pollution and its impact on the air we breathe has elevated in architectural discourse..$^{15}$ Coming out of an era of modernism, where architecture was regarded as a machine, architects and designers began rethinking the building envelope to critique its passive position of respiration in the design of airtight spaces, which was made possible only by air conditioning systems. ${ }^{16}$ Architecture became passive in its response to environmental conditions where it is only programmed to function but not adapt. For Francois Roche and his firm, R\&Sie(n), nature is not only proactive but it is reactive. ${ }^{17}$ This element of reaction is missing in most over-programmatic architecture today and Francois recognizes this lacking element that needs to be integrated into architectural design.

Dennis Dollens argues that "architecture reduced as a concept of a machine and object has lost its biological connections." ${ }^{18}$ The biological connection referred to by Dennis is the intuitive nature of living organisms that are able to react and adapt to changing environments. Like Francois Roche, Dennis sees the issue in architecture separated from nature. When buildings became hermetic containers (separate from nature) that relied so heavily on mechanical air exchange systems, they also became major energy consumers, thereby harming nature in its process of consumption. Even Le Corbusier, an advocate for architecture to be designed as machines, made increasing provisions for natural ventilation and shading in the latter part of his career to reduce the burden on mechanical systems (e.g., operable windows and shading devices in Unite D'Habitation). ${ }^{19}$ He observed that, "if architecture follows certain paths, it can provide city dwellers with good, true, God-given air, for the salvation of their lungs." ${ }^{20}$ Despite his approach that would later prove to be ineffective, Corbusier still had the aim of responding to the negativity of atmospheres affected by modern urbanization.

Fig 3.6 Plan Voisin (1925) Le Corbusier 
"Equally significant was his belief that if people were aggregated into housing towers, it would be possible to further mediate the deleterious effects of modern urbanization. For Le Corbusier, the tower promoted a better urban environment, as it permitted the planting of more green space and the surrounding of urbanites with fresh air."21

This observation, by David Gissen, marked clearly the repercussions that "buildings for all nations" had in its divide of space between the inside and outside. Although the intent was to increase green space and fresh air, the tower was still a machine that's unable to react to different conditions outside of what Corbusier considered.

Reyner Banham and Francois Dallegret saw the flaw of this existing state of architecture built as literal "air" barriers in their proposal of the Environmental Bubble as a critique on the reliance on mechanical systems. ${ }^{22}$ Discussions were stimulated regarding the prevailing condition of the vigorous dependence on artificial breathing systems that had become an integral component of architectural design. This led to many theories on how to rebel against the status quo of mechanical systems and to question the quality of the internal environment that was created by these hard systems.

Critics realized that the design for the natural had moved towards the artificial: "The modern retail environment is a deliberate and precise creation providing a spectrum of environments taking the consumer from the volatile outside, through a threshold of control yet assimilation to the natural, into the depths of complete consistence and artificiality." ${ }^{23}$ There is an unsettling amount of distress on the repercussions of using these mechanized systems to replace the vernacular way of architecture. According to Jurgen Mayer and Neeraj Bhatia in -arium: weather + architecture, "architecture is an attempt to separate one from weather. The layers of a building's skin are each systematically designed to control atmospheric conditions to provide 'ideal' interior environments." ${ }^{24}$

Amidst the unease of architecture being separate from nature, much of the discourse remained only as theories, without tangible, practical solutions. The rapid development of technologies used to enhance and improve the way we build had eclipsed the critiques of the environments that resulted from these technologies, further fueling the instability of architecture and the air we breathe. The concept of designing air remained to be merely theoretical, because of its abstract nature. ${ }^{25}$ The problem is not found in air

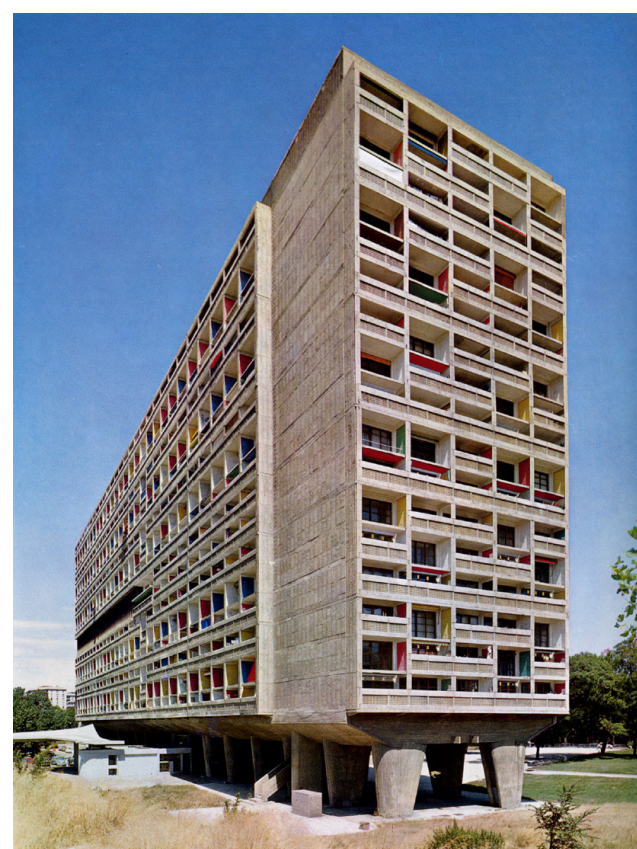

Fig 3.7 Unite D'Habitation (1952) Le Corbusier

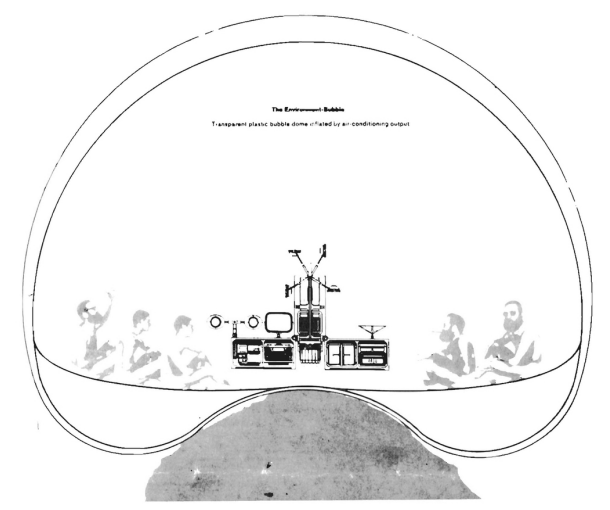

Fig 3.8 Environment Bubble by Reyner Banham and Francois Dallegret

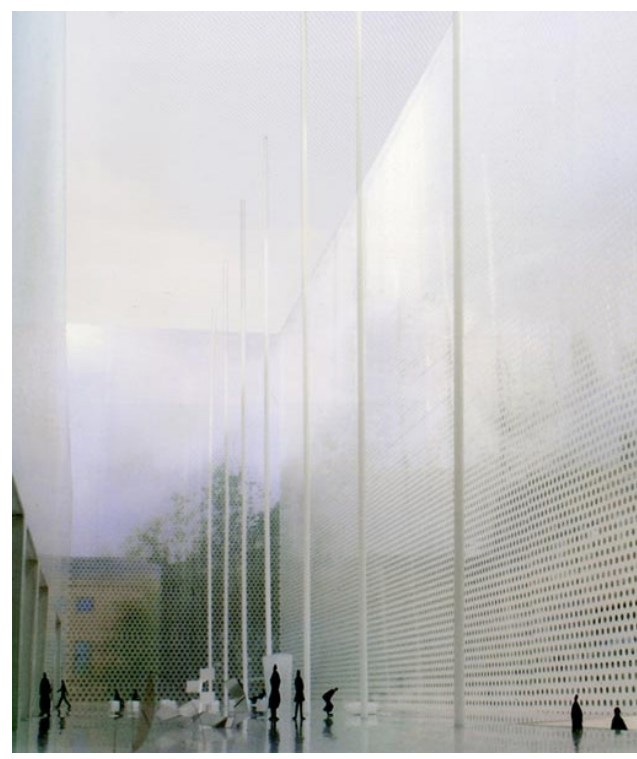

Fig 3.9 Valencia Institute of Modern Art (1989) SANAA. View of mediating space where weather and architecture meets 
itself, but rather what the urban environment has done to the air. Perhaps a slight shift in perspective or approach to the issue might garner better results in improving the state of the built environment. The presence of air is consistent and remains a constant. What changes is the quality of the air that gets corrupted by the toxins we inject into the environment. Therefore, air itself cannot be altered, but air quality can be improved.

The question becomes, then, how can we improve air quality? This question is increasingly important when, in 2013, the World Health Organization's ("WHO") cancer agency classified air pollution as a carcinogen, linking dirty air to lung and bladder cancer. ${ }^{26}$ That is where most architects and designers alike become conceptually stuck, because air is an invisible element that cannot be manufactured. As such, respiration emerges as a relevant discourse in architecture.

Thus, the focus ought to shift towards designing architecture that can breathe, come alive to react and adapt, rather than inactive spaces that have zero air exchange without employing mechanical systems. The removal of mechanical systems reveals the true nature of architectural spaces today - unbreathable. There has been extensive emphasis on air as an isolated element without consideration for respiration, which leads to the inevitably singledimensioned solution of using mechanical systems to provide air. The hermetic seal condition needs to be reexamined in light of respiration in order to design spaces that are able to once again respire like the vernacular.

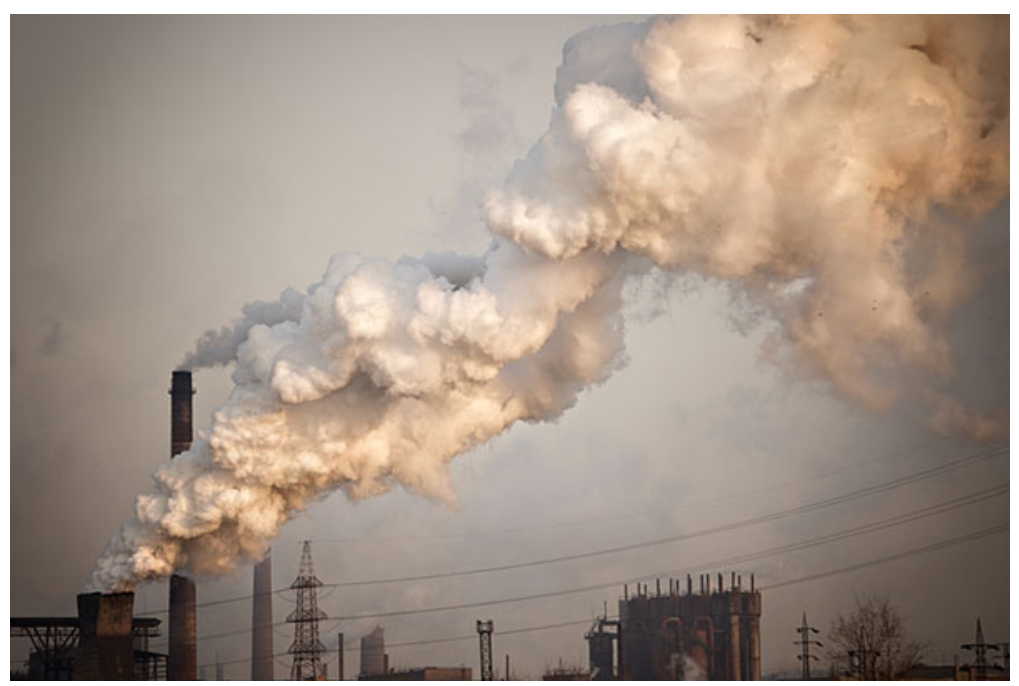

Fig 3.10 Air pollution within urban cities produced by industrial factories 


\section{Endnotes}

${ }^{1}$ http://www.merriam-webster.com/dictionary/respiration (accessed September 09, 2014).

2 Jane Farver. Francois Roche and R\&Sie(n). Sensorium: embodied experience, technology, and contemporary art. (Cambridge. The MIT Press, 2006). 85.

${ }^{3}$ Bruno Latour. Air. Sensorium: embodied experience, technology, and contemporary art. (Cambridge: The MIT Press, 2006). 106.

4 Ibid.

${ }^{5}$ Philippe Rahm. Philippe Rahm architects. Radical Nature. (London: Koenig Books Ltd, 2009). 184.

${ }^{6}$ http://www.cbc.ca/news/health/air-pollution-kills-7-millionpeople-every-year-globally-who-finds-1.2585505 (accessed September 15, 2014).

${ }^{7}$ http://www.merriam-webster.com/dictionary/respiration (accessed September 09, 2014).

${ }^{8}$ http://www.merriam-webster.com/medical/cellular\%20 respiration (accessed September 09, 2014).

${ }^{9}$ http://www.merriam-webster.com/dictionary/anaerobic (accessed September 09, 2014).

${ }^{10}$ MGR Canell, JHM Thornley. Modelling the components of plant respiration: some guiding principles. (1999). 45-54.

11 http://www.merriam-webster.com/dictionary/respiration (accessed September 09, 2014).

12 Ibid.

${ }^{13}$ http://www.merriam-webster.com/dictionary/respiratory $\% 20$ system (accessed September 09, 2014).

14 http://www.merriam-webster.com/dictionary/artificial\%20 respiration (accessed September 09, 2014).

15 David Gissen. Big \& Green : Toward sustainable Architecture in the 21st Century. (New York: Princeton Architectural Press, 2009). 12-13.

16 Ibid.

${ }^{17}$ Francois Rohe. Fiction Scripts. (Beijing: AADCU Publication, 2006). 80.

18 Dennis Dollens. Digital Botanic Architecture. (Santa Fe: SITES Books, 2005). 12.

${ }^{19}$ http://www.archdaily.com/85971/ad-classics-unite-d-habitationle-corbusier/ (accessed September 30, 2014).

${ }^{20}$ Mohen Mostafavi, David Leatherbarrow, 30.

${ }^{21}$ David Gissen. Subnature: Architecture's other Environments. (New York: Princeton Architectural Press, 2009). 73. 
${ }^{22}$ Reyner Banham. A Home is not a House. (2007). 159-166.

${ }^{23}$ Jurgen Mayer, Neeraj Bhatia. -arium: Weather + Architecture. (Ostfildern: Hatje Cantz,2010). 116.

24 Ibid., 30

${ }^{25} \mathrm{Ibid}$., 254.

${ }^{26}$ www.who.int/mediacentre/factsheets/fs313/en/ (accessed September 30, 2014).

\section{Image References}

1 http://36.media.tumblr.com/ dc7a349441f7d965b77a5a6490a6f2e6/tumblr msrm10jp9r1s3r80lo2_1280.jpg

2 http://www.bruno-latour.fr/sites/default/files/P-115-AIRSENSORIUMpdf.pdf

${ }^{3}$ https://thenanfang.com/wp-content/uploads/2015/01/airquality. jpg

${ }^{4}$ Kevin $\mathrm{Pu}$

${ }^{5}$ Ibid.

${ }^{6} \mathrm{http}: / / a c d n$.architizer.com/thumbnails-PRODUCTION/f5/00/ f500dc3a2dfa0dfba77bfb7d570ab7d0.jpg

${ }^{7}$ http://40.media.tumblr. com/658dcc9ea6978ed73ea8a5b39e6dbb43/tumblr mz1yzpLTiB1soavyuo1_1280.jpg

${ }^{8}$ https://studio4postindustrial.files.wordpress.com/2011/04/ picture-8.png

${ }^{9} \mathrm{http}: / /$ www.designboom.com/wp-content/uploads/2005/10/ sanaa-valencia.jpg

${ }^{10}$ http://media.canada.com/9e591aed-9747-4952-b147$1 \mathrm{~d} 6 \mathrm{ab} 8 \mathrm{db} 7 \mathrm{~d} 2 \mathrm{a} /$ steelplant.jpg 


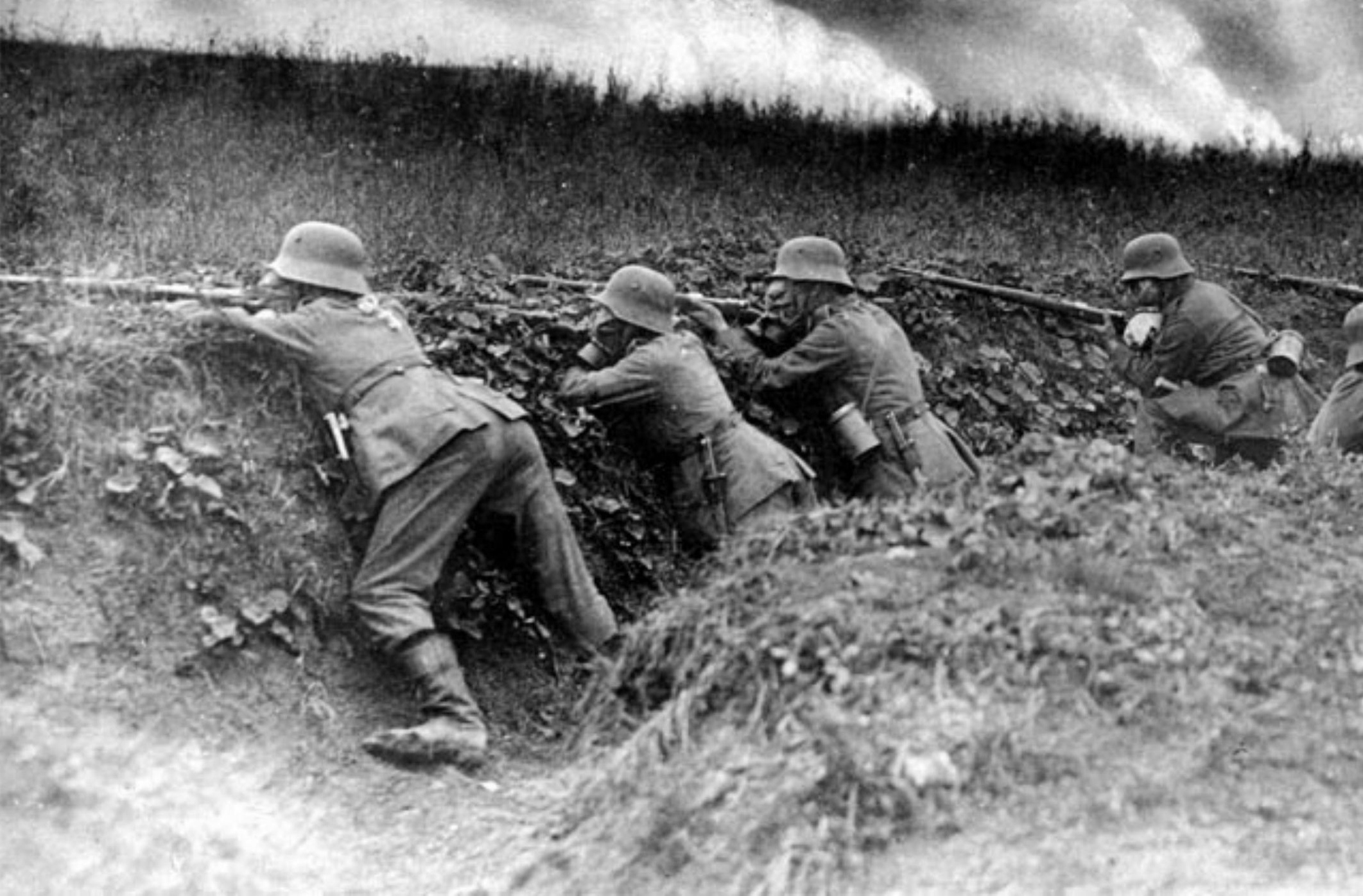




\subsection{The Four Parameters of Respiration}

Respiration, in the context of architecture, needs to be viewed as a holistic system similar to a biological respiratory system made up of a kit of parts (i.e., a system of organs functioning in respiration and, in humans, consisting of different functional components) where architecture can be designed to encompass the act of breathing in the space itself in order to do away with the need for mechanical systems. This is necessary since "air has entered the list of what could be withdrawn from us" as first experienced by the poor soldiers on the front line, deep in the trenches near Ypres in 1915. ${ }^{1}$ Air has since then been made explicit to become a relevant factor in the design of architecture. While a building itself does not require oxygen, the breather of this built environment does and poses an interesting opportunity for architecture to respond to the notion of breathability that it has never alluded to before. Latour argues that "air has been reconfigured; it is now part of an air-conditioning system that makes our life possible" and architecture needs to thereby adhere to the sustenance of healthy air for breathers. ${ }^{2}$ Similarly to cybernetics (the science that studies the communication and the structure of regulatory systems), this requires architecture to not be regarded as a separate entity, but an extension of the breather to be considered as one holistic respiratory system. "According to this approach (cybernetics), all different parts of an interrelated whole interact with and rely on each other for their survival, so that changes to one part affect every other part of the system"3 Buildings can no longer be designed without consideration of the breather. "Architecture is part of an ecosystem... a symbiotic growth dependent on human intelligence." ${ }^{\prime \prime}$ In order to reimagine architecture and its relationship with the breather, we need to understand the main principles of respiration. There are four major parameters that govern respiration: breathe, flow, exchange, and control. In the discourse of architecture, these four parameters can help break down the ingredients necessary for architecture to be designed to be capable of respiration.

Fig 4.1 Gas attacks in the trenches of Ypres in 1915 


\subsection{Breathe}

Breathing is the most obvious association when it comes to the term "respiration". "We all have to breathe, which makes pollution very hard to avoid. One of the main risks of pollution is that tiny particles can get deep into the lungs, causing irritation and other health concerns." ${ }^{\text {B }}$ Breathing entails the act of inhaling (absorbing oxygen) and exhaling (releasing carbon dioxide) as a function responsible for the transport of oxygen into blood. This transport route is essential for the majority of all living organisms. For architecture to "come alive", it will need to reconsider its current relationship with nature and breathing organisms where man have traditionally been considered as separate entities from the built environment. In his melodramatic critique of the state of nature after the modern era, Manacorda recognizes the need to rethink the state of architecture: "this attitude (interrogating the discipline itself), which also encouraged the rethinking of architecture's relationship to nature, promoted the drastic restructuring of man's relationship to the built environment."6 In the same way, there is a need to rethink the current relationship between man as the breather and the built environment. Buildings itself do not breathe nor does it need to, rather, it is a part of an extension of the human breather that requires it to provide a suitable breathing environment. Independent of the breather, spaces do not need oxygen, and this is the condition that needs to be rethought. As an integral parameter of respiration, architecture will need to explore the potential shift from providing ventilation in buildings towards an active system that allows for a process of inhaling and exhaling contributing towards the breathability of an environment.

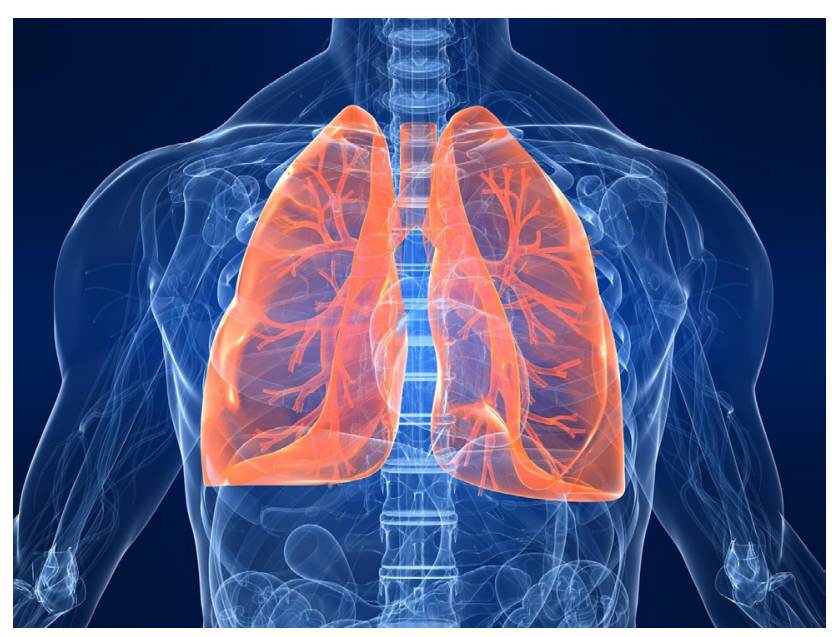

Fig 4.2 Diagram of the human lung 


\subsection{Flow}

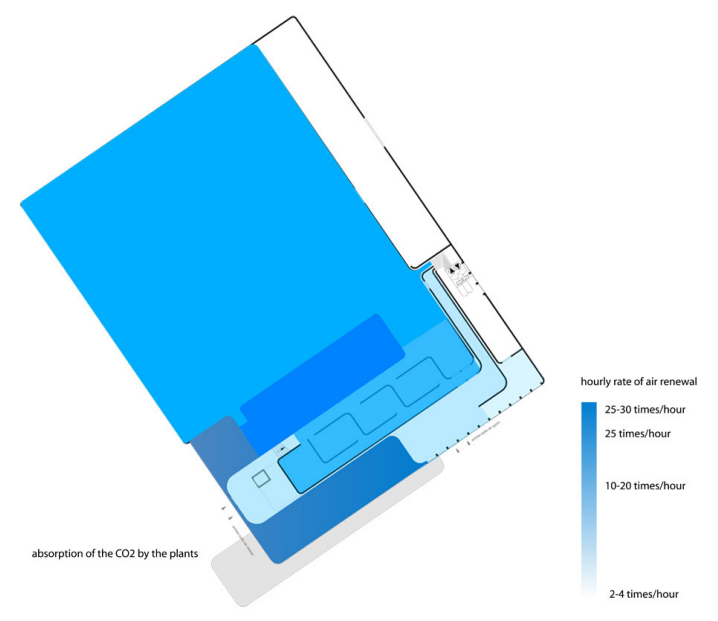

Fig 4.3 Plan of Airflux (2007) Philippe Rahm

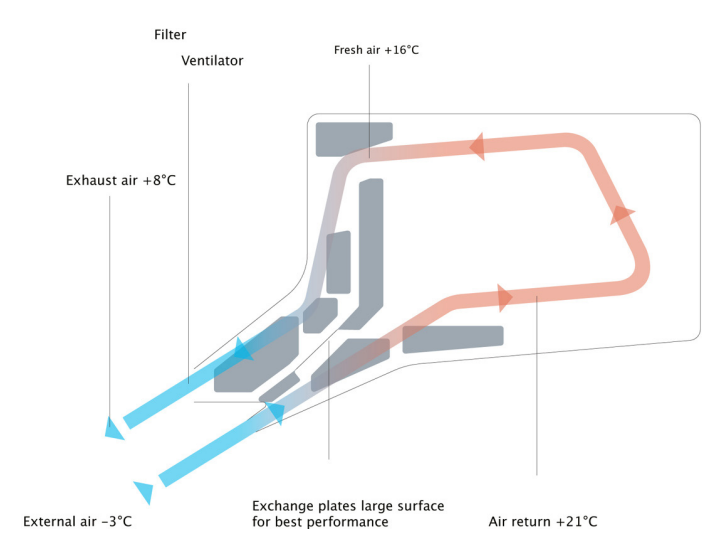

Fig 4.4 Windtrap (2009) Philippe Rahm. Diagram of air exchange.
The flow of air points to the movement of air through space. Respiration requires a constant flow of moving air that circulates out stale air and brings in fresh air. Without a constant current, respiration becomes difficult without fresh air. In considering the role of flow in recent contemporary work, it appears that architects are less taken with the particular psychological impact of air flows that has a subtle but direct influence on the experience of the breather, e.g., recirculated air causes sickness, or insufficient oxygen levels cause drowsiness. The existing state of enclosed buildings has already yielded the sick building syndrome that describes a situation whereby breathers experience symptoms of illness directly linked to indoor air qualities. Experimental architect, Philippe Rahm, considered the particularities offered by air flows that can repurpose architecture into an entirely new setting in which architecture contributes to the respiration of the breather. "Reducing the question of the architecture of a sports hall to that of ventilation and aeration, that is to say re-establish the architectural project literally for the need to bring oxygen into the building and to air out the waste produced during respiration." In his project Airflux, Rahm reduces architecture to the essential of providing a breathable environment for the breather that allows him to focus the sports facilities on ventilation and aeration by bringing oxygen into the building through the form of the architecture that permits continuous flows. Rahm's exploration in air flow is in fact an investigation between interior and exterior air, generating a new real-time dialogue between his building, and the breather within it. This approach provides a new perspective on the way architecture can be designed to allow for natural flows of air to move and circulate the environment when needed. On the other hand, at a much broader level, flow also speaks to the movement of people, dust and other air-borne particles, smoke, heat, and energy, that all impact the respiration of a person.
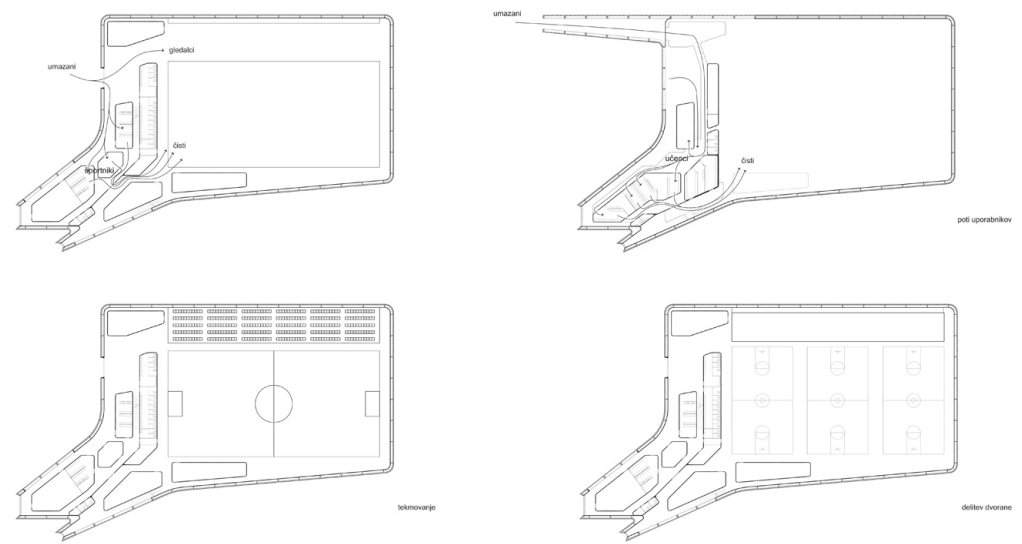

Fig 4.5 Plans of Windtrap (2009) Philippe Rahm 


\subsection{Exchange}

An exchange occurs in the act of respiration when nutrients transfer from one place to another. At a macro level, there are constant exchanges happening in the air, e.g., through the mixing of cool, fresh air with warm, stale air (including dust and pollutants, oxygen and carbon dioxide from human breathing), and temperature exchanges from light rays. In their book, On Weathering: The Life of Buildings in Time, Mohsen Mostafavi and David Leatherbarrow highlight the constant exchange that occurs back and forth between nature and the manmade.

"Paradoxically, weathering produces something already there by subtraction. This exchanges the roles of art and nature. In design, art is assumed to be the power or agency that forms nature; in the life of a construction, however, nature re-forms the 'finished' art work."

Mostafavi and Leatherbarrow's description of weathering is the embodiment of a constant exchange that happens between the forces of nature and architecture. The intermediary transience meeting between the two entities creates a codependent relationship that involves a give and take dynamic. Opening windows allows for a direct exchange in air while the use of HRVs (heat recovery ventilator) conduces a more subtle exchange. On a micro level, there occurs thousands upon thousands of particles interacting with each other through exchange. The increase of heat causes atomic electrons to speed up in exchange for the increased energy. In the realm of biomimicry, researchers look at respiration in the microscopic levels to find answers: "The microscopic pores (stomata) on plant leaves control the rate of evaporation and the exchange of gases involved in photosynthesis. When temperatures increase the stomata open wider, which causes more water to evaporate and allows the plant to stay cooler than its surroundings."

At both micro and macro levels, energies are constantly in exchange with each other. These interactions that take place, from the atmosphere to microscopic pores, directly impact the breather in the environment and affect the quality of air for respiration. In light of architectural design, we need to evaluate a new relationship of exchange between the atmosphere and the breather in the space. 


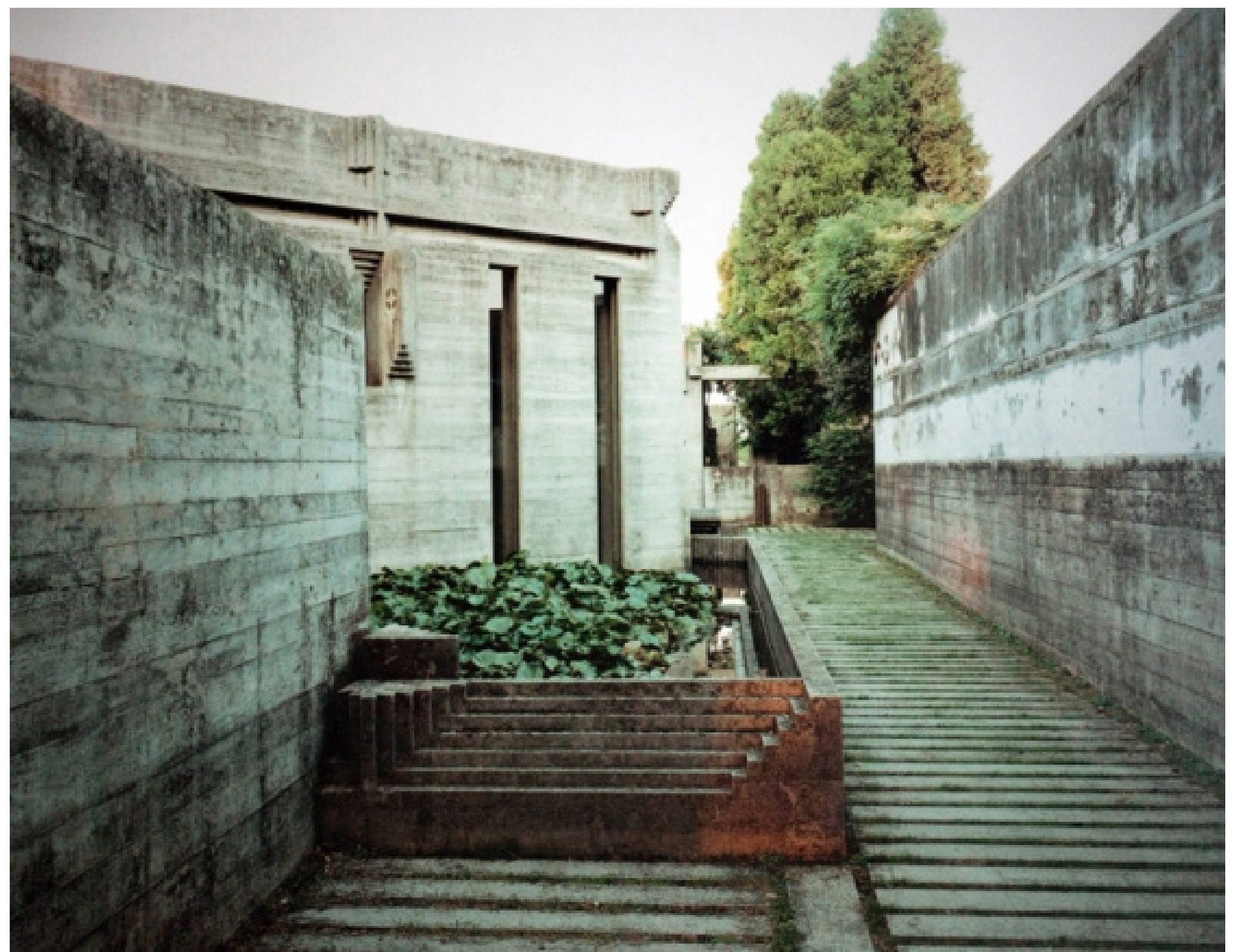

Fig 4.6 Brio-Vega Cemetery (1981) Carlo Scarpa. Weathering: nature's re-form of "finished" architecture 


\subsection{Control}

The idea of control has been consistent throughout architecture, as architects design to control the activities within the built environment. According to Jane Farver, "much of contemporary architecture provides its users a controlled existence, disassociated from the environment and free of things that offend the senses or cause discomfort." ${ }^{10}$ Humans have taken it upon themselves to be in control of their own environments, removing natural processes to have human control take possession. This led architecture to be a product of the process in its response to human control, rather than being the process towards a breathable environment. Lally puts it this way:

"As architects, we readily acknowledge that in the interiors of buildings exist climates that we manipulate and control. This is what essentially permits a near-standardized building construction of the domestic home in the US, as the interior, regardless of where the structure is located, can be maintained and controlled nearly equally, regardless of any geographic or climatic difference."11

In regard to respiration, this control needs to be redefined and the object or focus needs to be recalibrated to ameliorate the toxic state of our atmospheres. With the rise and advancement of mechanical systems, "architects explored the potential of air-conditioning... structures was widened to the point where natural illumination was replaced completely with artificial." ${ }^{2}$ The architect's control became one of simulation rather than regulation of natural processes. The design of spaces slowly omitted the relevant factors of passive strategies and fixated itself on the quantities of height, square footage, and occupancy. However this control was only made possible through the advent of mechanical systems, which made architecture highly unstable with its success solely dependent on a singular machine:

"As walls became more robust, a yearning to create a connection to the outside world emerged and materialized in the form of windows. As structural systems and material inventions became more complex, loads could be concentrated and allow for expansive glazing. A full visual connection was enabled to the exterior without the sacrifice of a controlled interior climate. This control, however, depended largely on HVAC systems to heat and cool buildings." 13 


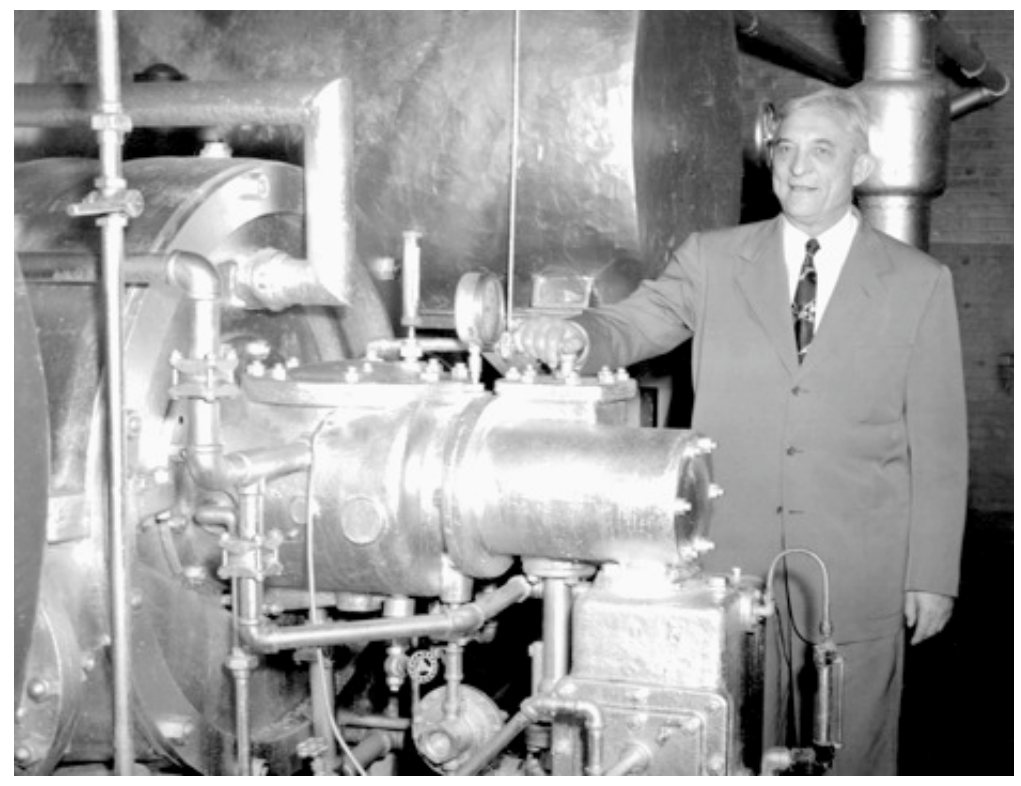

Fig 4.7 First air conditioner invented by Willis H. Carrier

The element of control, therefore, needs to be redefined to one that resembles the role of control in natural respiratory systems. All natural organisms actively respond intuitively to execute control over its own ideal environment (i.e., suitable for its own respiration and survival). Their control is not conditionally programmed but inherently embedded into their DNA to ensure their survival. This results in control exercised in precision that allows respiratory systems to proactively adapt to fluctuating environmental conditions. For "respiration" to occur in architecture, the element of control changes from the process of simulating artificial environments to a regulation of natural processes. 


\section{Endnotes}

${ }^{1}$ Bruno Latour. Air. Sensorium: embodied experience, technology, and contemporary art. (Cambridge: The MIT Press, 2006). 105.

2 Ibid.

${ }^{3}$ Francesco Manacorda. There is no such thing as nature. Radical Nature. (London: Koenig Books Ltd, 2009). 12.

${ }^{4}$ Dennis Dollens. Digital Botanic Architecture. (Santa Fe: SITES Books, 2005). 12.

${ }^{5}$ http://www.cbc.ca/news/health/air-pollution-kills-7-millionpeople-every-year-globally-who-finds-1.2585505 (accessed September 15, 2014).

${ }^{6}$ Francesco Manacorda, Air, 10.

${ }^{7}$ Philippe Rahm. Architecture design as a movement of air. Airflux. www.philipperahm.com/data/projects/airflux/index.html (accessed November 13, 2014)

${ }^{8}$ Mohen Mostafavi, David Leatherbarrow. On Weathering: The Life of Buildings in Time. (Cambridge: The MIT Press, 1993). 64.

${ }^{9}$ Michael Pawlyn. Biomimicry in Architecture. (London: RIBA Publishing, 2011). 81.

10 Jane Farver. Francois Roche and R\&Sie(n). Sensorium: embodied experience, technology, and contemporary art. (Cambridge: The MIT Press, 2006). 85.

11 Sean Lally. Eat me...Drink me... Territory: Architecture Beyond Environment. (Chichester: John Wiley \& Sons, 2010). 16.

${ }^{12}$ David Gissen. Big \& Green : Toward sustainable Architecture in the 21st Century. (New York: Princeton Architectural Press, 2009). 12.

${ }^{13}$ Jurgen Mayer, Neeraj Bhatia. -arium: Weather + Architecture. (Ostfildern: Hatje Cantz,2010). 154.

\section{Image References}

1 http://3.bp.blogspot.com/-K3ltSQmpdAU/ VB7k2EnHJSI/AAAAAAAA9zY/2q2iEr-eQgc/s1600/

Animals\%2Bin\%2BWorld\%2BWar\%2BI\%2B\%282\%29.jpg

2 http://i.livescience.com/images/i/000/031/456/i02/lungsdiagram-120926.jpg?1348765086

${ }^{3}$ http://www.philipperahm.com/data/projects/airflux/index.html

${ }^{4}$ http://www.philipperahm.com/data/projects/windtrap/index.html

${ }^{5}$ Ibid.

${ }^{6}$ http://dressingtheair.com/uploads/74/awB3Y8jp60R7DMA6.jpg

${ }^{7}$ http://www.williscarrier.com/images/gallery/1922WHC_ OnonPottery2_92684.jpg 


\subsection{How the City Breathes}

Urban growth in cities drastically altered the conditions of humanity and its relationship with architecture in the natural environment. According to a 2014 report by the United Nations, $54 \%$ of the world's population lives in urban areas where the proportion is expected to reach $66 \%$ by $2050 .{ }^{1}$ The overwhelming numbers in city developments have caused skeptics to question the entire process of urbanization due to extreme climate changes experienced across the world. Environmentalists have connected urban developments as the cause to climate change as a result of the immense carbon dioxide emissions from energy consumption. In the United States, where over $90 \%$ of its people live in urban cities, buildings account for $44.6 \%$ of its national $\mathrm{CO}_{2}$ emissions while transportation accounts for $34.3 \% .^{2}$ There is an undeniable relationship between cities and the natural environment where the latter seems to deteriorate as the former increases in size. $\mathrm{CO}_{2}$ emissions and other pollutants are making the atmosphere harder to breathe in. Instead of investigating ways to resolve the increasingly toxic state of the atmosphere, people have chosen to ignore reality by simply turning to artificial environments instead. While artificial environments induced by mechanical systems do solve the immediate issue of respiration, it is only a temporary fix without consideration of the bigger picture of the natural environment. In order to seek a long-term solution that resolves the breathability of a city, one must understand how a city breathes.

In many ways, cities have a similar respiratory system to living organisms. In fact, Herbert Girardet describes cities as 'super organisms' in his book, Cities People Planet: Urban Development and Climate Change, where he uses the colonial infrastructures of termites as an analogy to city dynamics. ${ }^{3}$ Similar to termite mounds, the city structure itself does not need to breathe but the people living within it do. While termites have taken that understanding to application in its collective effort to actively alter its city-like network within the mound to achieve breathability, city planners and architects alike seem to miss the point. Cities composed of largely buildings and infrastructure lack a cohesive system that is able to provide a breathable environment at large. Instead, people rely on the two largest contributors to $\mathrm{CO}_{2}$ emissions (i.e., buildings and transportation) to simulate breathable interior environments to mask the reality of the exterior. At the cost of the natural environment, people have chosen to disengage from nature and resort to a simulation of breathability and comfort. 
"Within the writings of Tafuri, the only hope for architecture as a humanist discipline was its disengagement freedom from integrating those constructs that simply transform architecture into a tool of expanding economic development. Absorption of the environment is rejected in favour of an architecture that is aloof relative to the given context. Tafuri, and the architects with whom he shared influence, such as Aldo Rossi or Peter Eisenman, refused to integrate their buildings directly into the environment, as it was conceived." 4

Despite its separation, the city still breathes in a way that is comparable to cellular respiration. Alike the arteries that carry oxygen throughout organisms, carbon dioxide emission get transported throughout the city in the forms of highways where countless vehicular traffic pass through. Buildings constantly consume energy in order to maintain the artificial interior environment to be suitable for breathers, thereby pumping more carbon dioxide into the environment. Contrary to the process of respiration, much of urban cities' 'respiration' has a negative impact on its environment. This has to do with the way buildings and transportations breathe in its process of converting energy. Despite seemingly contradictory, both the respiration and combustion processes results in a transformed energy process, whether it is from oxygen to carbon dioxide or vice versa. It is therefore important to understand the process of how a city breathes in order to deal with the issue of breathability directly. 


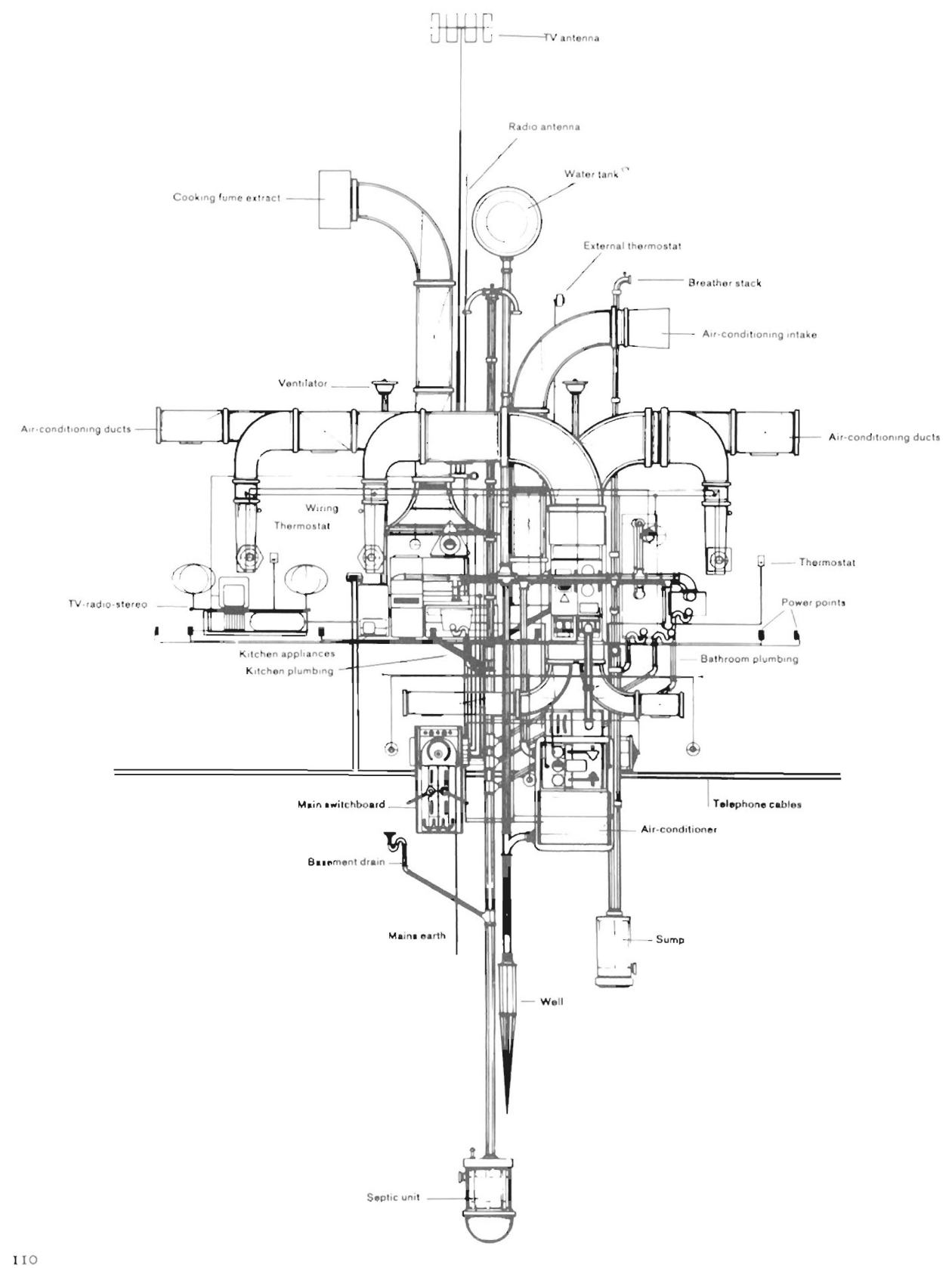

Fig 5.1 Anatomy of a Dwelling (1965) Francois Dallegret 


\subsection{HowBuildings Breathe}

Vitruvius describes architecture as "the Primitive Hut" that has become a standardized theory in architectural history. ${ }^{5}$ However, architecture has evolved significantly since the times of Vitruvius that serves more than the fundamental needs of shelter. The idea of "the Primitive Hut" is no longer primitive due to the increasingly complex nature of technology and building science. In A Home is Not a House, Banham criticizes the modern building as "environmental machinery" due to the widespread dependence on HVAC mechanical units that no longer values the fundamentals of architecture. ${ }^{6}$ This shift in architecture brings the topic of respiration into discussion as buildings are becoming increasingly airtight to rely more on mechanical systems to respire.

As architects, we readily acknowledge that in the interiors of buildings exist climates that we manipulate and control. This is what essentially permits a near-standardized building construction of the domestic home in the US, as the interior, regardless of where the structure is located, can be maintained and controlled nearly equally, regardless of any geographic or climatic difference. ${ }^{7}$

Francois Dallegret's illustration of Anatomy of a dwelling illustrates a powerful image of how the building's mechanical layout can be compared to the human anatomy. Similar to the human lung, the building takes in supply air into a central air-handling unit for processing. Arteries in the form of mechanical ducts carry fresh air throughout the building interior. The exhaust air then gets extracted back through separate exhaust ducts and then released back outside. As one integrated system, buildings seem promising in its ability to breathe. However, this system is highly dependent on mechanical systems that are apart from architecture. Without the system, the building itself cannot breathe. Instead of viewing architecture as a self-reliant respiratory system, it should be viewed as an extension of the breather. This takes away the misconception that buildings need to breathe but rather focuses on the source of the need that allows the architecture to be able to be reconsidered apart from mechanical systems. 
Fig 5.2 Anatomy of HVAC. How Buildings Breathe.

HOW BUILDINGS BREATHE
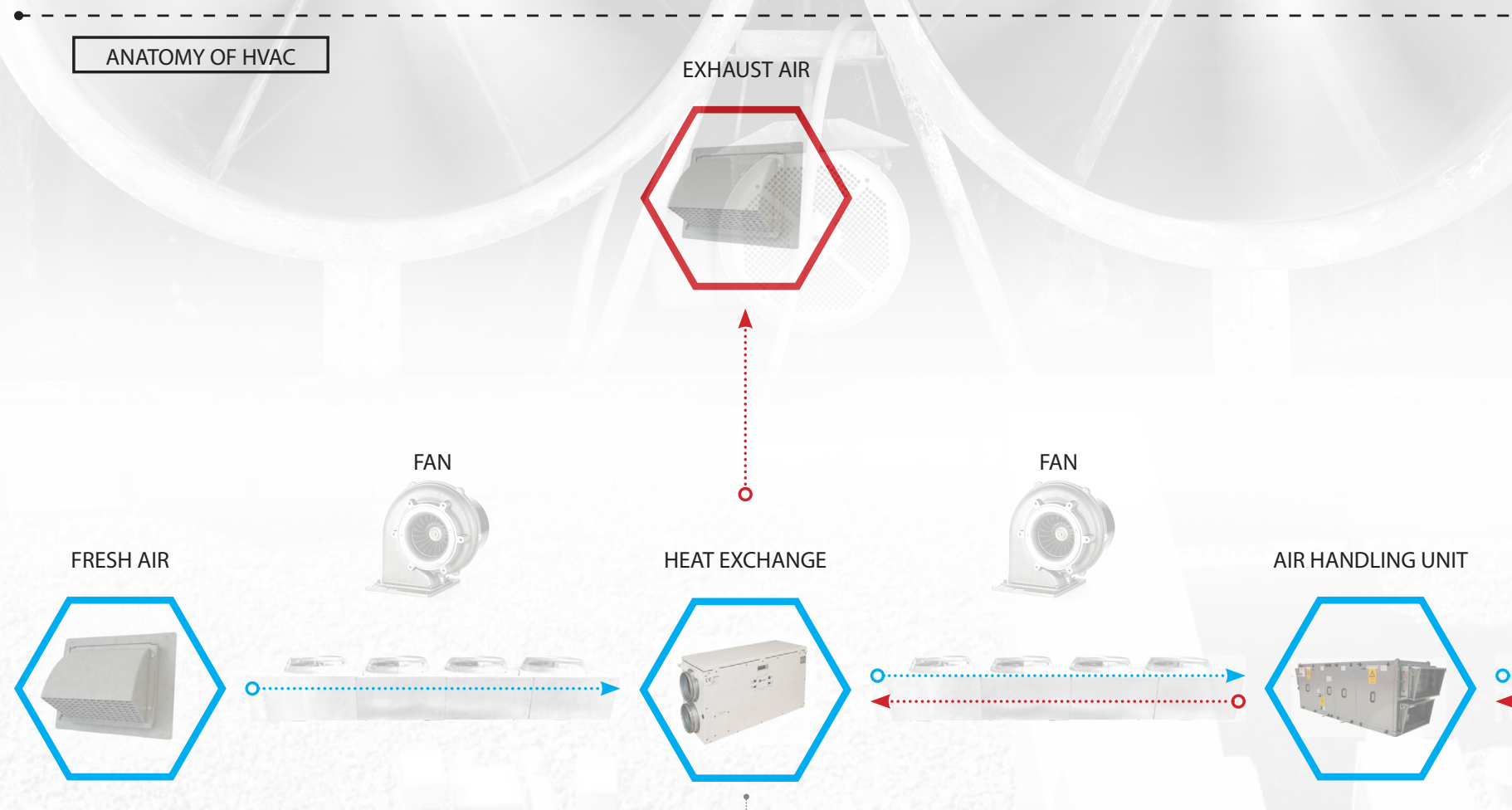
CHILLER
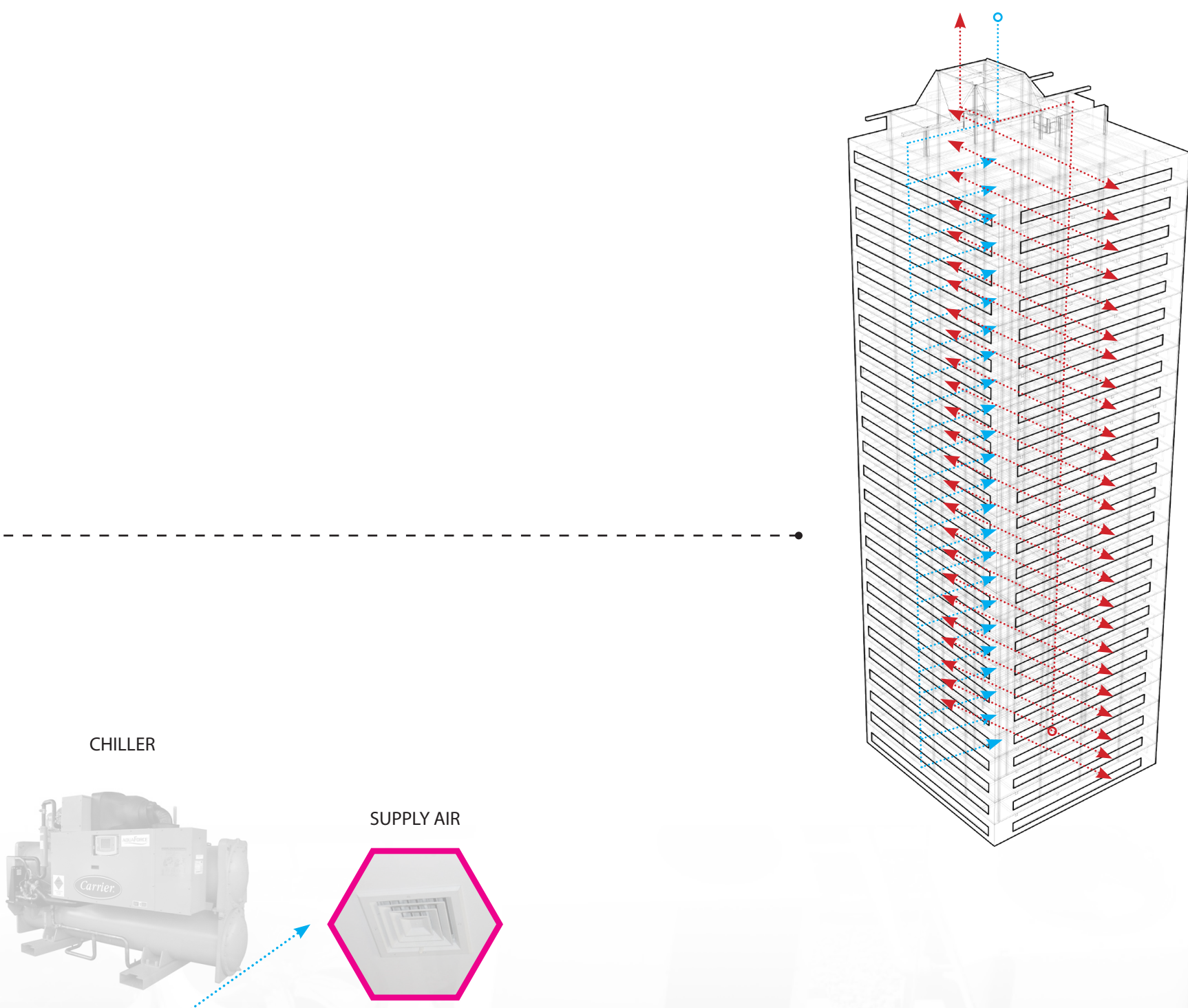

$\left[\begin{array}{l}2 \\ 0\end{array}\right.$

RETURN AIR

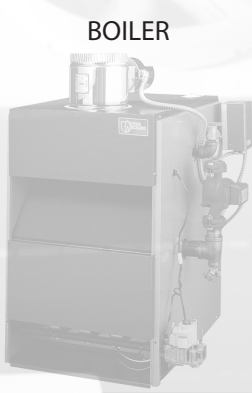

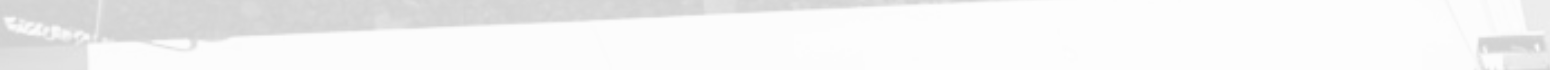


Fig 5.3 Anatomy of Vehicles. How Vehicles Breathe.

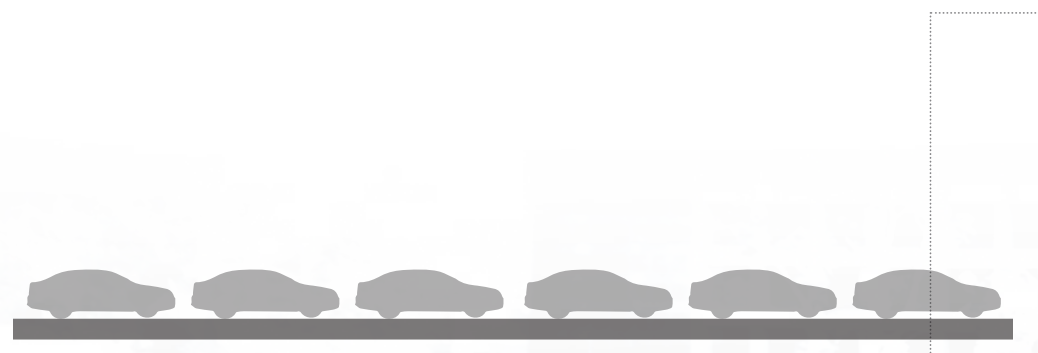

High volumes of vehicular traffic are often found on city highways and busy intersections, leading to high concentrations of carbon dioxide pollution surrounding major road arteries. In Toronto, $60 \%$ of the city's carbon emission is associated with traffic pollution. Highways become the city's urban arteries that's responsible for transporting carbon emissions throughout the city. In a way, the city's respiratory system is manifested through vehicular traffic moving throughout highways carrying carbon dioxide similarly to the movement of oxygen throughout the human lung.
The spark plug delivers an electric current to the combustion chamber to ignite the compressed mixture of fuel and air to allow the gasoline to combust at the required high temperature
Air gets drawn into the intake valve where it then releases the oxygen to oxidize with the gasoline in the combustion chamber

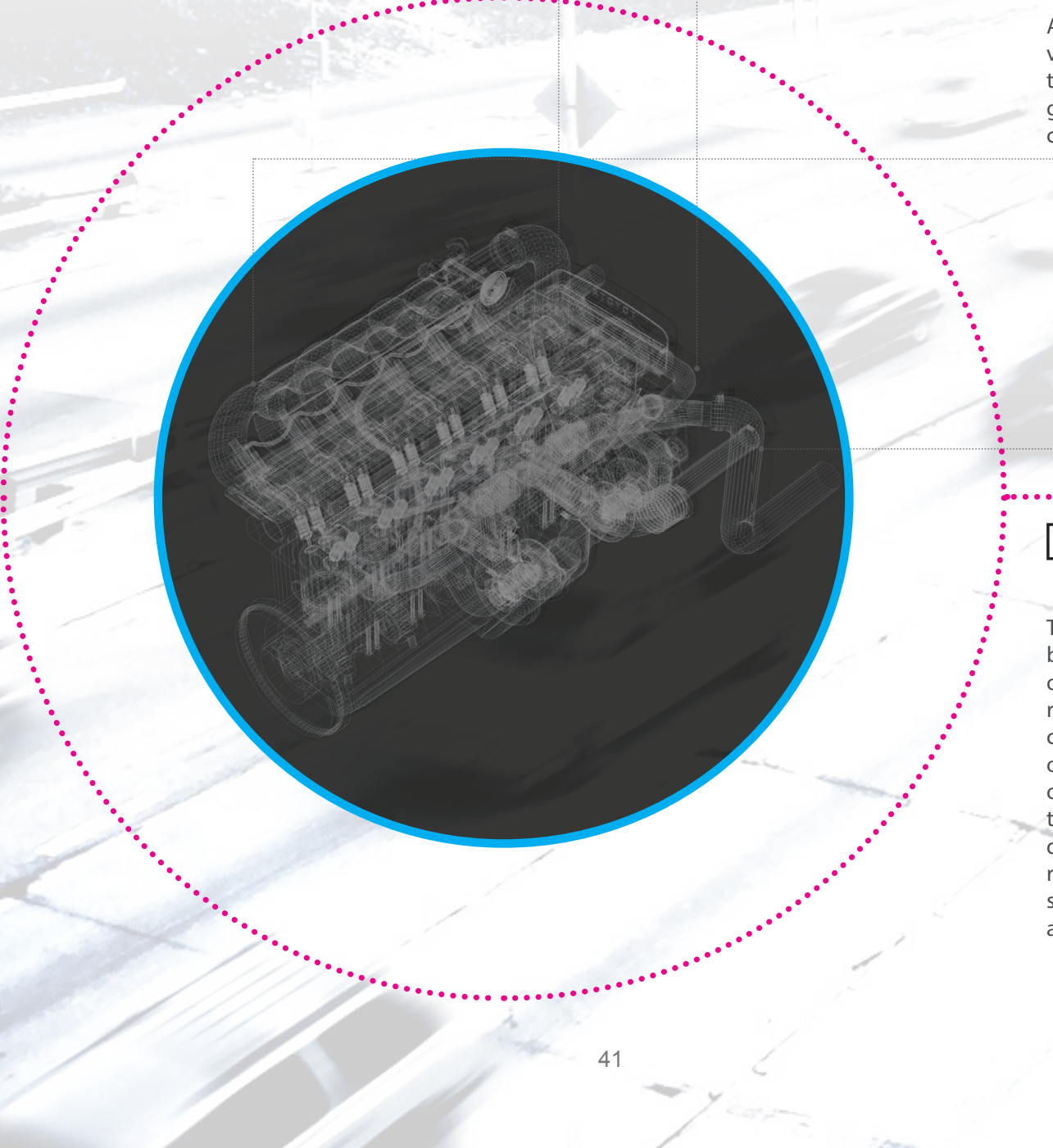

VEHICULAR "RESPIRATION"

There are many similarities between the combustion that occurs in a car's engine and cellular respiration. Both are a result of a complex process that involves the oxidation and fragmentation of organic compounds leading to a transformation of elements. The dividing difference lies in the final result where combustion produces significantly more carbon dioxide and energy 

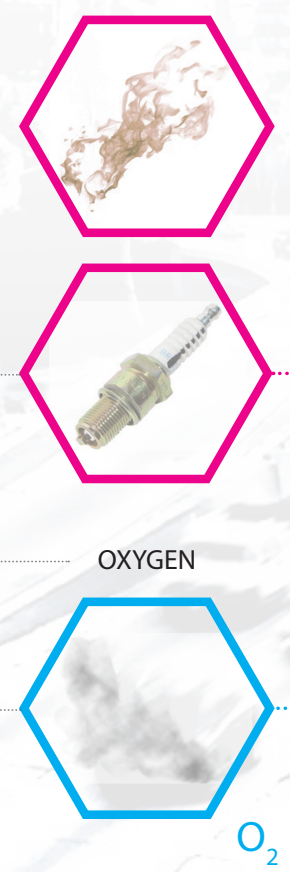

$\mathrm{O}_{2}$
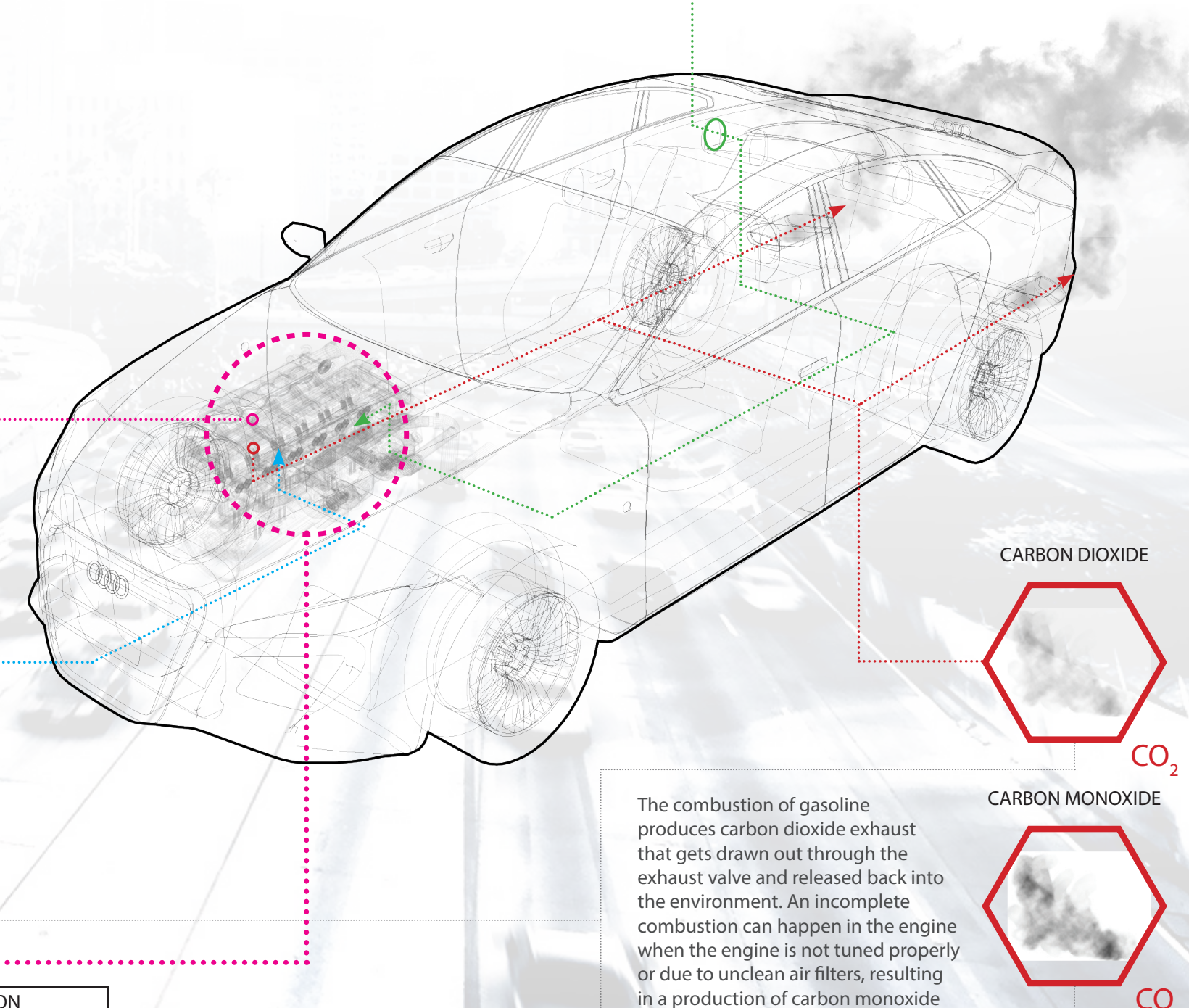

CARBON MONOXIDE produces carbon dioxide exhaust that gets drawn out through the exhaust valve and released back into the environment. An incomplete combustion can happen in the engine or due to unclean air filters, resulting

Chemical Process of Combustion
Hydrocarbon + Oxygen
$\mathrm{C}_{\mathrm{x}} \mathrm{H}_{\mathrm{y}}+\mathrm{O}_{2}$
$\rightarrow \mathrm{CO}_{2}+\mathrm{H}_{2} \mathrm{O}$
Carbon Dioxide + Water
Gasoline + Oxygen
$2 \mathrm{C}_{8} \mathrm{H}_{18}+25 \mathrm{O}_{2}$
$>16 \mathrm{CO}_{2}+18 \mathrm{H}_{2} \mathrm{O}$
Carbon Dioxide + Water
Incomplete Combustion

Gasoline + Insufficient $\quad \mathrm{C}_{8} \mathrm{H}_{18}+8.5 \mathrm{O}_{2} \quad$ • Oxygen

Glucose + Oxygen
Biological Process of Cellular Respiration

$\mathrm{C}_{6} \mathrm{H}_{16} \mathrm{O}_{6}+6 \mathrm{O}_{2} \quad \cdots \quad 6 \mathrm{CO}_{2}+6 \mathrm{H}_{2} \mathrm{O}$

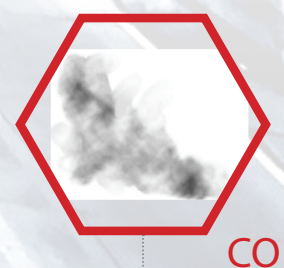

$\mathrm{CO}$ 


\subsection{How Vehicles Breathe}

As the second largest contributor to carbon emissions in urban cities, vehicular pollution is a major symbolism representing the epitome of urban air pollution. ${ }^{8}$ Unlike city buildings, transportation pollution has drawn significantly more attention as a point of emphasis in the pursuit of a more sustainable future. Governments across the world have put policies in place to strategically lower vehicular pollution. From HOV lanes (high occupancy vehicle) to incentives on hybrid and electric cars, urban cities have recognized the growing problem of traffic congestion leading to urban pollution and began targeting it. In an extremely congested city like Beijing, China, municipal government officials have enforced a new oddeven rule in a strategic attempt called "road space rationing" to effectively limit the number of vehicles allowed on the roads each day. ${ }^{9}$ This strategy restricts drivers with license plates ending either in odd or even numbers to drive on alternating days in efforts to decrease traffic congestion in half. ${ }^{10}$ Beyond the statistical impact of vehicular pollution, cars also represent an active flow of pollution that gets transported throughout the city in networks of road infrastructure. Currents of "bad" air get distributed and eventually dissipate into the air that we breathe. Metaphorically, this process of combustion in vehicles can be paralleled to respiration as both processes involve the transformation of energy in the forms of oxygen and carbon dioxide. As a result, the process of combustion in vehicles can be understood to be a variation of respiration.

Similar to the human respiratory system, cars have a central respiratory regulator in the form of a mechanical engine. Cars draw in fresh air into the combustion chamber where a chemical process occurs to oxidize gasoline for energy needed to run the car. Compared to the biological process of cellular respiration, combustion takes place at a much higher temperature induced by the ignition of spark plugs to stimulate the process. The end result of both processes result in the production of oxygen transformed into carbon dioxide; however, vehicular combustion produces much more carbon emissions per process. For this reason, vehicular combustion is deemed far more negative than the cellular respiration even though both results are comparatively similar. Further, with the growing affordability of cars as well as the urban population, there are increasingly more vehicles brought into cities without an effective solution to respond to the consequence of vehicular respiration. This makes vehicular pollution a pressing concern in the context of a city's urban respiration that needs 


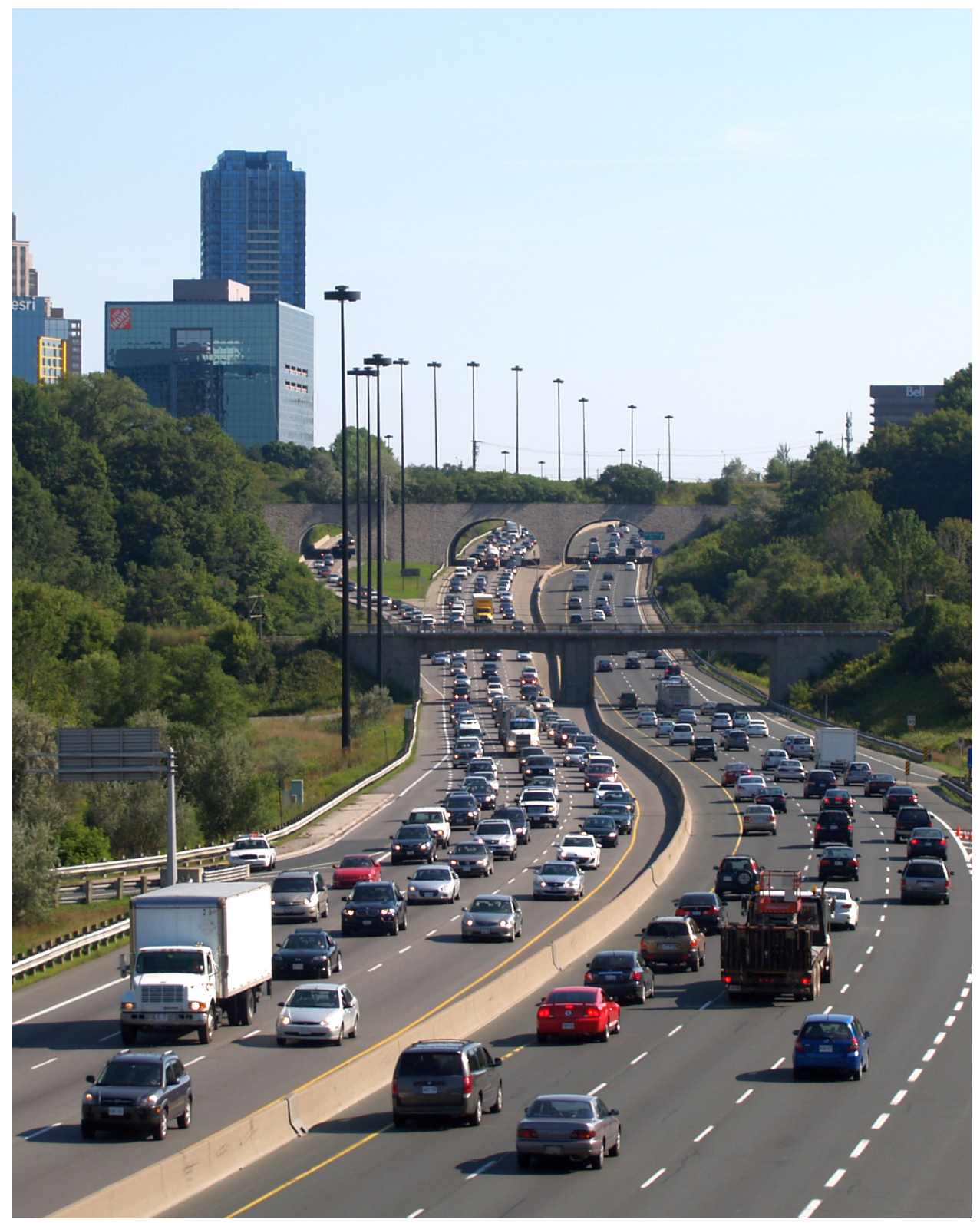

Fig 5.4 Vehicular traffic on the Don Valley Parkway in Toronto

to recognize this issue at hand and actively rethink the future of city developments that can deal with mediating the byproducts of vehicular respiration directly. Albeit ineffective, Le Corbusier himself recognized this need in a time that was far less extreme in comparison to cities today through his master plan design of Ville Radieuse.

He (Corbusier) believed that a buffer of greenery would provide refuge from vehicle exhaust, a concept that extends attitudes toward streets developed by nineteenthcentury British reformers. ${ }^{11}$ 


\subsection{Where to Breathe?}

Large urban cities around the world are the epicentres of society and social interaction. Each of these cities has its own identity that represents the people of the area and boasts of local urban development and economic prosperity. Because of this, these cities attract people - both inhabitants and visitors, from within and abroad - for a variety of reasons (e.g., business, education, tourism). As a result, these cities are the busiest and densest areas in any geographic regions. Despite the overwhelming benefits that are attributed to urban cities, there are equal, offsetting costs that confront urban dwellers. One of the most significant and visible of these costs is poor air quality.

There is a social phenomenon where urban city-dwellers choose to "get away from the city" and travel to comparatively more rural areas, in order to get "fresh air". Although this statement is not an all-encompassing representation of city dwellers, it is generally reflective of the subtle nature of urban city-dwellers' views of respiration. Even those who are not able to actually "get away from the city" often envision the prospects of getting out into the "fresh air". This is reminiscent of the industrial revolution era, where families would migrate to suburban areas to get away from the toxicity of urban pollution. To this very day, this is one of the main driving forces behind the boom of suburban neighbourhoods. As such, urban cities are barely adequate for living, and totally inadequate for life.

However, the temporary solution of running away from the problem has resulted in a compounding of the problem. People are moving further away from their places of work (i.e., in urban cities), increasing the distance commuted. Suburban cities continue to grow and develop simultaneously as the overall global population increases, resulting in the creation of urban centres within suburbs.

Thus, the issue of respiration within urban cities is imperative when designing for the future. As the global atmosphere grows increasingly toxic due to carbon emissions, there is an urgency to redefine the built environment in response to respiration. With a dwindling amount of natural resources and a strained process to mediate urban pollution, the question of "where to breathe" leads to the realization that urban cities need to have the ability to respire. Breathability within the urban context is the key to the continued viability of large urban centres. 


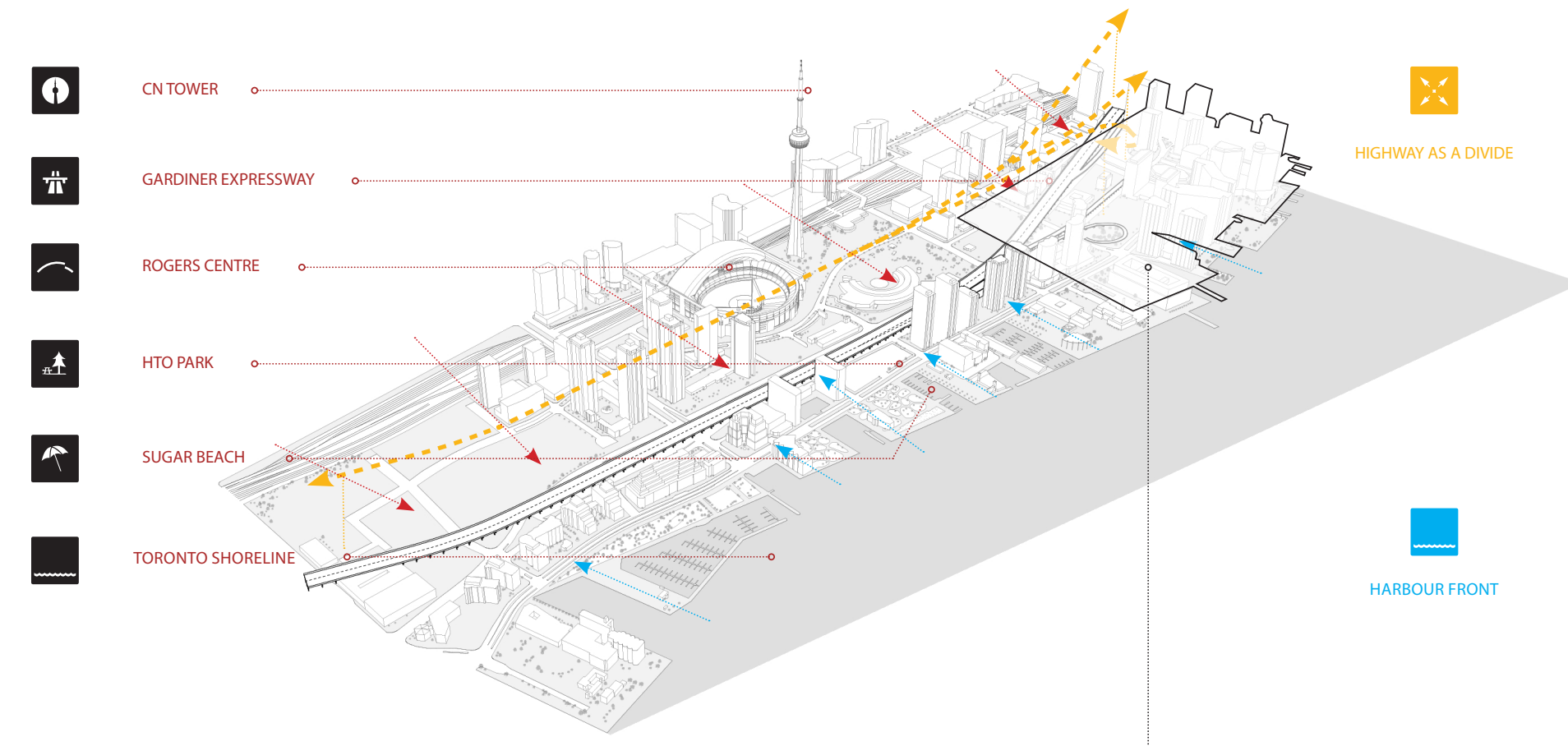

Fig 5.5 Diagram of the Gardiner Expressway dividing up the downtown core of Toronto

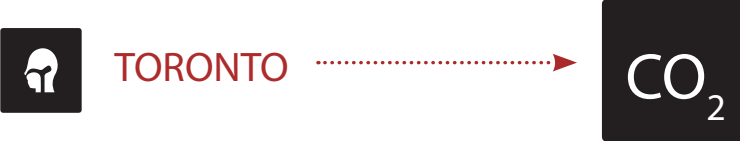

2012 TORONTO PUBLIC HEALTH REPORT:

$\approx 1,700$

PREMATURE DEATHS

\section{( 6,000}

HOSPITALIZATIONS

\section{$\boldsymbol{\lambda}$}

MAJORITY INVOLVE ELDERLY AND CHILDREN

\section{a}

1,200 CASES OF ACUTE BRONCHITIS PER YEAR
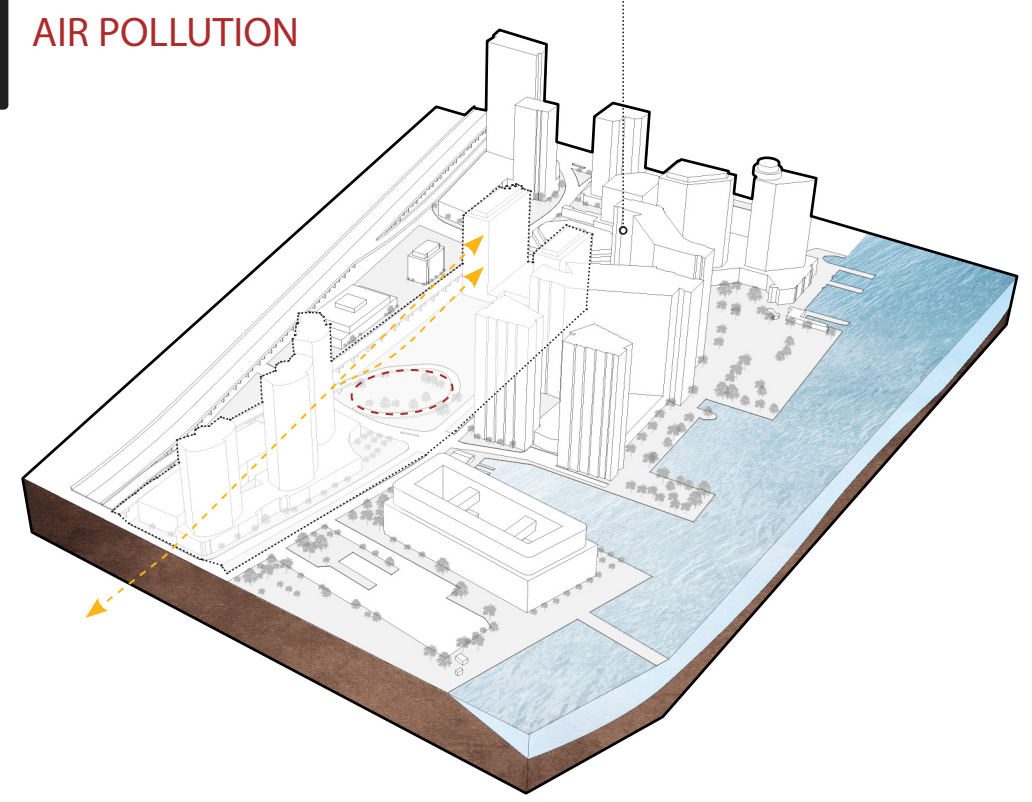

Fig 5.6 Site analysis of urban pollution in Toronto according to the 2012 Toronto Public Health Report 


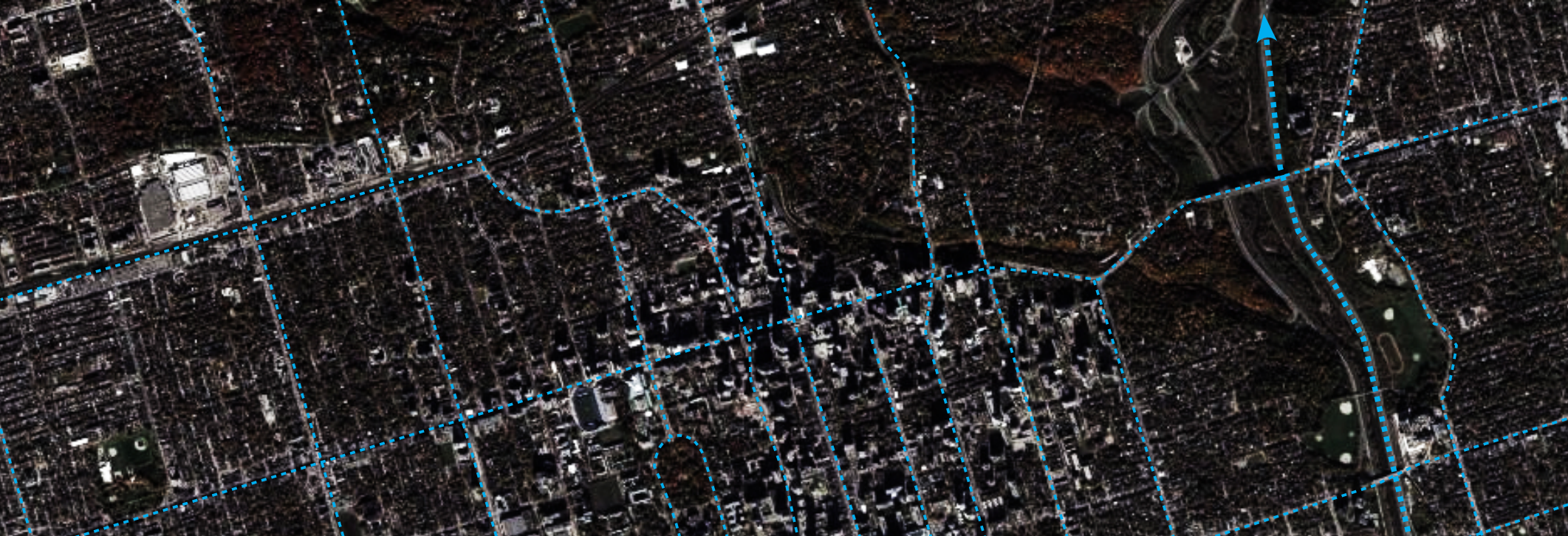




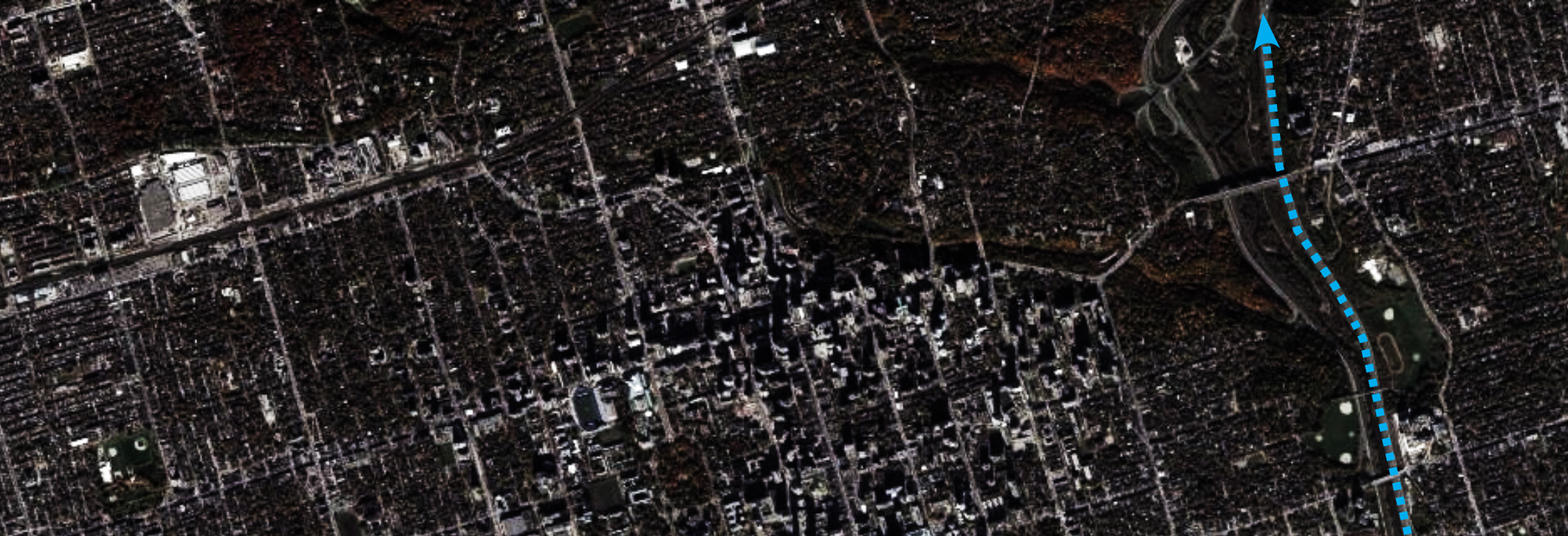



(1)

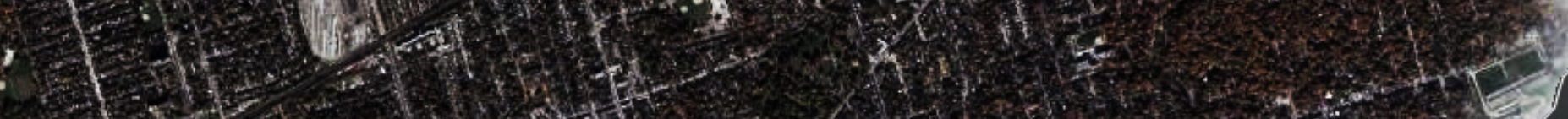

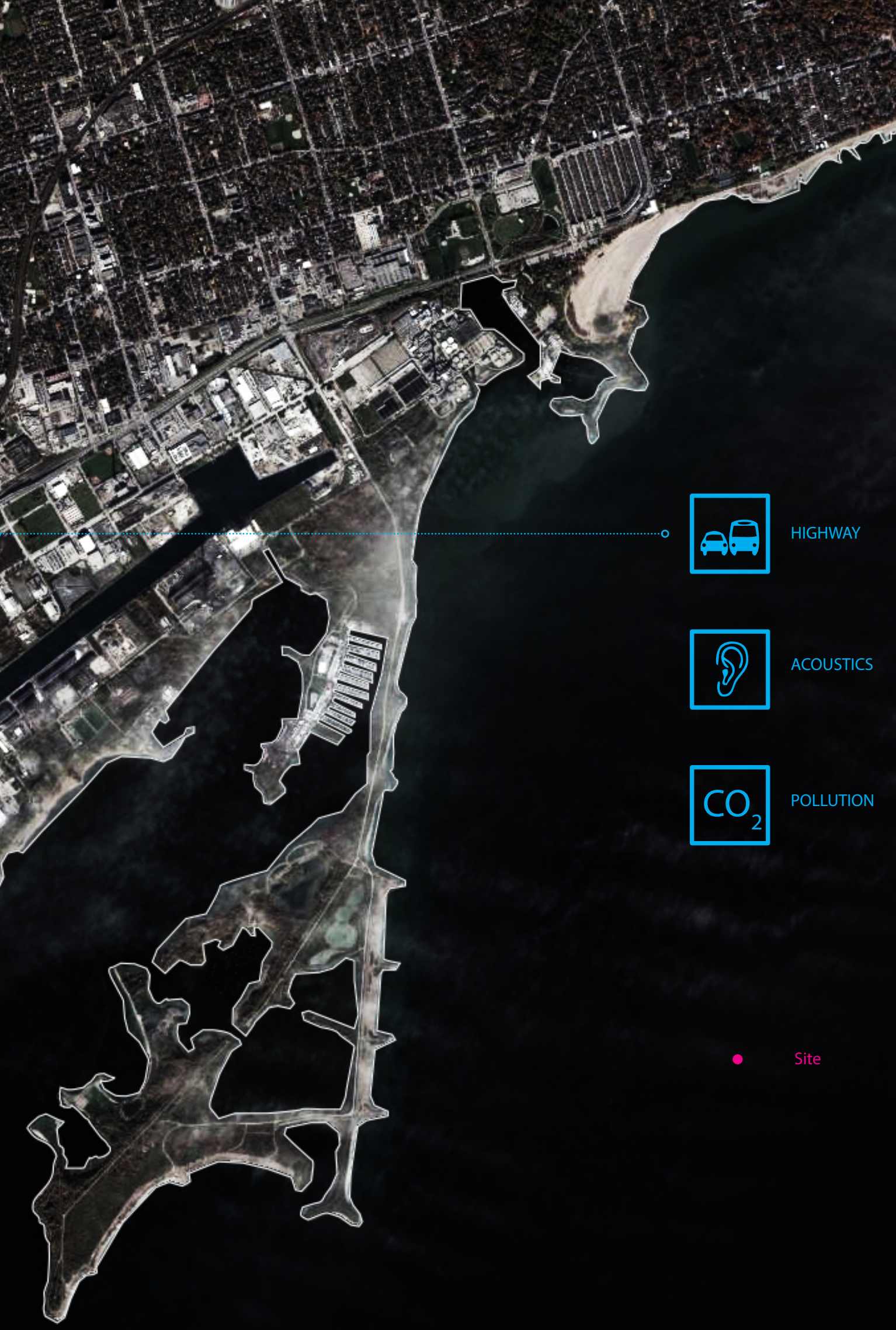

Fig 5.7 Map of the G.T.A (Greather Toronto Area) with statistics (Continued) 


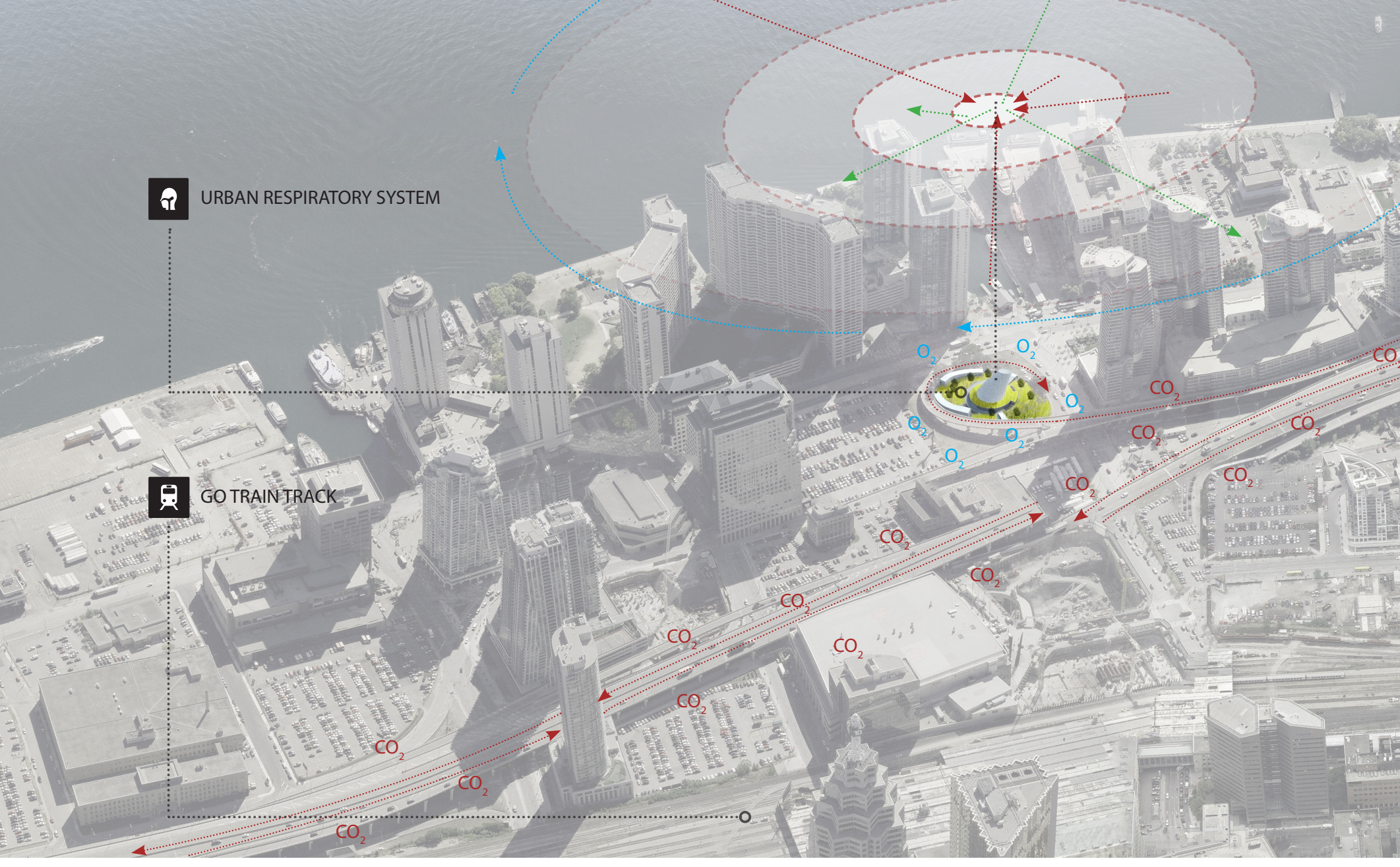

\subsection{Anti-Respiration}

With an understanding of how cities breathe, urban cities can be thought of as respiratory systems themselves - the process remains the same (albeit resulting in a completely different outcome). When viewed as a system, urban cities work counter intuitively against the biological process of trees and vegetation in transforming carbon pollution in the air. Not only are urban cities increasing the burden on these natural systems, but the constant development of the built environment also eradicates the already diminishing source of natural systems (i.e., trees). The relationship of urban density is inversely proportional to the number of trees as urban cities continue to expand into habitats of the natural environment. Consequently, the urban city can be identified as an "anti-respiratory" system, directly working against the natural environment's ability to breathe. 



\section{Endnotes}

${ }^{1} \mathrm{http} / / /$ www.un.org/en/development/desa/news/population/worldurbanization-prospects-2014.html (accessed January 10, 2015)

${ }^{2}$ Architecture2030.org/the problem/problem_climate_change (accessed January 10, 2015)

${ }^{3}$ Herbert Girardet. Cities People Planet: Urban Development and Climate Change. (Chichester: John Wiley \& Sons, 2008). 110.

${ }^{4}$ David Gissen. Territory: Architecture Beyond Environment. (Chichester: John Wiley \& Sons, 2010). 11.

${ }^{5}$ Vitruvius. The Ten Books on Architecture. (New York: Dover Publications Inc, 1960). 38.

${ }^{6}$ Reyner Banham. A Home is not a House. (2007). 159-166.

${ }^{7}$ Sean Lally. Eat Me...Drink Me... Territory: Architecture Beyond Environment. (Chichester: John Wiley \& Sons, 2010). 16.

${ }^{8} \mathrm{http}: / /$ www.who.int/hia/examples/trspt_comms/hge transport factsheet low-resdurban 30 11 2011. pdf?ua=1 (accessed March 2, 2015)

9 http://www.chinadaily.com.cn/beijing/2014-12/04/ content_19022525.htm (accessed March 2, 2015)

${ }^{10} \mathrm{Ibid}$.

11 David Gissen. Subnature: Architecture's Other Environments. (New York: Princeton Architectural Press, 2009). 73.

${ }^{12}$ Architecture2030.org/the_problem/problem_climate_change (accessed January 10, 2015)

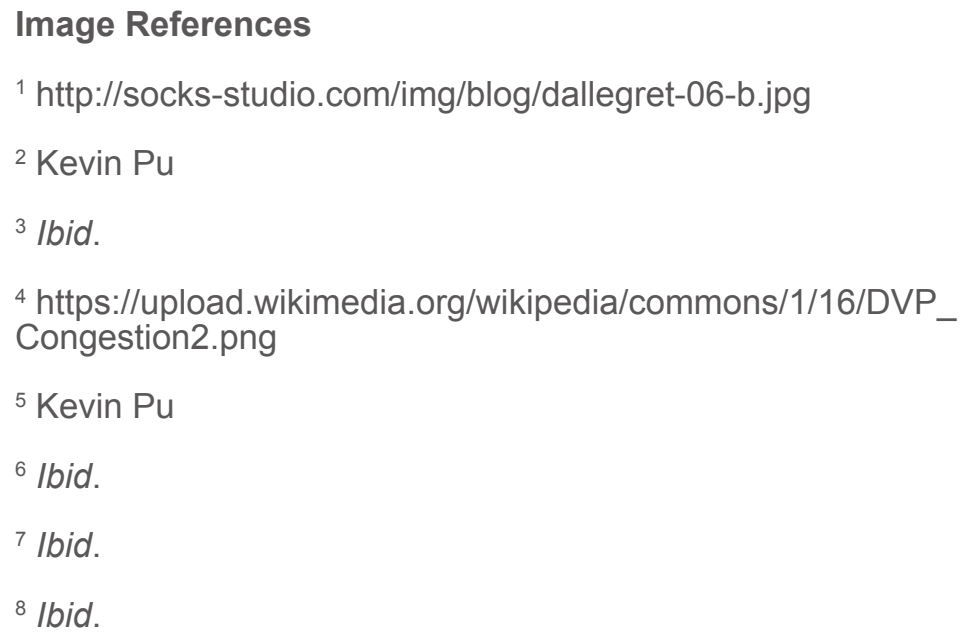

7 Ibid.

8 Ibid. 


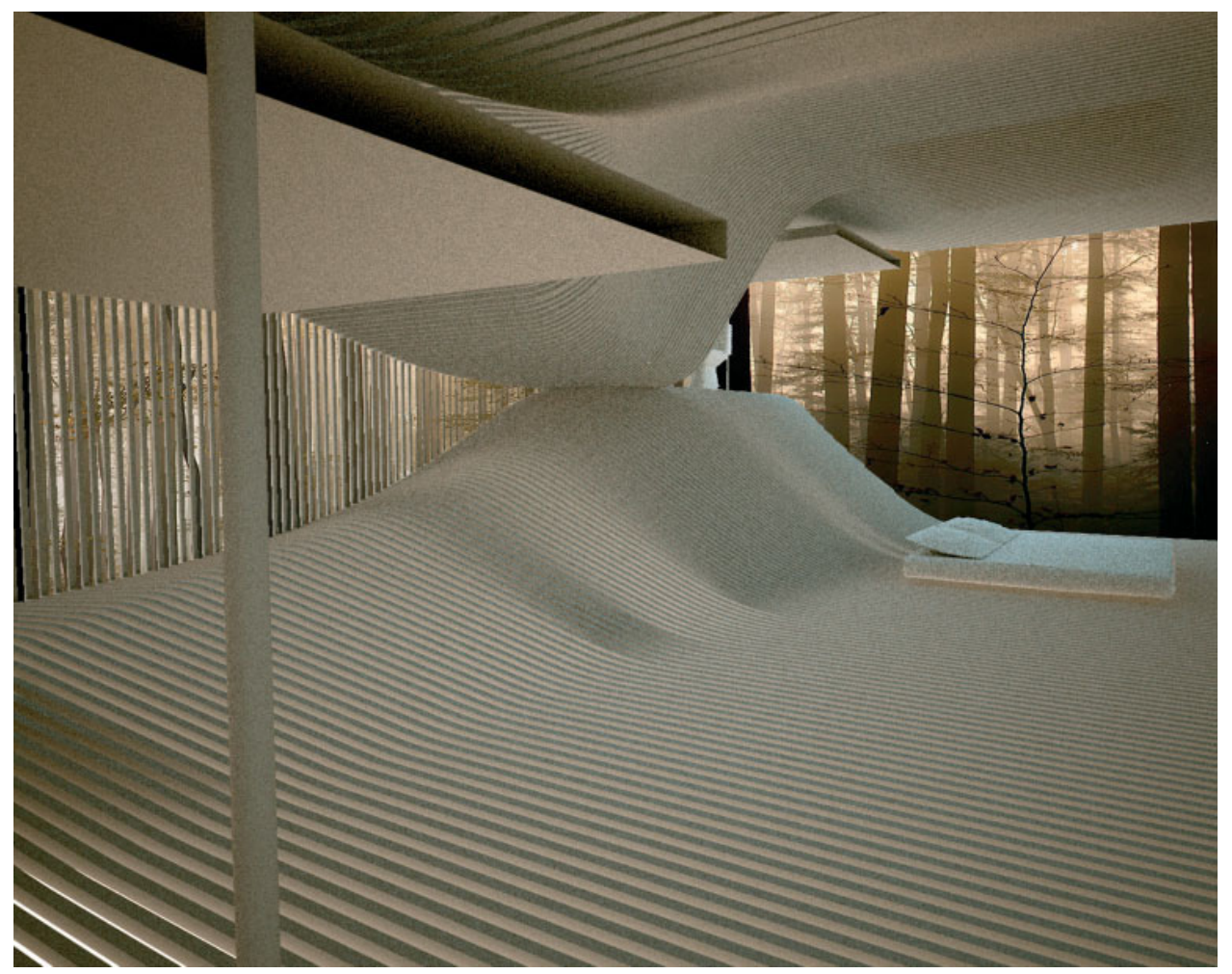

Fig 6.1 Interior Gulf Stream (2008) Philippe Rahm

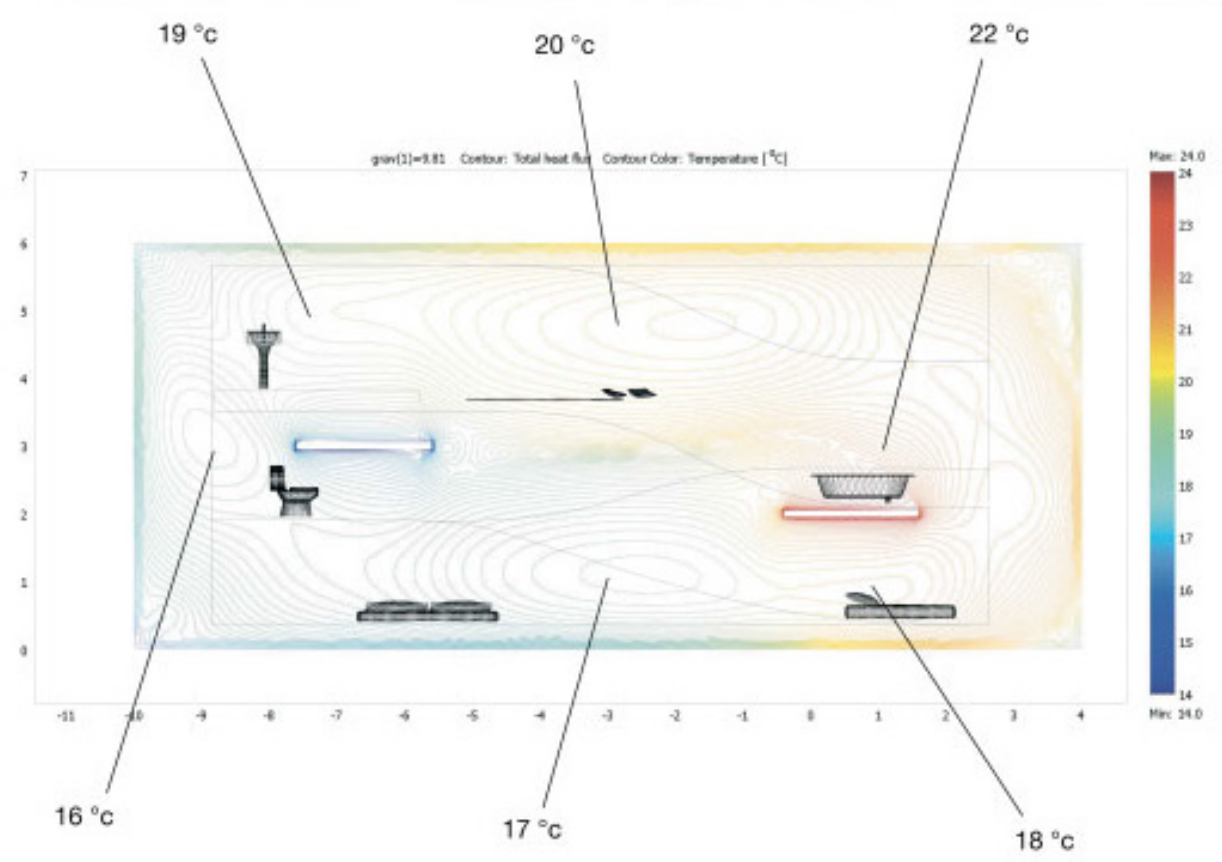

Fig 6.2 Diagram of convection movement in the Interior Gulf Stream Research House 


\subsection{Learning from Nature}

While architecture does not need oxygen, the breathers that it is designed to envelop do, which makes buildings a part of a larger respiratory system that impacts the breathability of the breather's atmospheres. In this regard, it is important to learn from natural respiration processes to inform architecture and its consideration for the breather. Manacorda identifies this learning process in Radical Nature and states that "the acts of copying, emulating, representing and reproducing are timeless and essential tools for both art and architecture."1 However, as oppose to biomimicry, learning from nature is not merely translating natural systems directly to architecture in forms of patterns, but learning how nature works intuitively and integrating respiration into architectural processes. Natural respiration comprises a series of exchanges that impact both the larger natural environment as well as the internal organism itself. In the same way, architecture is placed as an intermediate bridge between interior and exterior environments and has the potential to seamlessly link both atmospheres in a positive way. Metaphorically, drawing principles from nature makes a way for architecture to be a positive contributor towards both the natural environment at large as well as the interior atmosphere and its breathers. In doing so, architecture shifts from being static into a new responsive and proactive respiratory system. Philipe Rahm describes this potential in Meteorlogical Architecture:

"Architecture has to generate new nature in this artificial global environment. From inertia, architecture has to be breathing; from functionality and rationality, architecture has to become geography and meteorology."2

There are countless potential natural systems to learn from, all varying in different aspects and some with overlapping similarities. With the mandate of informing architecture's ability to integrate itself as a part of a larger respiratory system, it is less important which natural system is chosen and more critical to pick systems that can effectively be applied to architecture. Therefore, picking systems with different levels and types of respiration can best inform architecture in a holistic approach. The following chapter will investigate the respiratory processes of trees (closed loop system), flies (surface area to volume), and termite mounds (systematic process) that will provide a fair range of understanding on how natural respiration processes occur. 


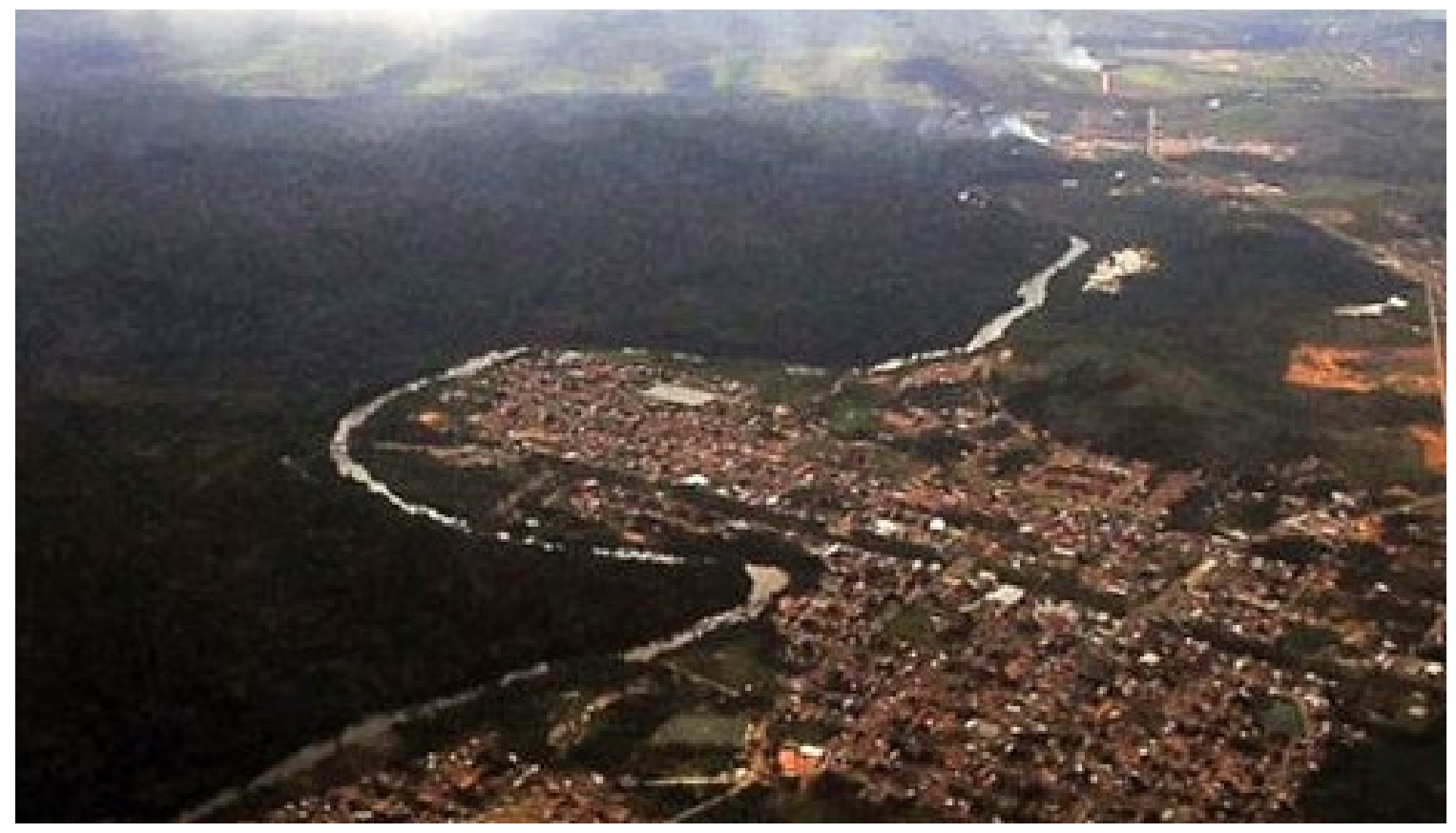

Fig 6.3 City of Parauapebas, Brazil. Urbanization in one of Brazil's fastest growing cities leading to expanisve deforestation into the Amazon rainforest

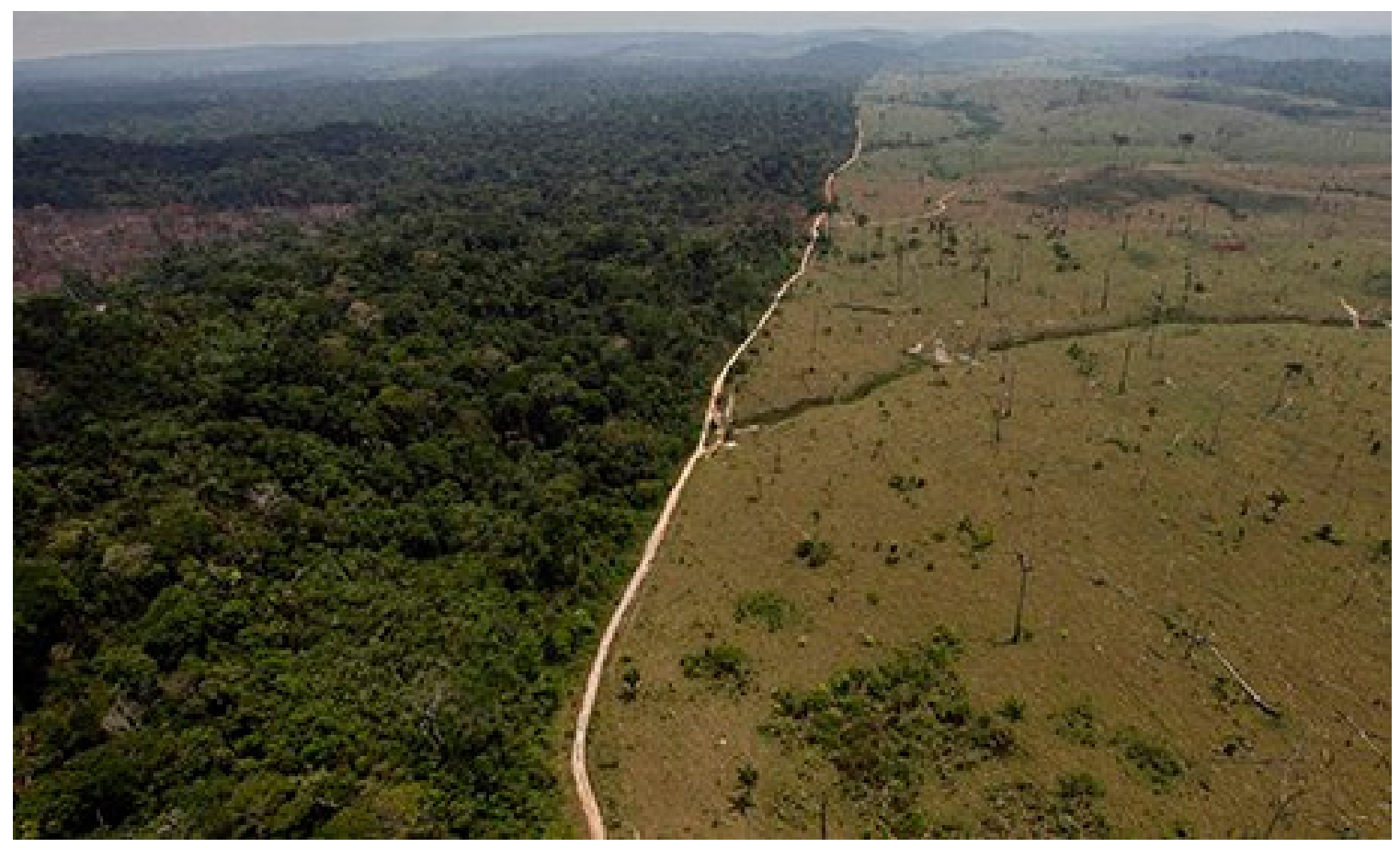

Fig 6.4 Deforested area near Novo Progresso in Brazil's northern state of Para 


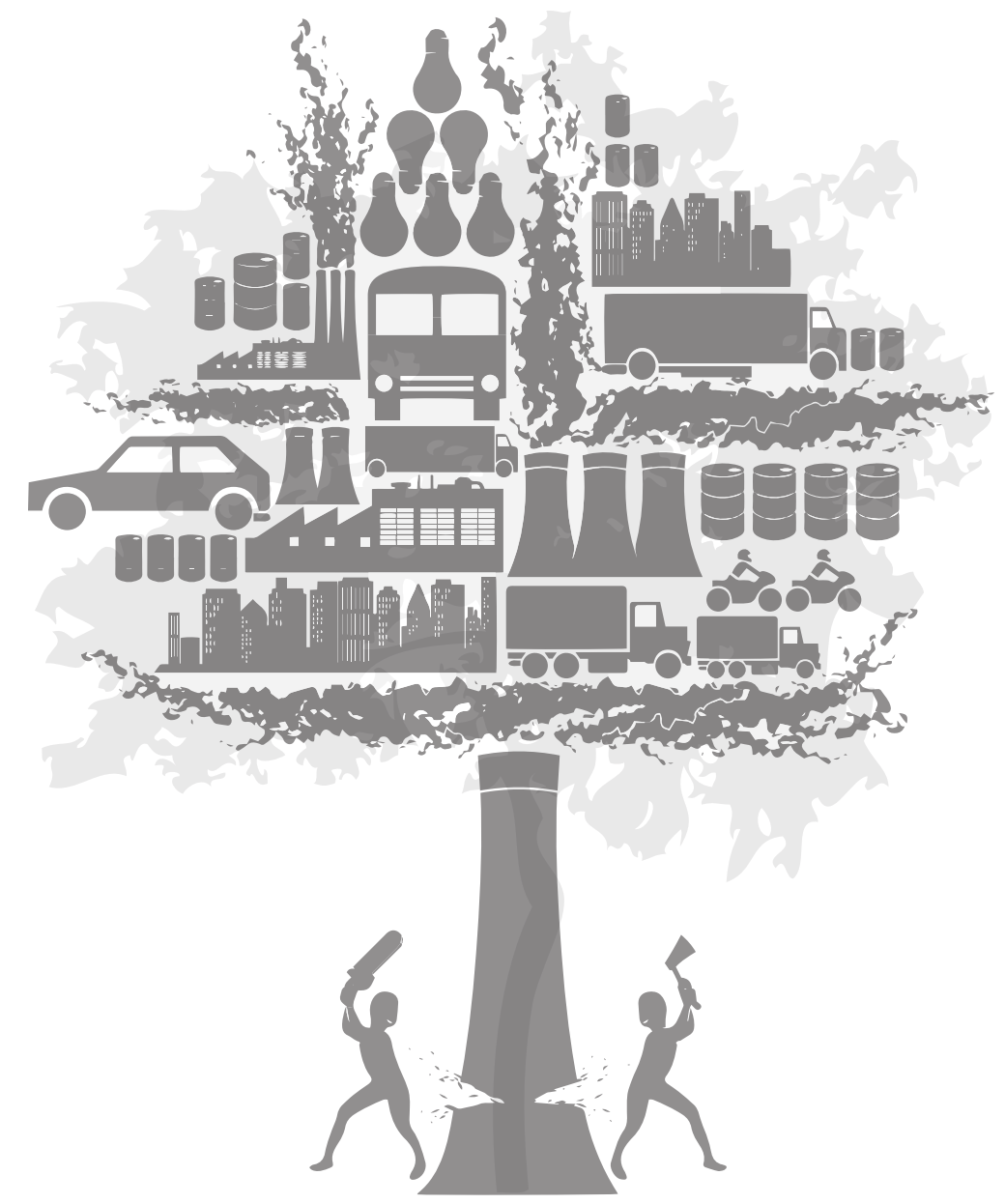

\subsection{Tree}

Trees are an important presence in the natural world. Trees are responsible for much of the earth's carbon dioxide absorption and release of oxygen back into the atmosphere. "A single mature tree can absorb carbon dioxide at a rate of $48 \mathrm{lbs} /$ year and release enough oxygen back into the atmosphere to support 2 human beings." ${ }^{3}$ Most effective when grown in groups, trees have an amazing ability to remove carbon dioxide and produce oxygen in the natural process of photosynthesis. However, with an unsustainable growth rate, urban cities are continually cutting down trees without a viable solution towards replacing the diminishing trees and their oxygen production. The very existence of architecture threatens the planet's primary method of carbon reduction and needs to be reconsidered to respond to the shrinking population of trees. Instead of merely reducing trees in the process, architecture can learn from trees to integrate tree-like properties in efforts to offset pollution of the natural environment. 


\section{LEAVES}

o

Specialized for photosynthesis

Maximizes exposure to light

Contains stomata pores to control carbon dioxide intake

Processes carbon dioxide to produce oxygen

\section{TRUNK}

\section{o}

Transports water + nutrients

Distributes food produced by leaves back to roots

Bark is waterproof and protective

Structural

\section{ROOTS}

\section{○}

Gathers water + nutrients

Supplies nutrients to all parts of the treet

Uses oxygen to respire

Anchors to the ground (foundation) 


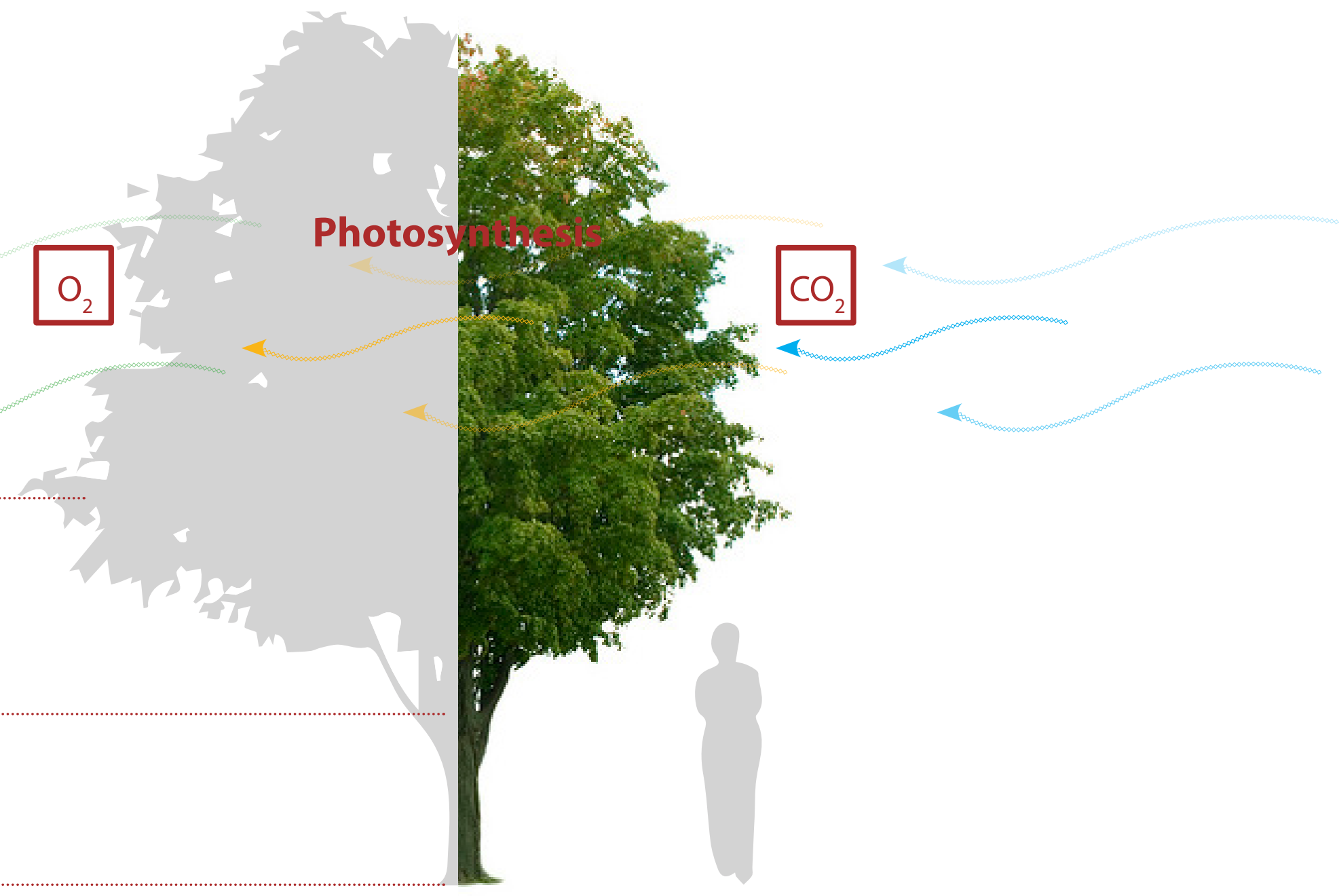

Fig 6.5 Diagram of a Tree 
Functioning in a closed loop system, trees have three major components that contribute towards the overall respiratory system. Starting from the bottom, a tree's roots act as its anchor to the ground and are responsible for gathering water and nutrients to supply the rest of the tree. Roots need oxygen to respire and they spread out to increase their surface area to volume exposure to gain oxygen. Moving up to the center of the tree structure, the trunk acts as the central transport route where water and nutrients flow up and carbon dioxide and energy flow down from the leaves. The trunk us the main distributor that allows for exchanges between the two ends of the tree. Raised above the rest of the tree for maximum exposure to the sun, numerous leaves form together as the tree's canopy that is responsible for absorbing the sun's radiation, which is needed for photosynthesis. At a microscopic scale, there are stomata pores that control the rate of evaporation and exchange of carbon dioxide and oxygen within the leaf. The leaf absorbs carbon dioxide from the air and in return releases oxygen back into the atmosphere. "When temperatures increase the stomata open wider, which causes more water to evaporate and allows the plant to stay cooler than its surroundings." ${ }^{4}$ As one integrated unit, the tree is able to remove airborne pollutants through filtering carbon dioxide (used in photosynthesis) to store carbon for energy needed for the rest of the tree and release oxygen as a byproduct. In working together, "one acre of trees annually consumes the amount of carbon dioxide equivalent to that produced by driving an average car for 26,000 miles. That same acre of trees also produces enough oxygen for 18 people to breathe for a year." 5

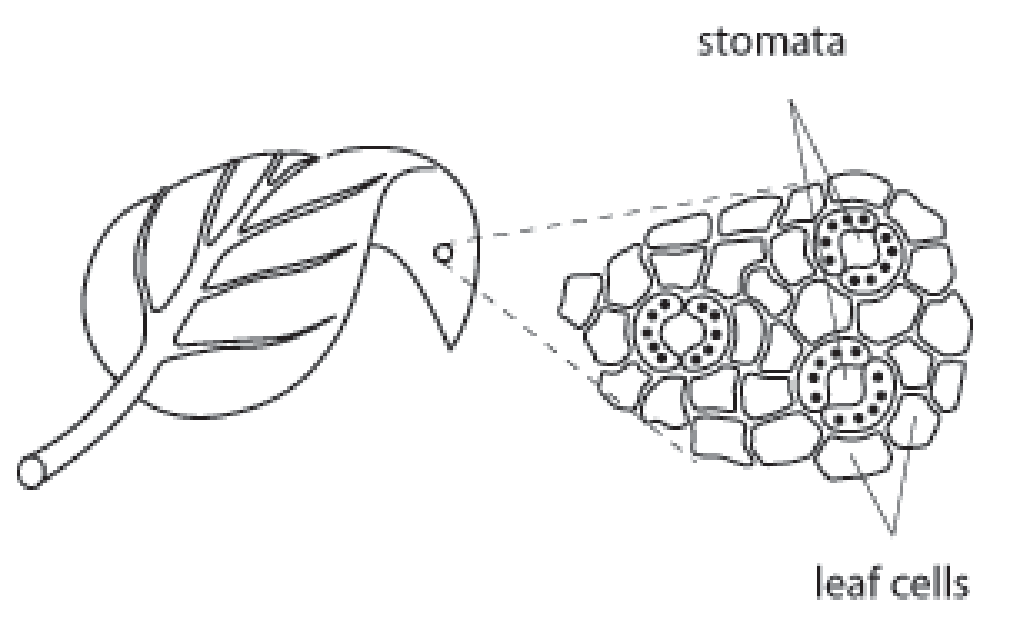

Fig 6.6 Stomata pore 


\section{EXPLODED AXO}

I SLOPED CANOPY TOWARDS CENTRAL FUNNEL

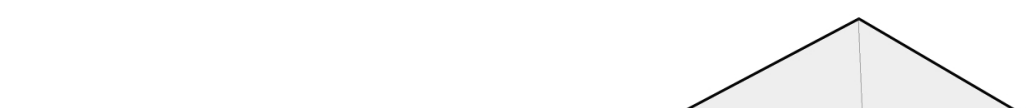

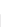

I SKYLIGHT OPENING

I INTAKE DUCT BRANCHED OUT TO EXTRACT OXYGEN

I FUNNEL OPENING TO COLLECT RAINWATER

\section{CENTRALIZED COLUMN}

I SOLAR AIR HEATER ON EXTERIOR FACADE
I INTERNAL VENT TOWARDS SOLAR AIR HEATER
I STORAGE NETWORK FOR ALGAE PURIFICATION

I SOLAR AIR HEATER ON EXTERIOR FACADE
I INTERNAL VENT TOWARDS SOLAR AIR HEATER SPACE.
I STORAGE NETWORK FOR ALGAE PURIFICATION

I SOLAR AIR HEATER ON EXTERIOR FACADE
I INTERNAL VENT TOWARDS SOLAR AIR HEATER S
I STORAGE NETWORK FOR ALGAE PURIFICATION
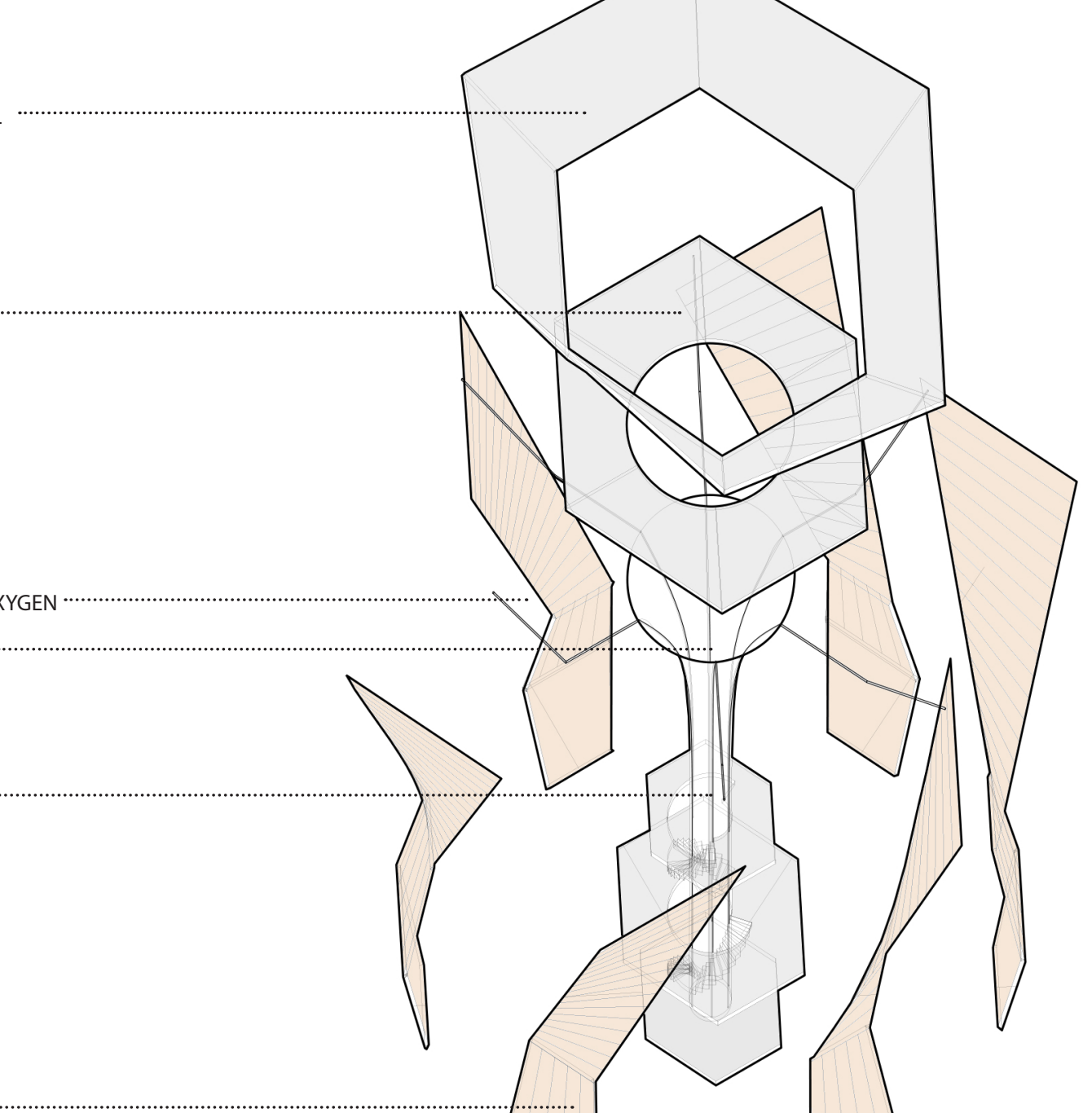


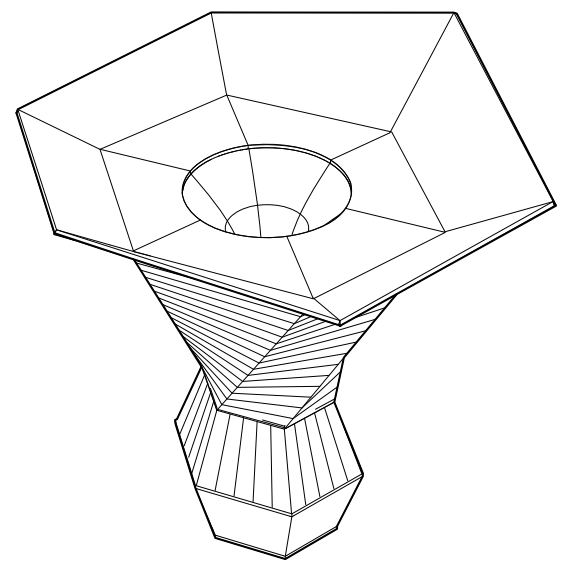
4 I RAIN WATER COLLEtion
Open funnel connects through centralized column to collect rainwater to storage tank below
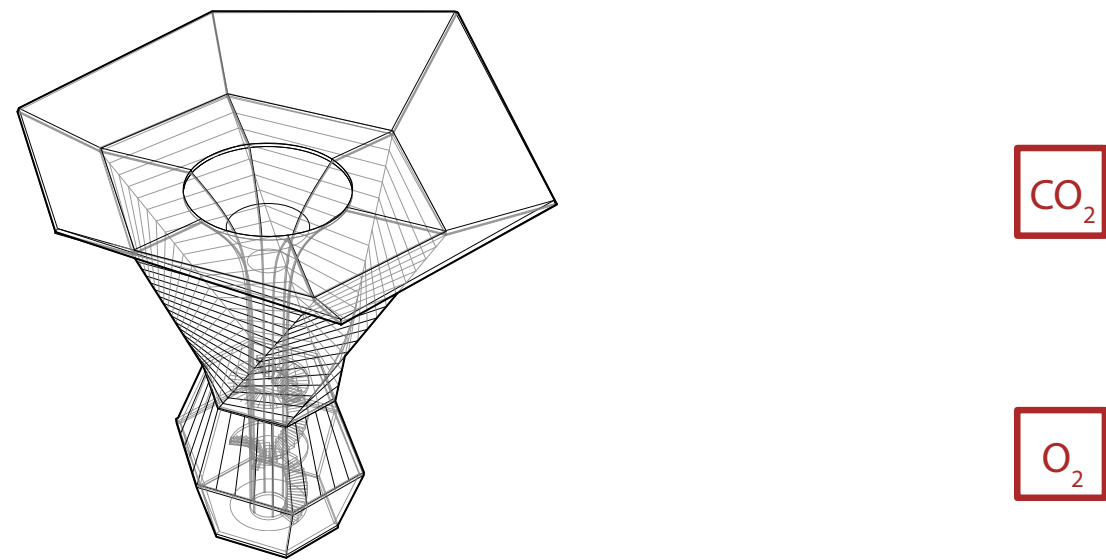
I INTAKE DUCT

Branched intake duct to extract fresh air
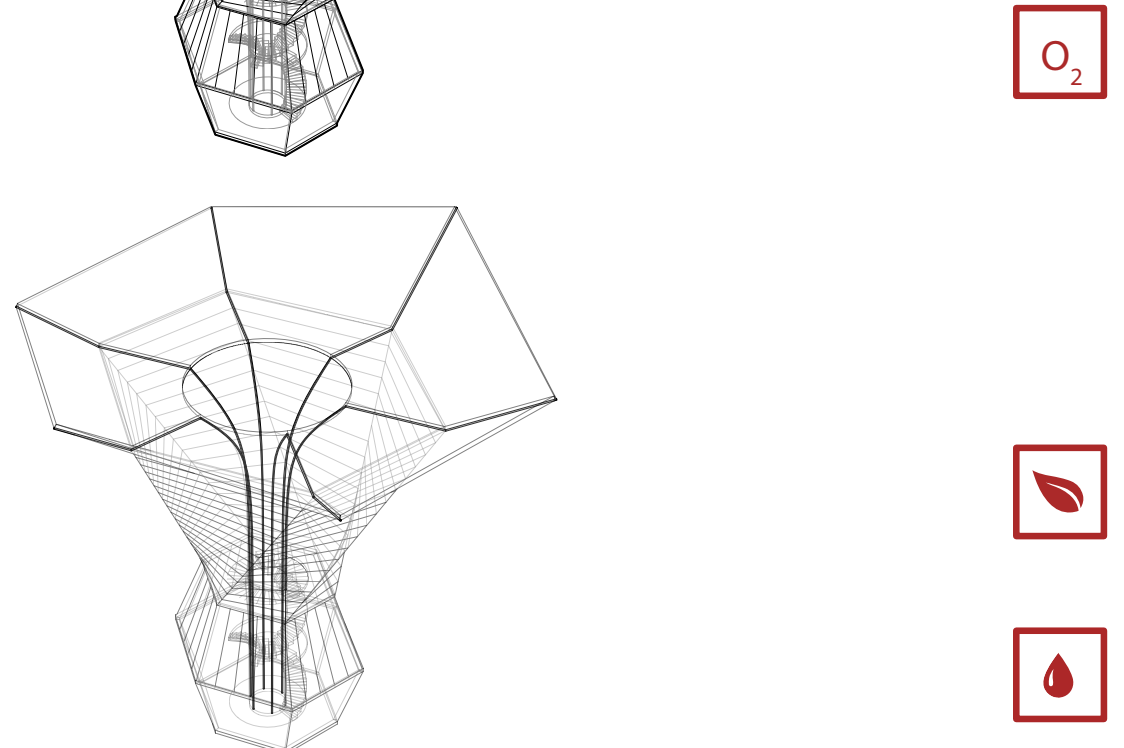

\section{SOLAR AIR HEATER}

Uses solar radiation to preheat the purified air from the algae storage system

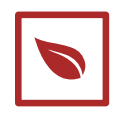

I ALGAE CARBON SCRUBBER

0

Uses rainwater and solar radiation to purify the extracted carbon dioxide

0

I WATER STORAGE

Stores rainwater to be used for the algae system 


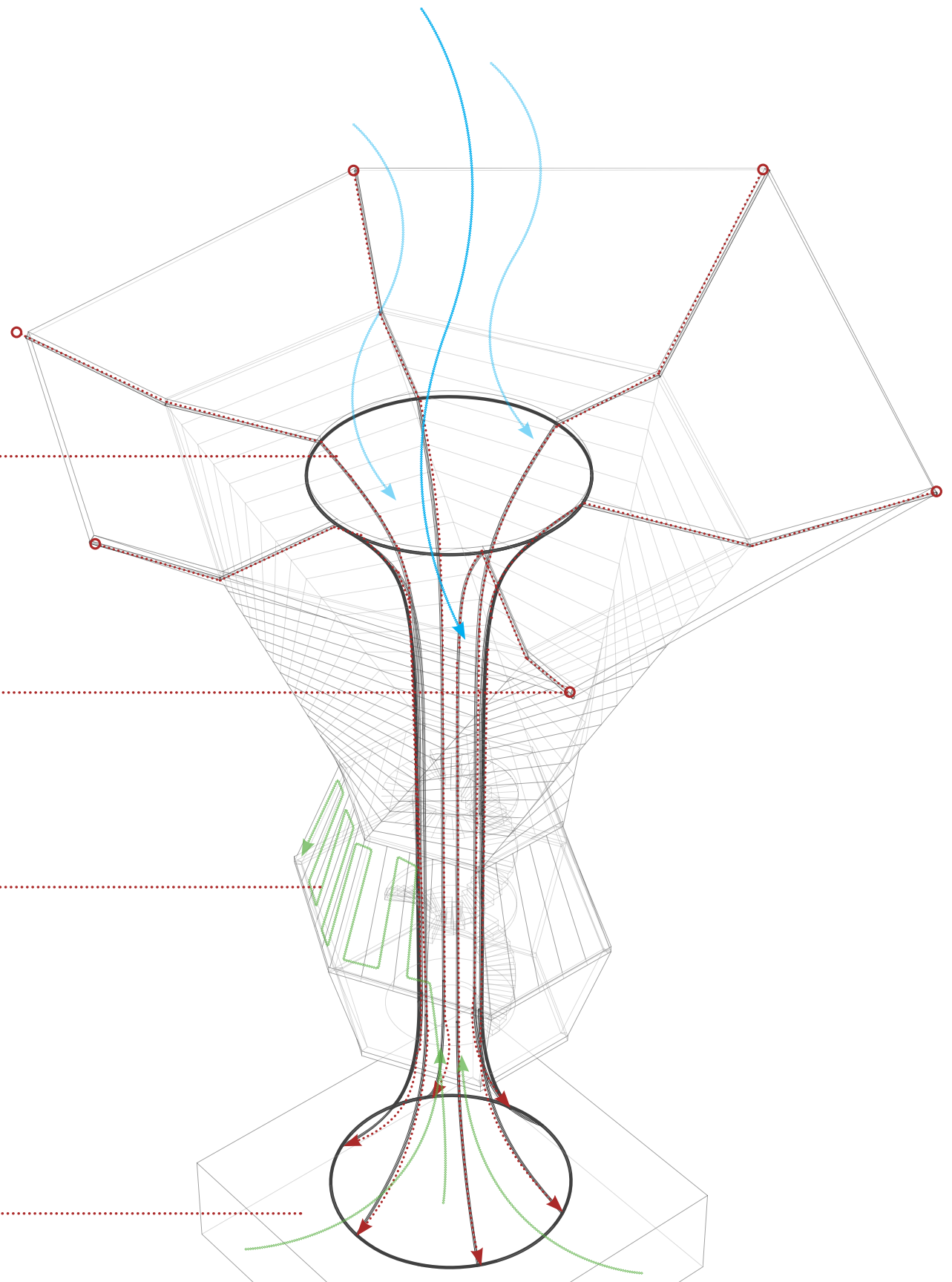

Fig 6.8 Diagram of Design Study's (Tree) program 
Trees are a prime example of different elements of a system coming together to work towards a single task of respiration. Each part of the tree has a role and contributes seamlessly to the overall system. A tree deals with respiration at both micro and macro levels that make the tree highly sophisticated and complex. It is constantly growing and adapting to its surroundings, having the ability to switch its respiration in reverse to absorb oxygen and release carbon dioxide at night. Most importantly, its net impact on the natural environment is positive because it is able to absorb harmful carbons in the atmosphere. Drawing from these principles, architecture has the potential to go beyond merely being carbon neutral to becoming a positive contributor to the natural environment.

In designing architecture to incorporate a similar respiratory system, the idea of structure needs to take on more than just structural loads. Similar to the tree's trunk, a centralized column can internalize a closed loop system that controls the building's various exchanges. For example, it can act as a control point for incoming air and water before redistribution throughout the building. Air can pass through intake ducts branched along the interior of the column and into a storage system that can then
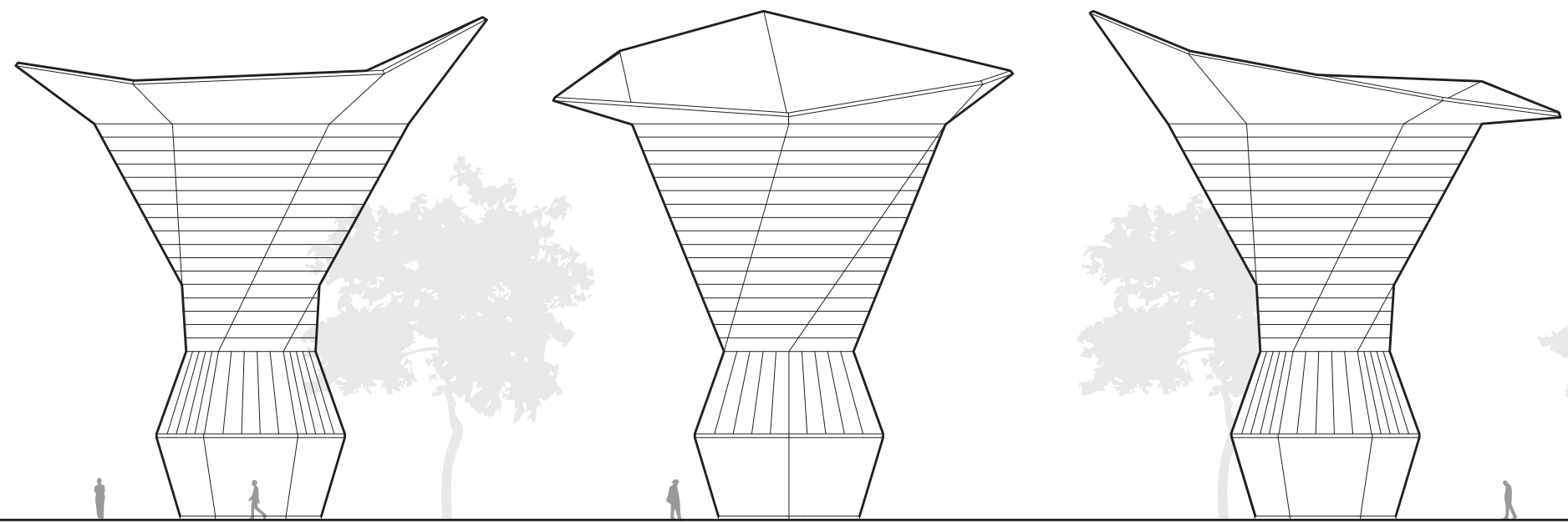
filter carbon particles through an algae carbon scrubber system. The filtered air then gets pumped into the façade, which can be equipped with solar air heaters that can preheat the air before it reaches the interior environment. This takes on the closed loop system of a tree that can impact both the micro environment within architecture and its macro impact on the natural environment. The focus on a closed loop respiratory system is reflected upon the form of the architecture that needs a small interior volume to large surface area ratio.

Fig 6.9 Elevation and Section of Design Study (Tree)

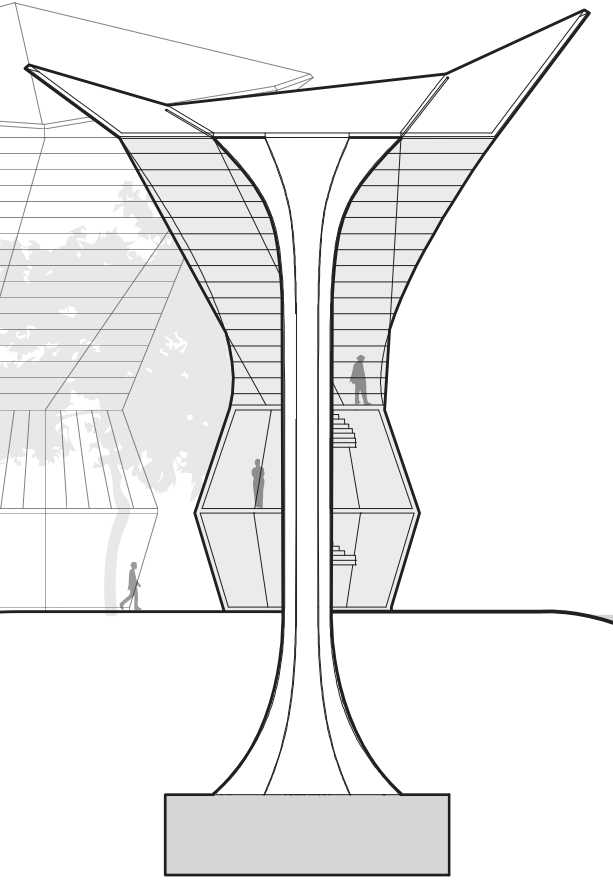




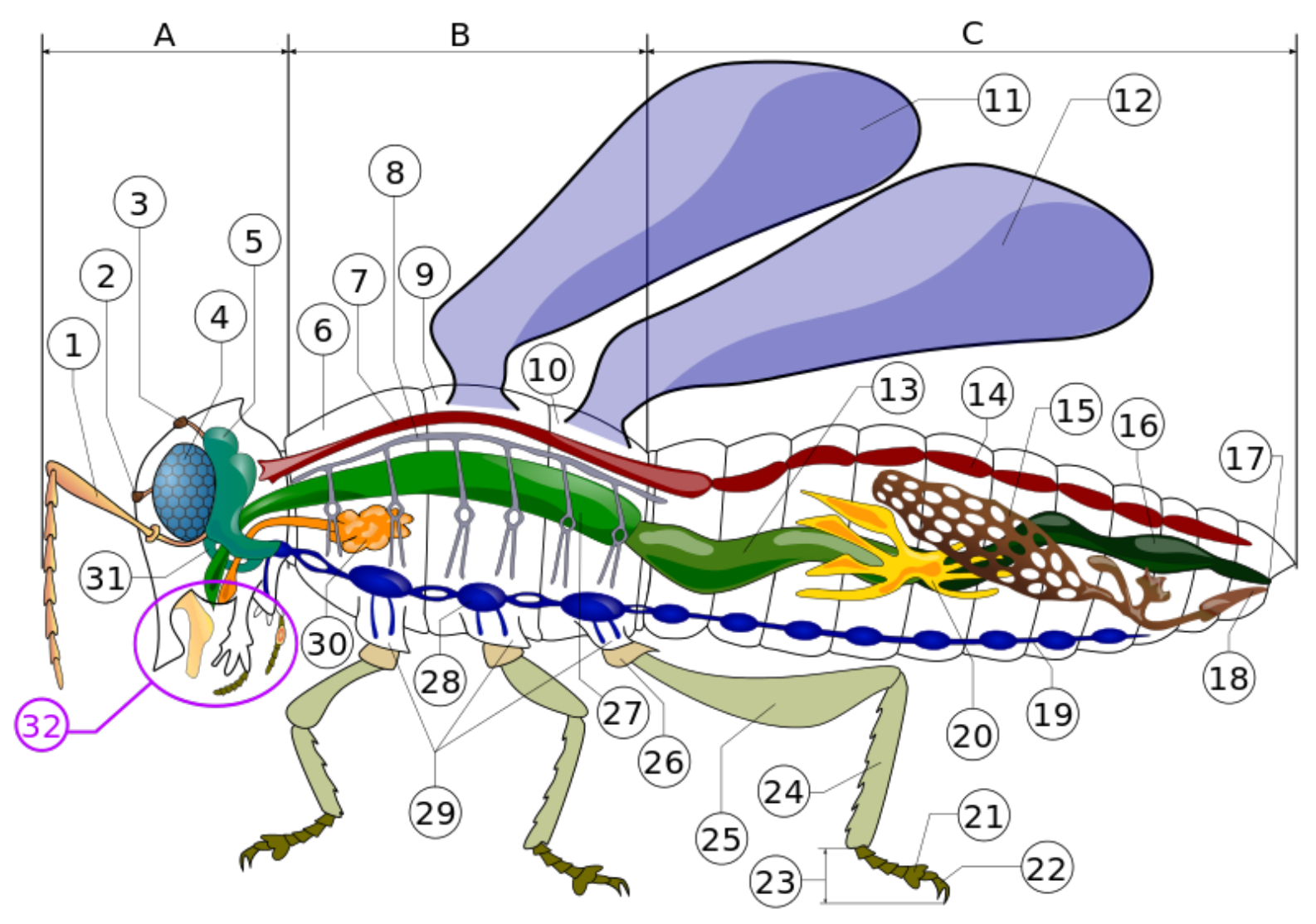

I TRACHEAL TUBES

(8)

Carries the air to different parts of the fly's body Intricate and complex network of tubes

Flight muscles take directly from the tubes

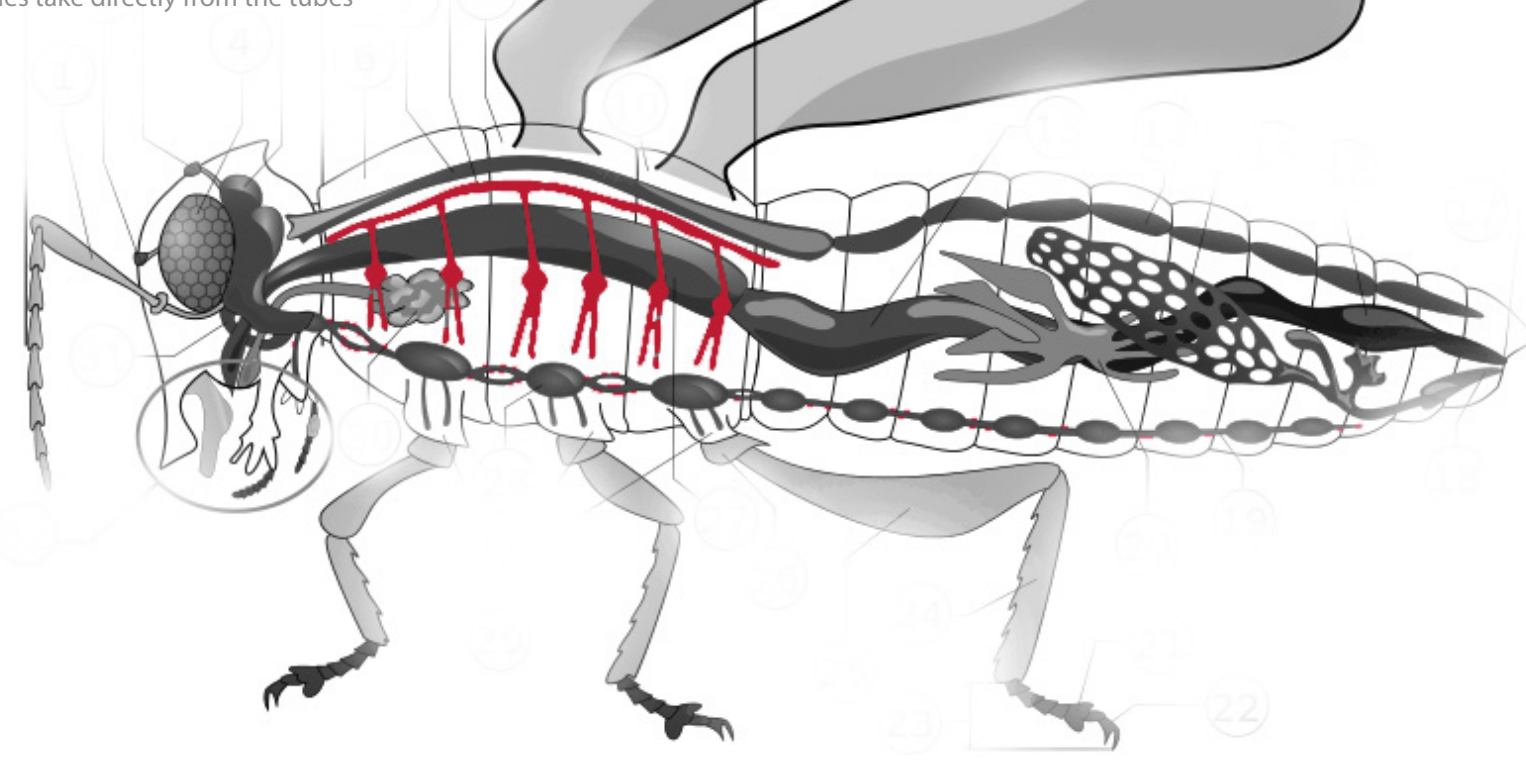

Fig 6.10 Diagram of the Fly's Tracheal System 


\subsection{Fly}

As an insect, a fly is incredibly small compared to mammals and reptiles. Due to its small size, a fly requires high levels of energy to sustain its flight. Consequently, there is a need for large volumes of oxygen flow in order to burn the extraordinary energy used. "The fly's need of oxygen is so high that there is no time to wait for the oxygen to be delivered to the body cells by the blood." ${ }^{6}$ To deal with this, the fly uses an exoskeleton respiratory system called the tracheal system that contains a series of air tubes spread amongst the fly's body in order to carry the air to different parts of the body efficiently. By being placed near the surface, the fly's flight muscles have direct access to oxygen that is needed in cooling down the muscles, which function at up to 1000cycles per second during flight. ${ }^{7}$ This arrangement is truly advantageous for the scale of the fly's body. With a small volume body, a fly has a greater surface area to volume ratio that allows for greater efficiency in its respiration process. Having greater surface area to its body volume means that the fly can have access to an overwhelming supply of oxygen to sustain the energy used to maintain its own flight. If the surface area to volume ratio were any less, the fly would have trouble breathing as it would overheat due to the lack of oxygen. The important consideration is the surface area to volume ratio, and not surface area or volume alone. For example, a $2 \times 2 \times 2 \mathrm{~cm}$ cube may seem to have less surface area $\left(24 \mathrm{~cm}^{2}\right)$ exposure to a $4 \times 4 \times 4 \mathrm{~cm}$ cube $\left(96 \mathrm{~cm}^{2}\right)$. However, once volume is taken into consideration, it is in fact the $2 \mathrm{~cm}^{3}$ that has a greater surface area to volume ratio (3:1 vs 1.5:1) that would make it more efficient for an exchange to occur through its surface as a mediator.

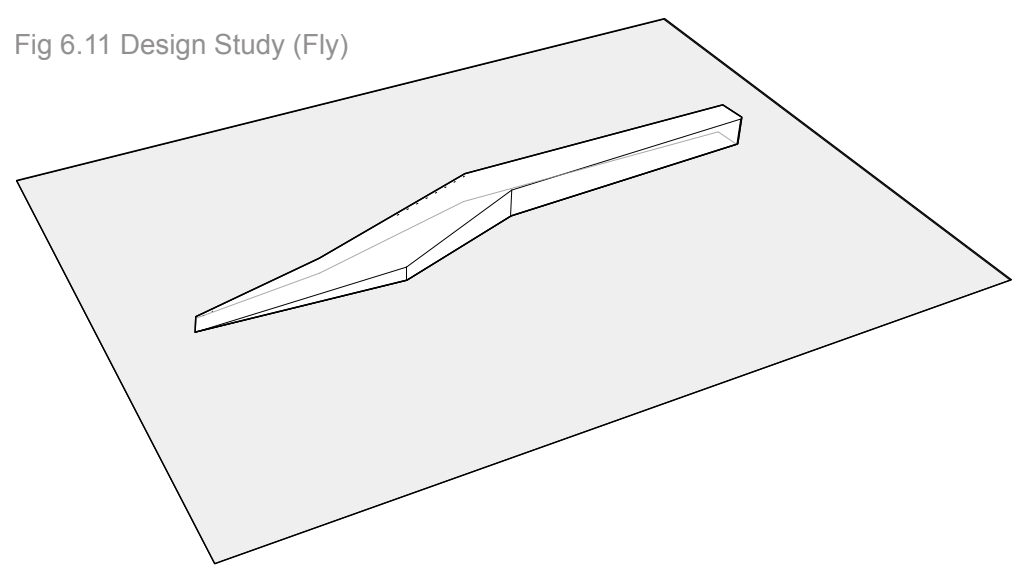

I GREATER SURFACE AREA TO VOLUME RATIO COMPARED TO A CUBE 
I SURFACE AREA OF ROOF CAN INCREASE

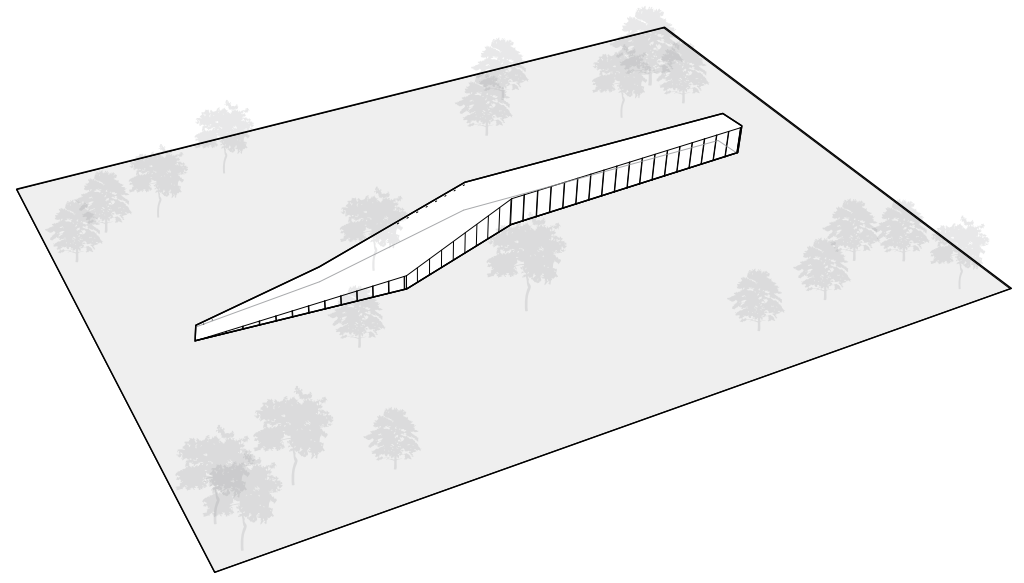

I SUBDIVIDE THE SURFACE OF THE ROOF

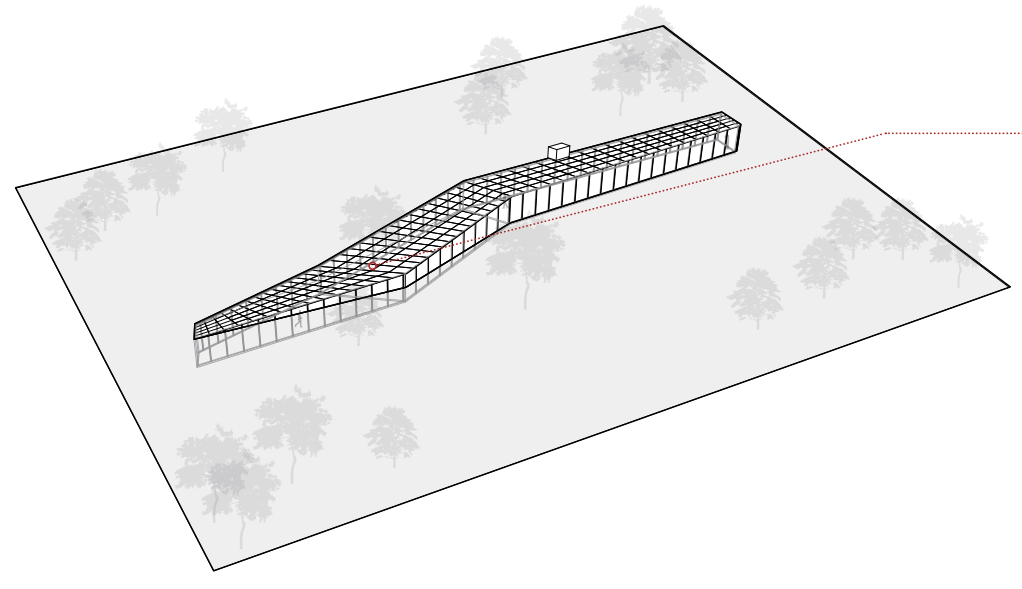

I PUSH AND PULL EACH SUBDIVISION TO INCREASE SURFACE AREA EXPOSURE

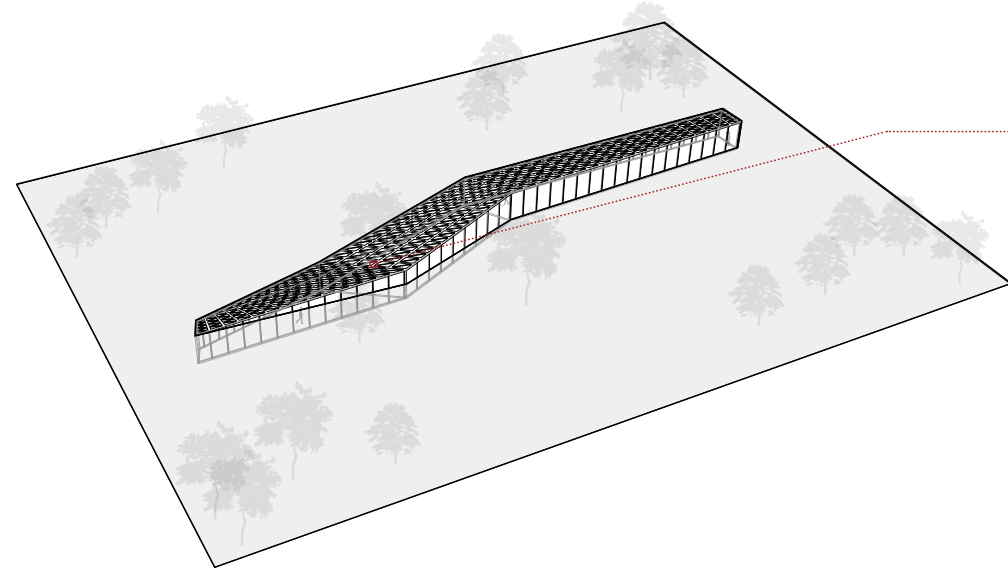

Fig 6.11 Design Study (Fly) continued 

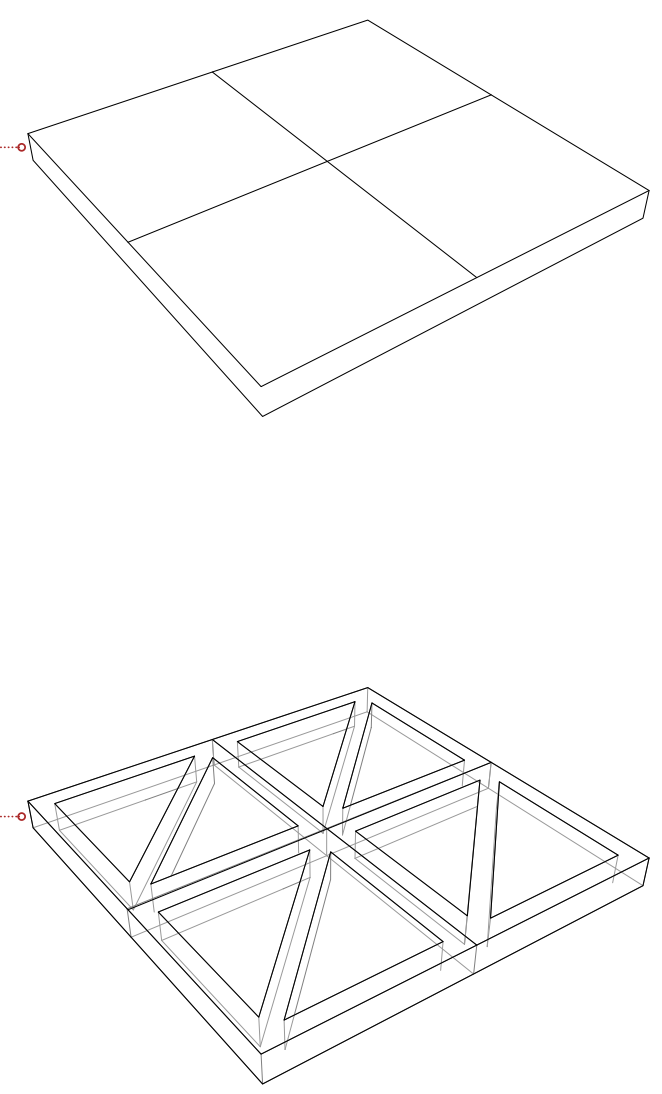

70 
I ROOF APERATURES OPEN UP TO ALLOW FRESH AIR EXCHANGE

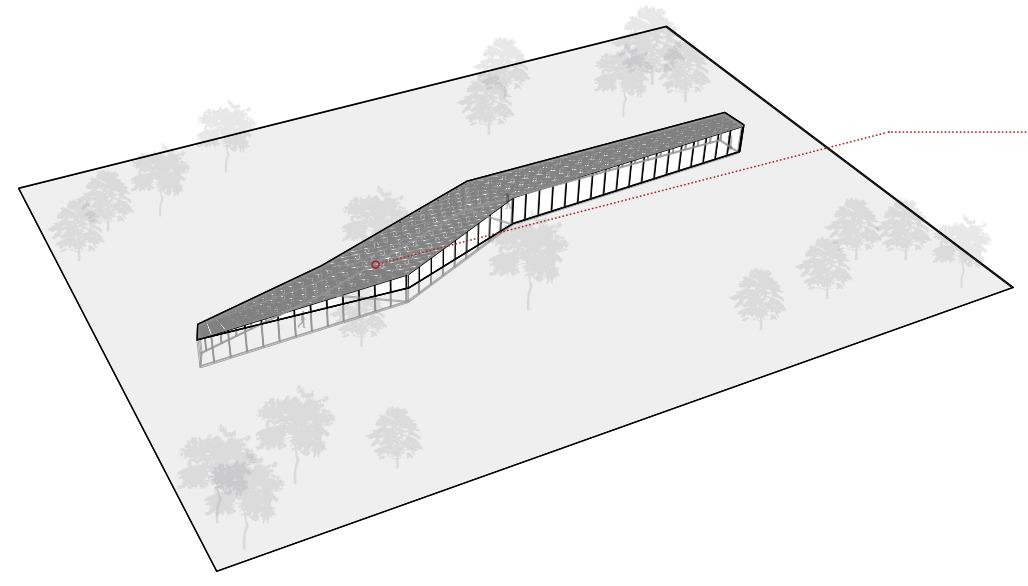

I REVERSE APERATURES OPEN TO EXHAUST STALE AIR

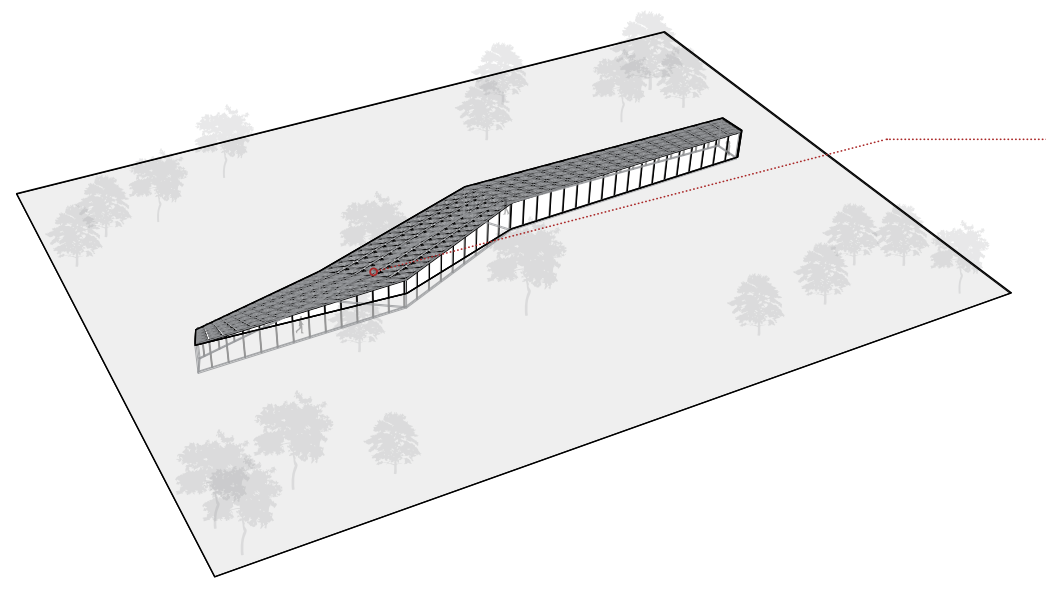

I BOTH APERATURES CAN OPEN TO MAXIMIZE BREATHABILITY OF INTERIOR SPACE

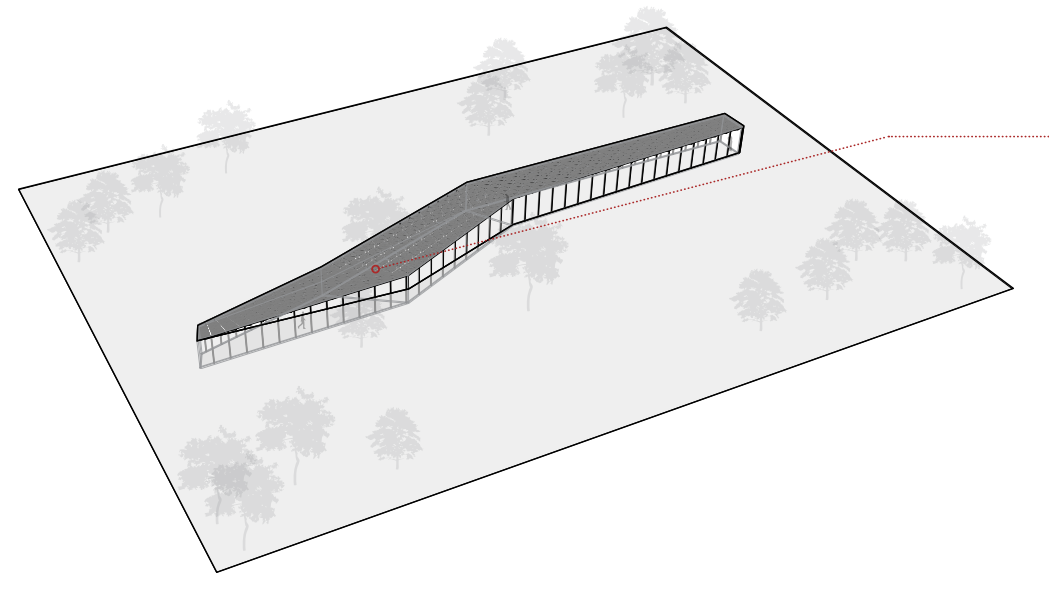

Fig 6.11 Design Study (Fly) continued 


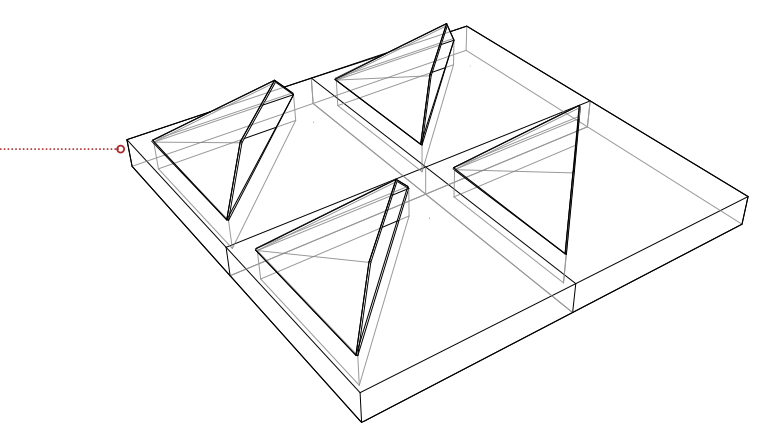

The exoskeleton respiratory system can be compared to the architectural skin where it is viewed as the point of contact between two atmospheres (as described by Pallasmaa). ${ }^{8}$ However, in the case of the fly, it is much more than a skin - it's a part of a larger respiratory system that sustains the life of the fly through its control of the needed flow of oxygen. The tracheal system encompasses more than just the skin and includes a vast network of tubes that is interconnected throughout the body. Together, the skin and the tracheal system manage the oxygen flow in and out of the body. This can help redefine the skin of architecture to be a control mediator between interior and exterior conditions. On its own, the skin can be viewed as a system of control points that have access to air flows at various parts of the surface. As an integrated system, the skin can play a part of the micromanagement of interior air as well as its impact on the greater natural environment beyond the skin.

Informed by the fly's tracheal respiratory system, a building can be articulated based on its form in order to achieve a positive surface area to volume ratio. Rather than simple extrusions, the form of architecture can be vastly different than the conventional push and pull manoeuvers used in massing design. With the objective of increasing surface area control points, the resulting form moves towards an organic aesthetic that can increase surface area exposure without significant volume increase. The skin expands beyond a flat surface in order to achieve better contact points in surface area. This articulation challenges the preconceived window as the predominant point of contact with exterior conditions and instead utilizes countless aperture pores (similar to the stomata) as a network of exchange hubs. 


\subsection{Termite Mound}

Termites are incredibly small, yet they build some of the most sophisticated homes in the entire animal and insect world. A termite mound incorporates a naturally designed cooling system that is capable of maintain a constant temperature that fluctuates no more than 2 degrees centigrade. ${ }^{9}$ This structure has fascinated scientists, designers, and architects who are interested in biomimicry.

Termites have one of the most complicated methods of constructing a "house" that is very different from what humans are familiar with. In tropical savannas, the mound can extend up to $9 \mathrm{~m}$ high. ${ }^{10}$ The form of the mound has been studied extensively,

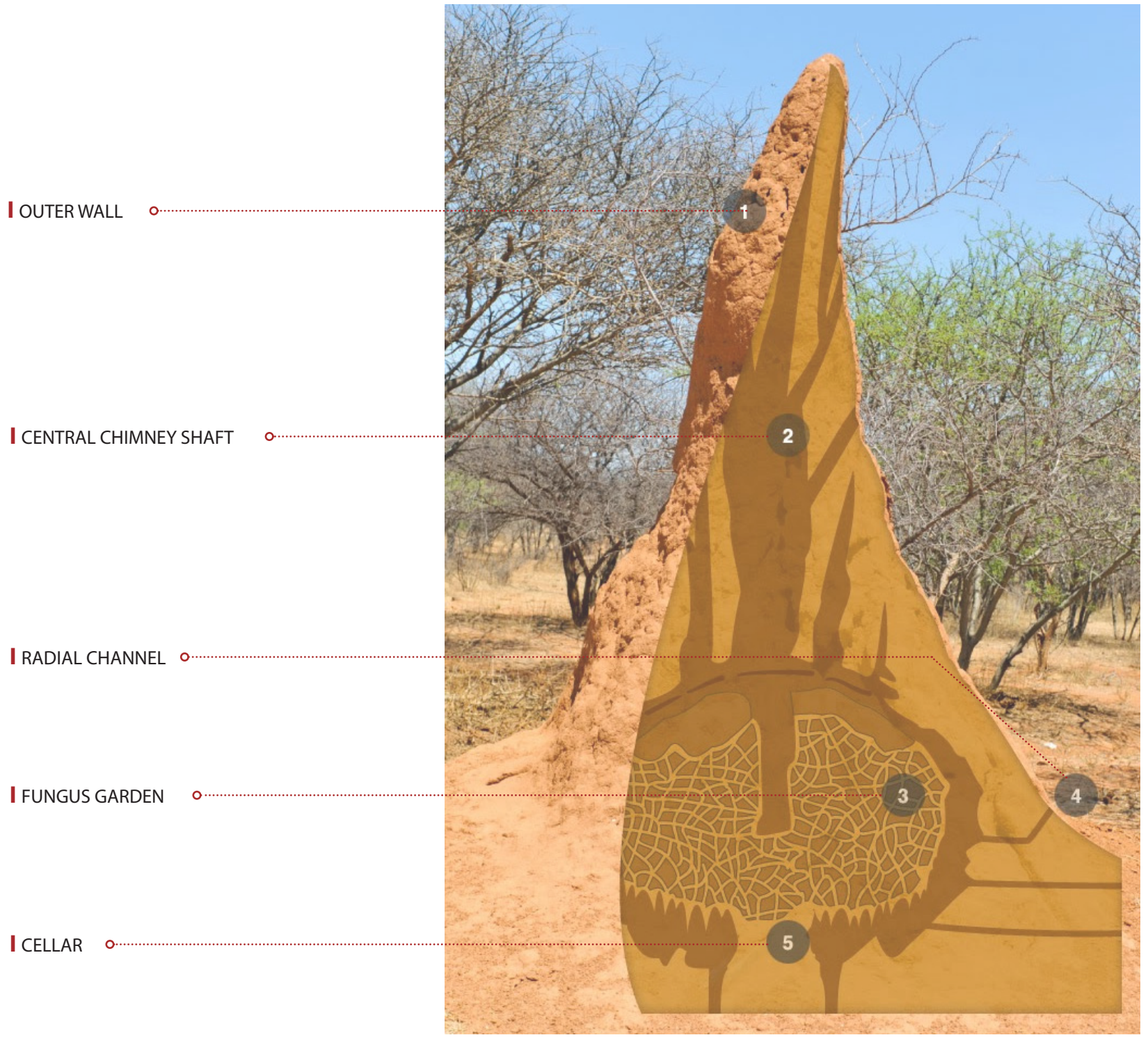

Fig 6.12 Diagram of the Termite Mound 


\section{A. Macrotermes michaelseni}

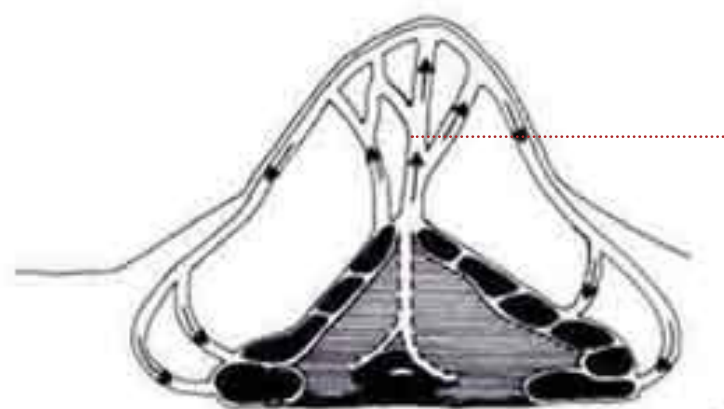

Direction of air movement

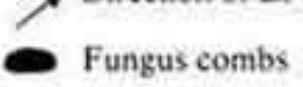

\section{B. Macrotermes subhyalinus}

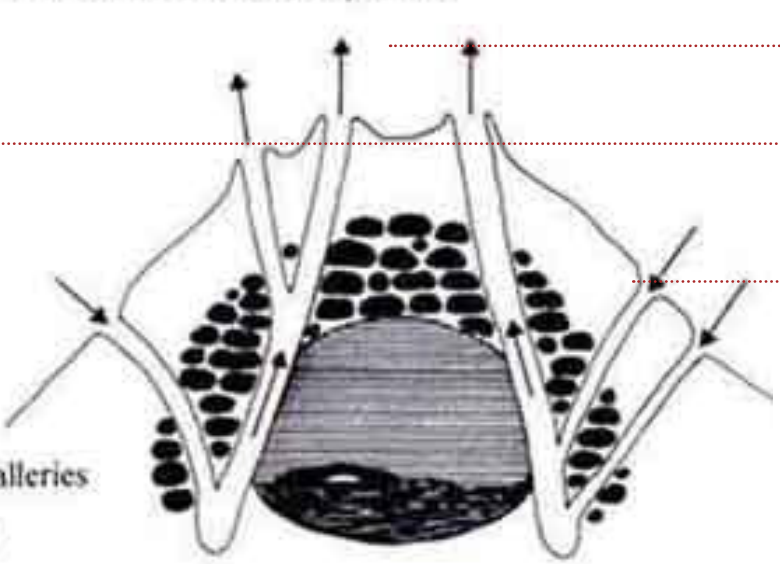

Fig 6.13 Diagram of the Termite Mound continued

but has often been misunderstood in the way it respires. The Eastgate building by architect Mick Pearce and Arup Associates has been often compared to the system of the termite mound. The mid-rise building in Harare, Zimbabwe has no air-conditioning or heating, yet is still able to regulate its interior temperature and environment all year round to effectively decrease its energy consumption by $80 \% .{ }^{11}$ However, this is only the first pass of an architectural understanding of the termite mound. Although the Eastgate building claims it draws its design from the passive cooling strategies of the termite mound, the termite mound is, in fact, an example of an active cooling system. The mound relies on an army of worker termites that alters the chimneys and vents of the mound throughout the day, depending on the surrounding context. What occurs is an exercise of precise control by the termites as a collective, rather than a simple passive structure that works on its own. These termites control the exchanges of stale and fresh air to where it is needed and keep moisture out from where it is unwanted. This idea of architecture as an active space is foreign and needs to be understood from examples like the mechanics of a termite mound.

When viewed in isolation, the mound itself does not breathe. On the contrary, as a system where the mound becomes an extension of the termite, the termite mound is able to achieve breathing through tight control exercised by termite workers in managing levels of air exchange within the space. Fresh air enters through side ducts that are opened and closed by termites while stale warm air travels upwards through a long chimney shaft. A deeper look into the termite mound from an architectural perspective reveals the vast potential in how architecture can be designed to be a dynamic system that allows the breather himself to control the micro environment.

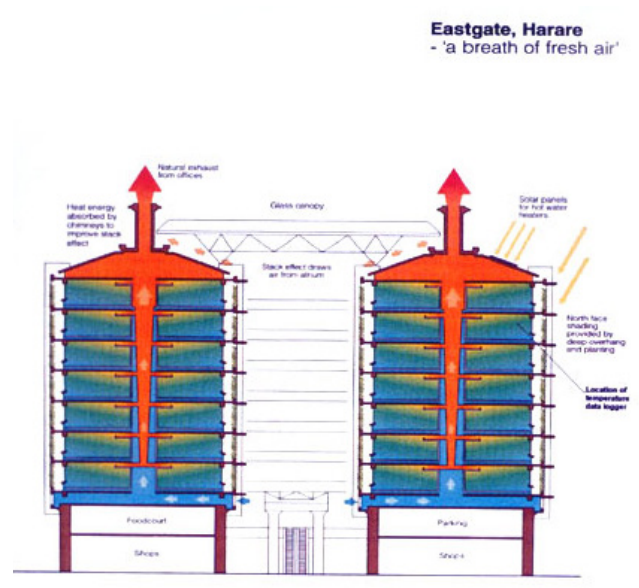

Fig 6.14 Section of the Eastgate building in Zimbabwe

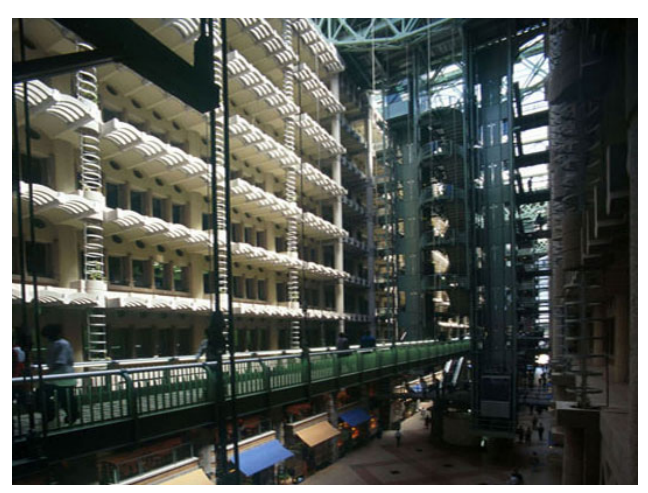

Fig 6.15 Eastgate building (1996), Mick Pearce. Atrium 


\section{CENTRAL SHAFT (STALE AIR EXHAUST)}

I INSULATED BROOD CHAMBER (TEMPERATURE CONTROL)

I AIR CHANNELS (FRESH AIR INTAKE)

Fig 6.16 Environment Bubble (1965) Reyner Banham and Francois Dallegret

Fig 6.17 Design Study (Critique of the Environment Bubble)
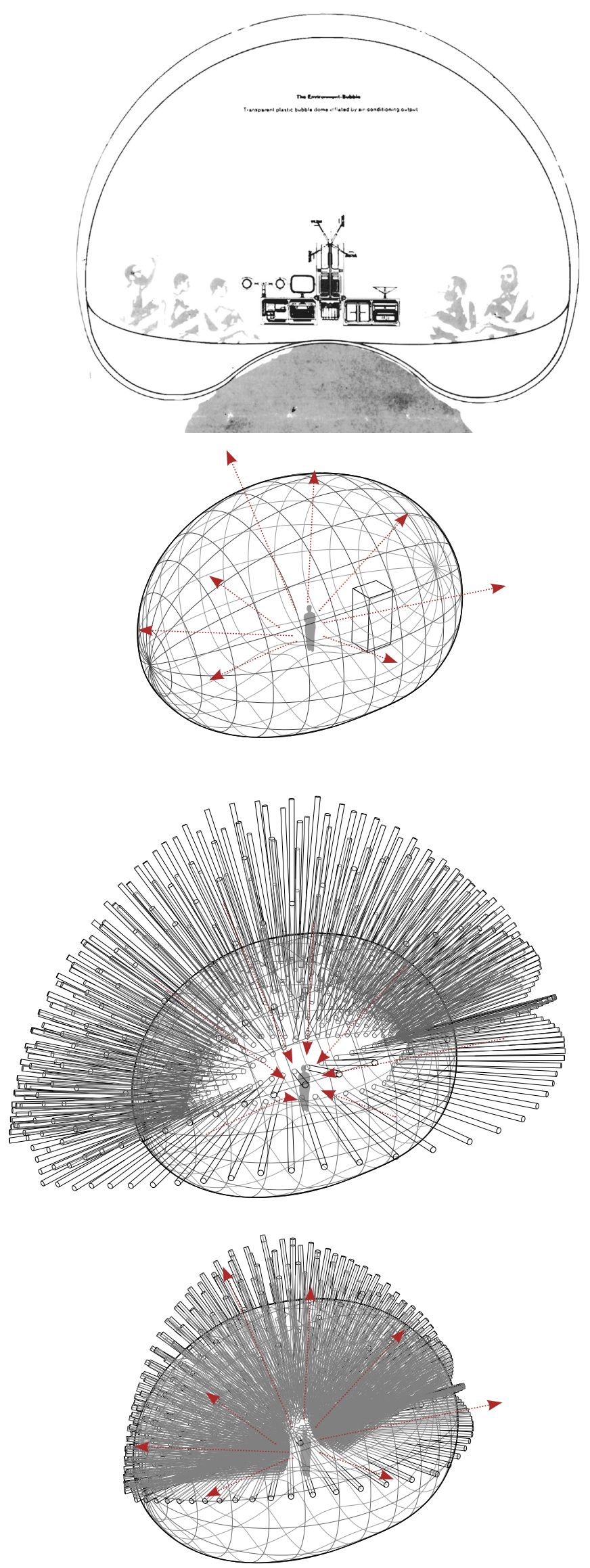
There are two approaches towards architecture informed by the respiration process of termite mounds. On one hand, at a more micro level for the user, architecture can give the breather complete control of its own interior environment through an active ventilation system - a critique on Banham's Environment Bubble where breathability is controlled exclusively by a mechanical system. In this approach, all mechanical systems are replaced by an analog system that requires manual control from the breather to modify the atmospheric conditions. Within a small enclosed space like that of the Environment Bubble, a series of thermally insulated tubes penetrate the threshold and act as mediators between interior and exterior conditions. During the day, the breather can push the tubes out for maximum solar exposure to make way for an open flow of interior space, while at night the tubes can be pulled in to create a warm intimate space where the tubes release the heat back into the space. This analog system gives the user complete and precise control over the ideal respiratory environment that is desired. The second approach takes the complex circulatory network of the termite mound to create architecture in the form of circulation that is conducive for air flow. In a series of passageways, the building can sink itself underground to utilize the thermal mass of the earth for

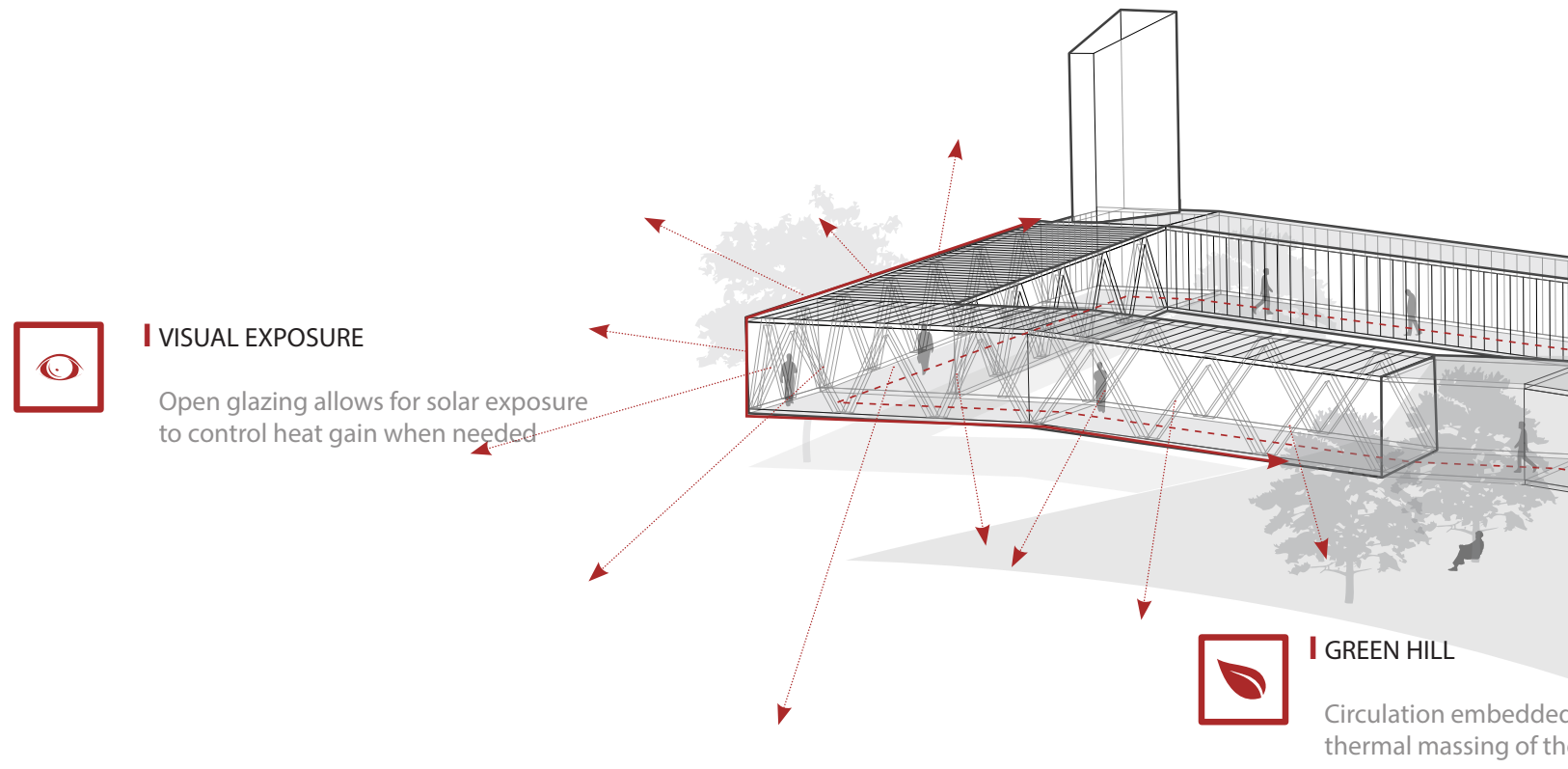

Fig 6.18 Architecture as a Network of Circulation Spaces (Diagram) Design Study 


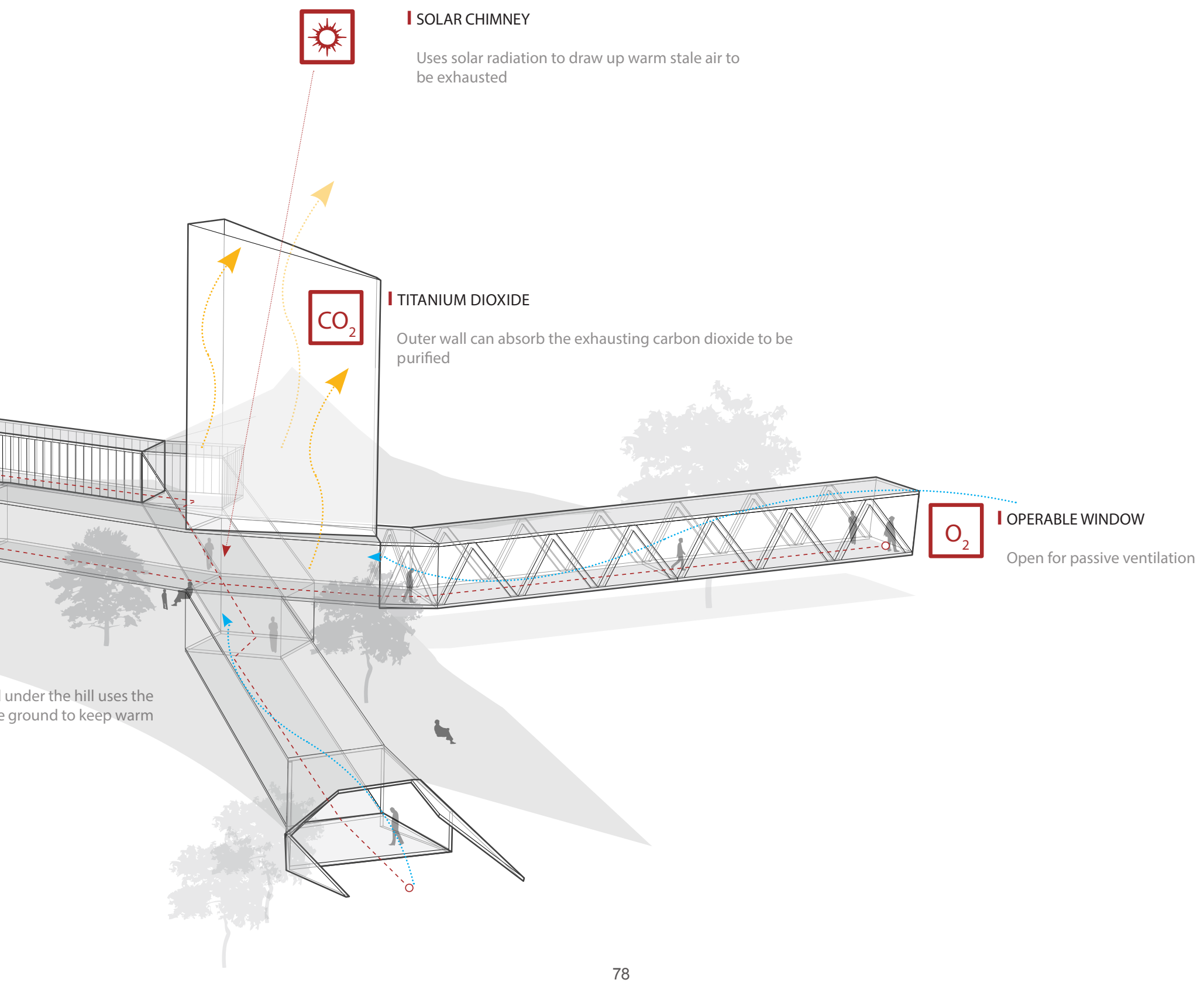


natural heating and cooling. Comparable to the flow of termites, the breather can migrate around the space depending on the fluctuating atmosphere. When it is humid and hard to breathe, the breather can walk out towards open tunnels that draw in fresh air through cross ventilation. The fresh air passes through the network into a central point where the used stale air can be drawn upwards through solar chimneys above. The form of a circulatory network allows for a constant flow of air in and out of the building that creates various environments throughout the space. The breathability of the space is dictated by the exchange of fresh and stale air passing through the walkways.

Fig 6.19 Architecture as a Network of Circulation Spaces (Open Network)
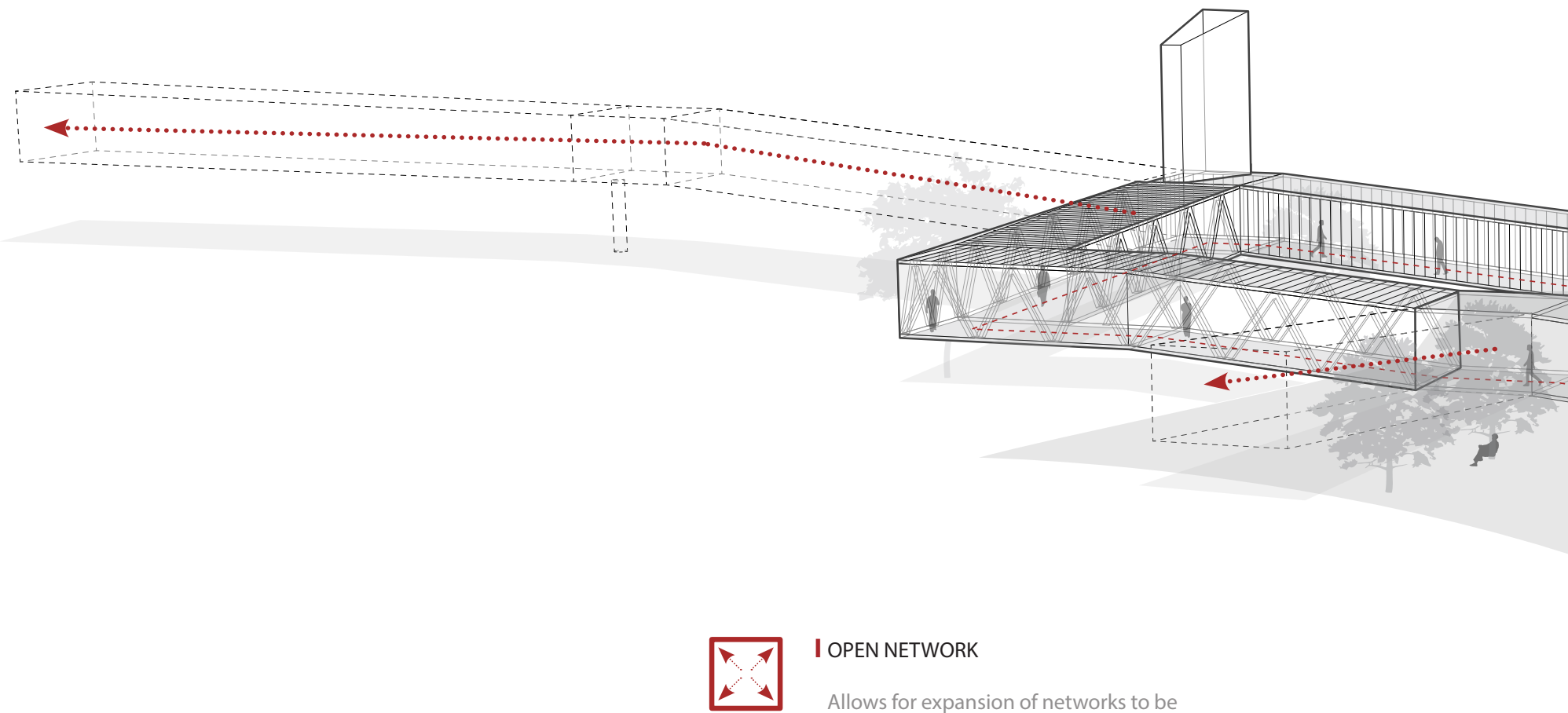

I OPEN NETWORK

Allows for expansion of networks to be connected into a series of controlled circulatory spaces 


\section{Endnotes}

${ }^{1}$ Franwe. (London: Koenig Books Ltd, 2009). 13.

${ }^{2}$ Philippe Rahm. Meteorological Architecture. Architectural Design. (Chichester: John Wiley \& Sons, 2009). 32.

${ }^{3}$ Mike McAliney. Arguments for Land Conservation: Documentation and Information Sources for Land Resources Protection. Trust for Public Land. (1993).

${ }^{4}$ Michael Pawlyn. Biomimicry in Architecture. (London: RIBA Publishing, 2011). 81.

${ }^{5}$ Environment Canada. Canada's Emission Trends 2012. ec.gc. ca/ges-ghg/default.asp?lang=En\&n=022BADB5-1 (accessed November 11, 2014)

${ }^{6}$ www.asknature.org/strategy/ b1cc81440b1fda03d40c236b0b66ad6f\#.VHS9UmTF9gg (accessed November 8, 2014)

${ }^{7}$ Ibid.

8 Juhani Pallasmaa. The Eyes of the Skin: Architecture and the Senses. (Chichester: John Wiley \& Sons, 2005). 10.

${ }^{9} \mathrm{http}: / /$ news.nationalgeographic.com/news/2014/07/140731termites-mounds-insects-entomology-science/ (accessed October 1, 2014)

${ }^{10}$ Ibid.

${ }^{11} \mathrm{http}: / /$ www.inhabitat.com/building-modelled-on-termiteseastgate-centre-in-zimbabwe/ (accessed October 1, 2014)

Image References

${ }^{1}$ http://www.philipperahm.com/data/projects/interiorgulfstream/

${ }^{2}$ Ibid.

${ }^{3}$ http://curitibainenglish.com.br/wp-content/uploads/2012/11/ article-0-0D568CE6000005DC-993_468x286.jpg

${ }^{4} \mathrm{http}: / /$ www.theguardian.com/environment/2013/nov/15/amazondeforestation-increased-one-third

${ }^{5}$ Kevin Pu

${ }^{6}$ http://horticulture.tekura.school.nz/assets/horticulture-images/ ht109-22.gif

${ }^{7}$ Kevin $\mathrm{Pu}$

8 Ibid.

${ }^{9}$ Ibid.

10 http://www.asknature.org/strategy/

b1cc81440b1fda03d40c236b0b66ad6f

${ }^{11}$ Kevin Pu 
${ }^{12}$ http://www-tc.pbs.org/wnet/nature/files/2011/10/termite_ mound.jpg

${ }^{13} \mathrm{http} / / /$ inhabitat.com/building-modelled-on-termites-eastgatecentre-in-zimbabwe/

${ }^{14}$ Ibid.

15 Ibid.

${ }^{16}$ https://studio4postindustrial.files.wordpress.com/2011/04/ picture-8.png

${ }^{17}$ Kevin $\mathrm{Pu}$

18 Ibid.

19 Ibid. 


\subsection{Driven by Respiration}

Throughout history, there has always been a fascination towards the way nature operates. Organisms seem to have an innate ability to respond to changing environments intuitively but some scientists argue that it may be a result of a long evolutionary process. The hypothesis suggests that organisms require repetitive events in order to learn and adapt.

"It is about learning from a source of ideas that has benefited from a 3.8 billion year research and development period. That source is the vast array of species that inhabit the earth and represent evolutionary success." 1

However, in the context of respiration where breathing is an important component to life, it seems questionable that organisms can only breathe efficiently after a long process of evolution. On the contrary, what if organisms were designed as a system that is capable of adapting by detecting changing inputs of the environment? Such a design can be broken down from its system of data processing to understand how organisms can intuitively respond. This approach allows natural systems to be extrapolated into design parameters that can then inform architecture whereas the outdated approach to biomimicry once only focused on the resulting patterns that seem to achieve certain functions without a true understanding of the process or system that allowed that to happen in the first place. "Throughout history, architects have looked to nature for inspiration for building forms and approaches to decoration." ${ }^{2}$ Instead, leading biomimicry experts are now looking to nature with the intent of understanding its system as a collective begins to allow architecture to move past the literal mimicry of nature in decorative patterns. As such, architects must also seek to learn from these processes to help inform the design for actively breathable architectural systems.

In the three studies of natural systems in chapter 5 , each case study represents a distinctive spectrum of respiratory organisms in nature; yet, they all have one commonality in achieving respiration. It is important to note the criticality in how each of these systems (i.e., trees, flies, and termite mounds) achieves breathing as a process. Most people look to these systems and think of form without an understanding of how the form came about. Instead, what ties these seemingly varying systems is to understand nature as a process through respiration happens. This 


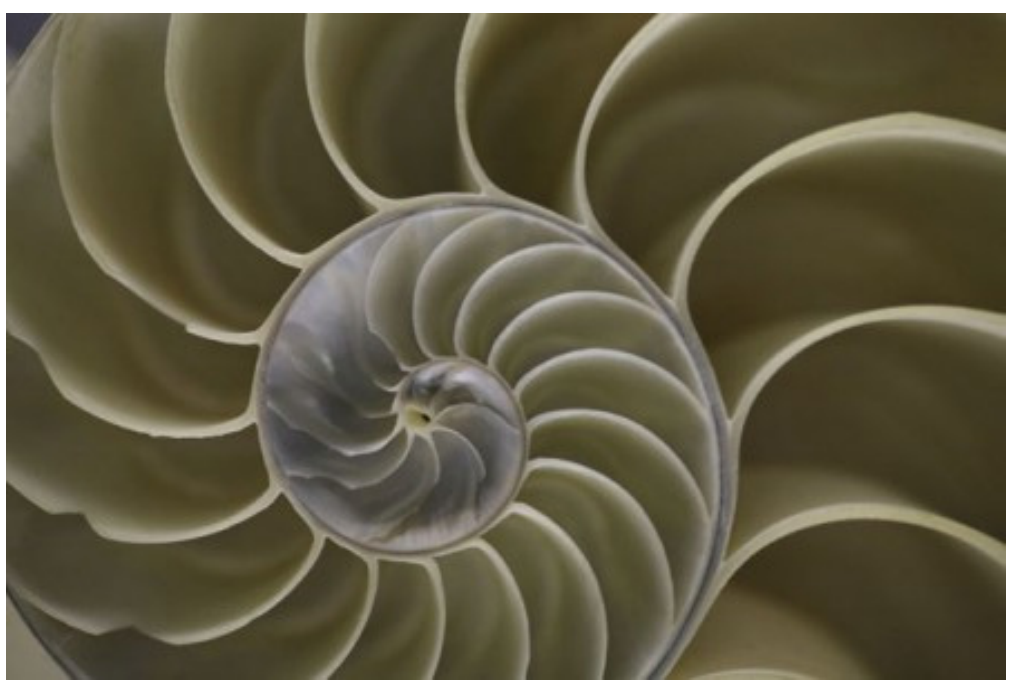

Fig 7.1 Picture of a snail shell

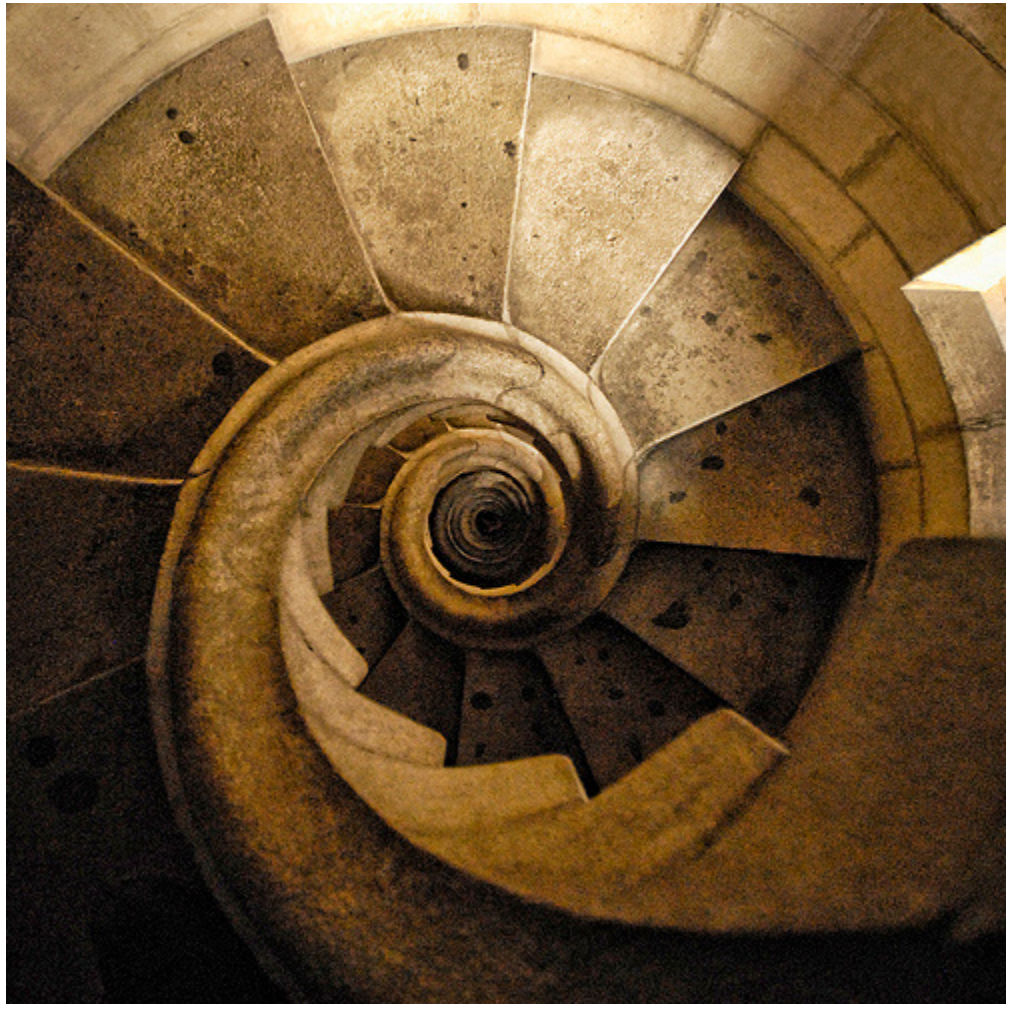

Fig 7.2 Bell Tower staircases at the Sagrada Familia (Antoni Gaudi). Gaudi took inspiration from the snail shell in his design of the $118 \mathrm{~m}$ bell tower staircase. 


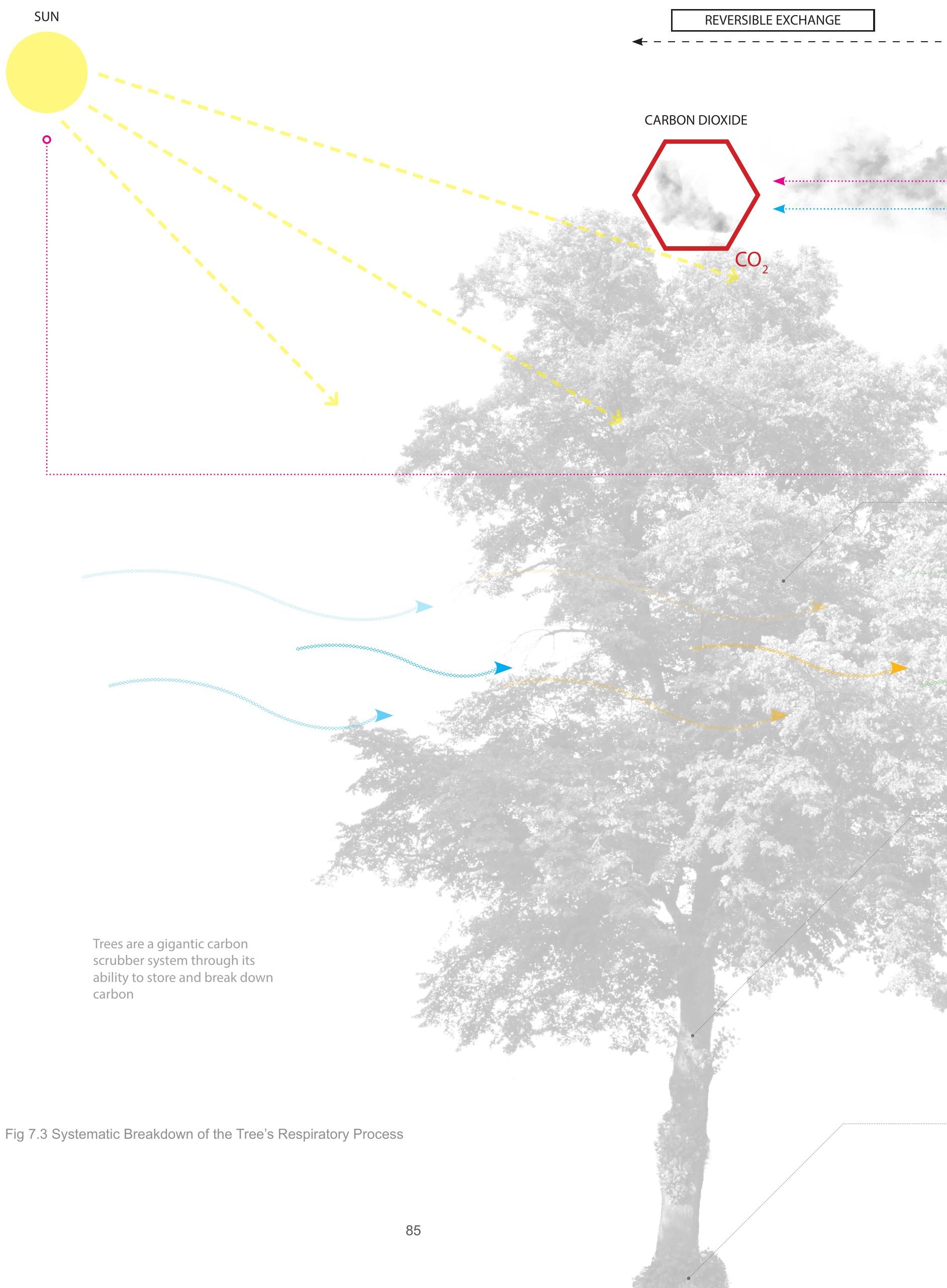


The cycle of carbon dioxide

absorption and oxygen

release can reverse at night

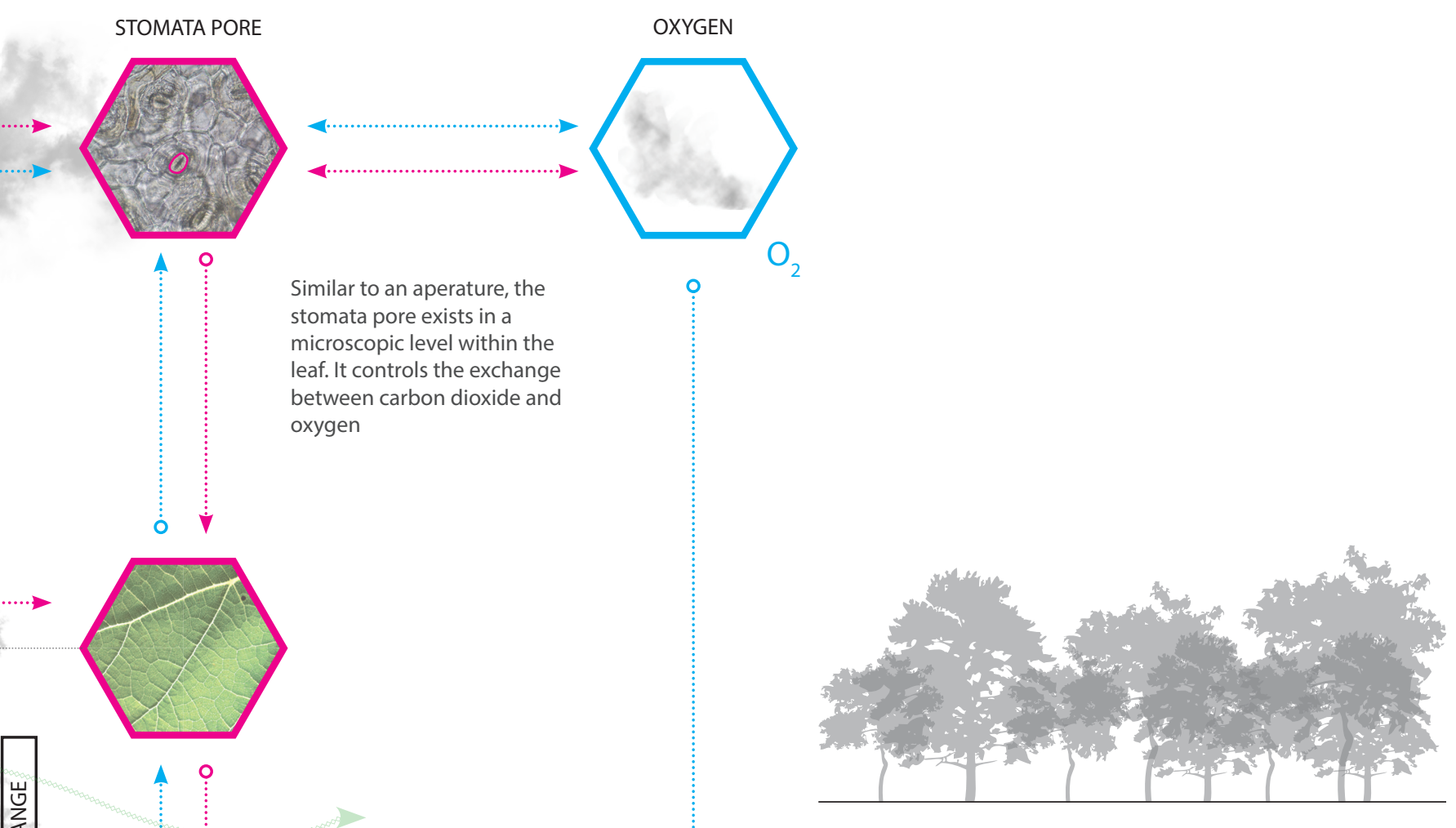

Trees are most effective when grown in groups with the ability to remove carbon dioxide and produce oxygen at large scales all the while creating and housing thousands of species within its own structure. A single mature tree can absorb carbon dioxide at a rate of $48 \mathrm{lbs} /$ year and release enough oxygen back into the atmosphere to support 2 human beings.

The trunk acts is the central

exchange route between

nutrients and water up and down from the roots and leaves

The roots of a tree requires oxygen to grow. It also absorbs water for the photosynethisis process

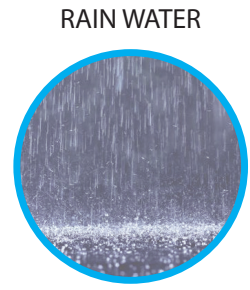


requires an understanding of the entire system as a kit of parts to give context to the final solution that most designers latch onto for inspiration. In asking how the natural systems breathes at a larger system removes the attention away from the single act of breathing and shifts it towards relationships of components.

Trees achieve respiration as a collective. From the scale of the stomata pore all the way to a large network of trees in a forest, every component contributes towards the single task of respiration. An exchange occurs at each of the varying levels as a series of inputs and outputs that comes together to achieve a broader purpose. Independently, a snapshot of any element on its own (ex. The trunk) is useless without the entire tree to enable respiration. On a much smaller scale, the fly appears to be less complex compared to tree. However, size is not indicative of the organism's complexity. In fact, it is arguable that the fly is more sophisticated since its entire respiratory network is compacted down to the scale of its own body. It still functions based on an input to output process that starts with oxygen entering its thorax (abdomen) through a series of tiny holes called spiracles. Rather than having a central breathing system, the entire body plays a part in its respiration as oxygen circulates throughout the body through a system of tracheae tubes. Through these exoskeleton tubes, oxygen reaches all parts of the body to feed muscle cells to sustain flight. The main process for respiration in flies occurs through diffusion, a vastly different process compared to the familiarities of the human lung. Lastly, termite mounds may have the most interesting system that uses the power of the collective to its advantage. Although the termites are the primary organisms that require oxygen in its survival, we look at the entire mound

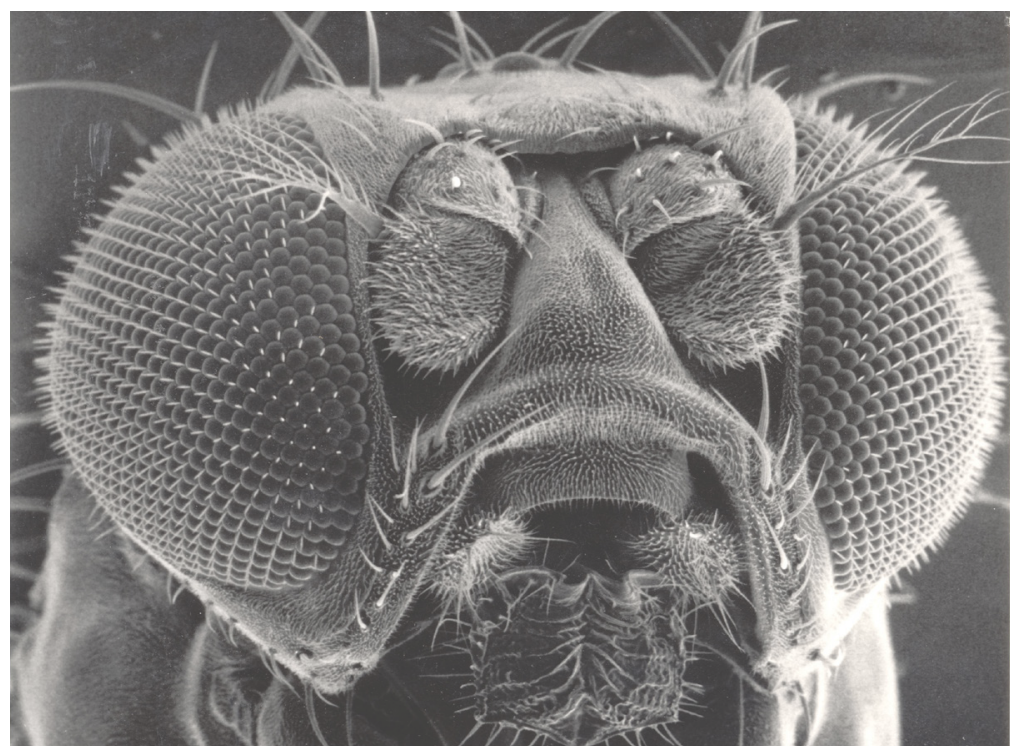

Fig 7.5 Close up of the fly 
Fig 7.6 Systematic Breakdown of the Fly's Respiratory Process

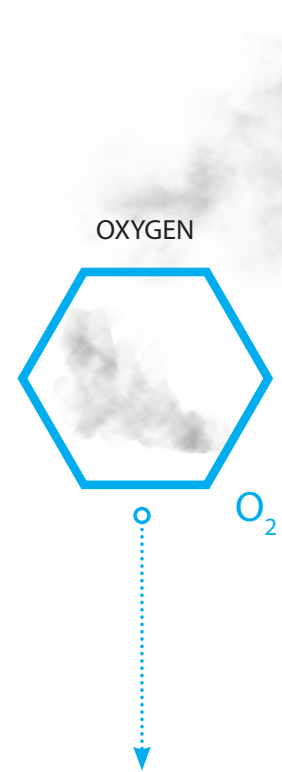

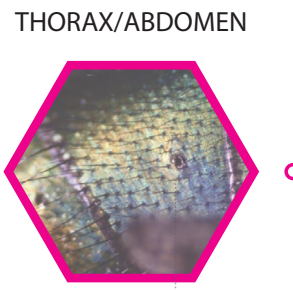

The adbomen of the fly contains a series of tiny holes called "spiracles"

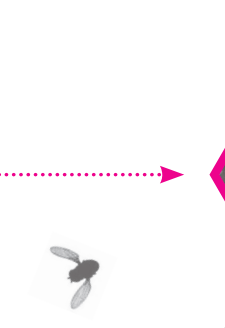

\section{Oxygen passes} through the spiracle opening and into the fly

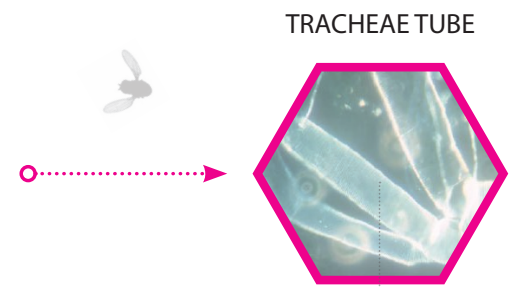

Oxygen then proceeds down a network of air-filled tracheae tubes

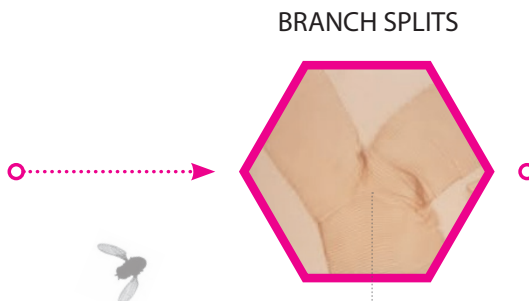

The tracheae tubes branches throughout the fly's body

RESPIRATION PROCESS

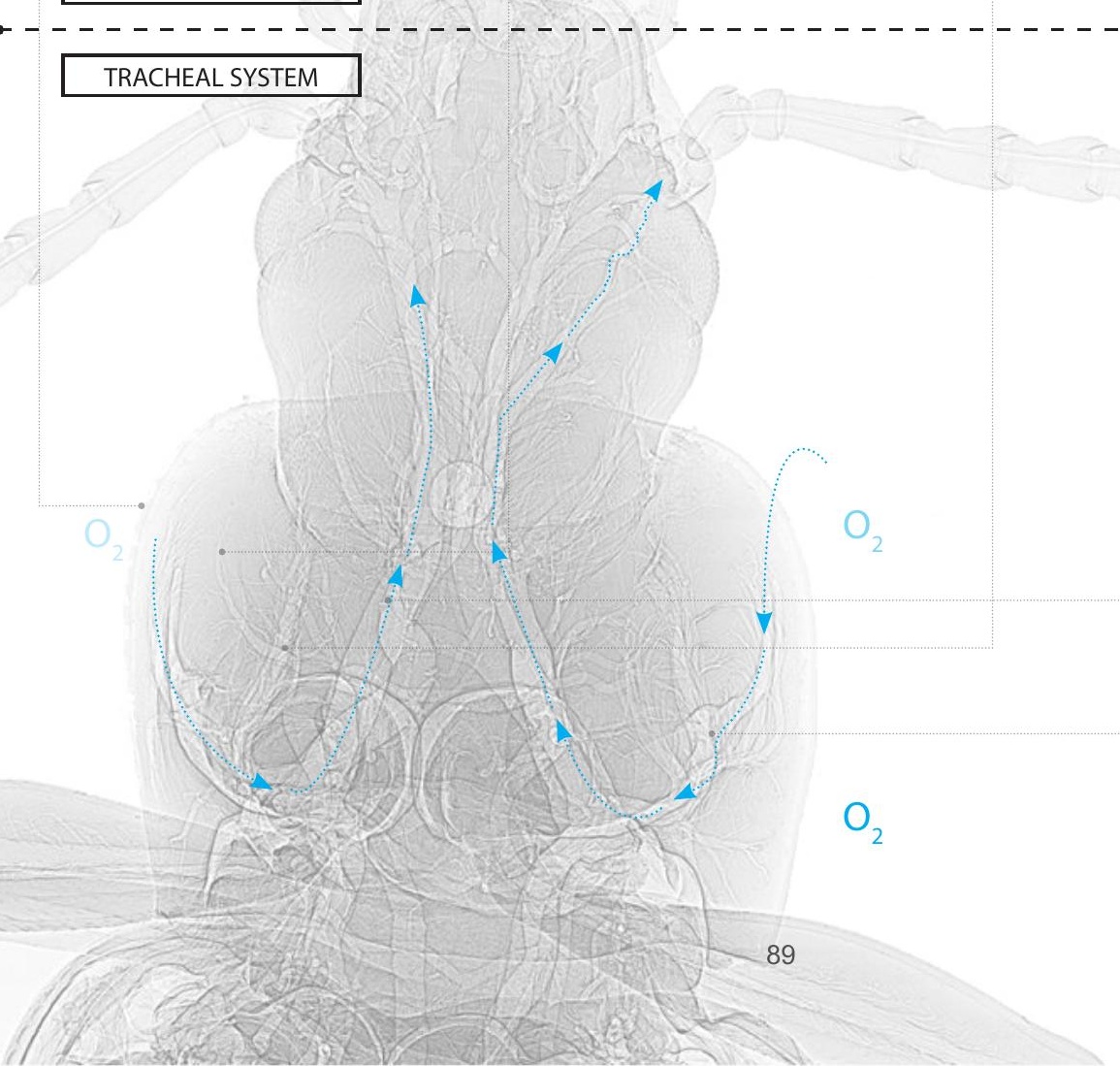




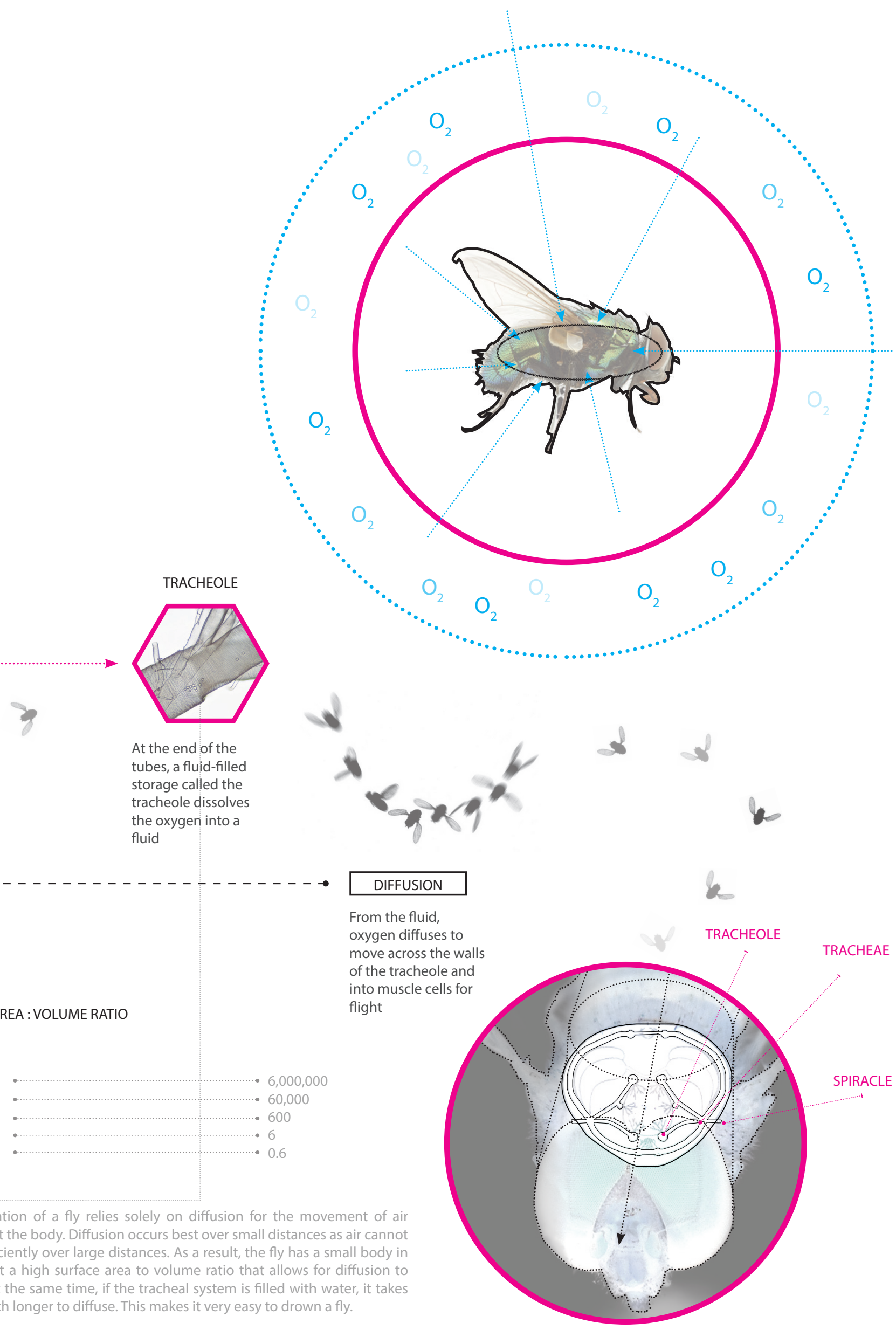

The respiration of a fly relies solely on diffusion for the movement of air throughout the body. Diffusion occurs best over small distances as air cannot diffuse efficiently over large distances. As a result, the fly has a small body in volume but a high surface area to volume ratio that allows for diffusion to happen. At the same time, if the tracheal system is filled with water, it takes the air much longer to diffuse. This makes it very easy to drown a fly. 

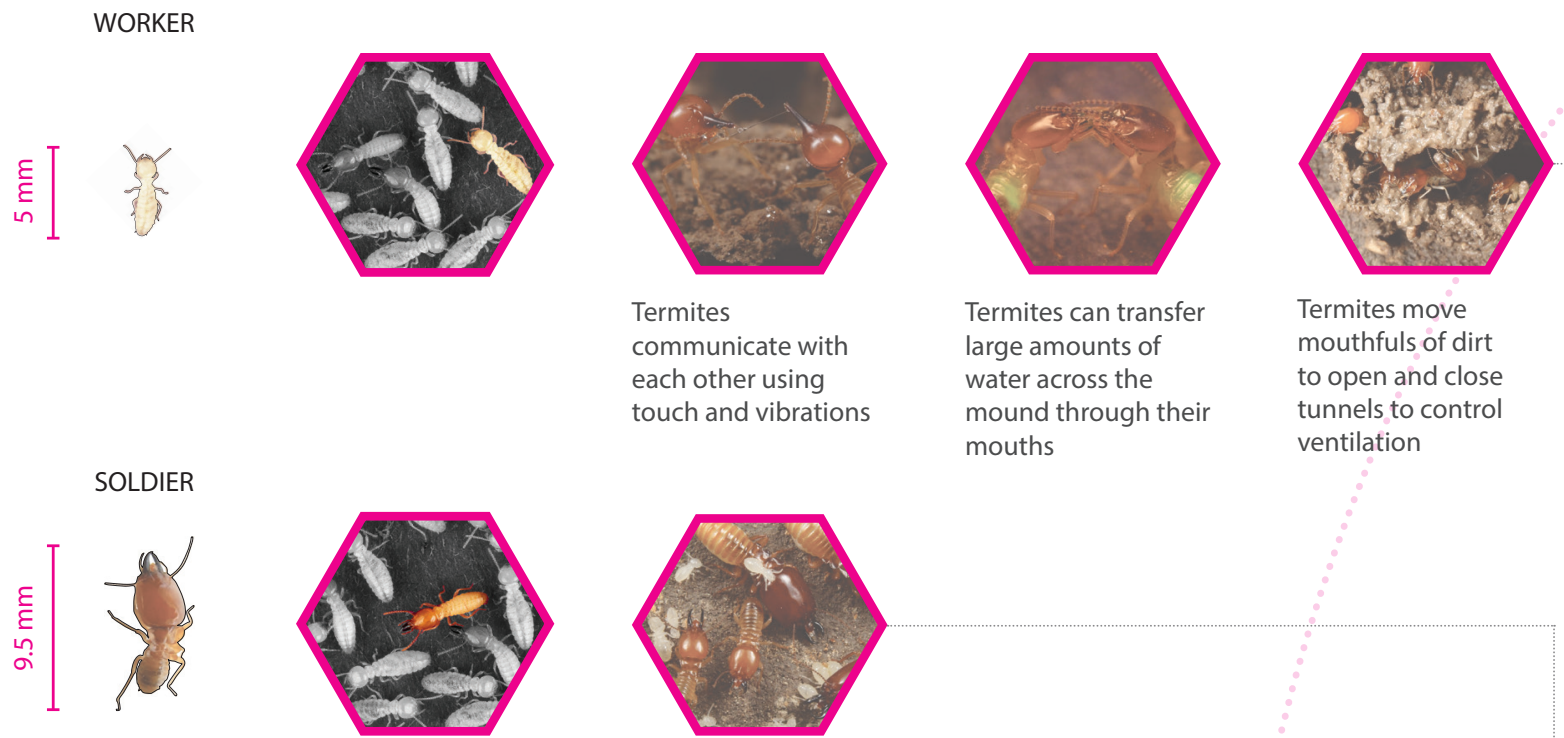

Termite soldiers act as protection and enforcers of the mound
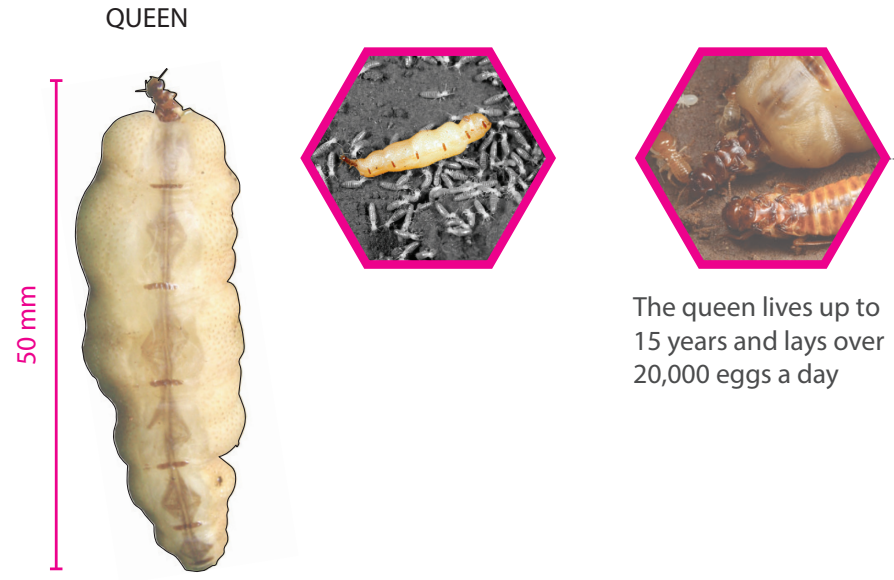

The queen lives up to 15 years and lays over 20,000 eggs a day

At merely $5 \mathrm{~mm}$, a single termite can barely survive on its own. But in a collective of a million or more, termites are architects that can construct mounds up to 9 $m$ high while moving up to 550 lbs of soil.

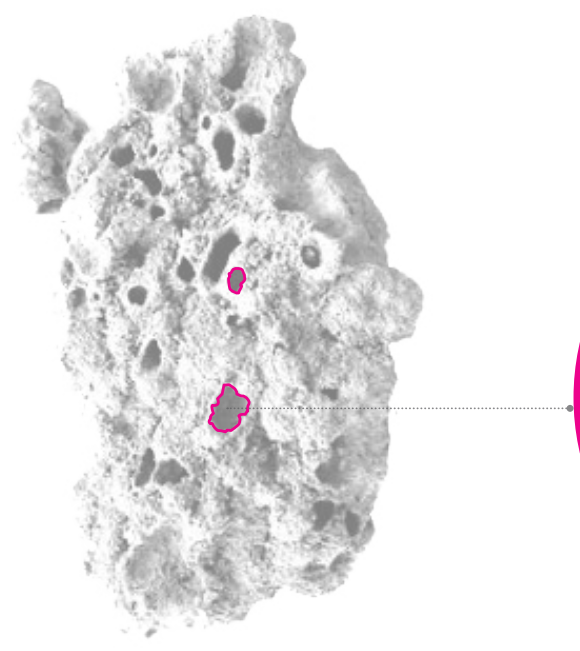

Below the queen's chamber lies a fungus garden that is the termite's main source of food. The fungus requires a controlled atmosphere that doesn't fluctuate more thản 2 degrees centigrade. For this reason, the termife actively responds to control the interior atmospheric conditions
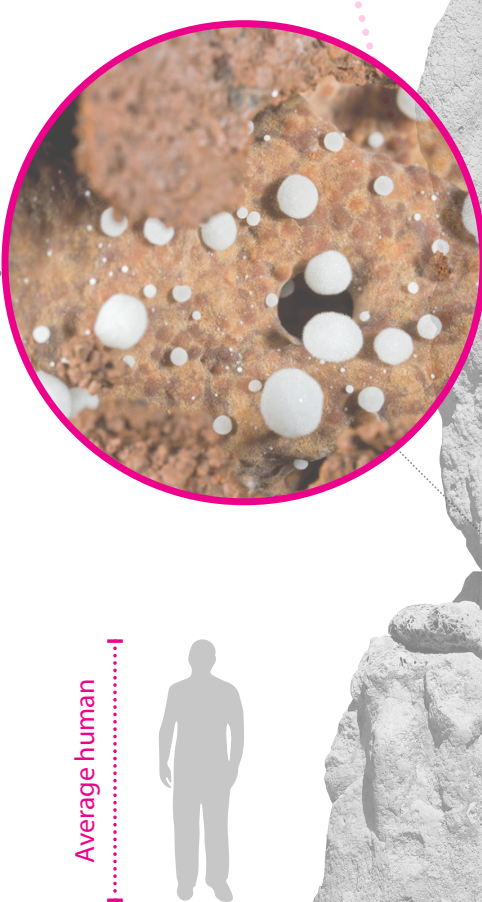


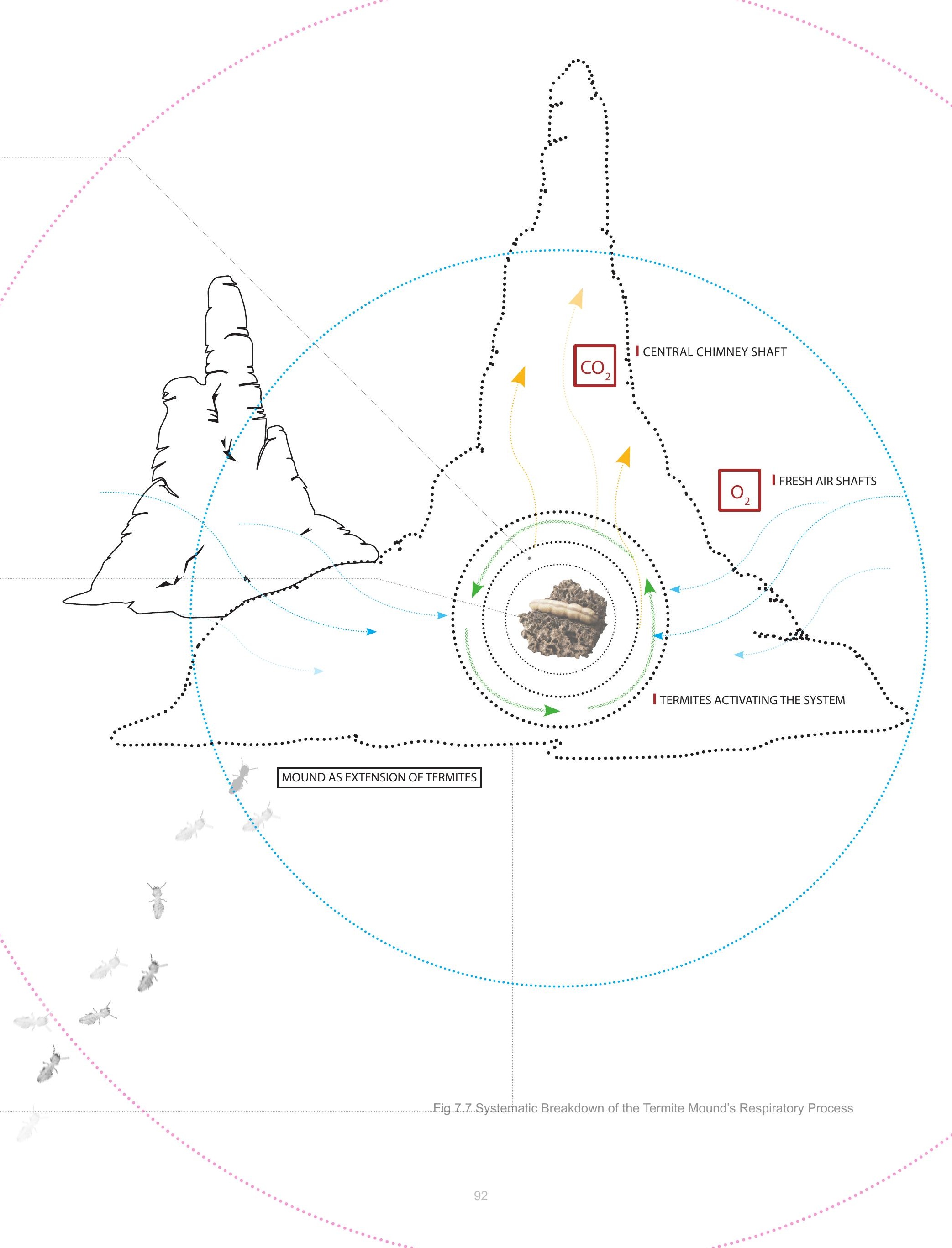


because the termites treat its habitat as an extension of its own body. Each termite has a specific role towards achieving the larger goal of a suitable breathing environment. Groups of termite workers would shift dirt around to open and close networks of tunnels that help bring in fresh air and ventilate stale air. There's a direct relationship between the termites and its mound, similar to the breather and architecture.

Through an understanding of nature as a process of respiration through the 3 case studies in chapter 5 , a new approach can be applied in architectural design. Natural systems inspire a new way of looking at respiration as a discourse in architecture that critiques architecture driven by program. Instead, architecture ought to be driven by respiration instead so that it can become a part of a larger system that is able to break through the man-made constraints of interior and exterior conditions. Buildings can be an extension of the breather that is able to integrate and give back to nature as a system. Francesco suggests a similar relationship in his critical critique of nature, There is no such thing as Nature:

"Other practitioners demonstrate that even the most artificial built environment is part of the natural world; nature, in fact, does not exist as a separate entity: we are always inside an environment with a group of other interdependent living organism."3 


\subsection{RegenerativeArchitecture}

The term regenerative architecture implies that architecture needs to stretch beyond "doing less bad" but begin to think about how buildings can be a positive impact towards nature. Naturally, buildings are known to be consuming in operation that have coined them to have a measure of carbon footprints. In the point of view of air qualities, it puts architecture in a damaging character that is only capable of taking away from the natural environment. Compared with natural system, architecture does not address this ability to regenerate to have a net-positive influence within its placement in the environment at large. In the context of designing architecture that is capable of "breathing", buildings need to also consider how it can be designed similar to natural systems that can be a positive contributor towards the breathable environment at both micro and macro scales. LaMa studio describes this theory perfectly:

"A bicycle is a static system of interactive parts, governed by environmental forces and component relationships. The bicycle requires a skilled cyclist to become a dynamic system successfully operating in changing conditions. Like a bicycle under rider-power, an inhabited building is dynamic. Architects arrange a future building to suit its inhabitants; they become generative architects when they treat building design as component set invention, and if they subject the proposed components to design development using semi-autonomous or autonomous rule-systems." 4

To integrate natural systems into architecture means that architecture can adopt a new role in its relationship with the planet and become a natural component itself. If architects take on a broader perspective to encompass buildings as a part of nature, then it has the potential to dissipate the barrier that has been dividing architecture from nature since the modernist era. "It does not mean that we are going to flee out of "space ship earth," but that we are finally out of this strange idea of a nature that could remain infinitely distant from the fragile life-support system that we are slowly making explicit." 


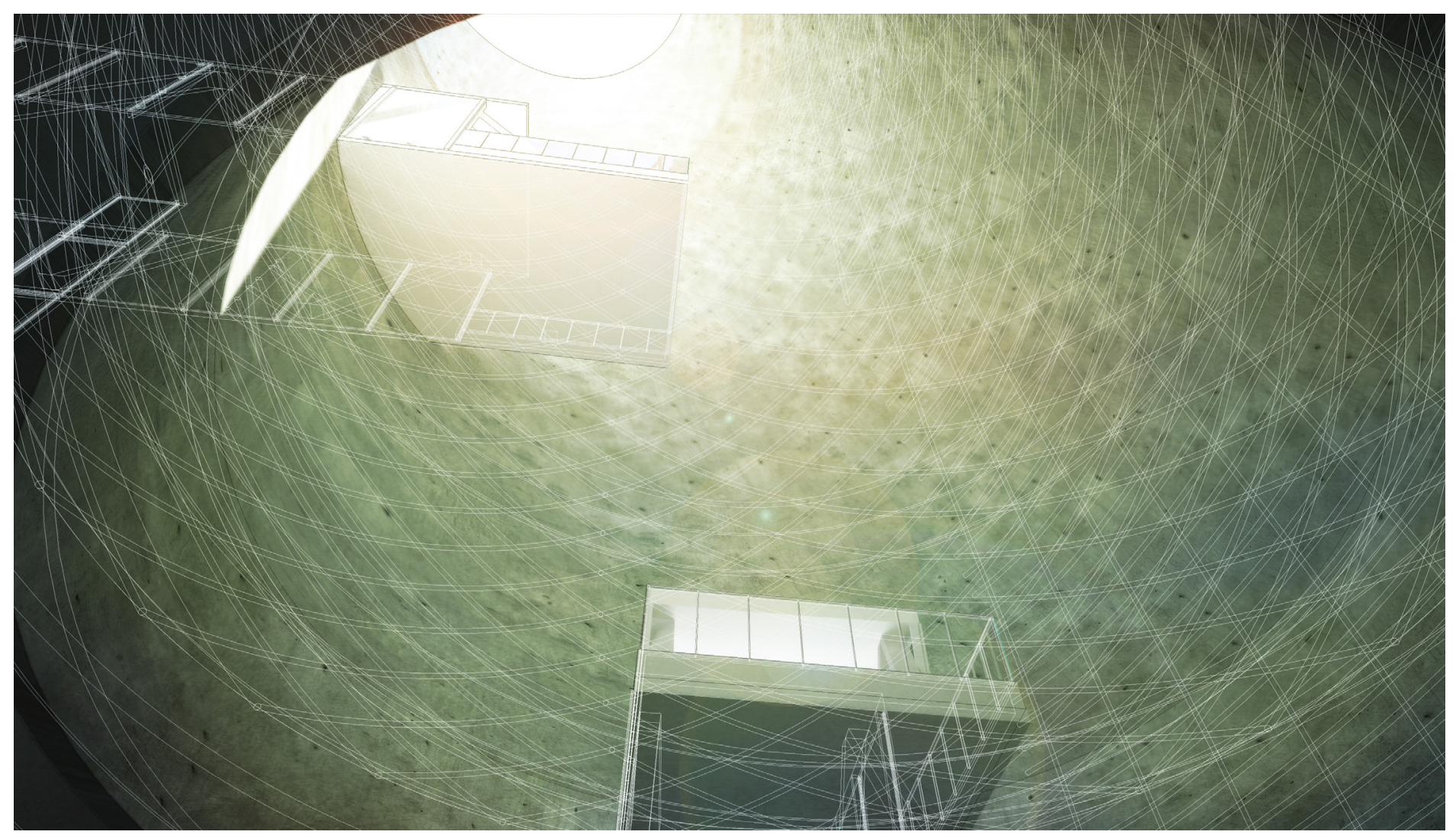

Fig 7.8 View up the solar chimney (central lung) of Aspiro

Through the lens of regeneration, architecture must proactively respond to both the micro and macro environments in order to produce a naturally breathable environment. Driven by the four parameters of respiration, buildings must move away from program in the form of functional spaces in order to allow the demand of respiration to be separated into controlled zones to dictate the architectural form of a building. Instead of relying on artificial breathing, architects must incorporate respiration into the design, thereby creating urban respiratory systems throughout the city. Comparable to the human lung, a central respiratory element with the ability to induce passive respiration was used in the design of Aspiro. As a large double skin solar chimney, this element acts as the core driver of the site for both respiration and the purpose of the building. Both air and breathers flow simultaneously through the building towards the central lung where it serves as both the thermal bath point and point of purification. 


\section{Endnotes}

${ }^{1}$ Michael Pawlyn. Biomimicry in Architecture. (London: RIBA Publishing, 2011). 1.

2 Ibid.

${ }^{3}$ Francesco Manacorda. There is no such thing as nature. Radical Nature. (London: Koenig Books Ltd, 2009). 15.

${ }^{4} \mathrm{http} / / /$ www.lamastudio.com/theory_GenerativeArchitecture.asp (accessed November 25, 2014)

${ }^{5}$ Bruno Latour. Air. Sensorium: embodied experience, technology, and contemporary art. (Cambridge: The MIT Press, 2006). 107.

Image References

${ }^{1}$ http://thisisthefuture.org/wp-content/uploads/2011/02/bio.jpg

${ }^{2}$ http://41.media.tumblr.com/tumblr_log6vnJkfp1qlc7vyo1_1280. jpg

${ }^{3}$ Kevin Pu

${ }^{4}$ http://massdosage.co.za/galleries/africa/south_africa/ honeymoon/hi-res/p1030643.jpg

${ }^{5}$ http://viewpoints.iu.edu/science-at-work/files/2012/05/ flyheadsolo.jpg

${ }^{6}$ Kevin $\mathrm{Pu}$

${ }^{7}$ Ibid.

${ }^{8} \mathrm{Ibid}$. 


\subsection{Responding to User}

Gissen states that "architecture has been and remains a significant feature of our perception, interpretation and interaction with pollution." Architecture has the ability to directly impact pollution in a positive way by engaging breathers with the invisible element. By drawing attention to the atmosphere, architecture can become a dynamic living system that responds to breathers in an intuitive way and begins to address the need for breathing architecture. As an experiment which combined digital fabrication and physical computing to design an installation that engages breathers with the architecture, Stomata is an interactive installation that begins to resemble what architecture as respiratory system would look like. Through a specific focus on responding to users, Stomata is an experiment in applying the four parameters of respiration to create a respiratory system in the form of a parametric installation.

Stomata, named after the Greek word for "mouth", is used in botany to describe pores found in the epidermis of botanic organisms that control gas exchange. ${ }^{2}$ The name for the installation is a metaphor describing the relationship of the changing apertures that respond to the proximity of human interactions as being similar to the stomata pores that respond to oxygen and carbon dioxide levels.

The static forms of the parametric apertures activate when they are approached by the breather through carbon dioxide sensors. Designed for control, these carbon dioxide sensors are placed throughout the room to detect carbon dioxide levels within the room. As the number of breathers in the room increases, so do the carbon dioxide levels, thereby maintaining a constant exchange between breathers and the architecture. The carbon dioxide sensors pick up the change in oxygen levels and send the information back to a central Arduino computer chip as input data. The output data flows through an air compressor that pumps free oxygen back into the space through apertures scattered throughout the installation to mediate the microclimate. This creates a constantly changing environment that engages with each individual in a unique way. The experience of the installation allowed the public to feel engaged in their direct relationship with the apertures simply by being there. Effectively, Stomata connects people to an active system that allows them to manipulate their surroundings. People are able to control the atmosphere as they journey through the installation without ever encountering the same experience. In this respect, Stomata comes to life similar to the function of organisms that are always responding to surrounding conditions.
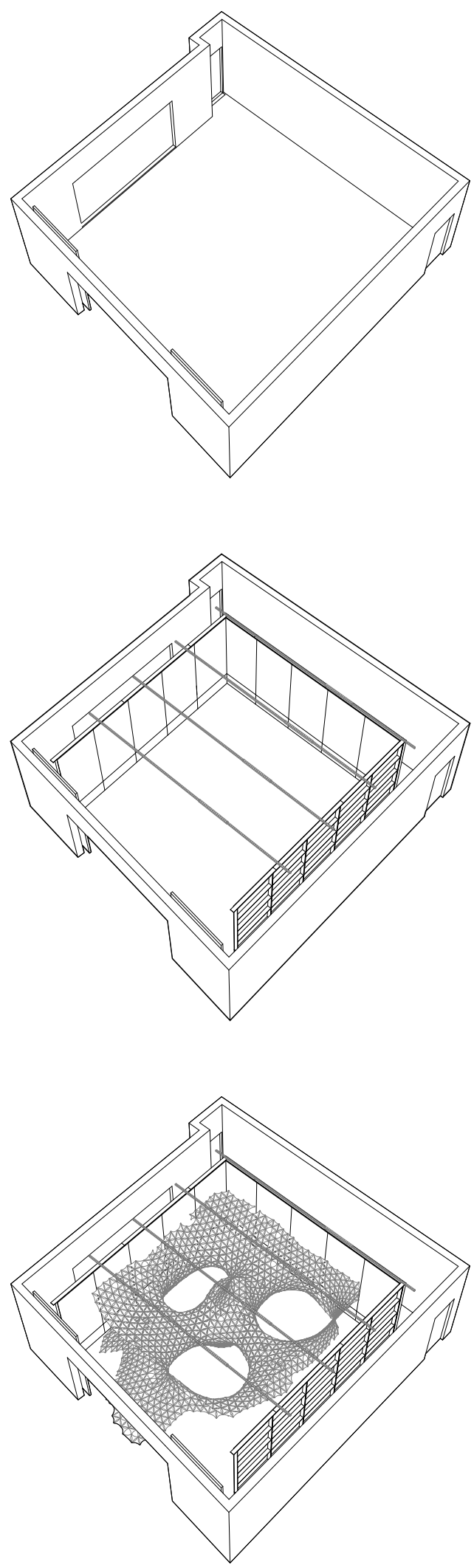

Fig 8.1 Diagram of installation on site 


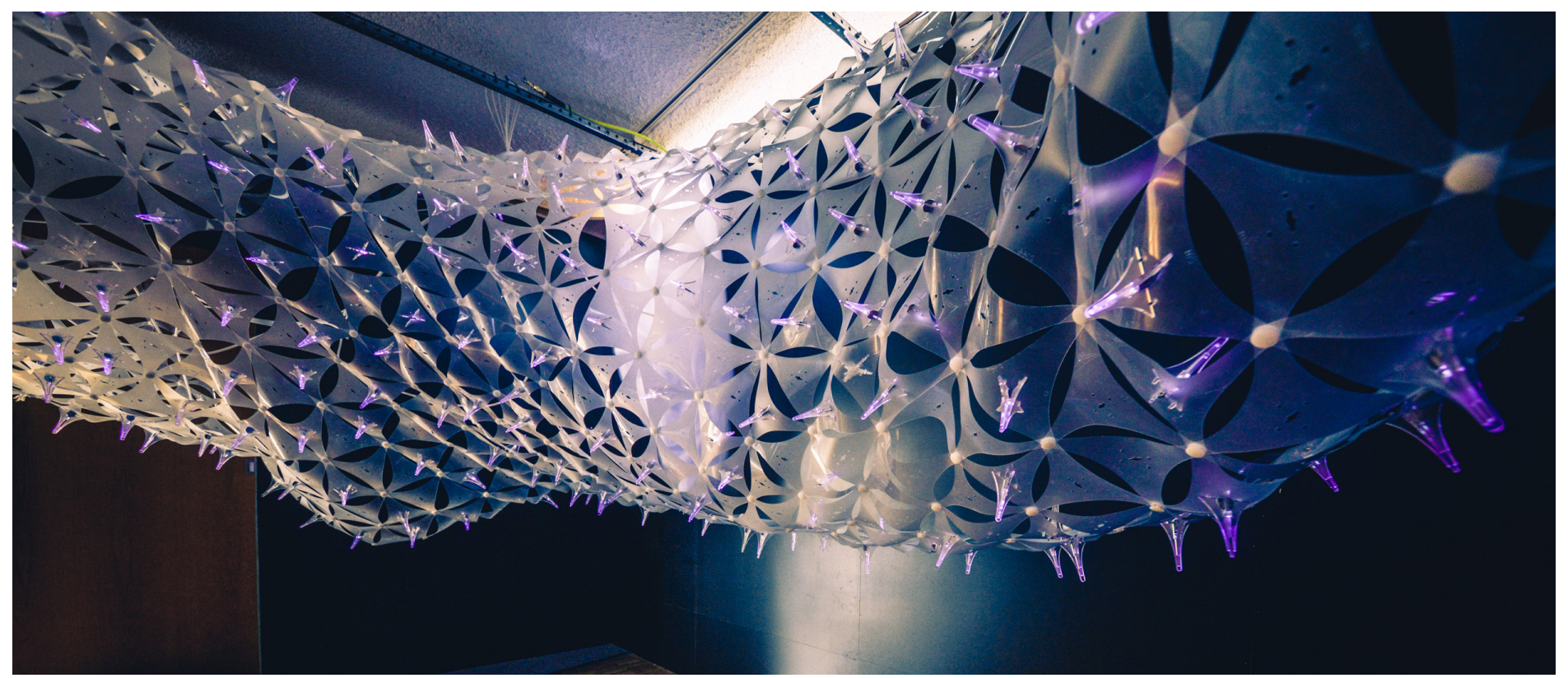

Fig 8.2 Photographs of Stomata taken by Remi Carreiro

I STOMATA PORES

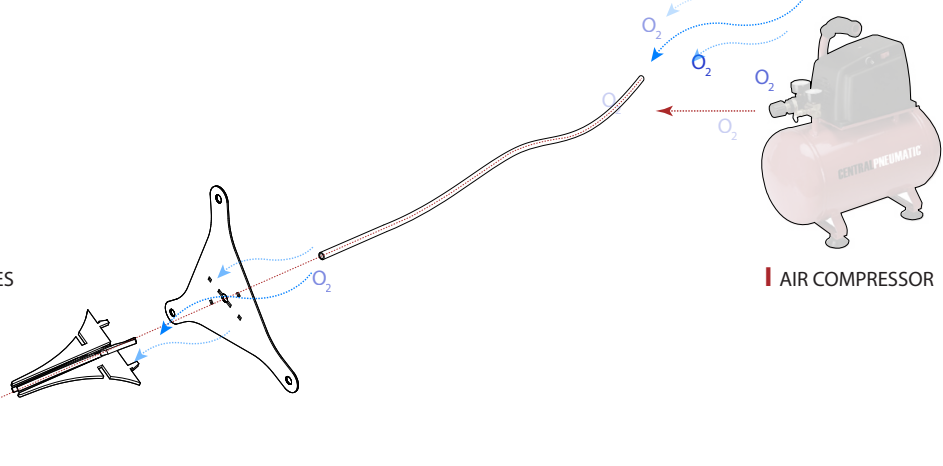

$\mathrm{CO}_{2}$

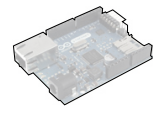

I ARDUINO

I CARBDON DIOXIDE SENSOR

1

Fig 8.3 Flow process of data from carbon dioxide input to oxygen output

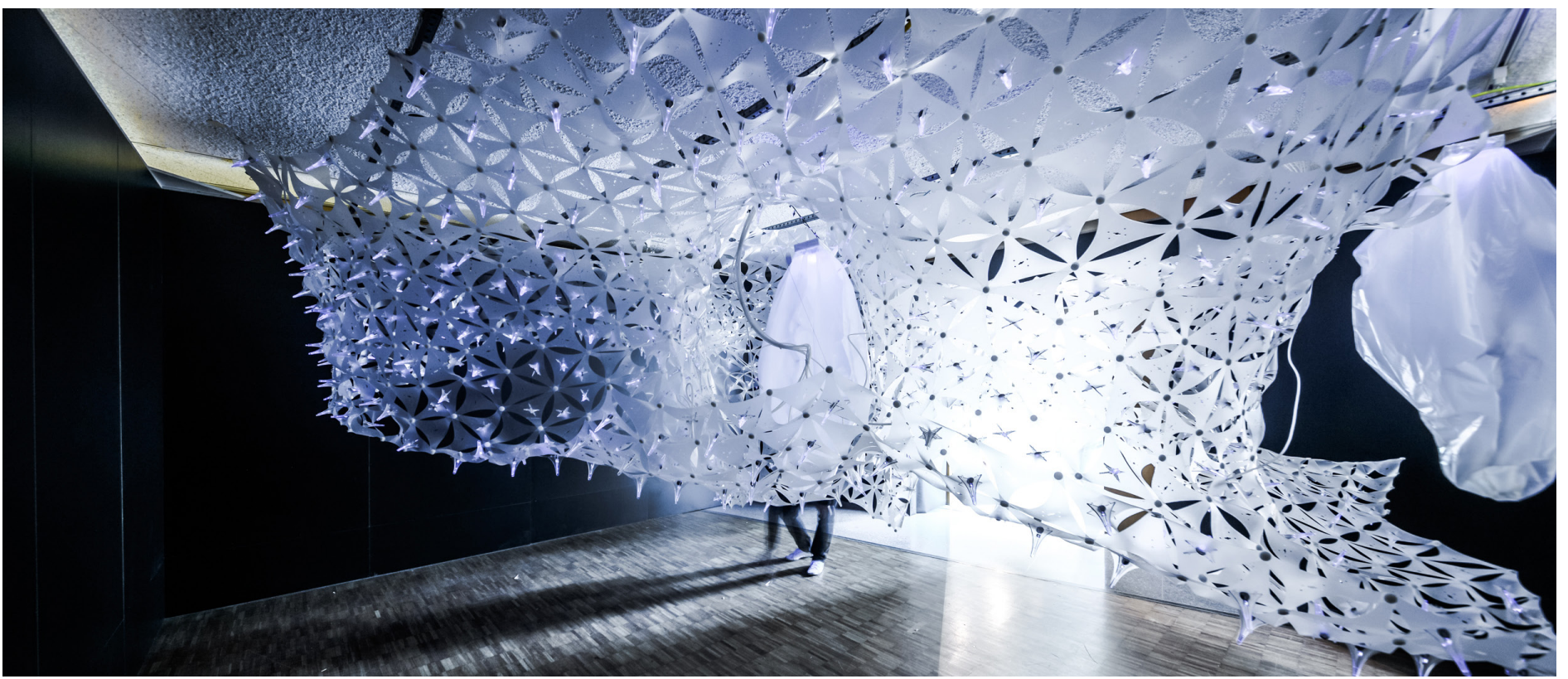

Fig 8.2 Photographs of Stomata taken by Remi Carreiro (continued) 


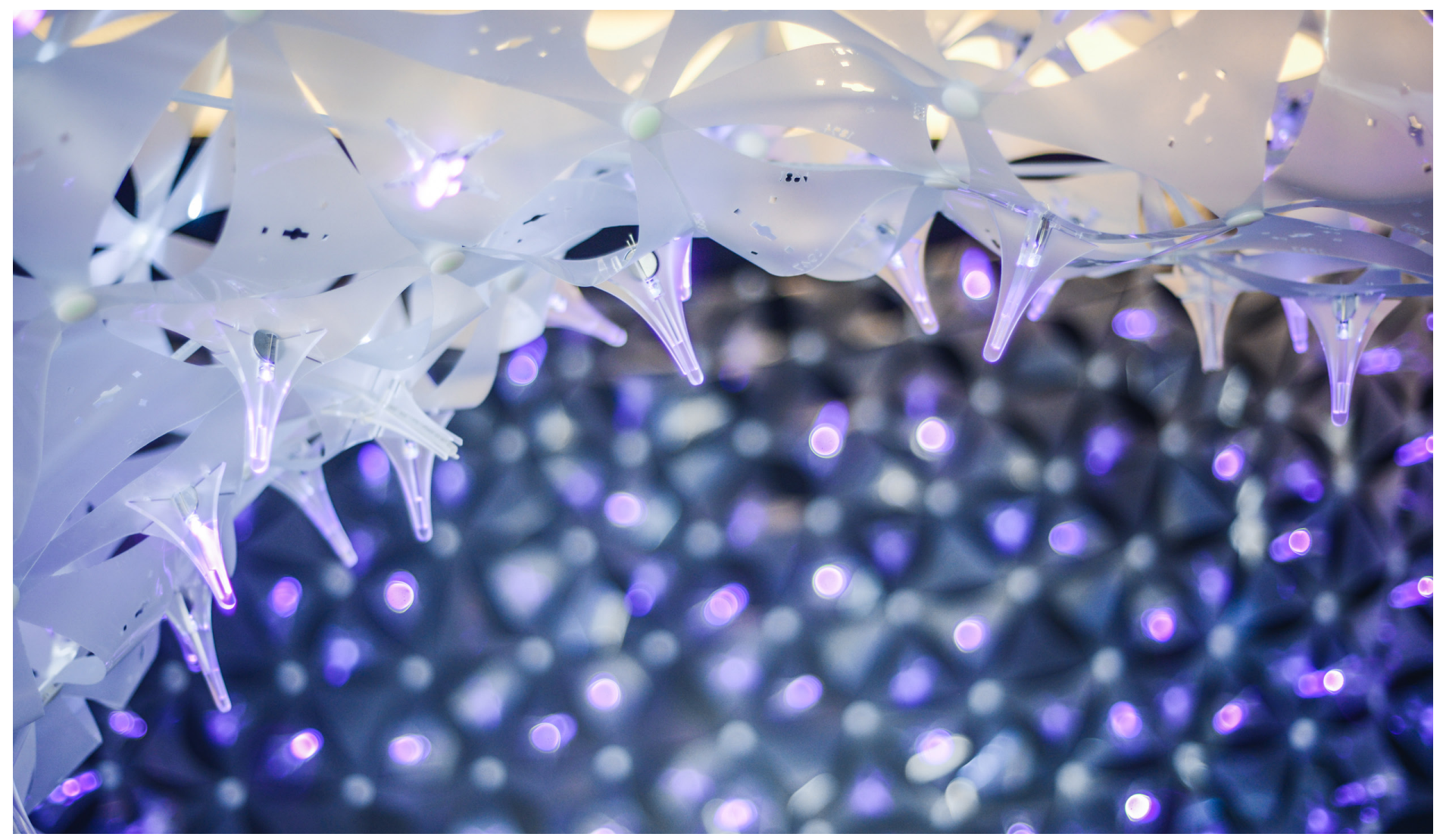

Fig 8.2 Photographs of Stomata taken by Remi Carreiro (continued)

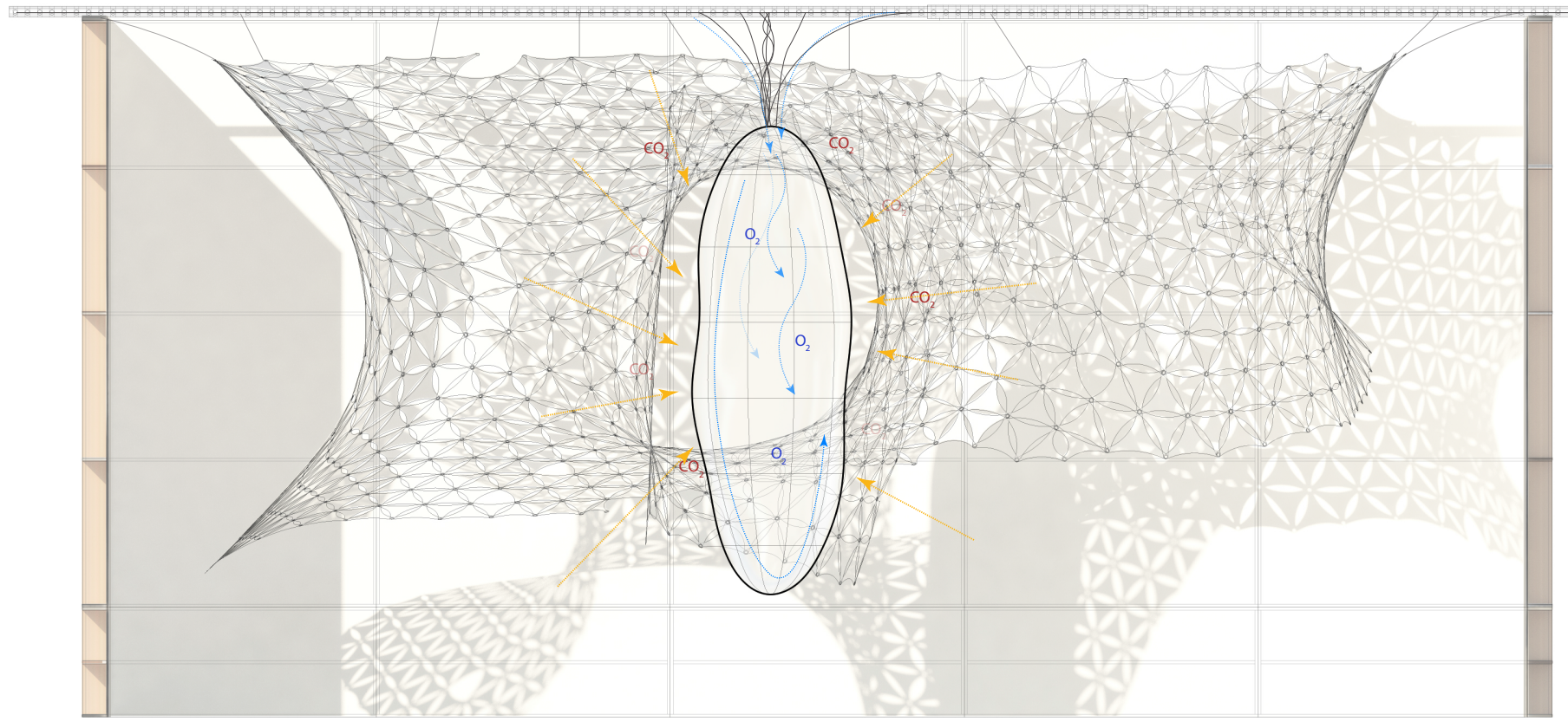

Fig 8.4 Sectional Diagram through the "breathing" bag 

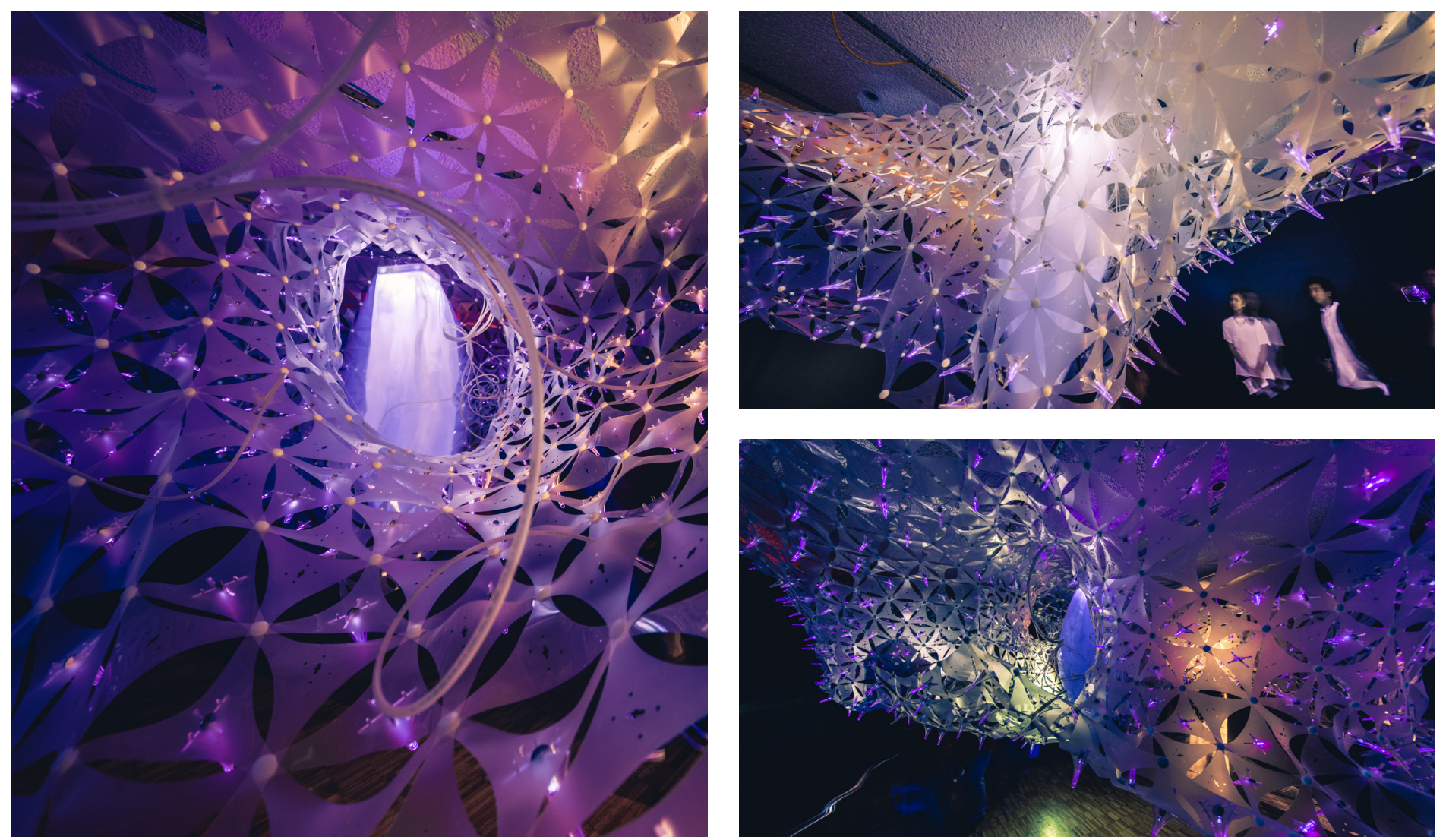

Fig 8.2 Photographs of Stomata taken by Remi Carreiro (continued)

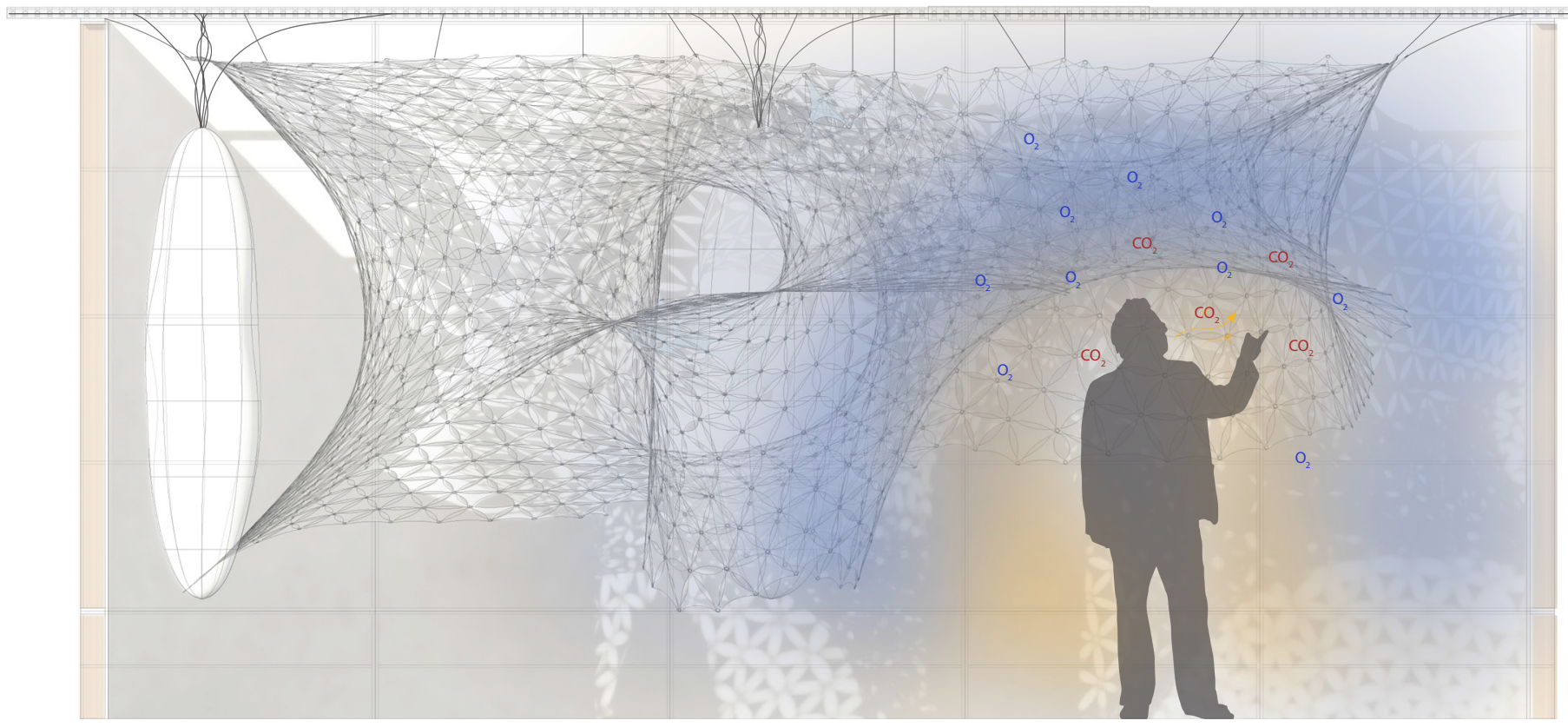

Fig 8.5 Diagram of Stomata's interaction with a breather and his micro climate 


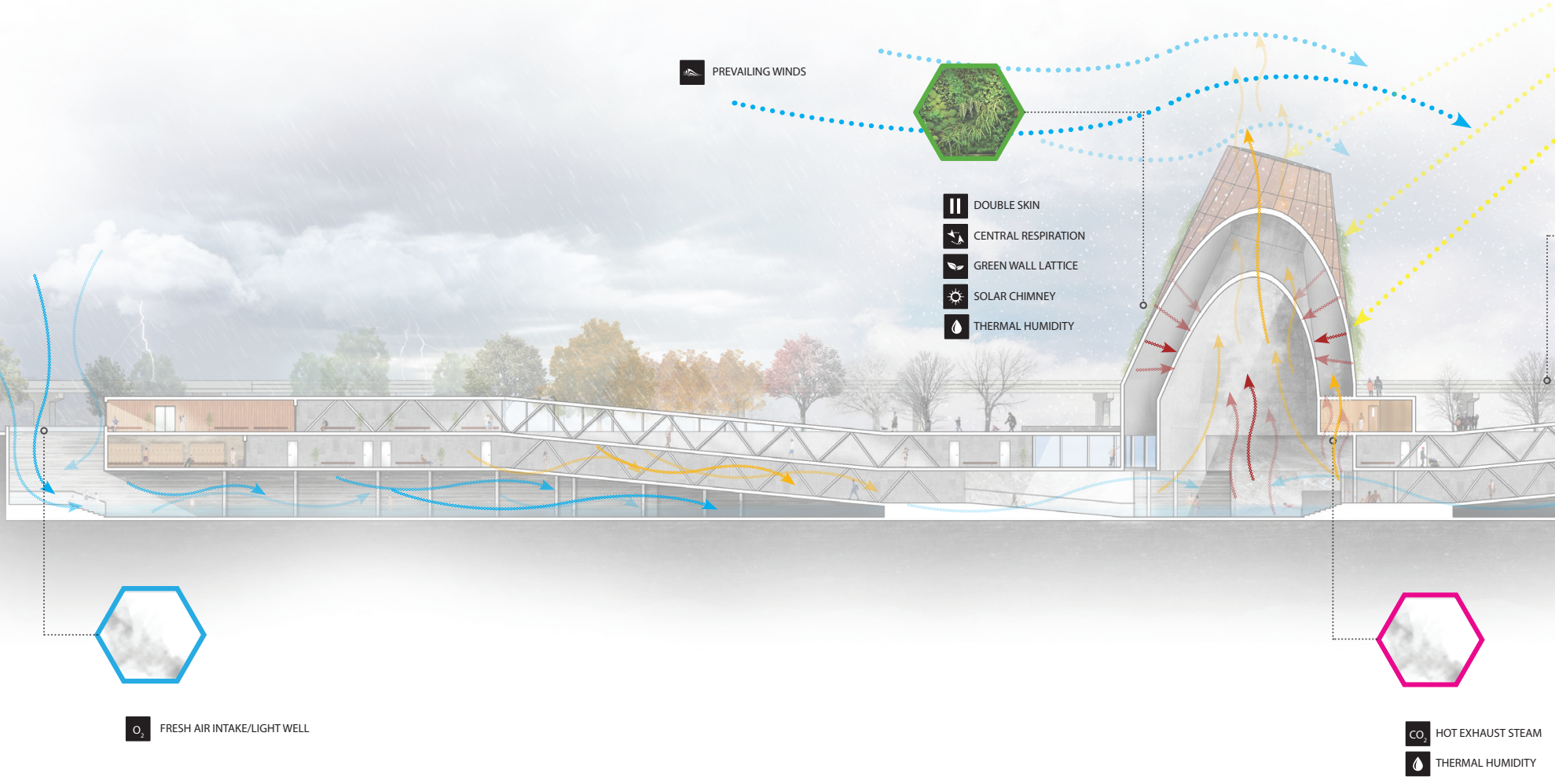

Stomata's meaning, function, and design challenges the conventional relationship between breathers and architecture. The embedded computational technologies add a new layer of information for breathers to experience in an engaging and tangible way. People are able to explore the installation on their own through Stomata's embedded ability to respond and alter the environment. This way, Stomata takes a unique design intent and translates it to an infinite amount of different interpretations. Stomata is successful in demonstrating how architecture can respond to the demands of breathers in space through addressing the simple exchange of oxygen and carbon dioxide. However, at the scale of the installation in a room, Stomata only addresses the microclimate while neglecting the macroclimate of what happens beyond the confines of the room. Design elements such as site and program are lacking in a user-centric design. Despite being designed in response to the breather, the installation disregards the city scale of users and how architecture can respond to the issues of urban sustainability. These shortcomings in Stomata helped inform the final thesis design project, Aspiro, in regards to how to move beyond the singular breather and consider the greater context of the urban environment. As such, Aspiro directly engages with the urban atmospheres of vehicular and urban pollution by extracting and purifying vehicular exhaust and urban pollution to produce both a naturally breathable interior environment and a positive contribution back into the urban fabric. 


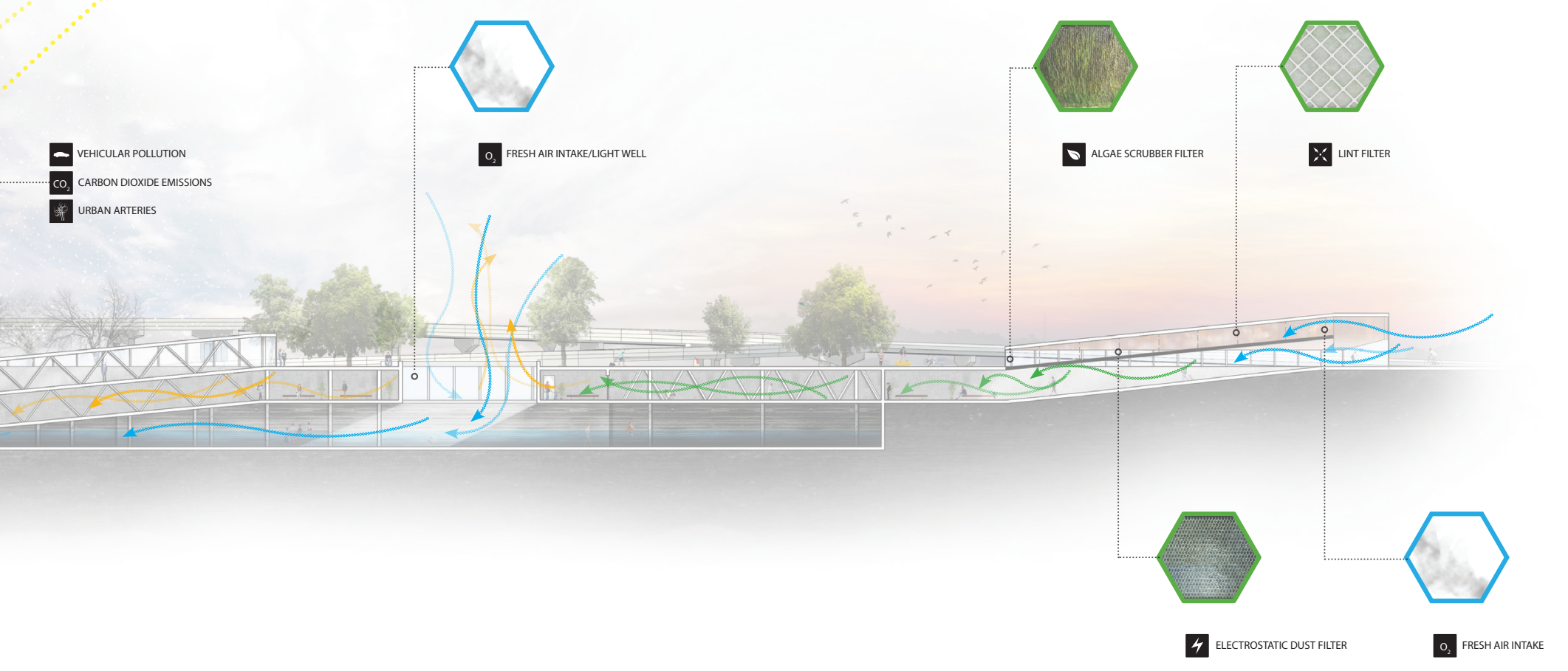

Fig 8.6 Experiential section of Aspiro showing the flow of air and breathers simultaneously throughout the site

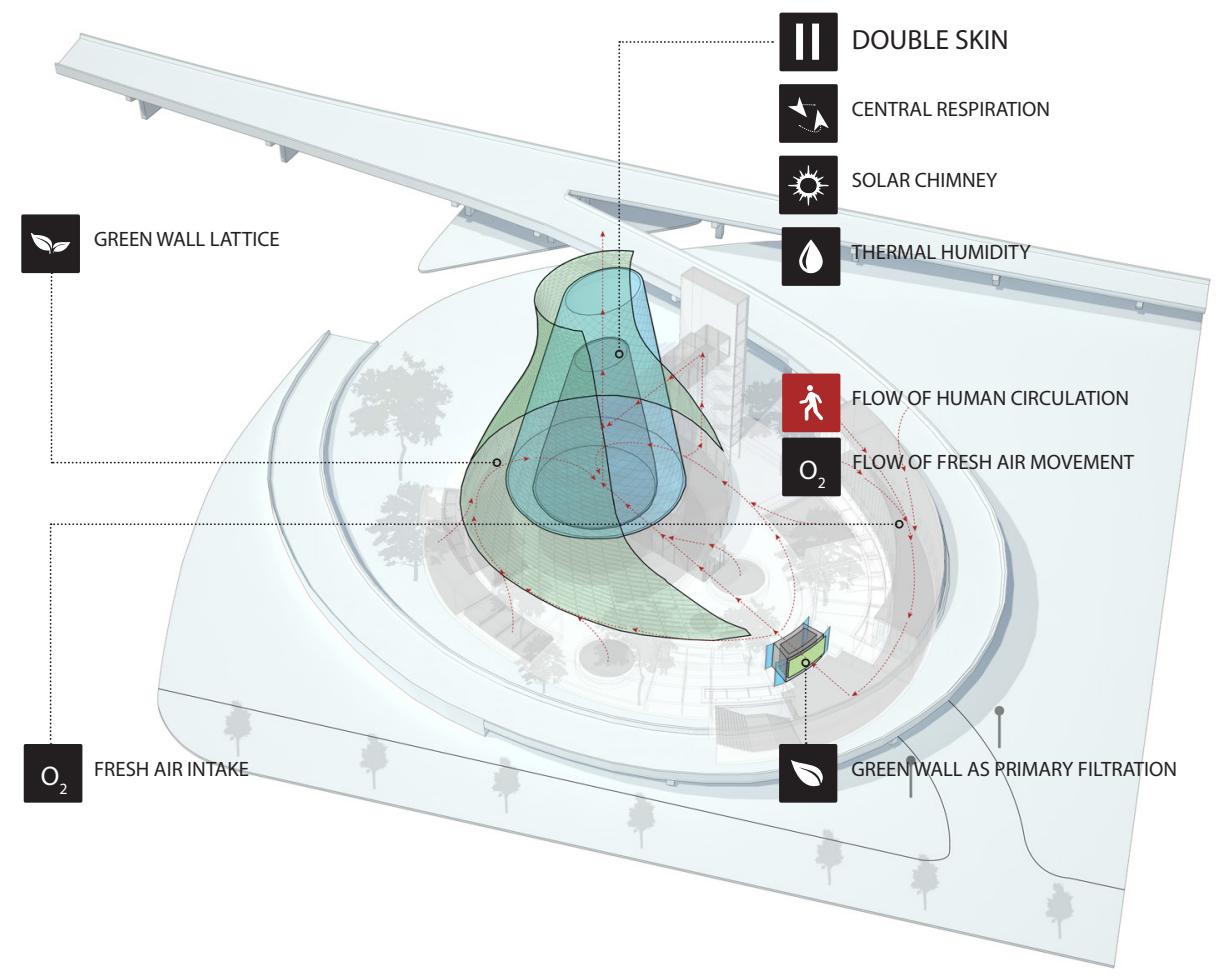

Fig 8.7 Diagram of Aspiro's filtration process that mediates the macroclimate to provide a breathable micro-environment 


\subsection{Responding to Program}

Since Stomata only deals with responding to the individual breather, it lacks programmatic elements that can alter the dynamics of an interior microclimate. Although program is not imperative in the discourse of respiration in architecture, it is often the driving influence behind architectural forms. Through the lens of respiration, program becomes an interesting component when looking at breathable architecture. Programmatic functions can dictate the level of respiration needed depending on the intended program. As a result, the West Don Lands Adult Learning Centre was an experiment to test how the organization of programmed spaces can flow together to define the architecture of a building.

The new West Don Lands development is a unique micro community of density integrated with mixed-use programming that aims to revitalize the neighbourhood. However, the context of its location is that it sits adjacent to the Gardiner Expressway, which both divides and distinguishes the heart of downtown Toronto. As an urban community, it is important for architecture to respond to the atmospheric qualities generated from carbon emissions carried through the highway. Architecturally, the ability to induce and simulate a breathable environment allows architecture to remove itself from nature as an independent component. The consequence of this separation manifests itself through smog and its impact on the quality of air, and by extension, life. Therefore, the West Don Lands Adult Learning Centre is designed to challenge the static seal of buildings to transform the immediate neighbourhood into a breathable community. 


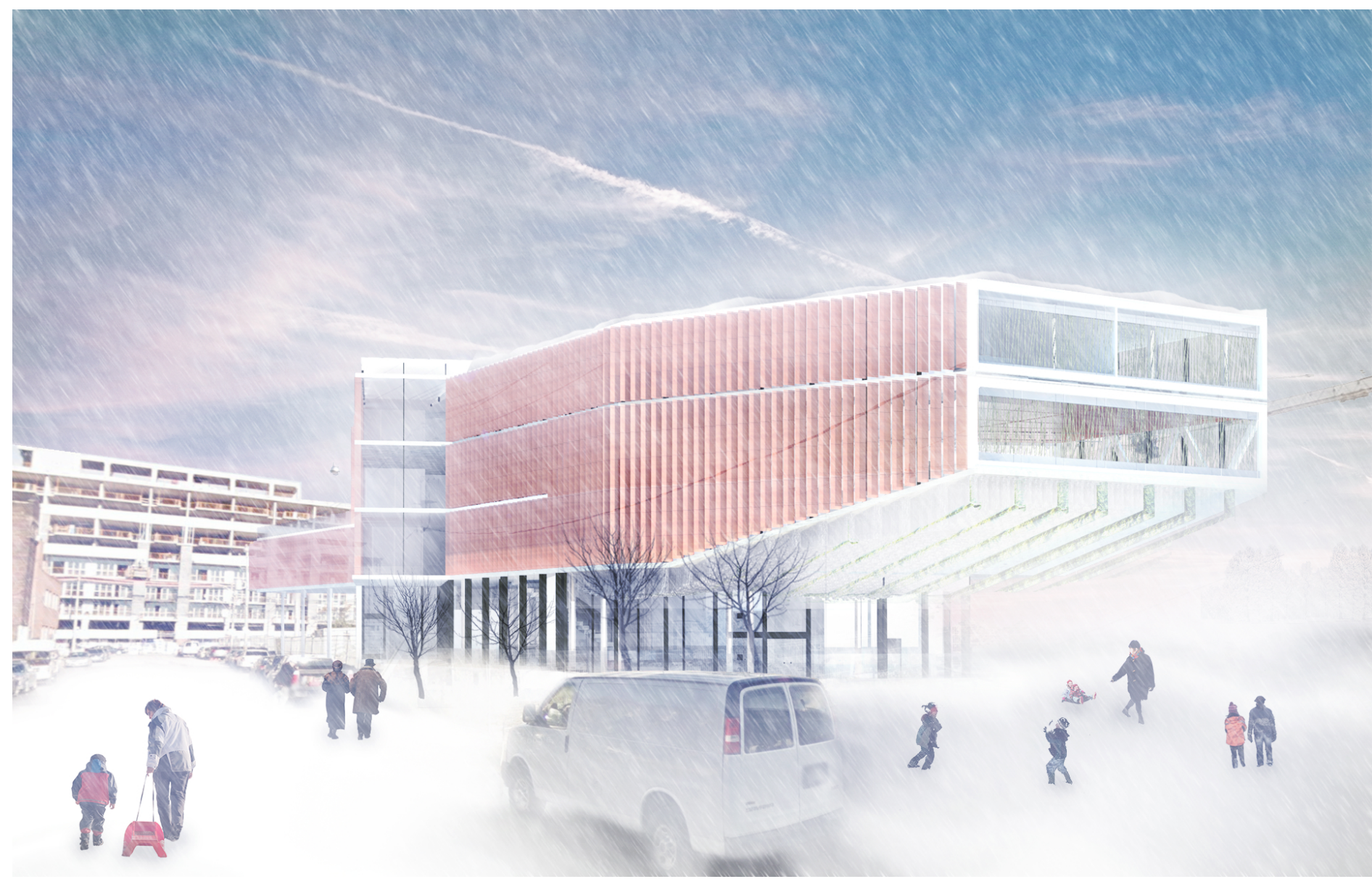

Fig 8.8 Winter render of The West Don Lands Centre

\section{WEST DON LANDS}

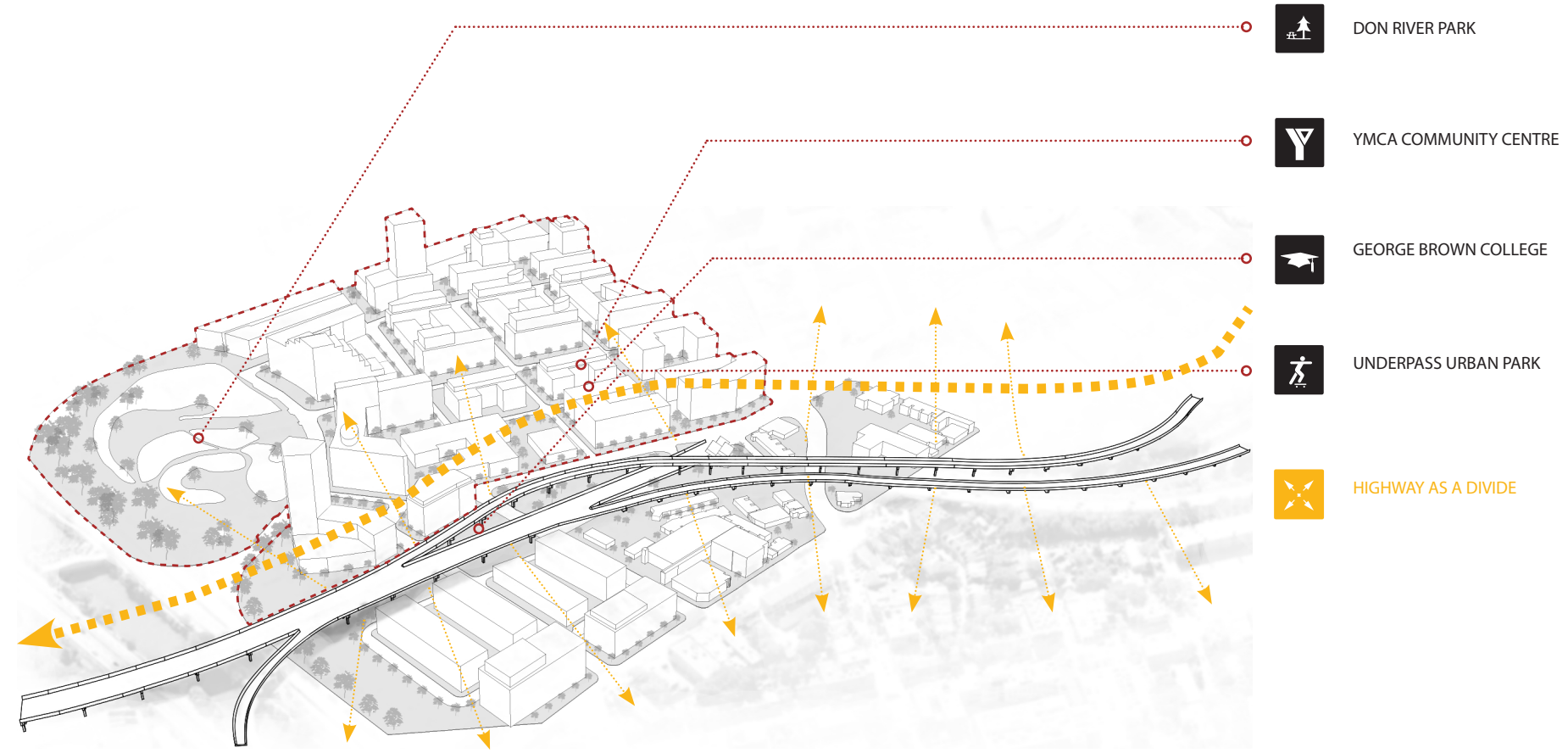

Fig 8.9 Diagram of the West Don Lands development and the Gardiner Expressway 

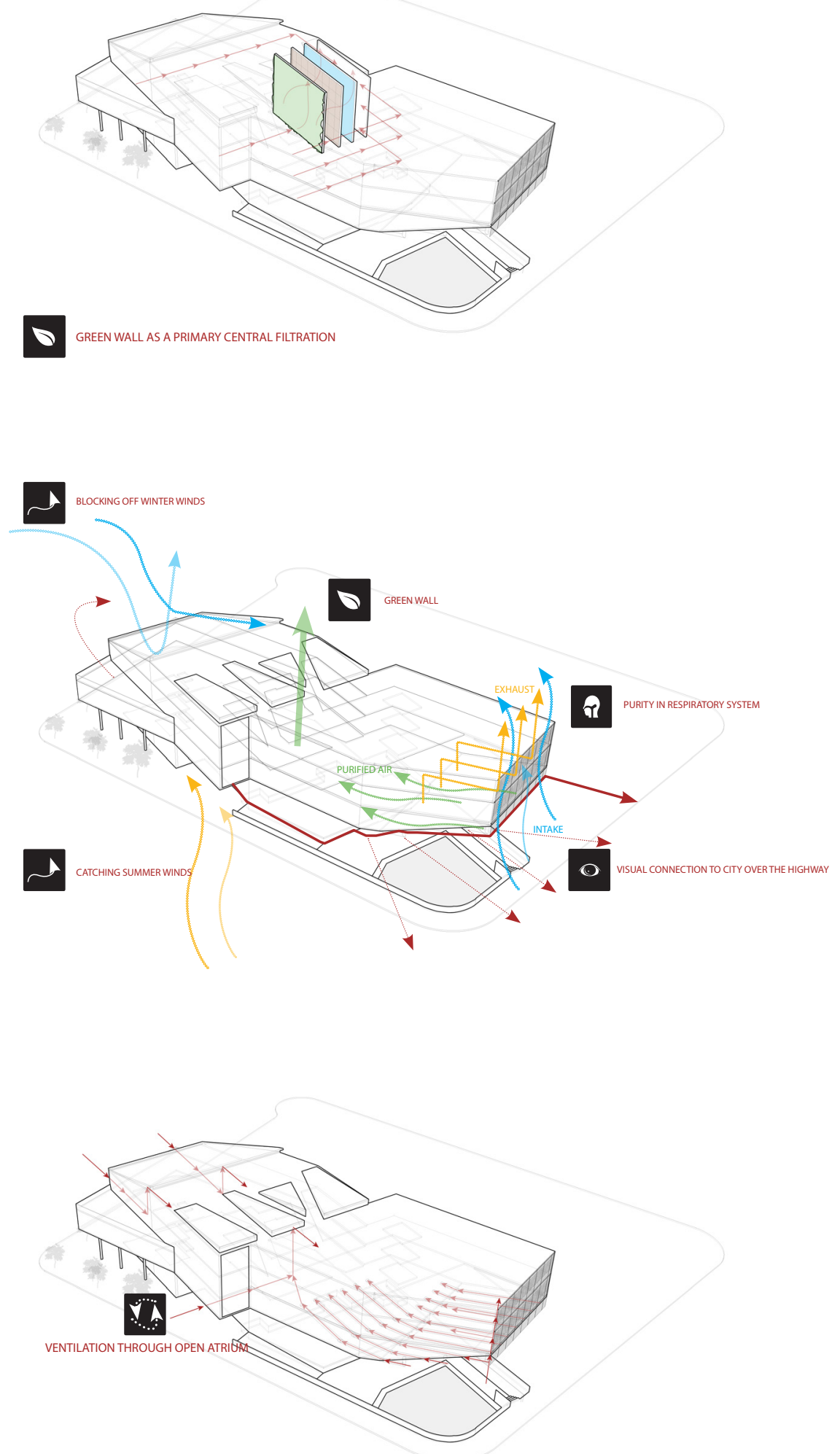

Fig 8.10 Diagram of respiratory systems within the building 


\section{EXPLODED AXONOMETRIC}

I SKYLIGHT AND OPENING FOR VENTILATION

I GREEN WALL

I OPEN ATRIUM

I MECHANICAL LOUVERS COATED WITH TITANIUM DIOXIDE

OPEN STUDIO

I MICROALGAE CARBON SCRUBBER TUBES

I AUDITORIUM/LECTURE HALL

I DAYCARE

I REFLECTIVE POOL

I INTERIOR ATRIUM TREE

I DAYCARE PLAYGROUND
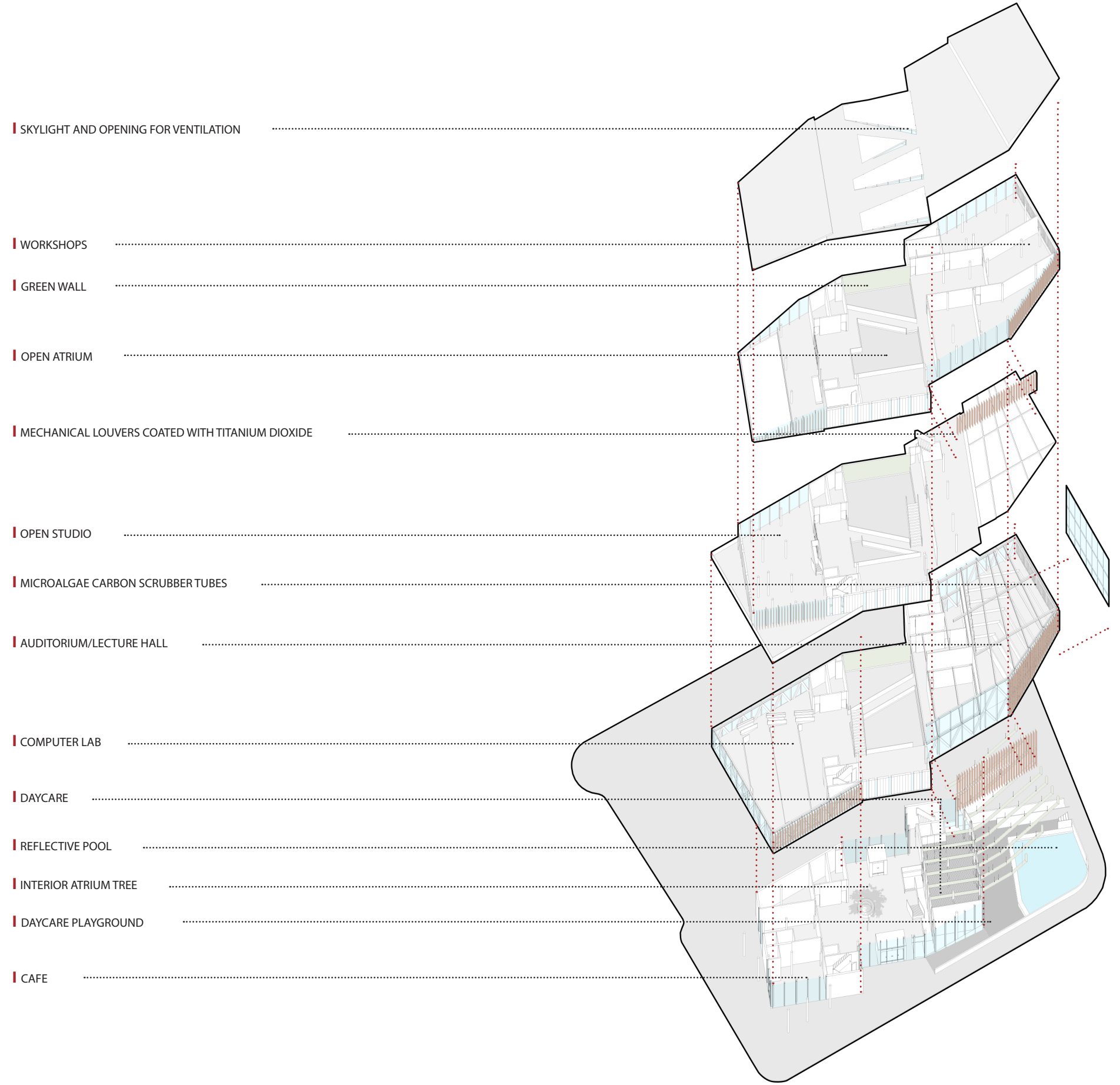

Fig 8.11 Exploded Axonometric 

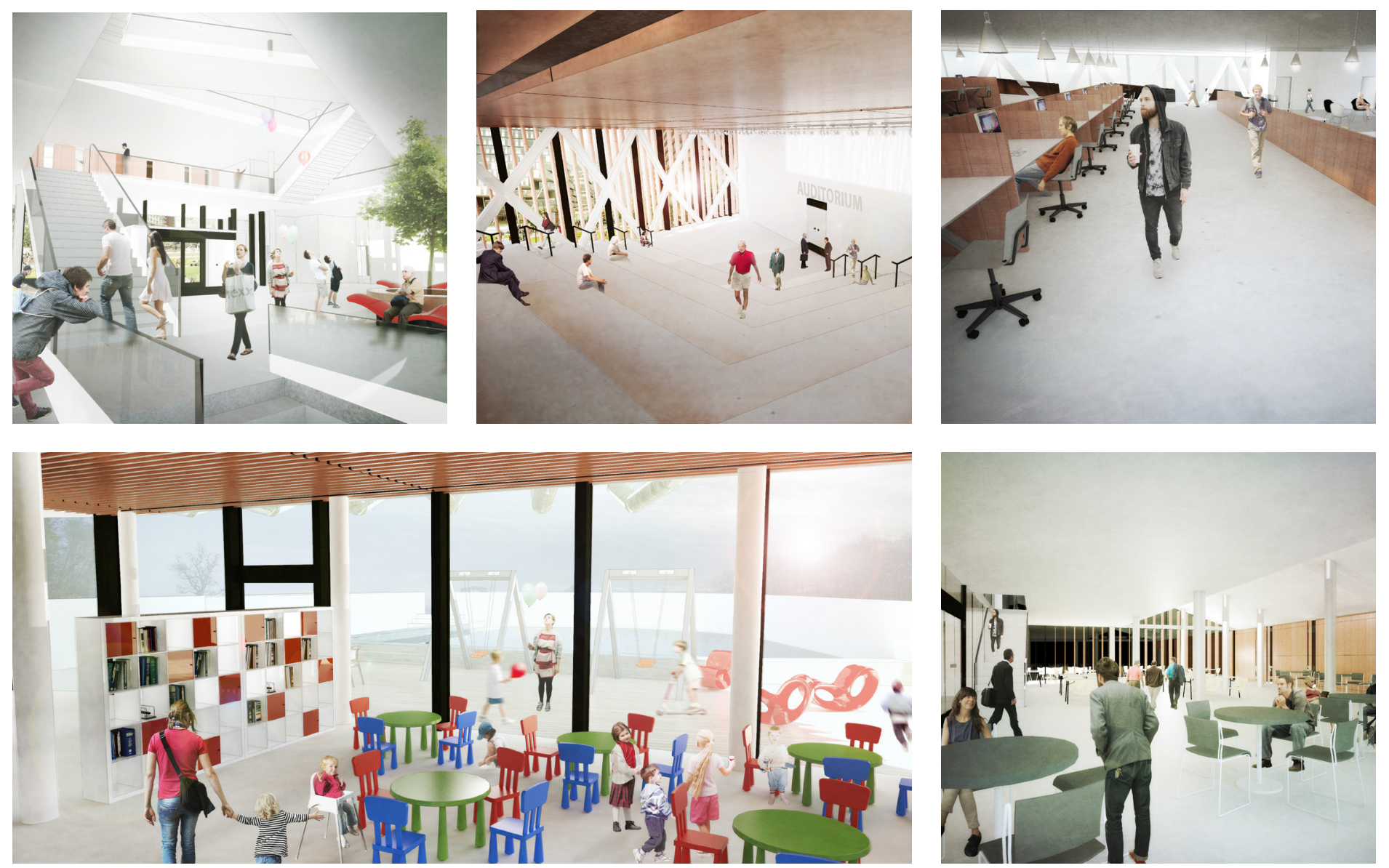

Fig 8.12 Interior renders of open concept spacing

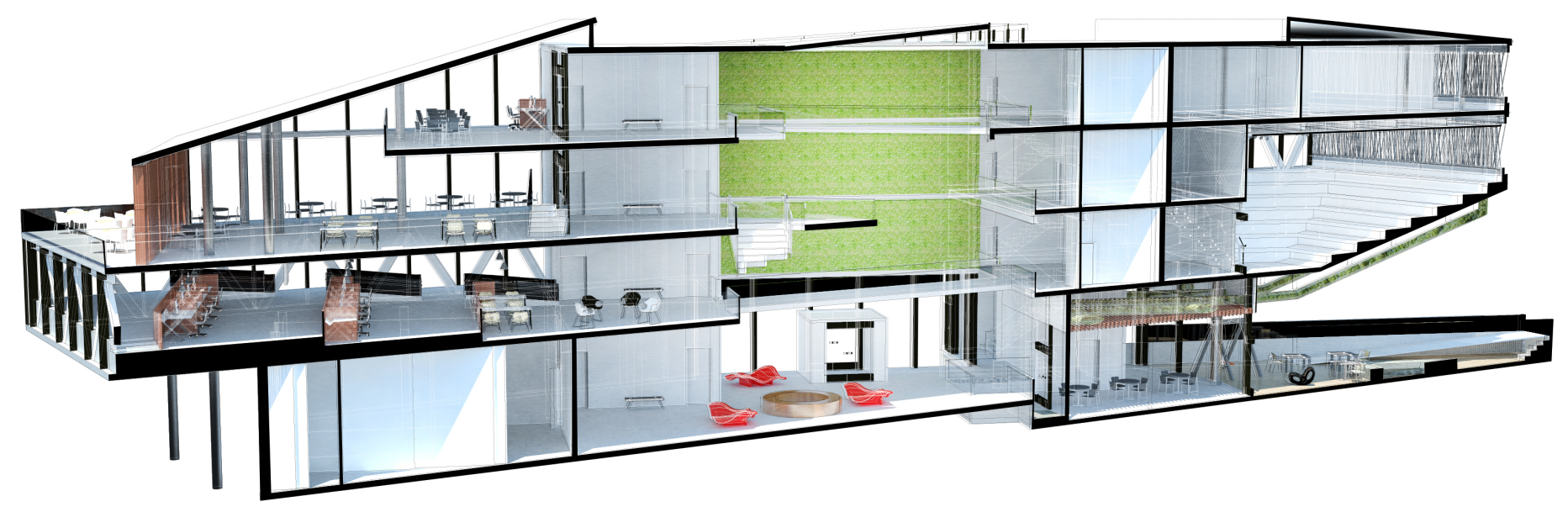


Fig 8.14 3D wall section detail of double skin facade with algae scrubber filters

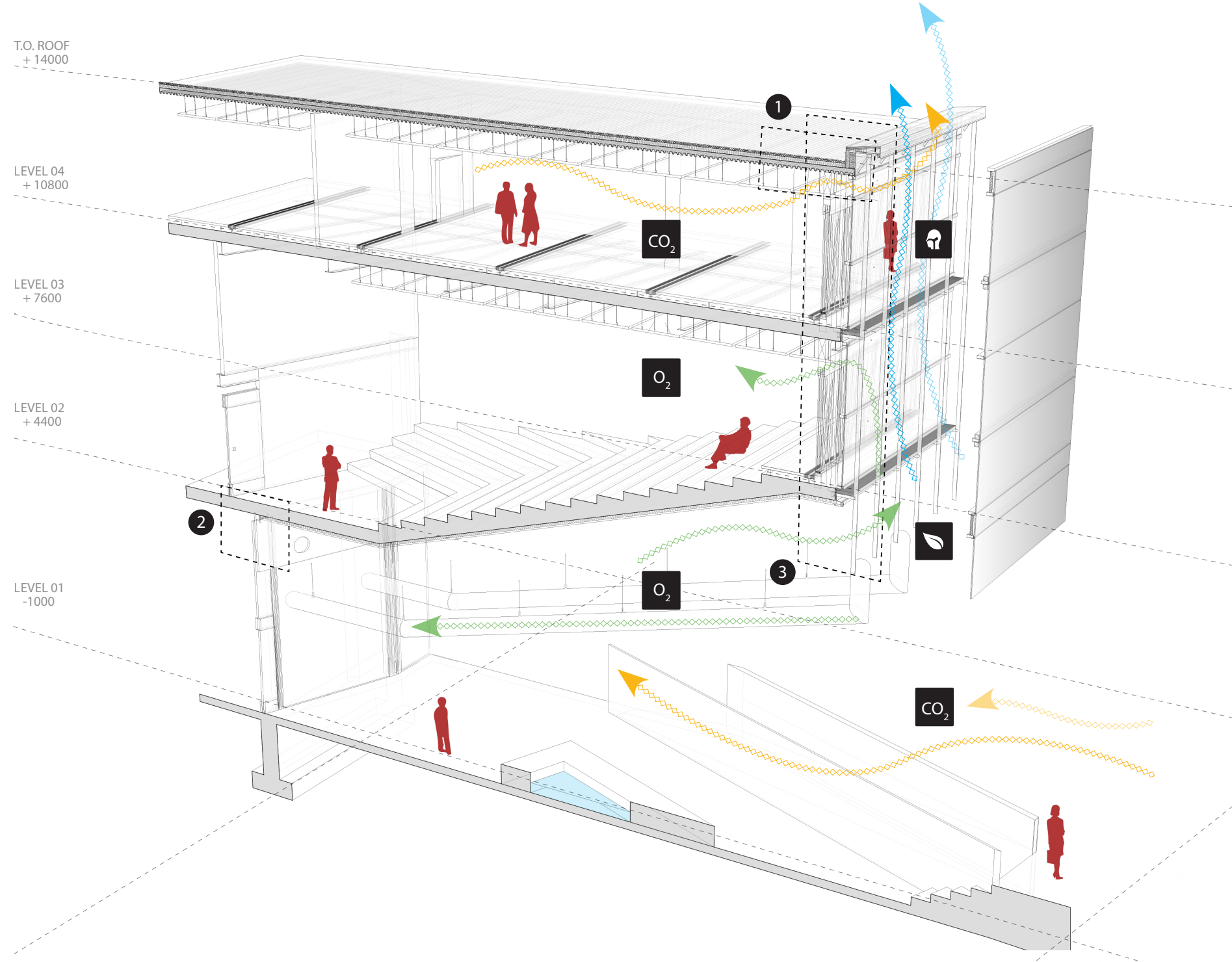

(1)

DETAIL 01 : PARAPET

METAL FLASHING UNDERLAYMENT

$20 \mathrm{~mm}$ PLYWOOD WOOD BLOCKING

$50 \mathrm{~mm}$ RIGID INSULATION

ROOF MEMBRANE

STEEL PLATE PARAPET

GLAZING REBATE

\section{CURTAIN WALL TO PARAPET}

COMPOSITE LIGHTWEIGHT CONCRETE/STEEL DECK

$150 \mathrm{~mm}$ RIGID INSULATION

$150 \mathrm{~mm}$ STEEL STUD BACK UP

CONTINOUS STEEL CHANNEL MOUNTED TO STEEL BACK UP

STEEL BRACKET BOLTED TO STEEL CHANNEL @500mm O.C.

STEEL ANGLE BRACE BOLTED TO STEEL BRACKET @500mm O.C.

EXTRUDED ALUMINUM MULLION ATTACHED TO STEEL ANGLE BRACE
2

DETAIL 02 : ALGAE DROP PANEL

$1000 \mathrm{~mm}$ DROPED PANEL

MECHANICALPUMP@ $500 \mathrm{~mm} 0 . C$

$200 \mathrm{~mm}$ ALGAE TUBES SLOPED AT $5^{\circ}$

STEEL BRACKET FITTED TO 200mm ALGAE TUBE

HANGER WIRES
3

DETAIL 03 : DOUBLE SKIN FACADE

DMART GLASS CURTAINWALL

CAPLESS EXTRUDED ALUMINUM MULLION WITH STRUCTURAL SILICONE ATTACHED TO STEEL CHANNEL

STEEL BRACKET BOLTED TO STEEL CHANNEL @ $500 \mathrm{~mm}$ O.C.

STEEL ANGLE BRACE BOLTED TO STEEL BRACKET @500mm O.C.

STEEL BRACKET BOLTED TO RECESSED CURTAIN WALL ANCHOR

$750 \mathrm{~mm}$ CAVITY (CATWALK) SPACE

DOUBLE SKIN FACADE TO ALGAE TUBE SOFFIT

SHADOW BOX

METAL PANEL

50mm RIGID INSULATION

METAL AIR BARRIER PANEL

HANGER WIRES

$200 \mathrm{~mm}$ ALGAE TUBES 
The West Don Lands Adult Learning Centre serves as a symbolic landmark in the beginnings of a breathable city. Rather than wasting more time in the discussions of the future fate of the Gardiner Expressway, the West Don Lands Adult Learning Centre is the result of immediate action in addressing the extreme urban conditions that the highway imparts on the city. Not only does the building respond actively to the physical demands of the atmosphere, but it also gives back to the community at large by providing an adult learning centre, designated for the Toronto Community Housing population nearby. The project is a catalyst for an otherwise overlooked part of the city due to its urban context. However, given the breadth of program for the adult learning centre, the overall design of the West Don Lands Adult Learning Centre presents a generic form of architecture that is not conducive in highlighting the exciting spatial and form aspects of regenerative architecture that can actively respire. This is a result of allowing program to overtake the formal manipulation of the building rather than using the main concept of respiratory architecture as the core design inspiration. Instead of responding to program, Aspiro approached the issues of program in the form of respiratory zones. Programmatic elements were devised based on air quality demand ranging from low respiratory zones in low occupancy areas to high extreme respiratory zones in high occupancy areas. Organization of space based on respiratory zones created varying thermal experiences that flowed from one to the other, thereby producing a dynamic spatial form in the architecture that is unique in its character and distinctive for its function as an urban respiratory system.

\section{FROM PROGRAM TO RESPIRATORY ZONES}

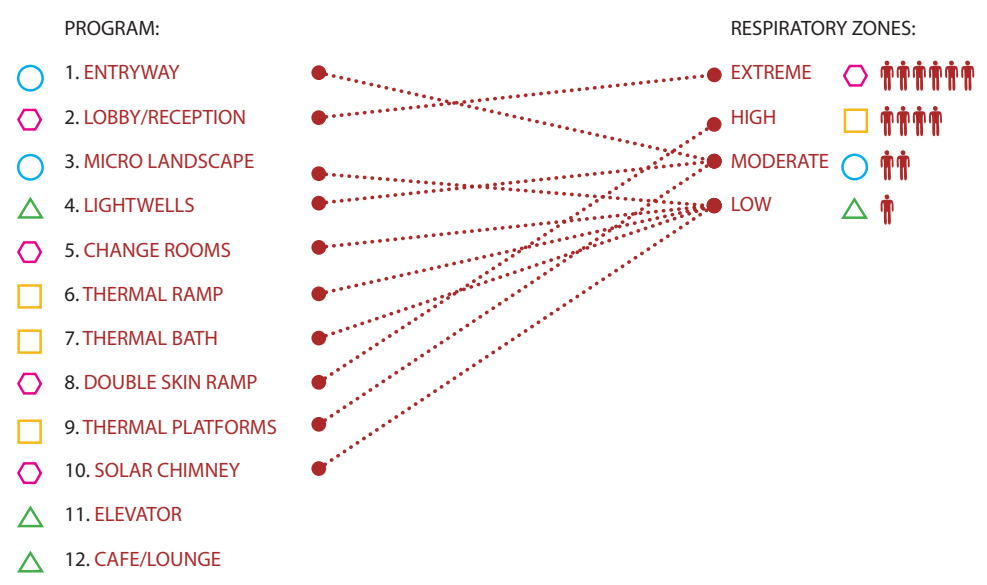




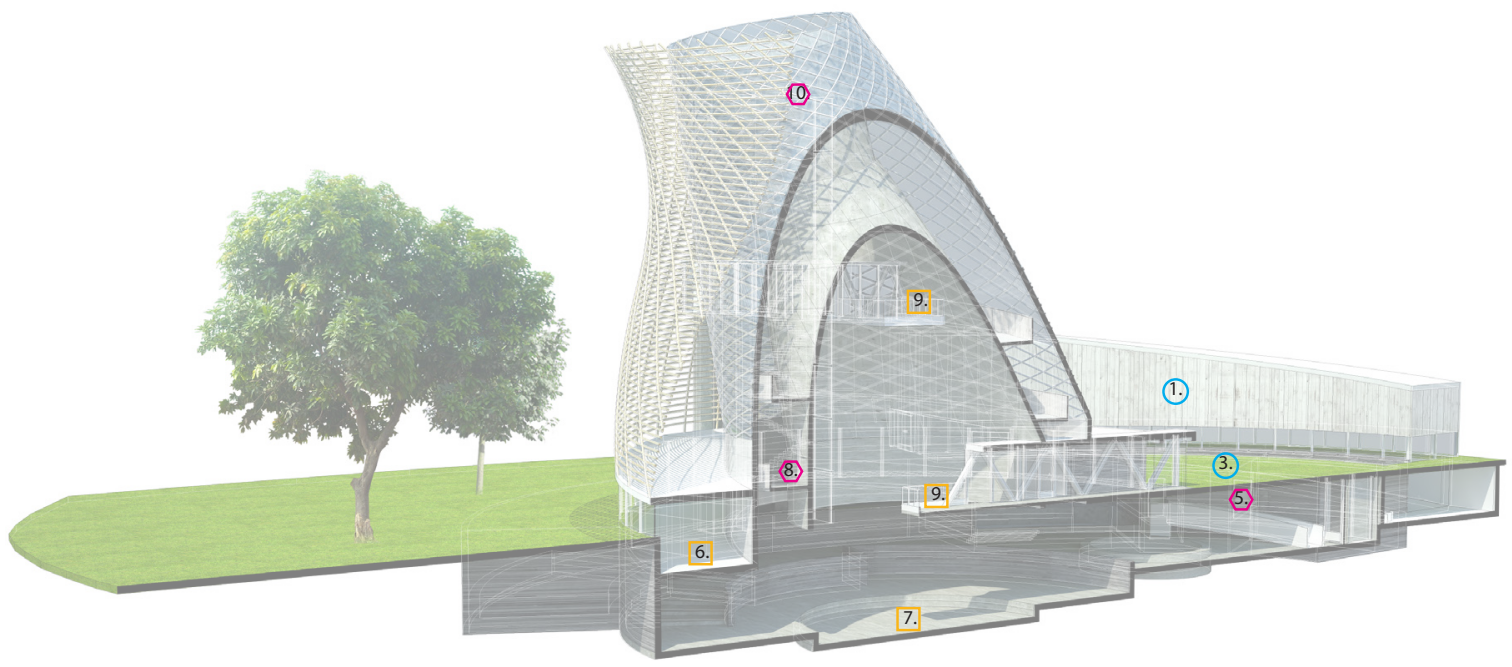

Fig 8.15 Sectional perspective of respiratory zones in Aspiro

\section{Endnotes}

${ }^{1}$ David Gissen. Toxic Territories. Territory: Architecture Beyond Environment. (Chichester: John Wiley \& Sons, 2010). 56.

2 http://www.eoearth.org/view/article/156262/ (accessed October 13, 2014)

Image References

${ }^{1}$ Kevin $\mathrm{Pu}$

${ }^{2}$ Remi Carrerio

${ }^{3}$ Kevin Pu

${ }^{4}$ Ibid.

${ }^{5}$ Ibid.

${ }^{6}$ Ibid.

7 Ibid.

${ }^{8}$ Ibid.

${ }^{9}$ Ibid.

${ }^{10} \mathrm{Ibid}$.

11 lbid.

12 Ibid.

${ }^{13} \mathrm{Ibid}$.

${ }^{14} \mathrm{Ibid}$.

15 Ibid. 


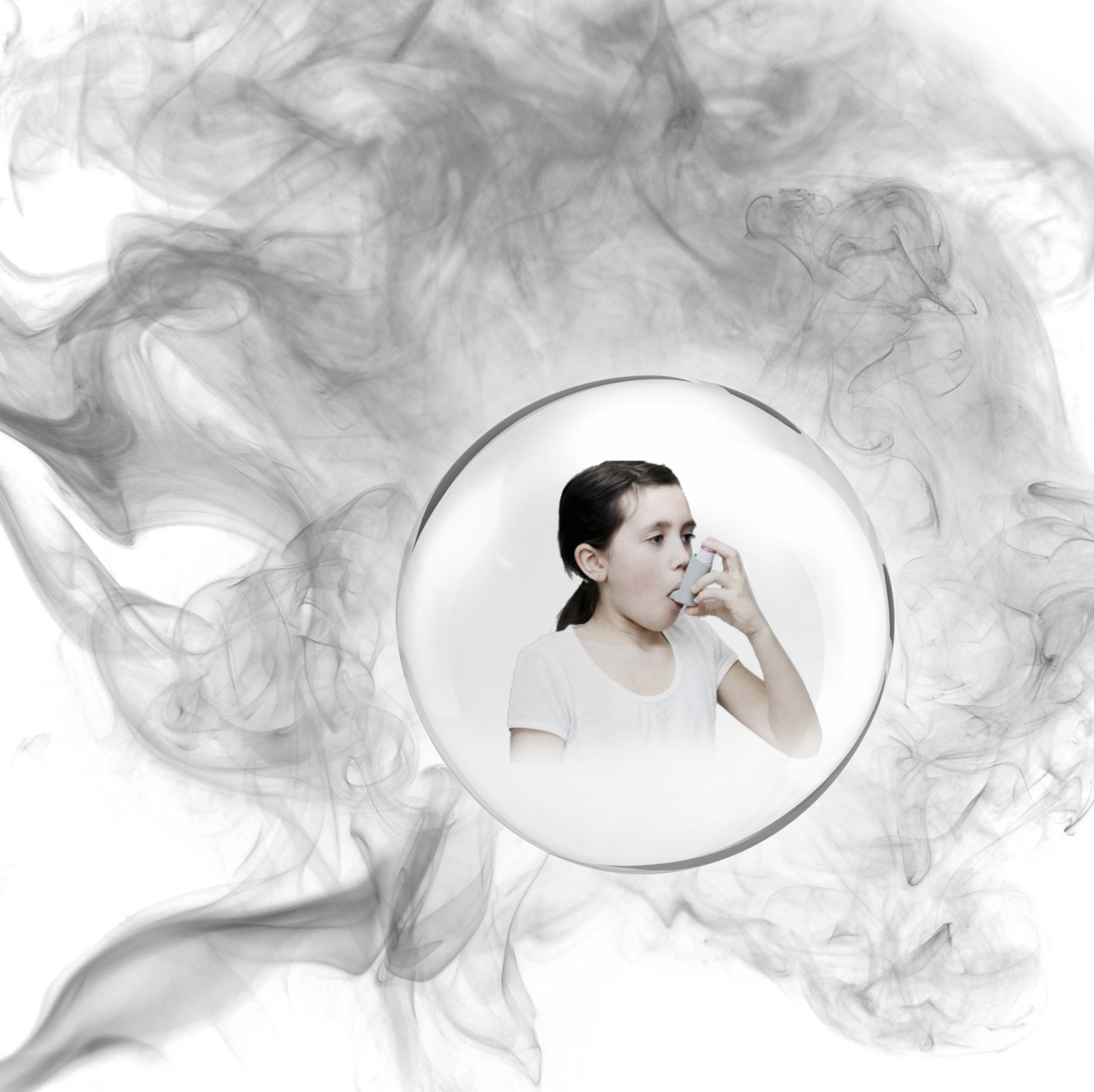




\subsection{Urban Respiratory System}

This collective body of research has informed a symbolic design proposal that attempts to raise awareness of the issues of respiration and air quality against current processes of architectural design. The dichotomy of dealing with architecture and atmosphere in either a micro or macro approach has caused a hermetic divide in our approach to architectural design. The interior atmosphere seems to deal more with the individual breather's perception with architecture while exterior atmospheres deal with the larger condition of the city and its relationship with built form. Despite the differences in scale, the root of the problem lies in this fine line that separates the two levels of approach (micro and macro). The building is often viewed as a "machine for living" while nature is everything but the built environment. ${ }^{1}$ The removal of the built environment from nature is the problem of architecture devoid of environmental concern. Both the building, as hermetically sealed environments, and nature needs to be considered holistically in order to rewire the city from a machine into an organism that functions as a proactive system, rather than a programmed object,

Therefore, the difference between architecture as "machines for living" and urban respiratory systems lies not in the building itself, but in the fundamental approach of humans and their role in nature. The following design aims to address the current architectural issues and their lack of consideration for the natural environment through the lens of respiratory processes. Through rethinking the role of architecture from one of a static program to a dynamic organism, Aspiro serves as a statement that humans need to reintegrate themselves as a part of nature to demonstrate the impact of buildings. 


\subsection{Urban Arteries}

When it comes to the leading cause of carbon emissions in urban cities, people often associate it with vehicular and traffic pollution. Unfortunately, there is no single cause to the highly complex nature of urban pollution. Vehicular pollution itself cannot be viewed in isolation, as there are a multitude of layered causes to a city's pollution. Comparable to the study of natural respiratory systems that require the holistic view of how a breathable environment is achieved, urban cities demand the same holistic lens. Divided into grids, urban cities are typically planned according to efficiency through a network of highways and roads. Initially, architects like Le Corbusier thought these networks of vehicular roads would drive the future of cities in his proposal for the Radiant City. ${ }^{2}$ However, these vehicular roads served more than what Corbusier had imagined. These roads became a network of urban arteries, transporting vehicular pollution in and throughout the city. Further, "forests" of high-rises tower over these arteries pump and breathe waves of carbon emissions as a result of simulating artificial interior environments. The urban city as an anti-respirator is structured as a closed-loop that constantly exhales carbon emissions into the heart of the city. Thus, any change in the way the urban city breathes must start from these urban arteries - to mediate the constant transportation of urban pollution. This collective research and design approach has informed a visionary design where Aspiro deals directly with the urban arteries in Toronto.
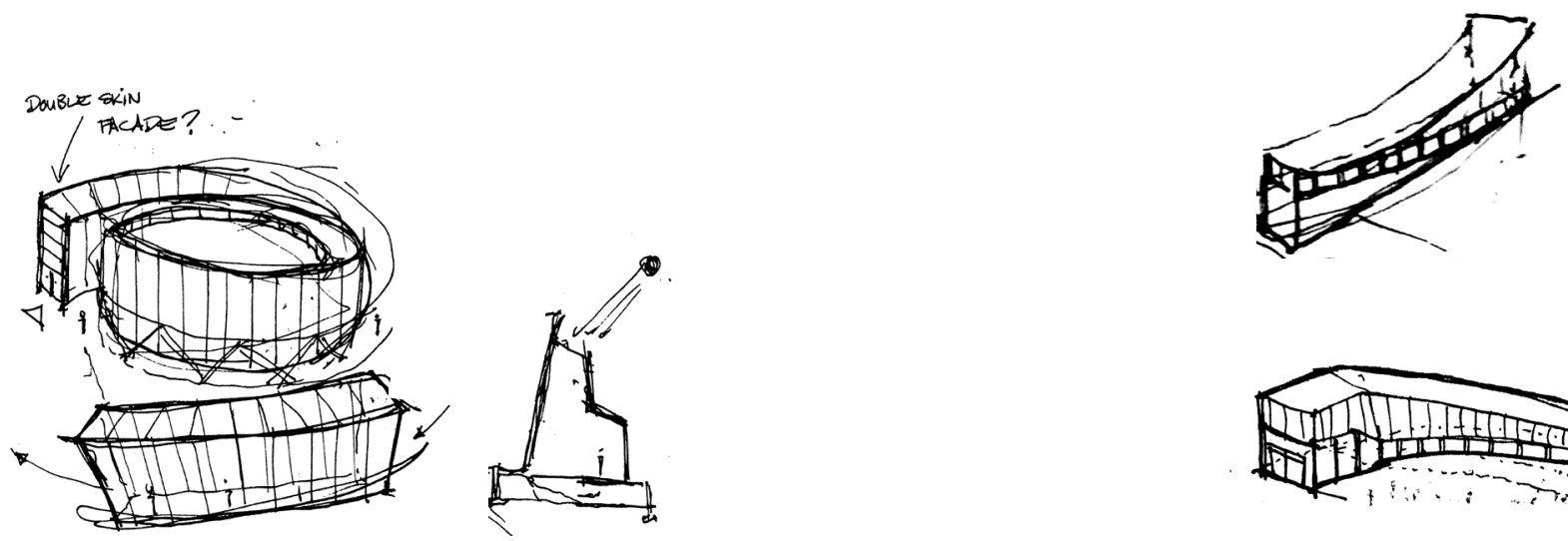

Fig 9.1 Initial sketches in response to anti respiration
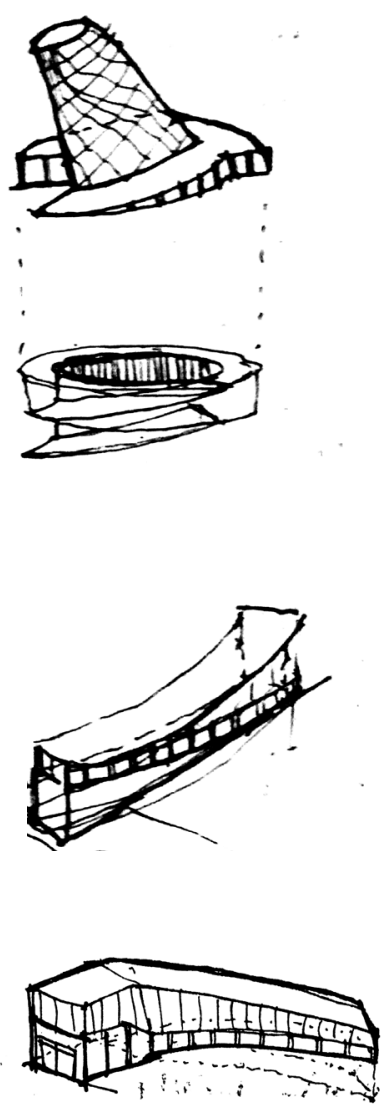


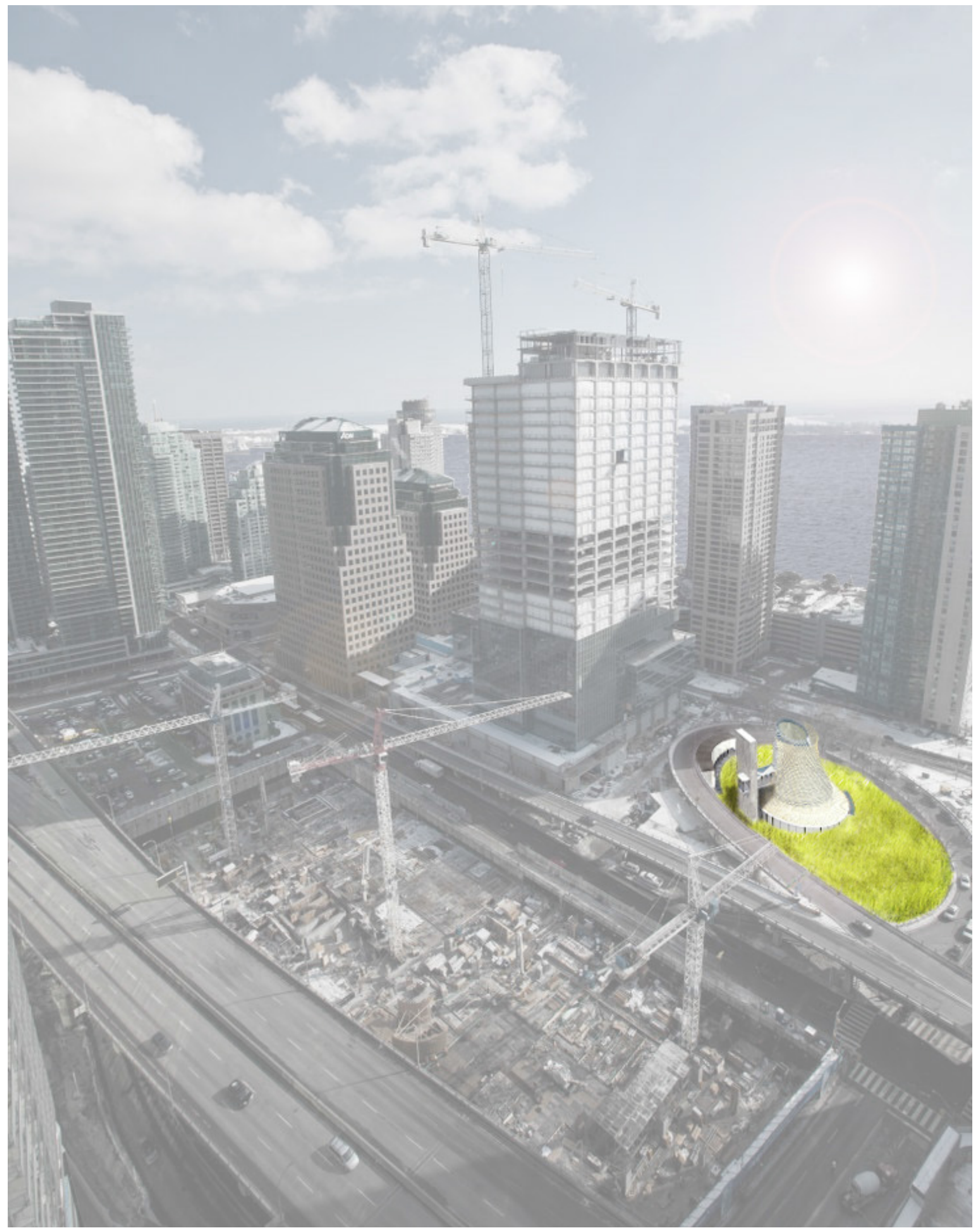

Fig 9.2 Aerial view of site adjacent to Gardiner Expressy off ramp on Queens Quay and York Street 


\subsection{Extreme Urban Conditions - Toronto}

Once nicknamed The Big Smoke, Toronto is an urban city that exemplifies all characteristics of an aniti-respirator. ${ }^{3}$ The city is heavily impacted by sprawl and relies on several highway arteries to connect its inhabitants to the sprawled out neighbourhoods. One of the main distinguishing characters of Toronto is the Gardiner Expressway that cuts through the heart of the downtown core, elevating vehicular traffic over the density of the city. Further, its situation in Canada puts it through extreme seasonal changes that range over 60 degrees Celsius, from freezing -30 degree winters to scorching +30 degree summers. As in any large city, Toronto struggles with the issues of gridlock. With an underdeveloped transit system that is mediocre at best, when compared to the leading transit based cities such as New York City and London, Toronto is known to suffer from tremendous traffic woes that are estimated to be a $\$ 6$ billion problem. ${ }^{4}$ Due to the nature of urban sprawl and the lack of a sophisticated transit system, most Torontonians rely on driving to work, thereby using the Don Valley Parkway (DVP) and the Gardiner Expressway to move in and out of the city, causing the city grid to be at full capacity during work days where traffic jams are the norm during rush hour (and even non-rush hour) periods. It is estimated that Toronto residents average 65.6 minutes on their daily commutes, the longest in the province. ${ }^{5}$ This situation is worsened when the city attempts to host large public events, such as the 2015 PanAm Games where the average commuting time increased by 15 minutes. ${ }^{6}$

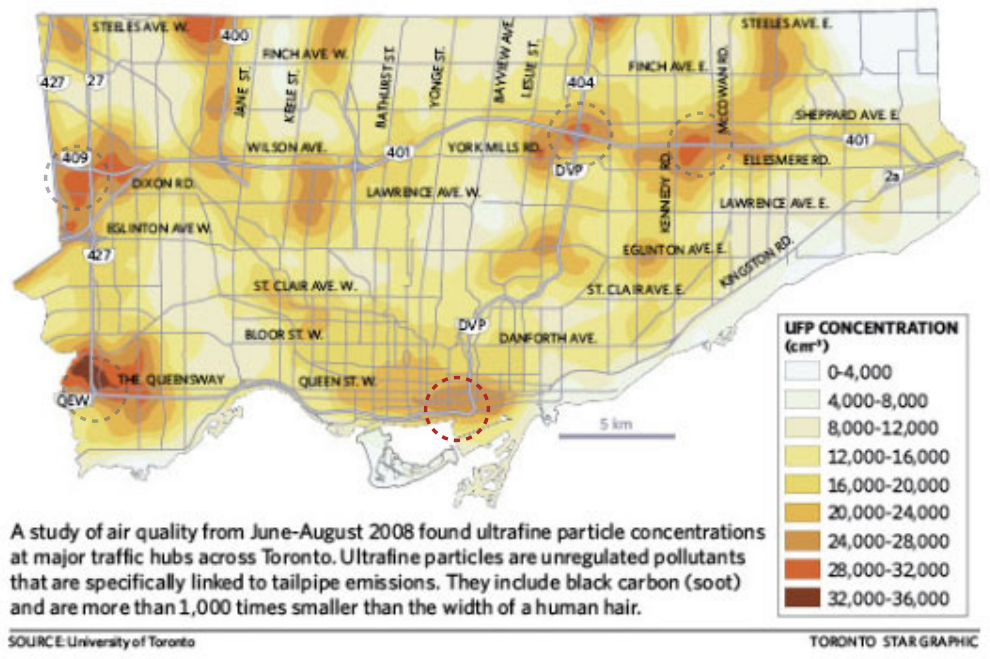

Fig 9.3 Air quality statistics in Toronto showing ultrafine particle concentrations around major highway sections 


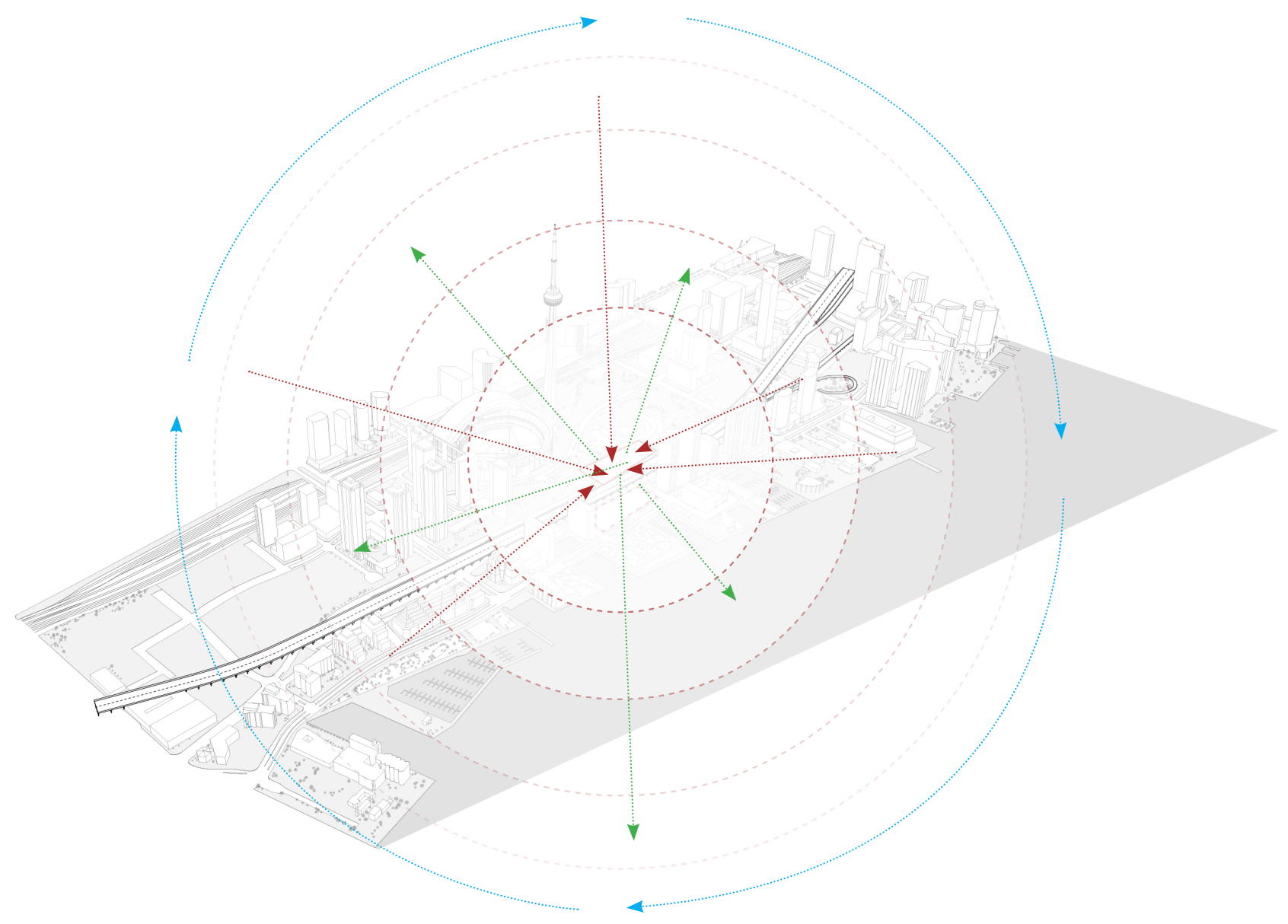

Fig 9.4 Responding to extreme urban conditions in Toronto

As such, the city of Toronto has a unique problem of density and pollution that creates extreme conditions in the built environment. As one of the major contributors of these extreme conditions, the Gardiner Expressway brings large amounts of traffic into the heart of the city, costing an annual average of $\$ 4.5$ million in maintenance repairs. ${ }^{7}$ Politicians and experts have done countless studies and speculations on how to improve these conditions such as the June 2015 debate on the fate of the East Gardiner amongst city counsellors, but there is still no concrete solution. Rather than wasting more time in the discussions of the future fate of the Gardiner Expressway, this thesis design project focuses on immediate action in addressing the extreme urban conditions that the highway has on the city. 


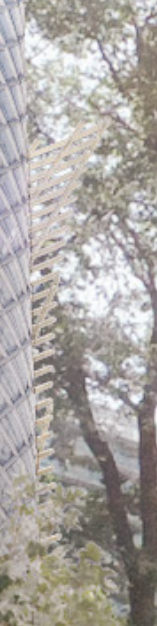

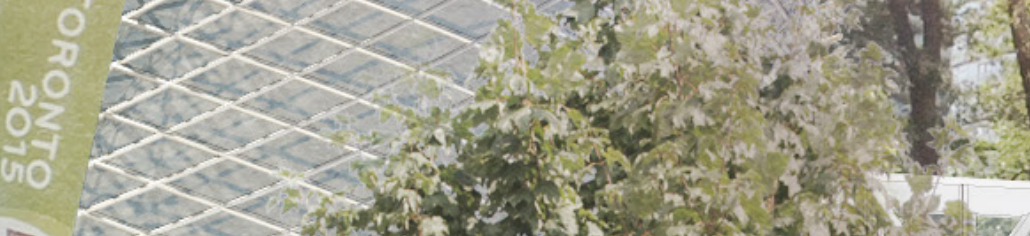

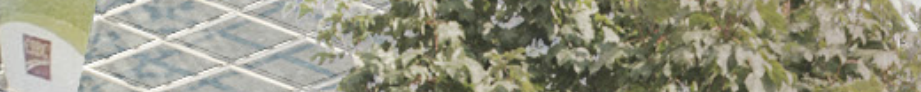

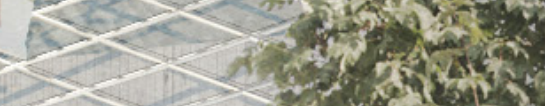

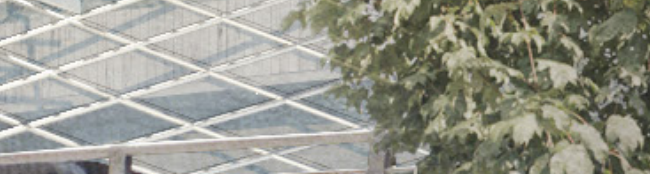
$\longrightarrow$ L

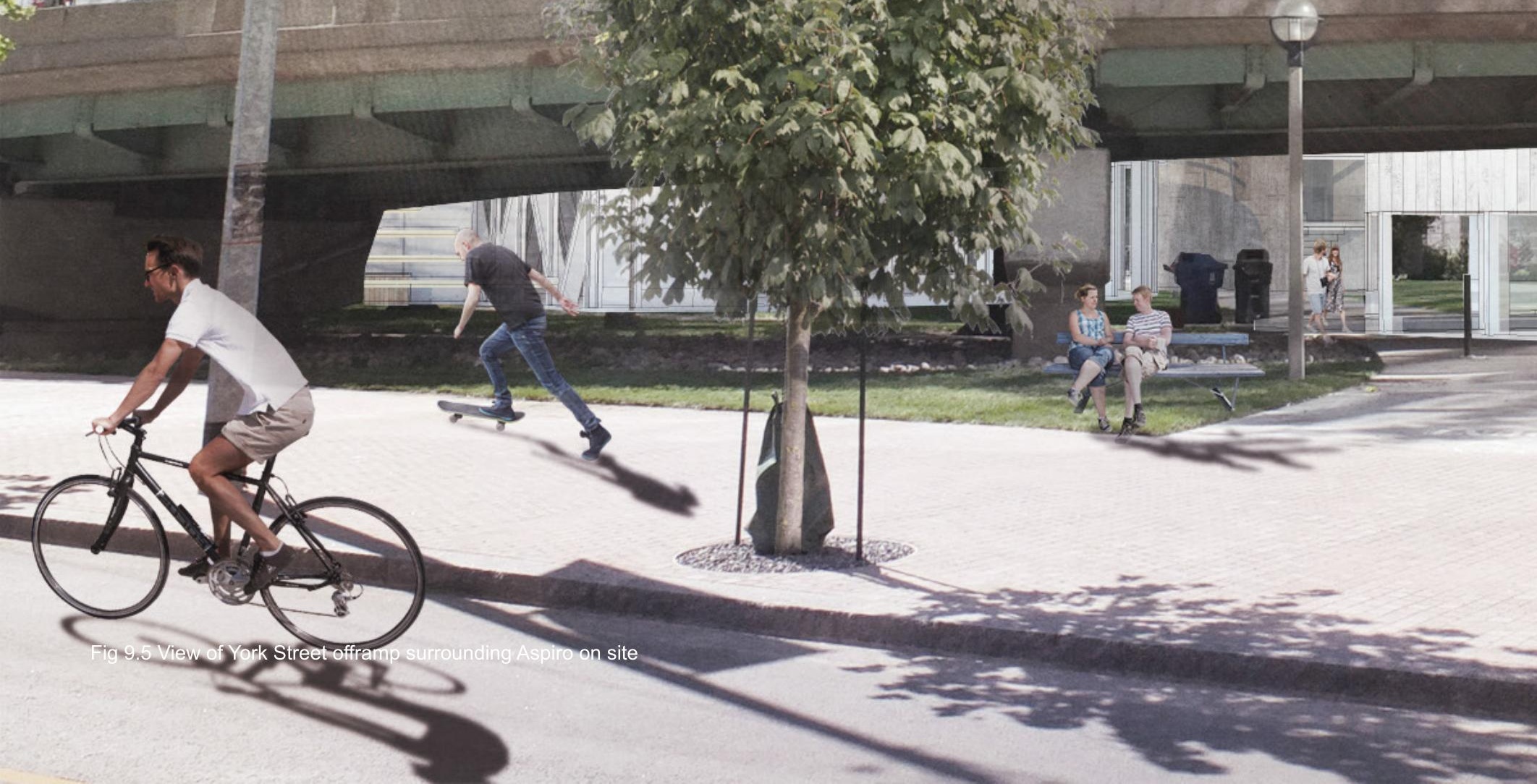
math $x=2$ W. cotes

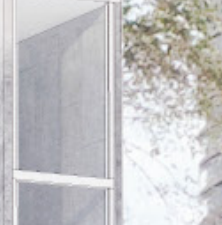

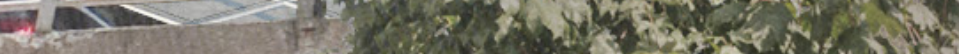

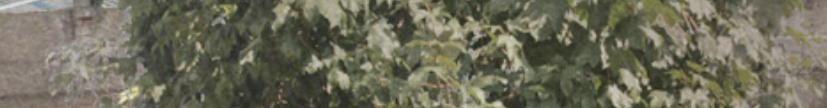

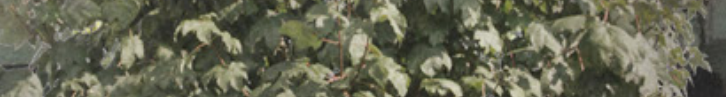

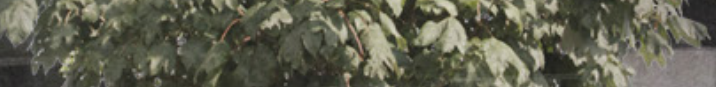
$\left.x^{2}, 1+4\right)$ 


\subsection{Aspiro}

Situated on the corner of Queens Quay and York Street, the Gardiner Expressway off-ramp has one of the highest levels of ultrafine pollutant particle concentrations amongst the city of Toronto. ${ }^{8}$ This is a direct result of dense traffic from throughout the Greater Toronto Area (GTA) funneling in towards the bottom of the DVP and into the Gardiner Expressway. The site is much more polluted than the majority of Toronto and it creates an intriguing opportunity for architecture to demonstrate the possibilities of designing with the four parameters of respiration (i.e., breathe, flow, control, and exchange). Through the understanding of regenerative architecture that is able to respond to both the user and program, respiratory architecture can begin to mediate extreme urban conditions such as those created by the Gardiner Expressway and inform a new generation of breathable architecture that is capable of purifying the air.

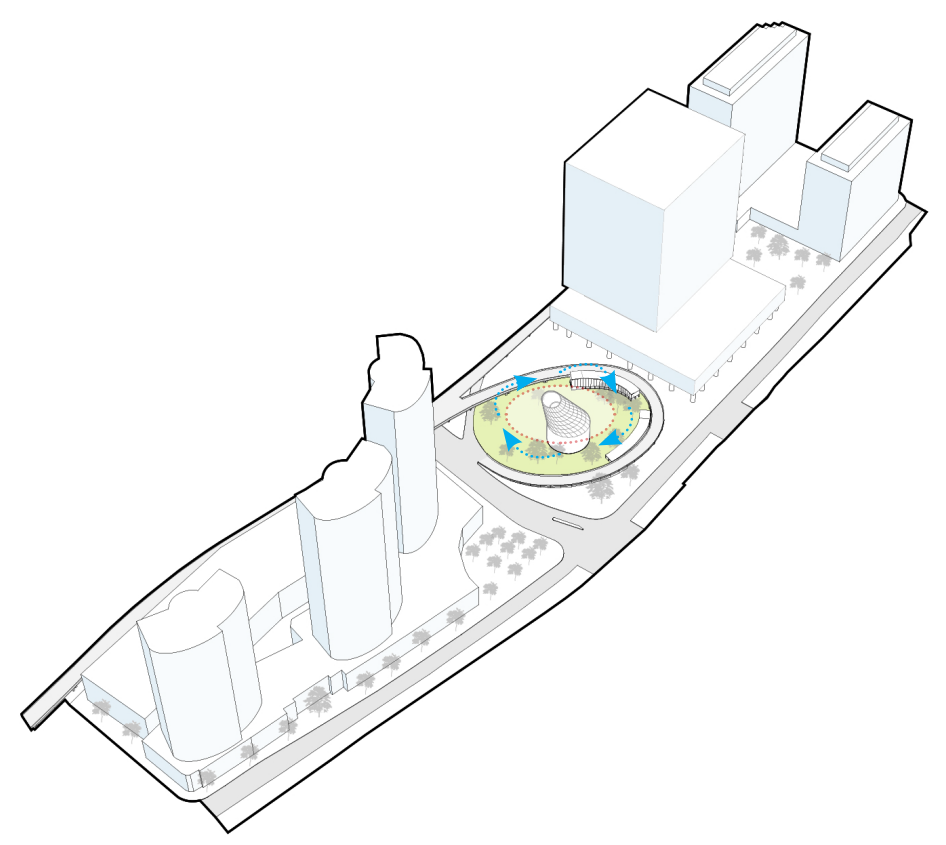

Fig 9.6 Diagram of solar chimney on site as the lung of both site and building 


\section{SITE PLAN 1:5000 (}

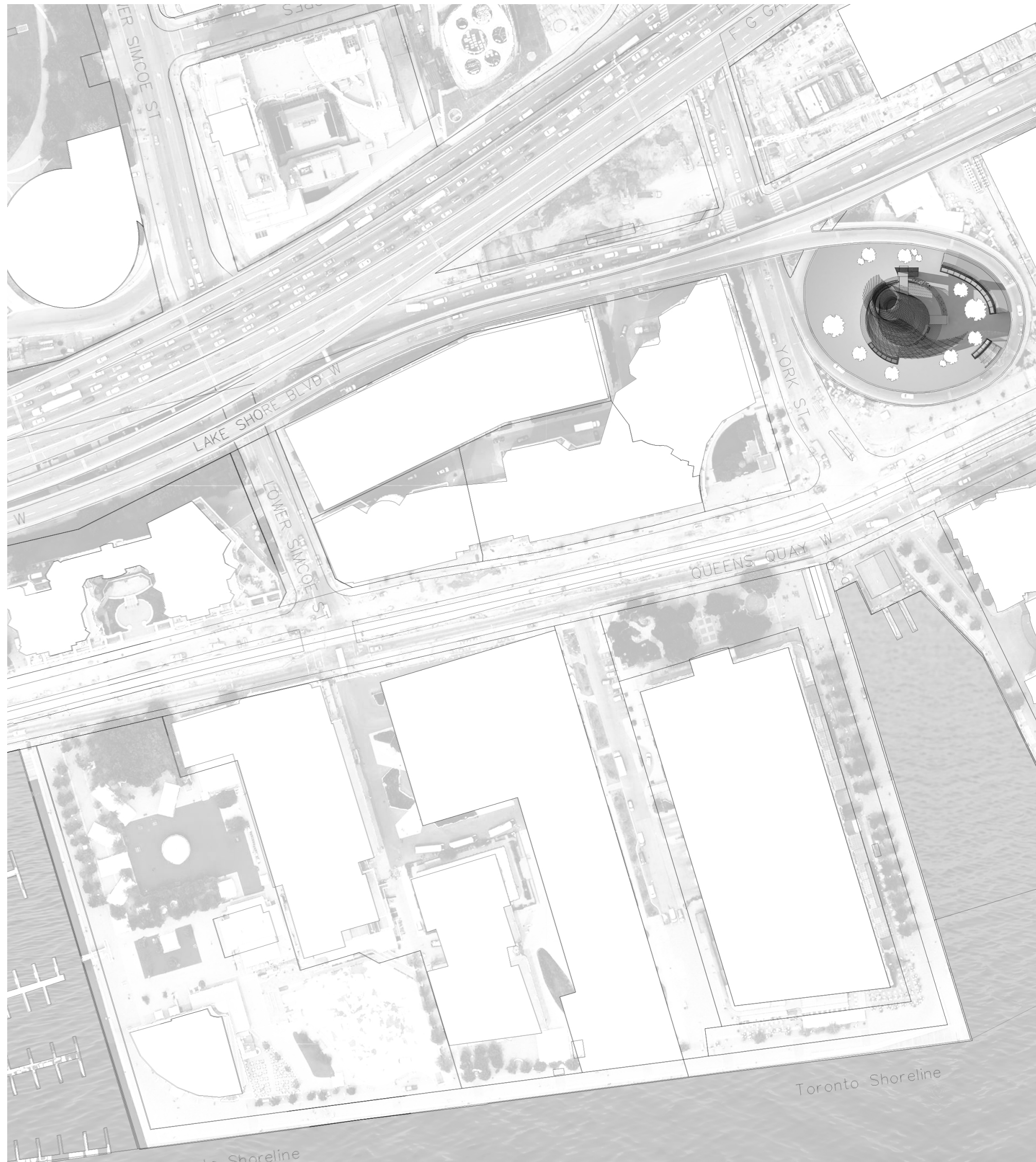




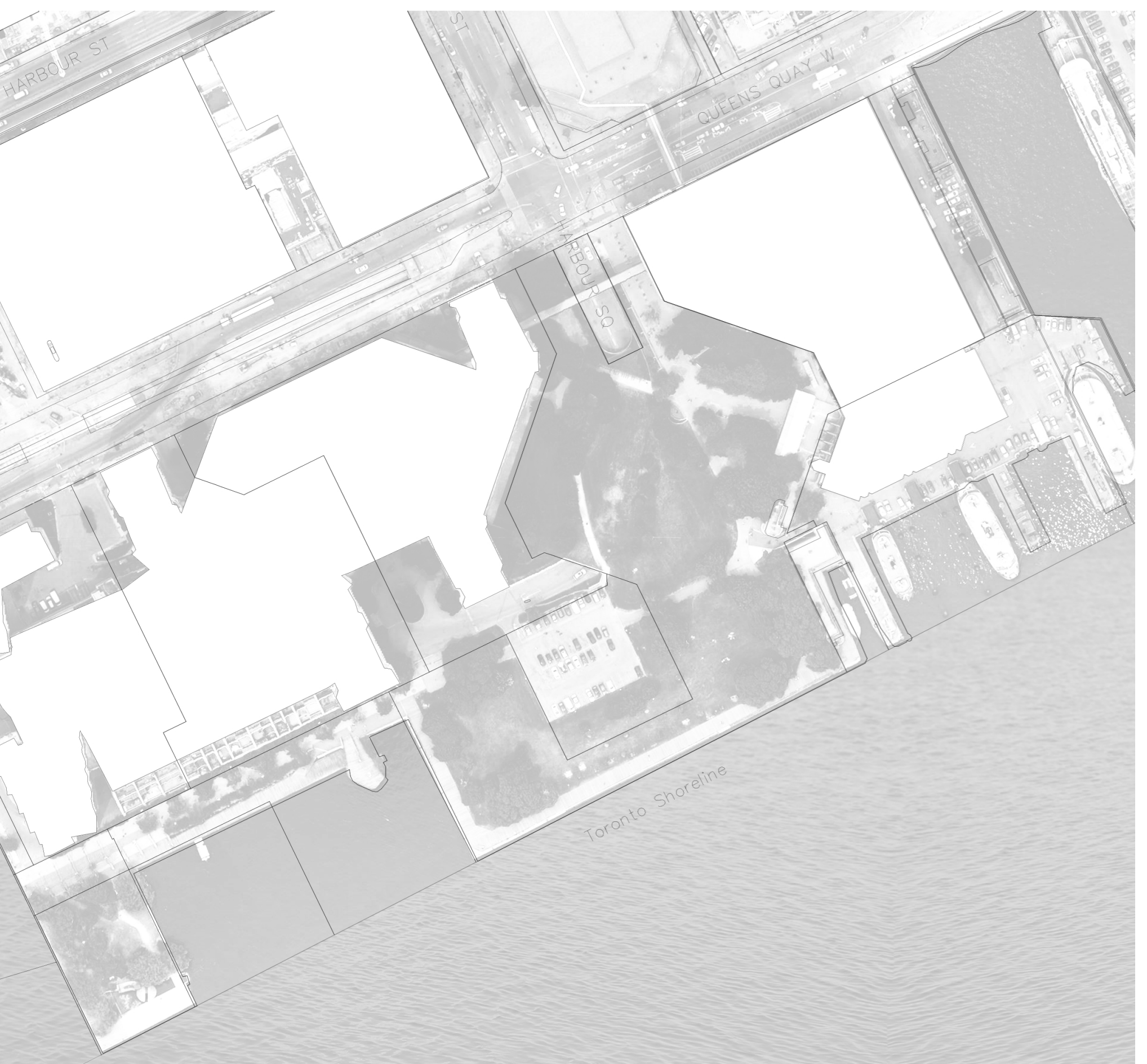

Fig 9.7 Site plan of Aspiro on site 
I VIEW OF CAFE/LOUNGE

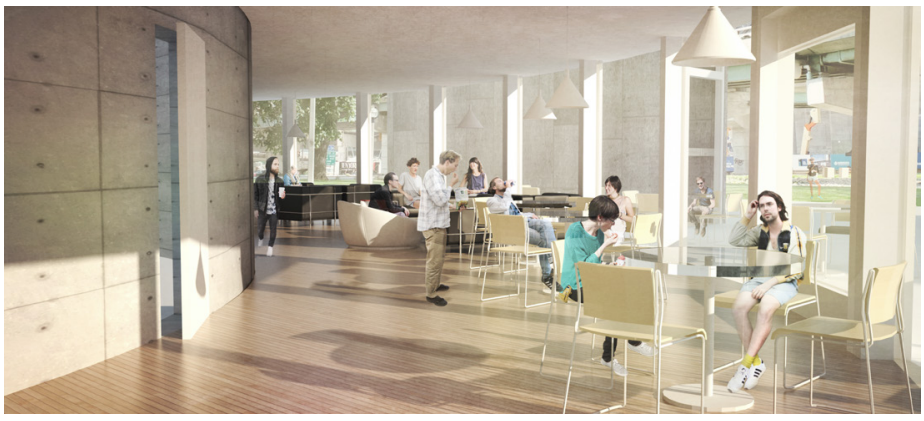

I VIEW OF THERMAL PLATFORM

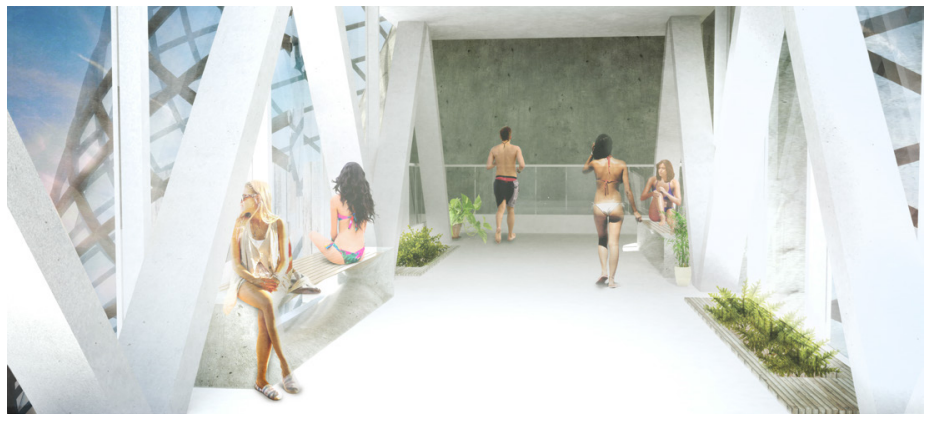

Fig 9.8 Interior renders of different thermal experiences throughout Aspiro

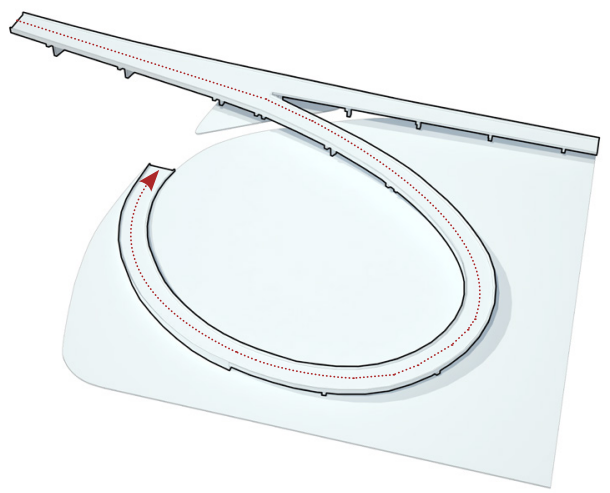

01
I SITE BECOMES A HARSH RESTRICTIVE SITE

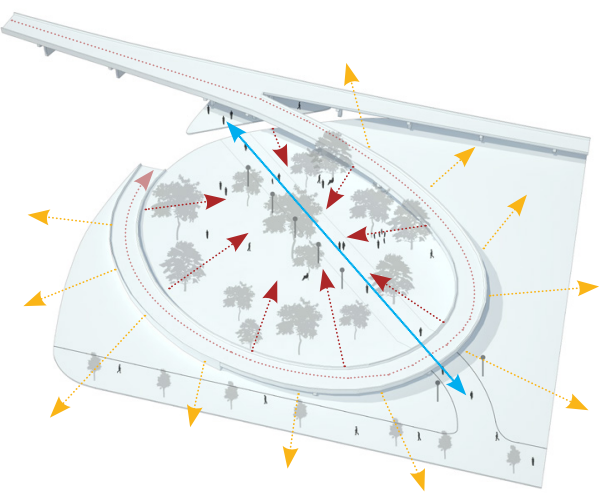

02
I SINKTHERMAL BATH FOR THERMAL MASS PROTECTION

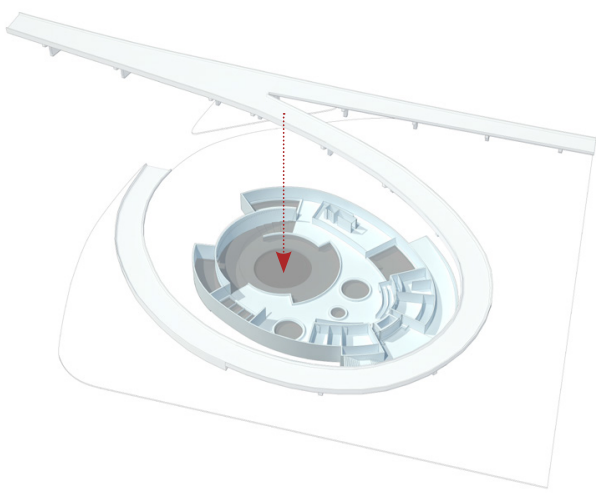

03

Fig 9.9 Diagram of formal design process of Aspiro in response to respiration on the constricting site of Queens Quay and York Street 
I VIEW OF MAIN LOBBY

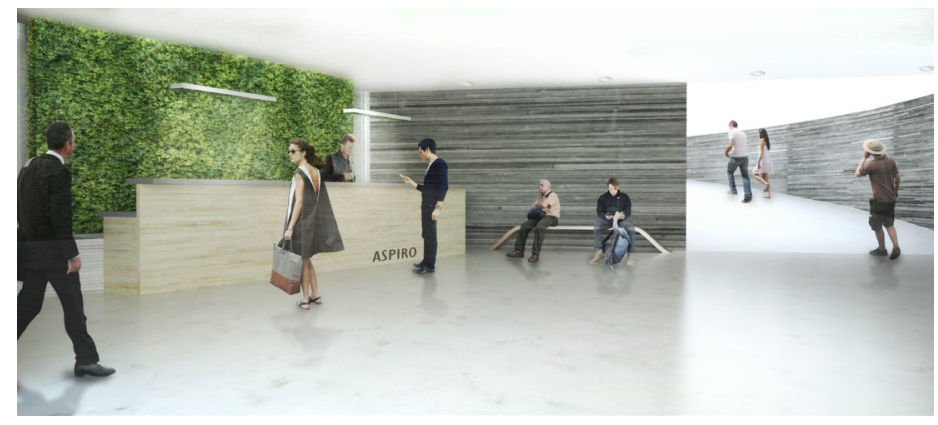

I VIEW OF DOUBLE SKIN SPIRAL RAMP

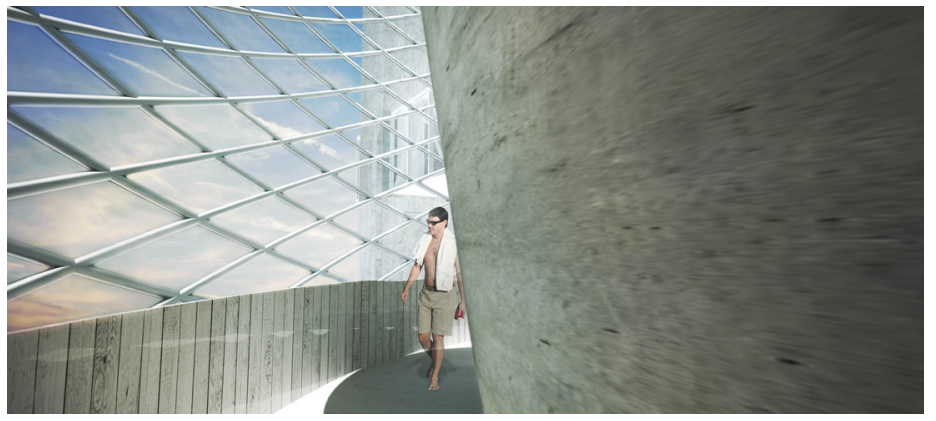

I CREATE VARIOUS THERMAL EXPERIENCES VIA AIR FLOW

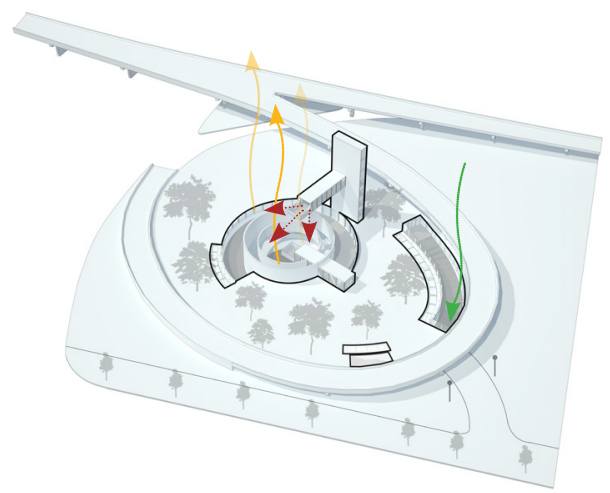

04
I SOLAR CHIMNEY TO NATURALLY DRIVE AIR MOVEMENT

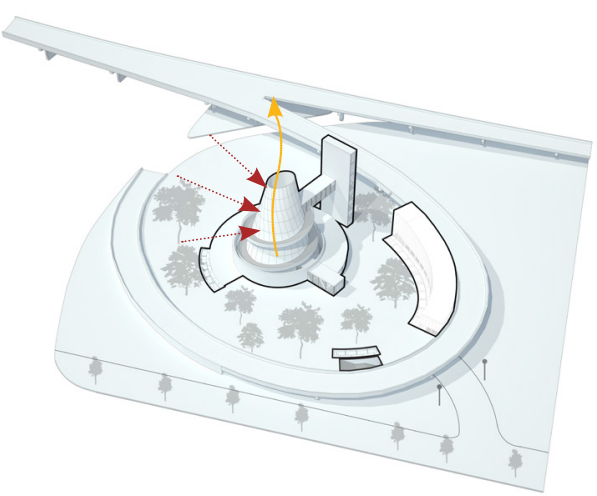

05
I RESPIRATORY SYSTEM TO PURIFY BOTH INSIDE/OUTSIDE AIR

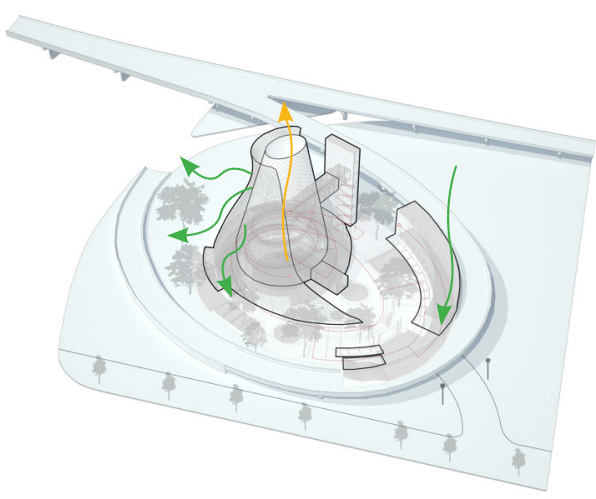

06 


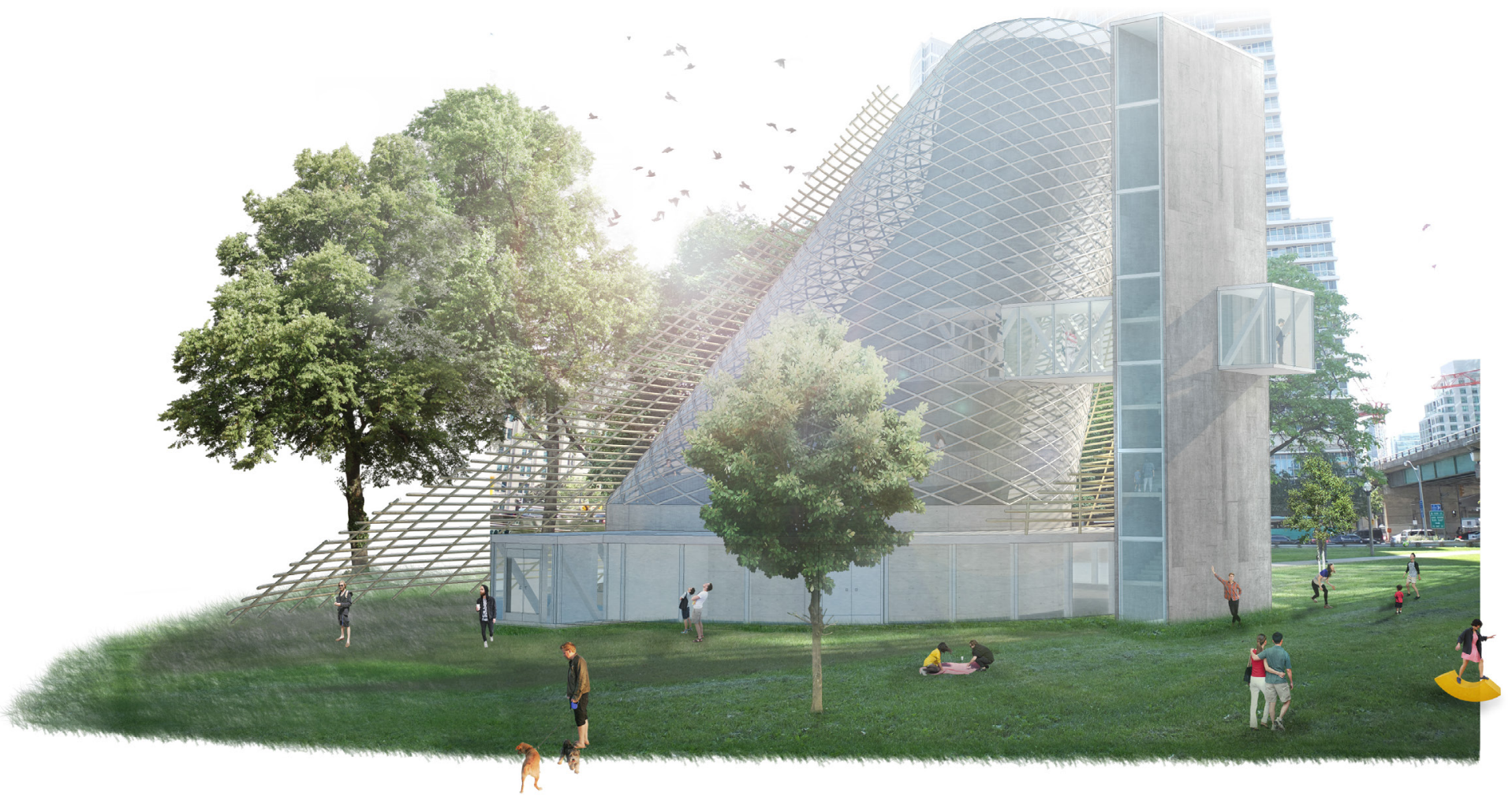

Fig 9.10 View of the green landscape within the micro landscape that Aspiro creates amongst the Gardiner off ramp

Aspiro is a new typology in architecture that responds to and interacts with the extreme urban conditions caused by the impacts of urbanization. Drawing principles of respiration from nature and with an understanding of how current cities breathe, Aspiro acts as a central lung on a site that is engulfed by a highway off ramp. The design of the project restores architecture back to its biological function of breathing. Governed by four parameters of respiration, the thermal bath purifies both interior and exterior air, thereby creating a dynamic micro and macro climate for both the immediate site and city at large. The focus of the building shifts from program to breathability in a hierarchy of respiratory zones based on human demands. This results in a controlled flow of both people and air as they are seen as equally important elements in breathable architecture. 
TOP PLAN

GROUND FLOOR

THERMAL BATH FLOOR

\section{(1)}

(1) MAIN ENTRANCE

(2) EXIT STAIRS

(3) SKYLIGHTS

4. CAFE/LOUNGE

(5) CAFE PATIO/GARDEN

6 EXTERIOR SEATING

(7) THERMAL PLATFORM

(8) THERMAL RAMP

9 OPENTO BELOW

(1) DOUBLE SKIN SPIRAL RAMP

(11) GREEN WALL FILTRATION

(12) MEN'S WASHROOM

(13) WOMEN'S WASHROOM

(4) HOT TUBS

(15) SULFUR BATHS

(16) ICE BATHS

(17) LOBBY

(18 MAIN THERMAL BATH
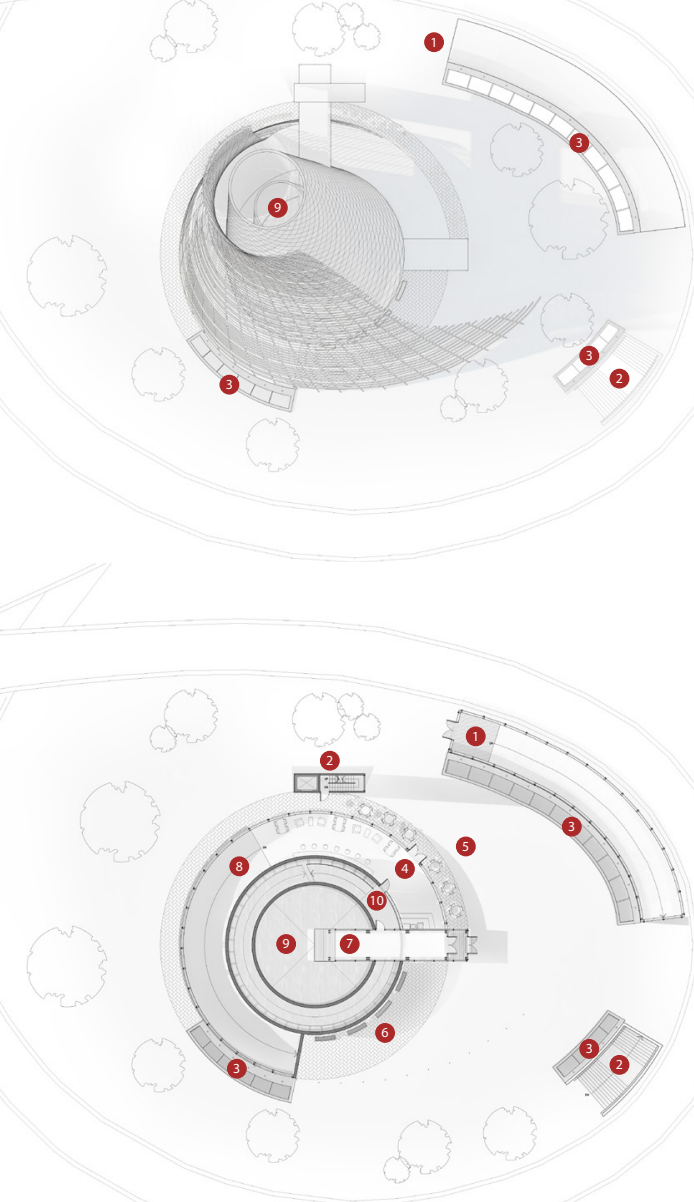

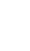




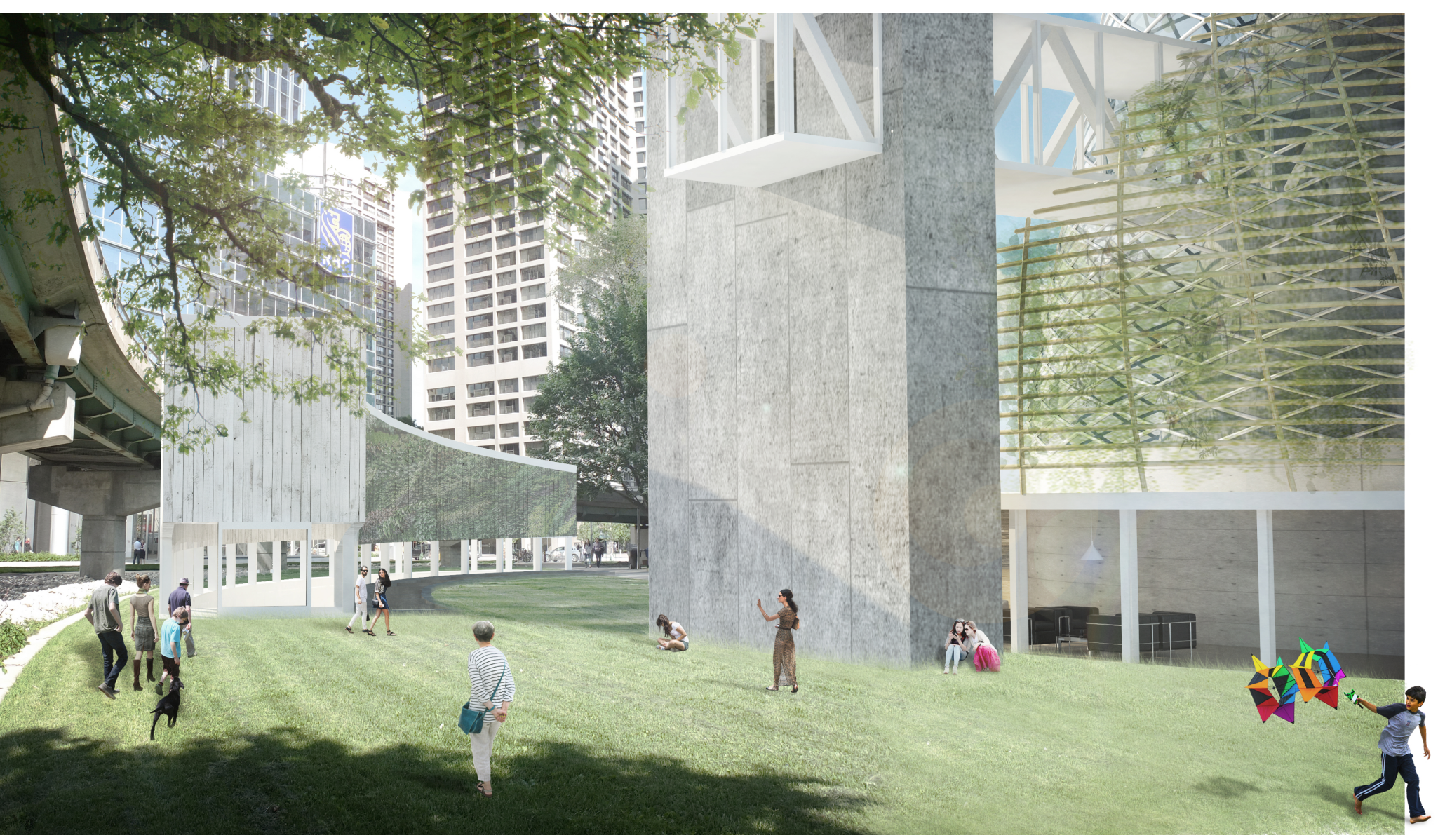

Fig 9.12 Views from under the Gardiner off ramp of Aspiro on site

Fig 9.13 Elevations and Sections
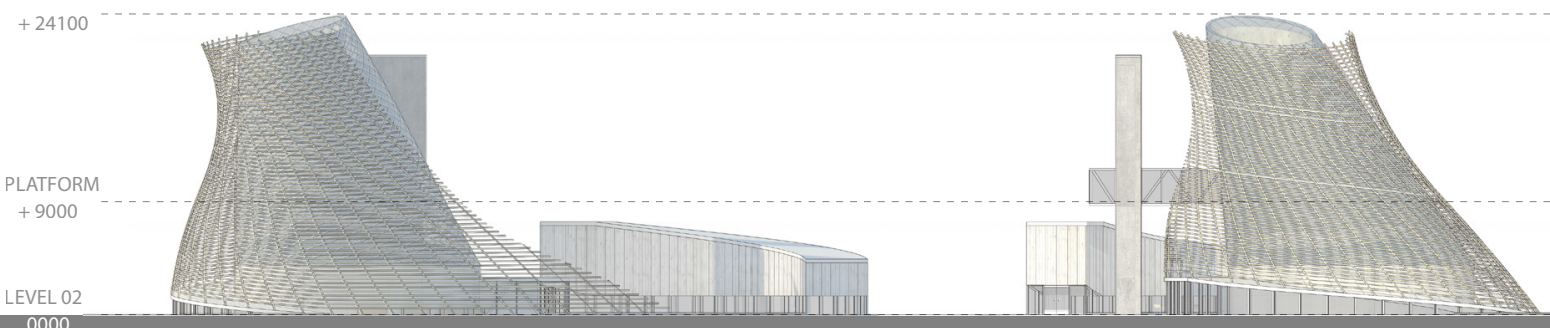


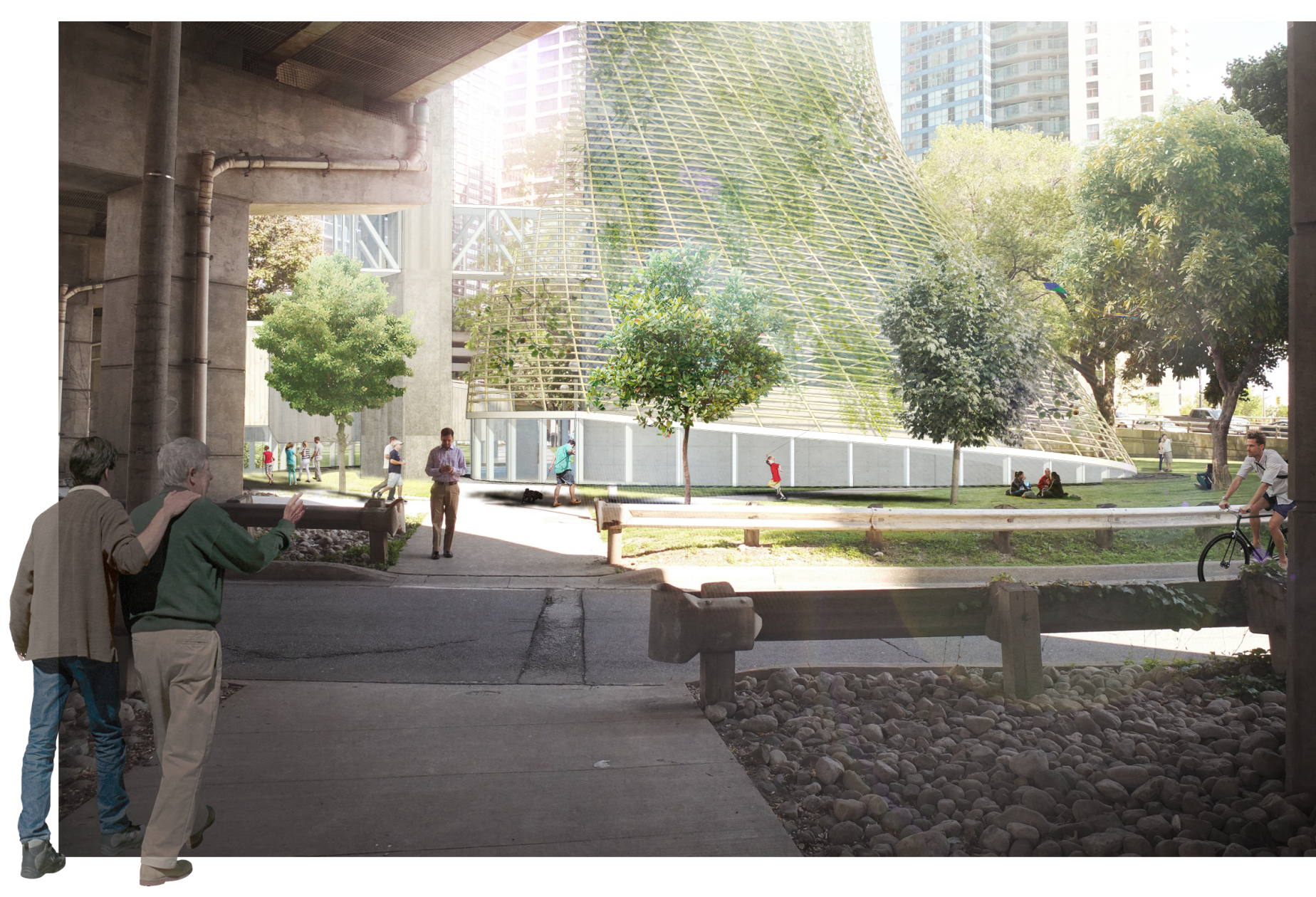

NORTH ELEVATION

SECTION

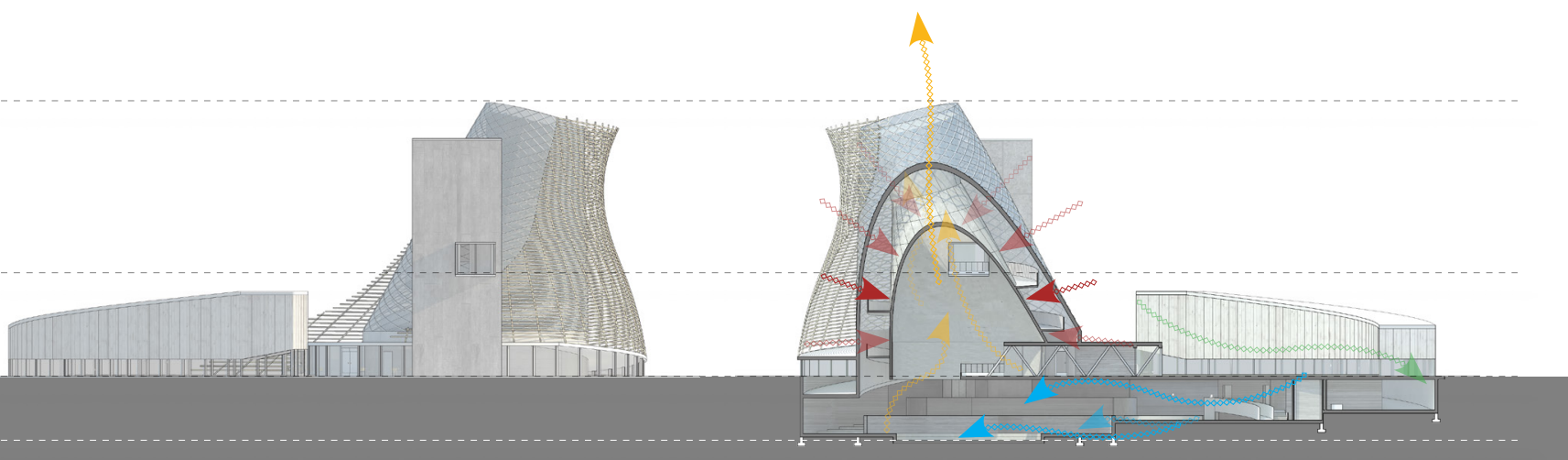




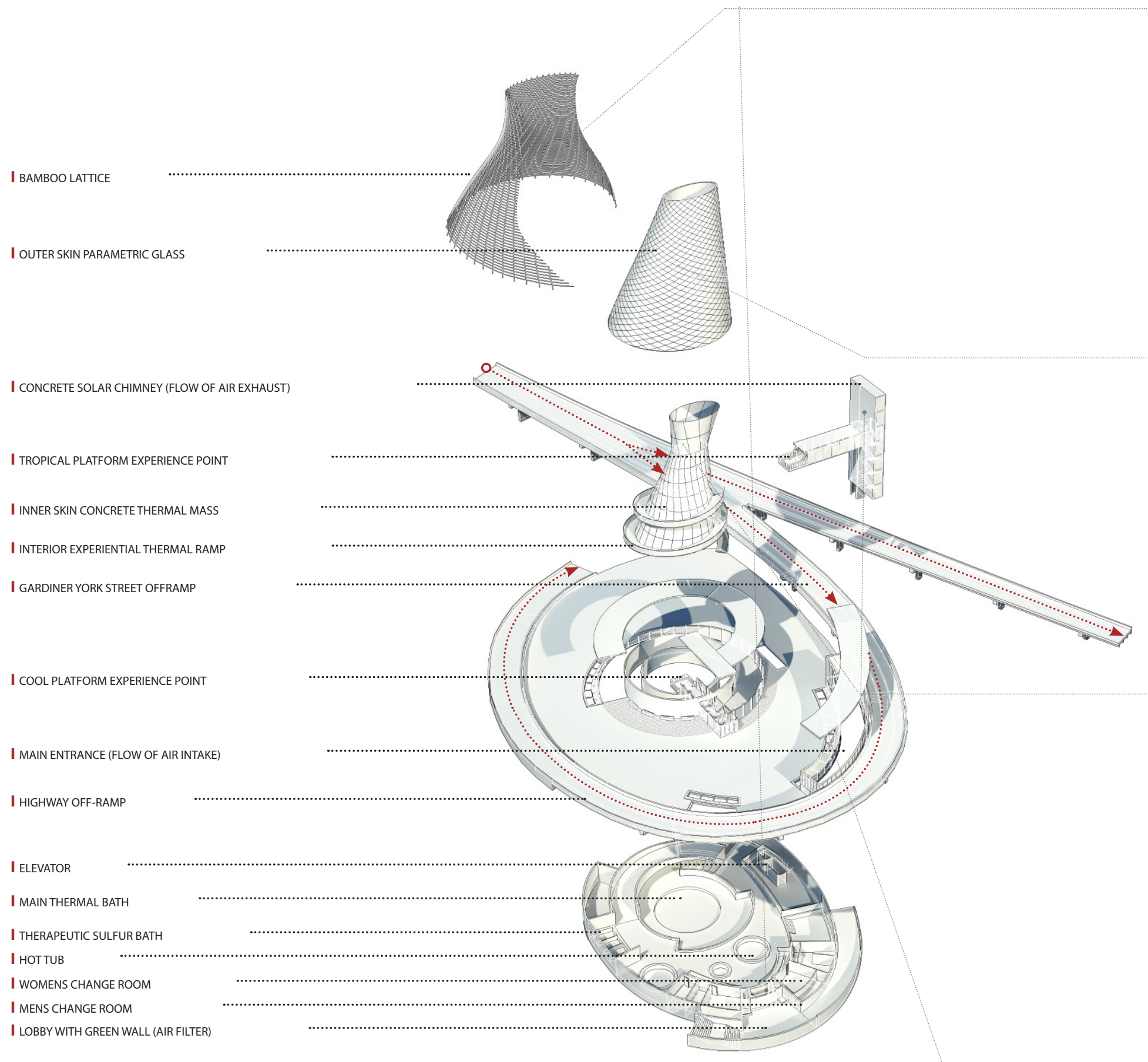

Fig 9.14 Exploded axonometric drawing of Aspiro and its components 


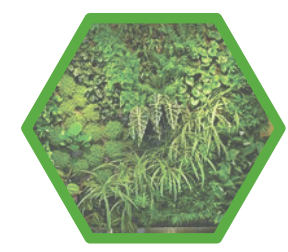

GREEN WALL LATTICE

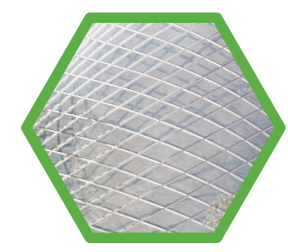

II DOUBLE SKIN GLASS

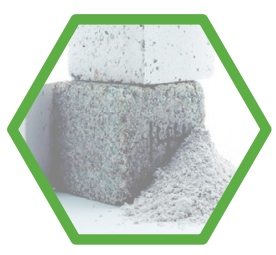

$\mathrm{CO}_{2}$ CARBON ABSORBENT CONCRETE

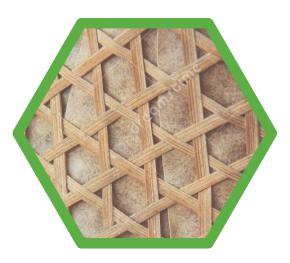

$\checkmark$ BAMBOO LATTICE

Beyond the four parameters of respiration that dictate the formal aspects of architecture as urban respiratory systems, materiality also plays an important supportive role in contributing to air purification. When viewed in isolation, materials are at most a tact on solution to a complicated issue of urban respiration. However, in conjunction with the four parameters of respiration, materiality serves as layers of filters in the process of breathing.

As both breathers and air flow into Aspiro for a controlled exchange of filtration, different layers of materials contribute to the biological functions of a breathing building. As the primary entryway for breathers that simultaneously breathes in carbon exhaust from the adjacent highway, the sloping ramp of the curvilinear ramp acts as a funnel for fresh air intake. Following the slope of the ramp, Aspiro uses a step down process to preliminarily extract and remove larger pollutants from the incoming air before entering the building. This process contains three layers: an electrostatic dust filter, lint filter, and an algae scrubber filter. The electrostatic dust filter serves as the first layer to remove larger dust particles while the lint filter works to remove more refine particles. Lastly, the algae scrubber filter removes carcinogens injected into the atmosphere by vehicles.

The filtered air then goes through the central lobby green wall that also tempers the air before it proceeds into the thermal bath. As the air gets used up by the breathers, the stale air gets drawn up through the core of the solar chimney that is made of a carbon absorbent concrete that also acts as a thermal mass. At this stage, the concrete absorbs both the heat and carbon dioxide from the air before it gets exhausted out to the exterior. The air passes through a bamboo lattice with hanging plants that serves as the final layer of filtration before the air gets released back into the atmosphere.

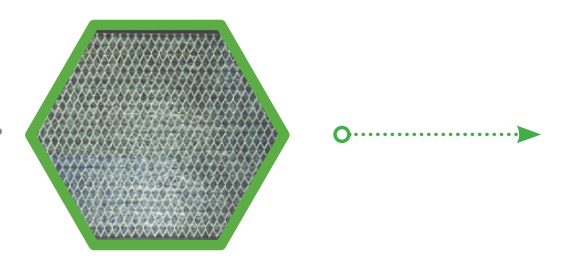

ELECTROSTATIC DUST FILTER
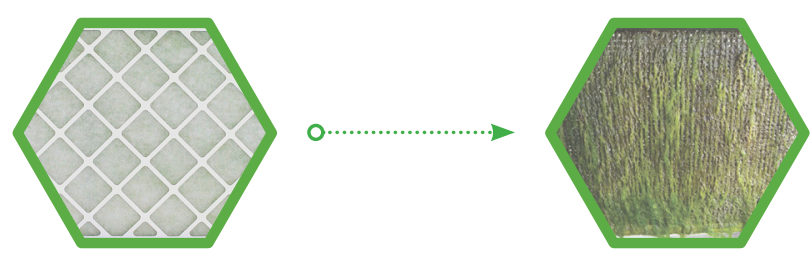

LINT FILTER
ALGAE SCRUBBER FILTER 


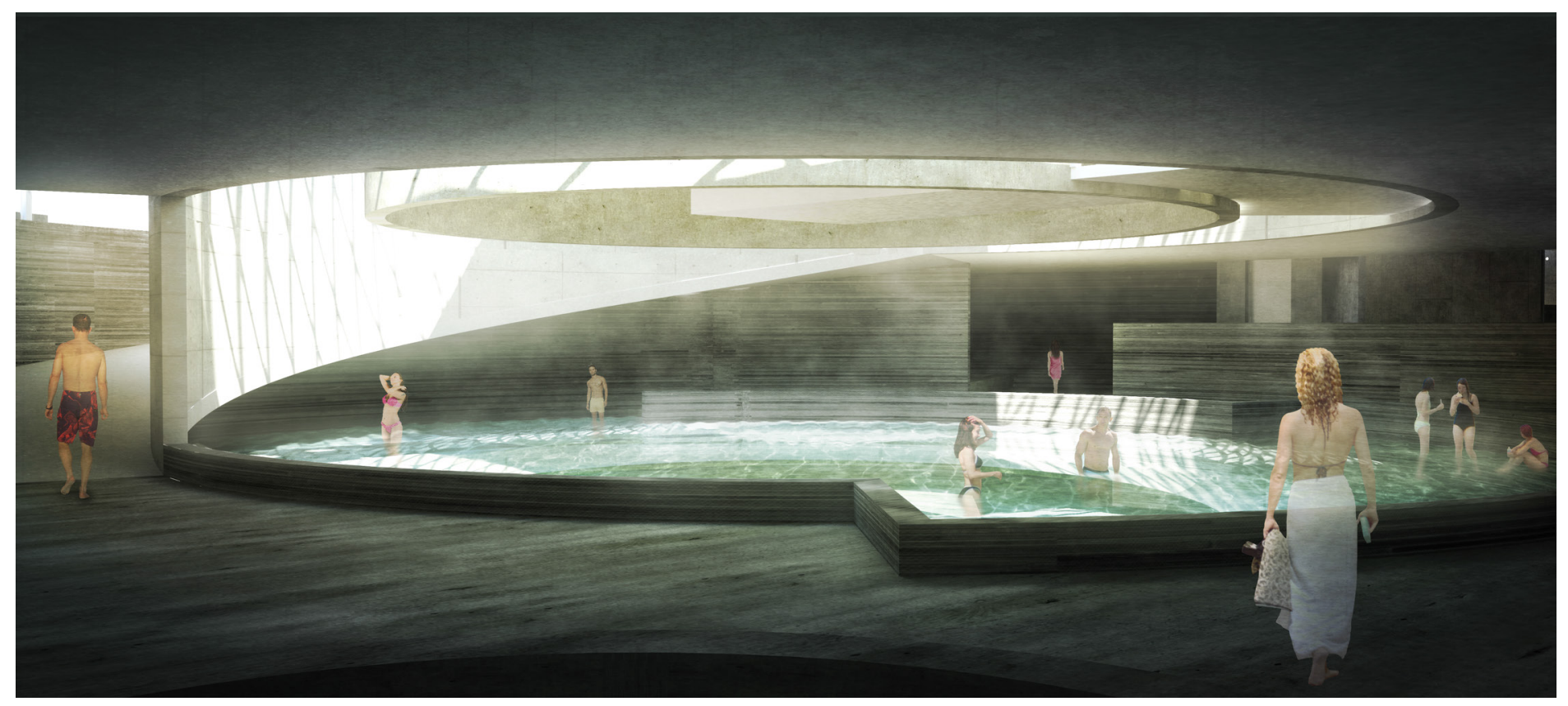

Using a double skin system, the design centers around a solar chimney that acts as the driving force of natural air flow. Polluted air from the highway off-ramp is taken in through the sloping entryway. Through a green wall filter and a series of step down filters, the air is purified as it enters the building through the main lobby. The last point of purification occurs through a green wall system that drives the incoming air through a humidifier before entering the controlled thermal bath environment. After use, the stale air exhaust is naturally driven up the open solar chimney, thereby increasing the thermal environment going up the building. Before the air returns back to the urban environment, it passes through a final green lattice to absorb any remaining air pollutants and purify the air. This effectively creates a symbiotic relation where the exterior directly impacts the interior experience and vice versa. 


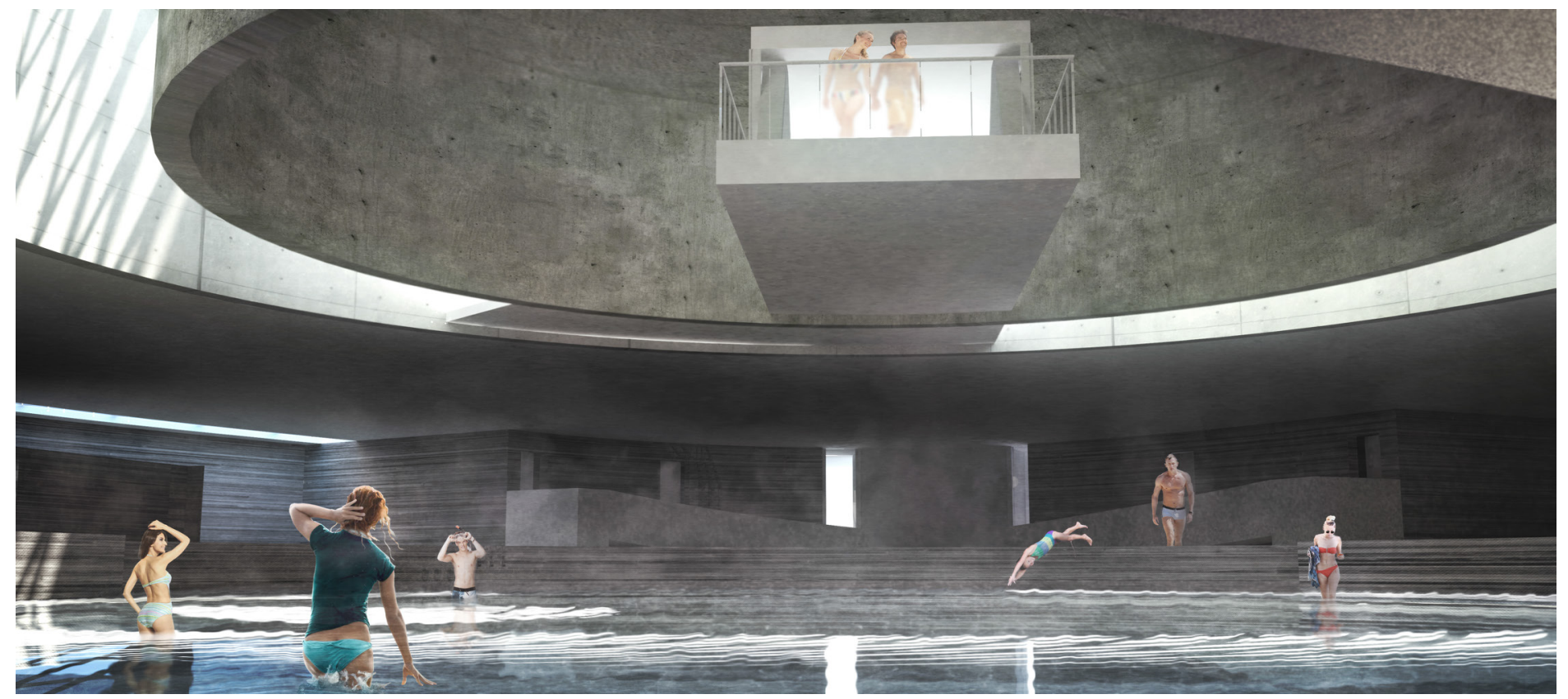

Fig 9.15 Interior renders of the solar chimney as a central component to both program and function of the thermal bath 


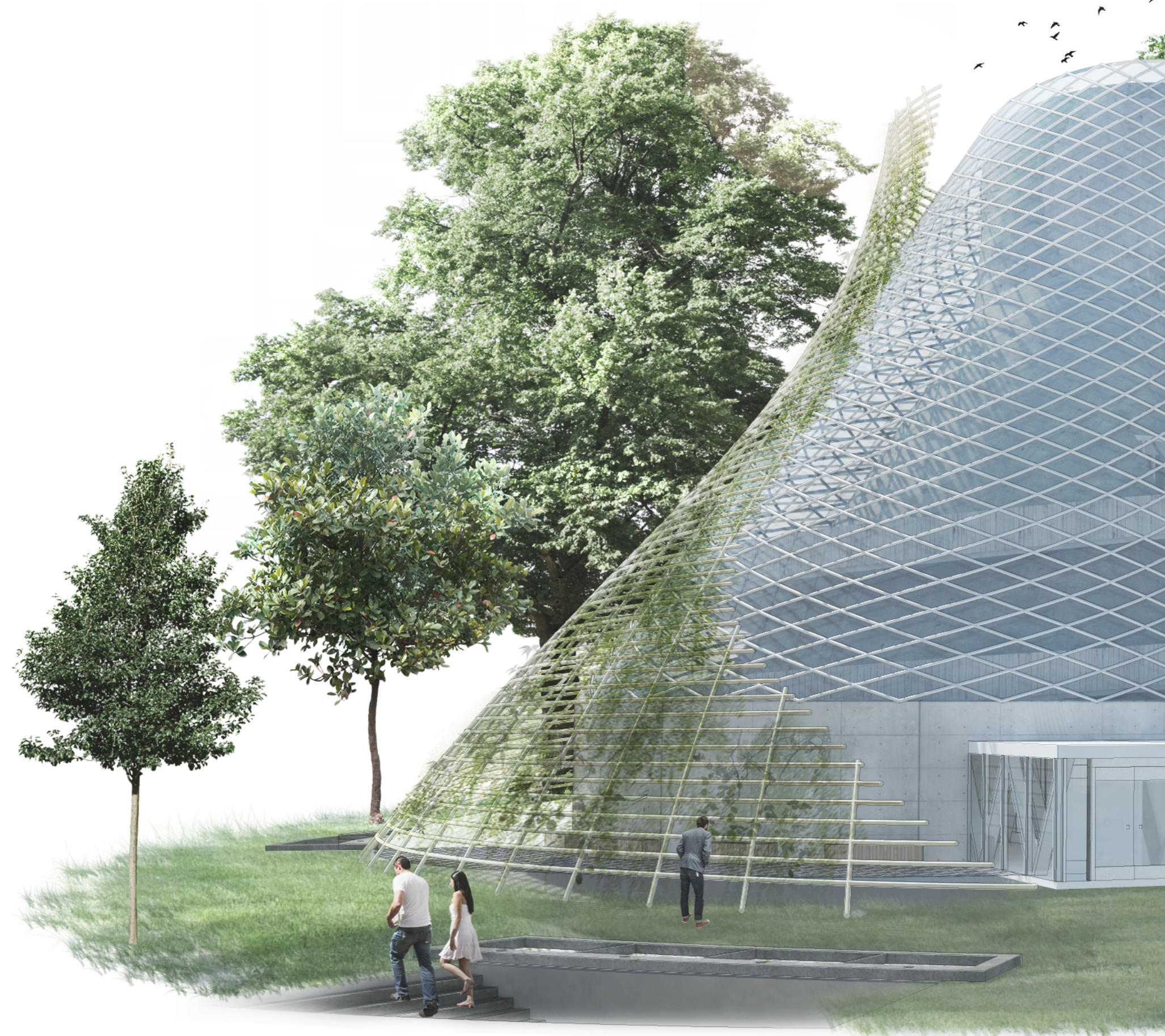

Fig 9.16 Overall view of Aspiro 


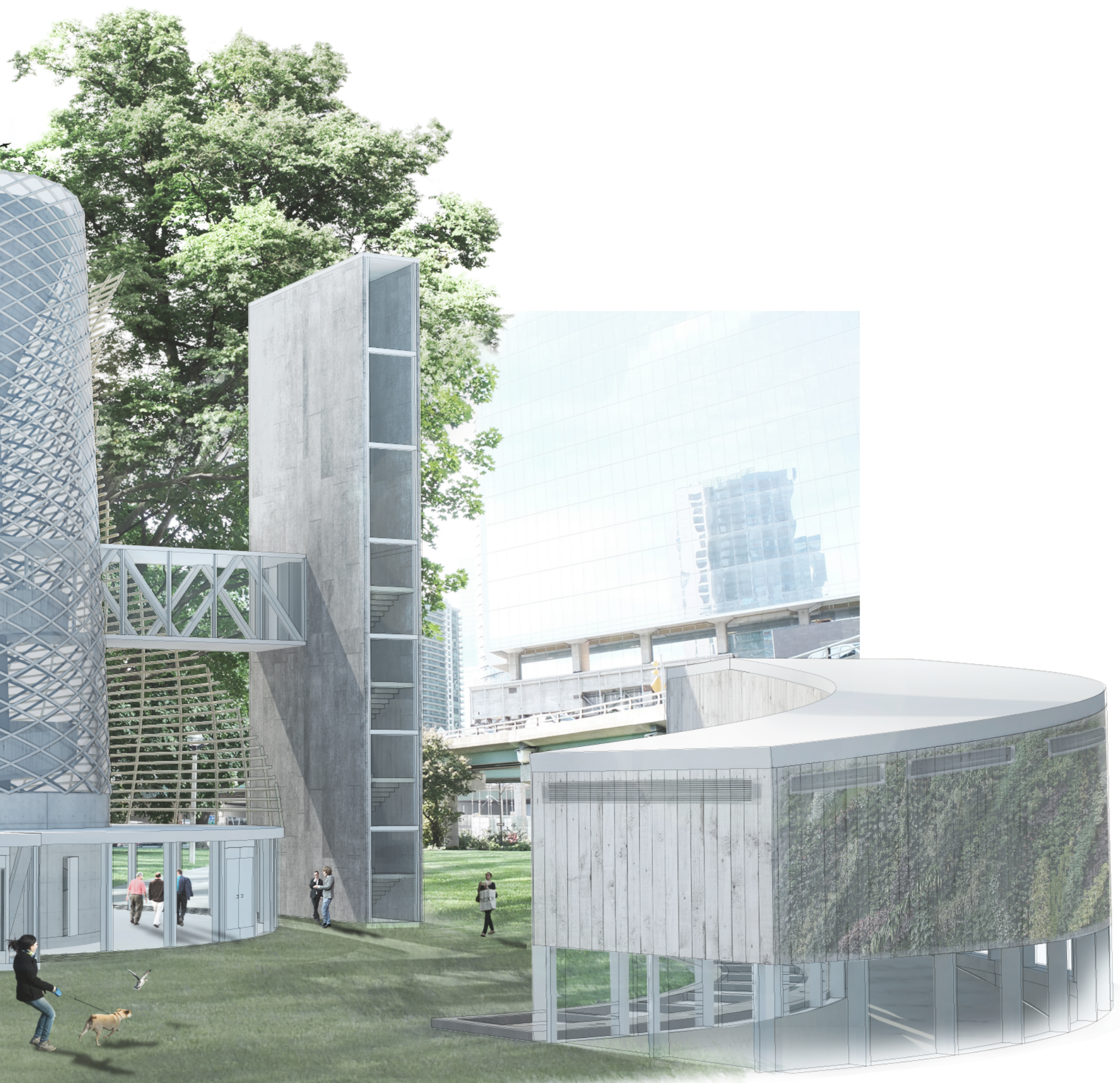




\section{Endnotes}

${ }^{1}$ Mohen Mostafavi, David Leatherbarrow. On Weathering: The Life of Buildings in Time. (Cambridge. The MIT Press, 1993). 16.

${ }^{2}$ Le Corbusier. The Radiant City. (New York: The Orion Press, 1933). 156.

${ }^{3}$ www.thestar.com/opinion/editorials/2014/04/21/toronto can do_more_to_reduce_premature_deaths_from_air_pollution_

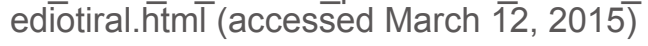

${ }^{4}$ http://www.thestar.com/business/2013/11/29/gridlock_the_6_ billion_at_least_problem.html

${ }^{5}$ http://www.thestar.com/news/gta/2014/04/28/toronto_area commutes_add_to_time_crunch_study_shows.html

${ }^{6}$ http://www.theglobeandmail.com/report-on-business/robcommentary/pan-am-games-offer-a-stress-test-for-ontariosoverburdened-roads/article25339773/

7 http://www.thestar.com/news/city_hall/2015/06/03/eastgardiners-fate-in-council-is-up-in-the-air-despite-tory.html

${ }^{8}$ http://www.thestar.com/news/gta/2015/04/21/air-quality-mapshows-torontos-most-polluted-neighbourhoods.html

\section{Image References}

${ }^{1}$ Kevin Pu

${ }^{2}$ Ibid.

${ }^{3}$ http://www.thestar.com/news/gta/2015/04/21/air-quality-mapshows-torontos-most-polluted-neighbourhoods.html

${ }^{4}$ Kevin $\mathrm{Pu}$

${ }^{5}$ Ibid.

${ }^{6} \mathrm{lbid}$.

7 Ibid.

8 Ibid.

${ }^{9}$ Ibid.

${ }^{10} \mathrm{Ibid}$.

11 Ibid.

12 Ibid.

${ }^{13}$ Ibid.

${ }^{14}$ Ibid.

15 Ibid.

${ }^{16}$ Ibid.

17 Ibid. 


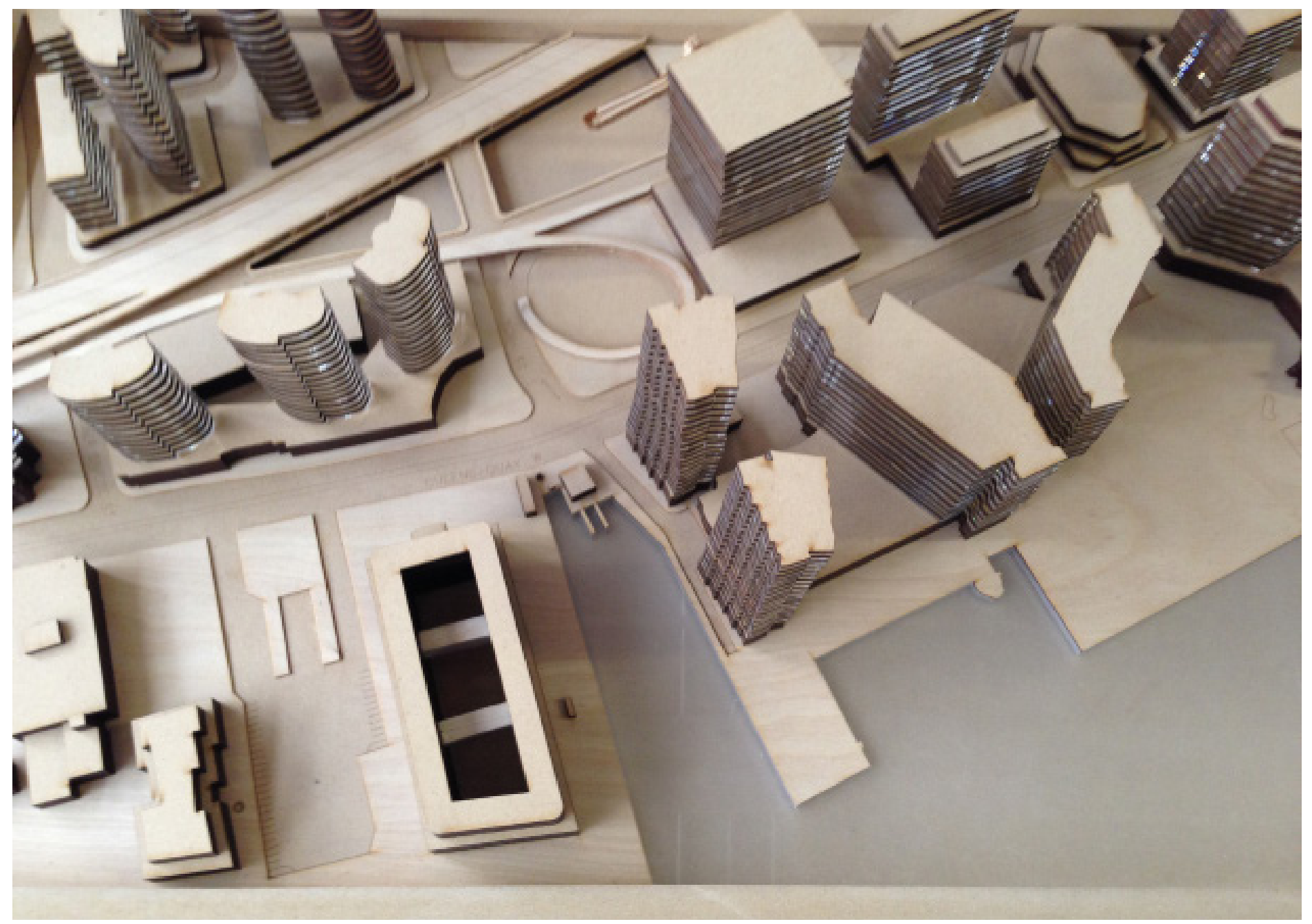

Fig 9.17 1:1000 model of the Queens Quay and York Street Gardinery Expressway off-ramp 


\subsection{Lessons Learned}

With buildings accounting for $44.6 \%$ of carbon dioxide $\left(\mathrm{CO}_{2}\right)$ emissions as the leading contributor to air pollution, architectural design automatically becomes a starting point to begin addressing respiratory issues within cities. ${ }^{1}$ Reexamining the way we build presents architecture with the opportunity to reinterpret how the city breathes in order for the urban fabric to reintegrate itself back into the natural environment. Humans can no longer be a separate entity from nature and architects ought to reconsider their role in the larger biological function of nature. Aspiro is a result of a body of extensive research that incorporated principles from natural respiratory processes to inform architecture and raise awareness to the city as an anti-respirator.

As a thesis that focuses on improving air quality through the way we build and approach architecture, this thesis raises a critical question of how effective urban respiratory systems can be. Although Aspiro was designed as a hypothetical framework to demonstrate the research of the four parameters of respiration (i.e., breathe, flow, control, and exchange) to make a bold statement on the current state of architecture, there are lessons to be learned in the success of how this approach towards architecture can really contribute to urban respiration in a city. While the main focus of Aspiro looked at the form of architecture and the design of flow to dictate air movement needed for natural respiration, much of the design also serves the need of materiality and vegetation to optimize the building's ability to filter and purify air. The form of Aspiro, influenced by the four parameters of respiration, came into fruition to support the active functions of the incorporated filtration systems integrated throughout the building. As a result, a rough estimate can be deduced as to the potential impact of Aspiro as an urban respirator.

Ubiquitously, humans have always known that plants are good for health because they can clean and filter pollutants from the air through a process known as photosynthesis. ${ }^{2}$ However, no one really knows the science or statistics behind this idea beyond the common knowledge of the public. In 1989, NASA proved that common house plants were in fact able to remove carcinogens in the air through experiments in which they exposed plants to volatile organic chemicals for 24 hours. $^{3}$ 
1 ton of plant dry mass $m 1.8$ tons of $\mathrm{CO}_{2}$ removed from air 33 grams of plant dry mass $m 59.4$ grams of $\mathrm{CO}_{2}$ removed from air

1 person exhales approximately $1.1 \mathrm{~kg}$ of $\mathrm{CO}_{2}$ each day

If this plant takes 2 months to grow to this size, each day this plant remove 0.99 gram of $\mathrm{CO}_{2}$

Then we need 1,111 of these plants to cover our 1 day exhaled CO2 !!!
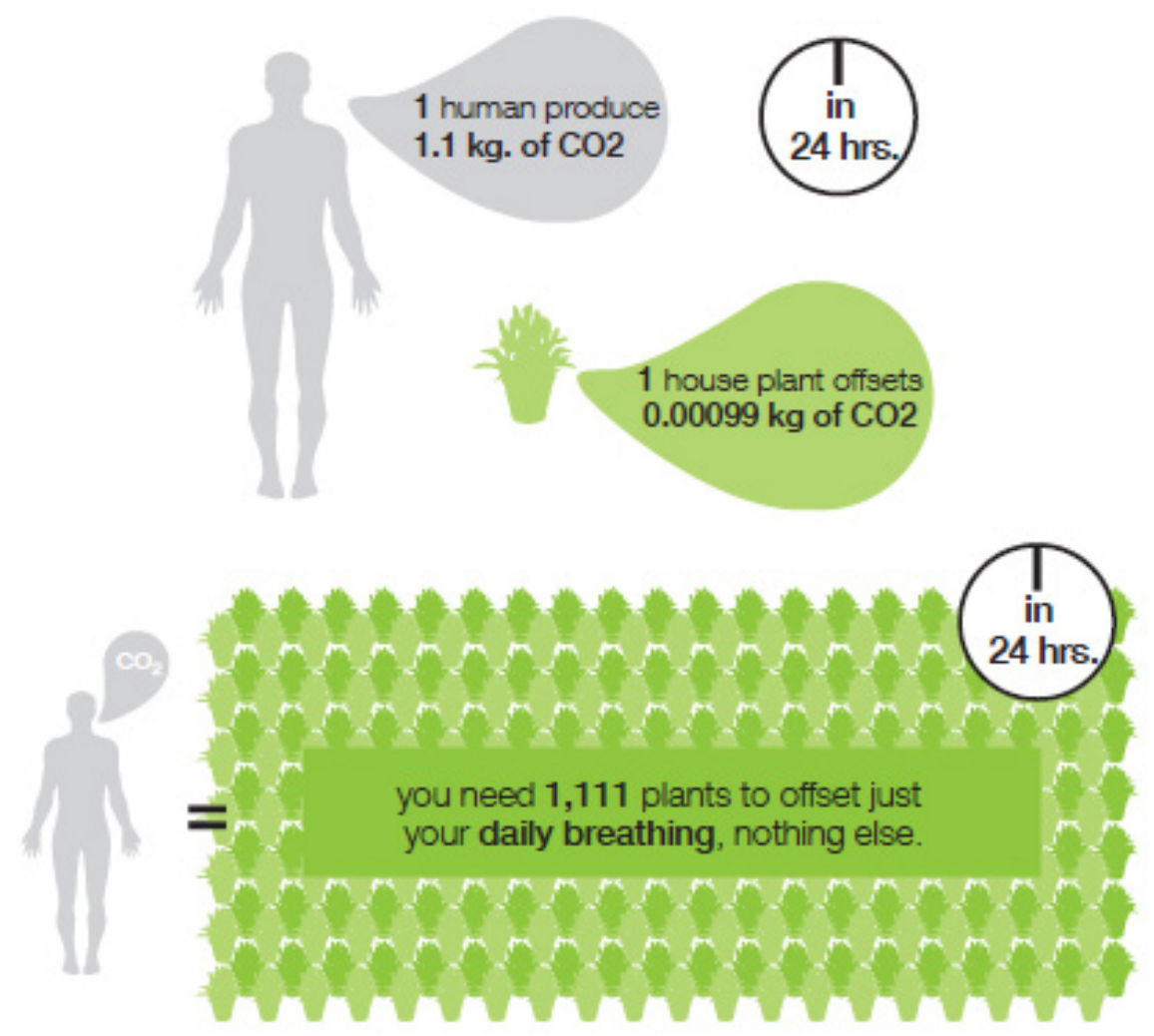

Fig 10.1 Natural Fuse (2011) Haque Design + Research. Diagram of the amount of plants needed to offset daily breathing 
Beyond the removal of $\mathrm{CO}_{2}$, the study showed that plants were also effective in the removal of benzene, trichloroethylene, and formaldehyde. ${ }^{4}$ Of the list of common household plants, bamboo on its own was not the most effective in removing the overall combination of carcinogens studied at approximately 3.65 micrograms $/ \mathrm{cm}^{2}$ in a day. With a total of 101 pieces of bamboo used in the lattice structure of Aspiro, the total surface area of the lattice is $10,984,744 \mathrm{~cm}^{2}$. At the rate of 3.65 micrograms $/ \mathrm{cm}^{2} /$ day, the bamboo lattice structure on Aspiro can approximately remove up to $40,094,315$ micrograms of carcinogens $/$ day or $0.04 \mathrm{~kg}$. That is not even close to the daily average of $1.1 \mathrm{~kg}$ of $\mathrm{CO}_{2}$ that humans produce in their daily breathing. ${ }^{6}$ This is largely due to the removal of bamboo as a plant to a structural material, thereby taking away its natural biological function of growth. However, when the lattice is fully covered with vegetation and plants, the lattice "comes alive" and exponentially increases its ability to purify the air. According to a research conducted by Haque Design + Research, it takes approximately 1,111 small household plants to offset the carbon dioxide of one breather per day. This ratio may seem daunting at first, but the large lattice structure of Aspiro can support up to the equivalent of 100,000 plants of the same scale, giving this layer of filtration the ability to filter and support 100 breathers a day on site. This assumes that the breather would stay on site for the entire 24hours. To further break this statistic down, 100 breathers produce approximately $110 \mathrm{~kg}$ of $\mathrm{CO}_{2}$ in 24 hours, which means the lattice layer alone can support and mediate up to $110 \mathrm{~kg}$ of $\mathrm{CO}_{2}$ a day. Without considering other various layers embedded into the design of Aspiro, the simple incorporation of a green lattice can offset the carbon dioxide loads generated by the thermal bath itself, demonstrating a powerful yet simple solution to the growing issue of urban pollution.

While it is relatively easy to estimate the effectiveness of a single component of Aspiro in its ability to purify air, buildings never function in isolation. The dynamic and power of Aspiro lies in the harmony of multiple components working together as one integrated system to achieve respiration. This rests in the quality of space that extends beyond numbers and calculations where Aspiro supports the idea that architecture can provide more than merely enclosed spaces, but also be a positive contributor to the city; similar to the role of a tree. With an assurance of continual growth in global population, architecture must turn to the framework of urban respiratory systems to offset the imminent decline of trees to make way for supporting human habitation. 


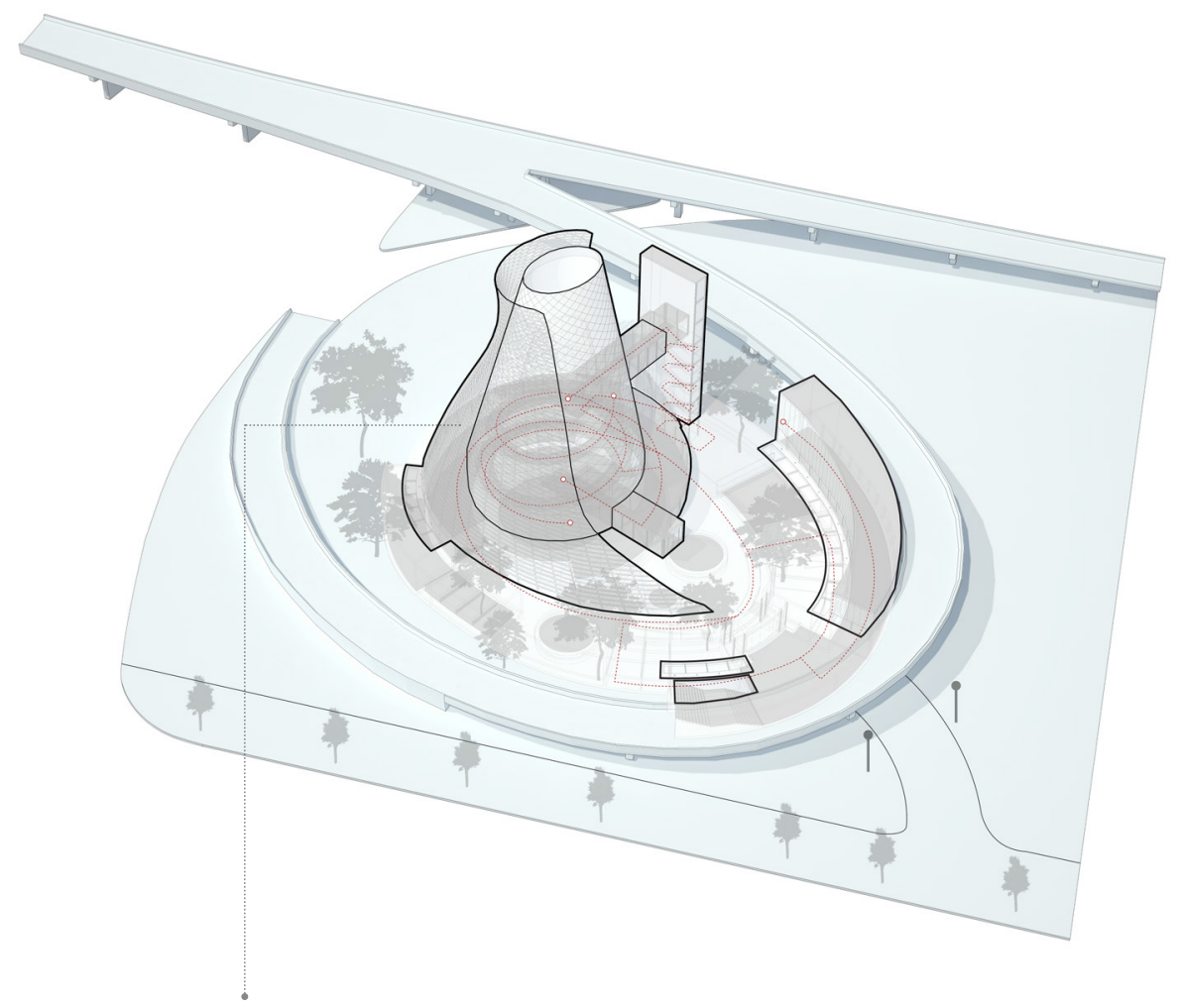

bamboo lattice
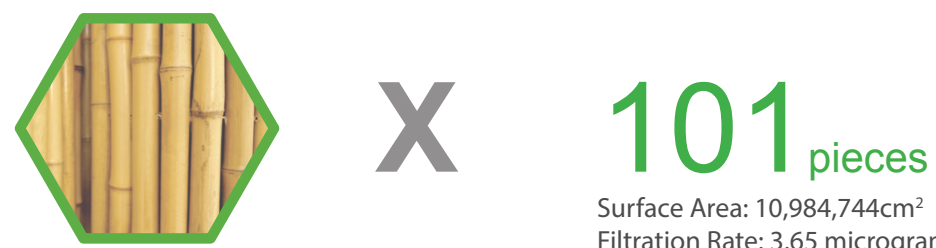

Surface Area: $10,984,744 \mathrm{~cm}^{2}$

Filtration Rate: 3.65 micrograms $/ \mathrm{cm}^{2} /$ day
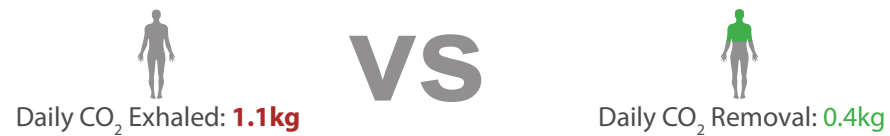

Daily $\mathrm{CO}_{2}$ Removal: $0.4 \mathrm{~kg}$

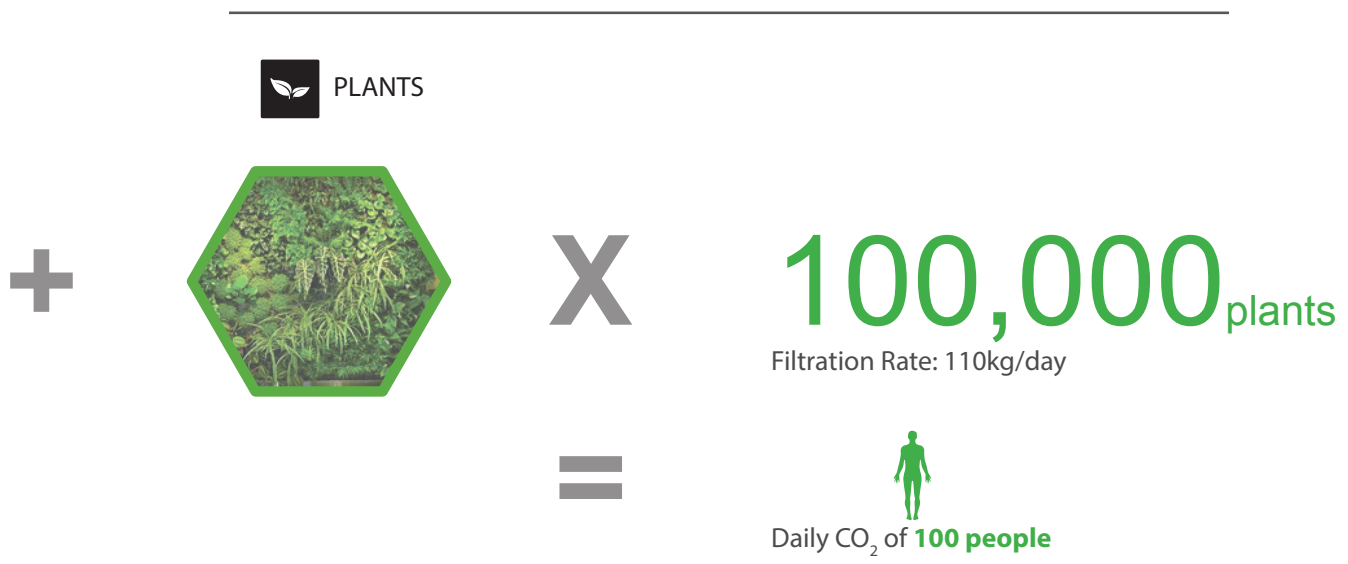

Fig 10.2 Diagram breaking down the filtration rate of Aspiro's green wall lattice 


\subsection{Conclusion}

The thesis research demonstrates the importance of turning to nature with the lens of regenerative architecture to learn from the processes of natural respiration in order to inform architecture and its role in fighting the impacts of urbanization. Air must be understood and considered as a tangible and valuable resource to cities through the discourse of architecture and its relationship with urban atmospheres. Gissen makes it clear:

Although some buildings begin to engage with pollution in startling new ways, we still visualize the thing itself - atmospheric pollution - in much the same ways we have before. This is curious considering that we now understand pollution to be much more than its particulate counts. It is more than hydrocarbons or $\mathrm{CO} 2 .^{7}$

Urban pollution should no longer be about numbers and statistics regarding the quantity of carcinogens but rather be focused on the quality of space in which we live in. Through this consideration of the air that cities breathe, the four parameters of respiration can break through the hermetic seals of traditional architecture and transform into dynamic living organisms that can serve both the provision of space and shelter as well as improve the quality of space. With urban respiratory systems, as defined through this body of research, cities can shed its adverse character of being urban pollution and assume the intrinsic qualities of nature through its respiration processes. As a discourse in architecture, respiration serves as a catalyst in bringing attention to the invisible and subconscious nature of air through the physical built form of architecture. 


\section{Endnotes}

1 http://www.un.org/en/development/desa/news/population/worldurbanization-prospects-2014.html (accessed January 10, 2015)

${ }^{2}$ www.ourhouseplants.com/guides/50-plants-that-clean-the-air (accessed August 29, 2015)

${ }^{3}$ Bill Wolverton. A Study of Interior Landscape Plants for Indoor Air Pollution Abatement. (1989). 2.

${ }^{4}$ Ibid., 7.

${ }^{5}$ Ibid., 8.

${ }^{6}$ Ai Hasegawa, Nitipak Samsen, Usman Haque. Structuring Participation for an Energy Commons. Sentient city: Ubiquitous computing, architecture, and the future of urban space. (New York: The MIT Press, 2011). 71.

${ }^{7}$ David Gissen. Toxic Territories. Territory: Architecture Beyond Environment. (Chichester: John Wiley \& Sons, 2010). 57.

\section{Image References}

${ }^{1}$ Ai Hasegawa, Nitipak Samsen, Usman Haque. Structuring Participation for an Energy Commons. Sentient city: Ubiquitous computing, architecture, and the future of urban space. (New York: The MIT Press, 2011). 71.

${ }^{2}$ Kevin $\mathrm{Pu}$ 


\section{List of Figures}

Figure 1.1: X-Ray of Lung

Source: https://theaiexpedition.files.wordpress.com/2013/04/

chestxray.jpg

Figure 1.2: Child with assistive breathing apparatus

Source: http://www.dreamcatchersforabusedchildren.com/wpcontent/uploads/2014/09/GTY_girl_wearing_oxygen_mask_ jt_140907_16x9_992.jpg

Figure 1.3: Collage of suffocating breathers in Toronto Source: https://egocentrista.files.wordpress.com/2013/12/ bhjevcxcaaa1ohj.jpg

http://i.huffpost.com/gen/1914147/images/n-CHINAPERFORMANCE-ART-POLLUTION-large570.jpg

http://i1.trekearth.com/photos/85209/dundas_square_toronto.jpg

Figure 2.1: Cyclists riding through an industrial area of China Source: http://www.trbimg.com/img-52dd9df6/turbine/la-sci-sn-china-exports-air-pollution-united-s-001/2048/2048x1273

Figure 2.2: An Experiment on a Bird in an Air Pump by Joseph Wright Derby. Oil on Canvas Source: http://www.nationalgallery.org.uk/upload/img/wright-experiment-bird-air-pump-NG725-fm.jpg

Figure 2.3: Dome over Manhattan by Richard Buckminster Fuller. Plan

Source:http://40.media.tumblr.com/50abdb32cb191e805e9ab1c374f5bed7/tumblr_mu4pe37nwG1qgpvyjo1_500.jpg

Figure 2.4: Dome over Manhattan by Richard Buckminster Fuller. Aerial View

Source: https://flavorwire.files.wordpress.com/2013/01/1-domeover-midtown1.jpg

Figure 2.5: Bubbles by Orproject. Interior Rendering

Source: http://www.treehugger.com/urban-design/beijing-bubbles-biome-clean-air-orproject.html

Figure 2.6: Bubbles by Orproject. Plan

Source: http://www.treehugger.com/urban-design/beijing-bubbles-biome-clean-air-orproject.html 
Figure 2.7: Bubbles by Orproject. Aerial View

Source: http://www.treehugger.com/urban-design/beijing-bubbles-biome-clean-air-orproject.html

Figure 2.8: Victory Mills Toronto Harbourfront

Source: https://c2.staticflickr.com/8/7122/7108328345_ be30568110_b.jpg

Figure 2.9: Clean Air Pod by Ant Farm

Source: http://i.kinja-img.com/gawker-media/image/upload/s--IImviB2w--/c_fit,fl_progressive,q_80,w_636/18qmdx2a175djjpg.jpg

Figure 2.10: $B \_m u$ Tower by R\&Sie(n). Sections

Source: http://www.new-territories.com/roche2002bis.htm

Figure 2.11: B_mu Tower by R\&Sie(n). Lattice

Source: http://www.new-territories.com/roche2002bis.htm

Figure 2.12: B_mu Tower by R\&Sie(n). Rendering

Source: http://www.new-territories.com/roche2002bis.htm

Figure 2.13: Open Columns by Omar Khan

Source: http://cast.b-ap.net/site/wp-content/uploads/2010/10/OC_4. .jpg

Figure 2.14: Stratus Project by RVTR

Source: http://acdn.architizer.com/thumbnails-PRODUCTION/11/31/1131ae6595196a8ee13dd22069570045.jpg

Figure 2.15: Stratus Project by RVTR

Source: http://acdn.architizer.com/thumbnails-PRODUCTION/11/31/1131ae6595196a8ee13dd22069570045.jpg

Figure 3.1: Breathing Architecture by WOHA

Source:http://36.media.tumblr.com/ dc7a349441f7d965b77a5a6490a6f2e6/tumblr_ msrm10jp9r1s3r80lo2_1280.jpg

Figure 3.2: Technical Illustration of gasmasks in use during WWI from Bruno Latour's short essay Air

Source: http://www.bruno-latour.fr/sites/default/files/P-115-AIRSENSORIUMpdf.pdf 
Figure 3.3: Use of facial masks in Beijing, China

Source: https://thenanfang.com/wp-content/uploads/2015/01/

airquality.jpg

Figure 3.4: Human Flow of Oxygen

Source: Kevin Pu

Figure 3.5: Human Respiratory System

Source: Kevin Pu

Figure 3.6: Plan Voisin by Le Corbusier

Source: http://acdn.architizer.com/thumbnails-PRODUCTION/

f5/00/f500dc3a2dfa0dfba77bfb7d570ab7d0.jpg

Figure 3.7: Unite D’Habitation by Le Corbusier

Source:http://40.media.tumblr.

com/658dcc9ea6978ed73ea8a5b39e6dbb43/tumblr_ mz1yzpLTiB1soavyuo1_1280.jpg

Figure 3.8: Environmental Bubble by Reyner Banham and Francois Dallegret

Source: https://studio4postindustrial.files.wordpress.

com/2011/04/picture-8.png

Figure 3.9: Valencia Institute of Modern Art by SANAA. View of mediating space where weather and architecture meets

Source: http://www.designboom.com/wp-content/

uploads/2005/10/sanaa-valencia.jpg

Figure 3.10: Air pollution within urban cities produced by industrial factories

Source: http://media.canada.com/9e591aed-9747-4952-b147-

1d6ab8db7d2a/steelplant.jpg

Figure 4.1: Gas attacks in the trenches of Ypres in 1915

Source: http://3.bp.blogspot.com/-K3ltSQmpdAU/

VB7k2EnHJSI/AAAAAAAA9zY/2q2iEr-eQgc/s1600/

Animals\%2Bin\%2BWorld\%2BWar\%2BI\%2B\%282\%29.jpg

Figure 4.2: Diagram of the human lung

Source: http://i.livescience.com/images/i/000/031/456/i02/lungs-

diagram-120926.jpg?1348765086 
Figure 4.3: Airflux by Philippe Rahm. Plan

Source: http://www.philipperahm.com/data/projects/airflux/index. html

Figure 4.4: Windtrap by Philippe Rahm. Diagram of air exchange

Source: http://www.philipperahm.com/data/projects/windtrap/ index.html

Figure 4.5: Windtrap by Philippe Rahm. Plans

Source: http://www.philipperahm.com/data/projects/windtrap/ index.html

Figure 4.6: Brio-Vega Cemetery by Carlo Scarpa. Weathering: nature's re-form of "finished" architecture

Source: http://dressingtheair.com/uploads/74/ awB3Y8jp60R7DMA6.jpg

Figure 4.7: First air conditioner by Willis $\mathrm{H}$. Carrier

Source: http://www.williscarrier.com/images/gallery/1922WHC_ OnonPottery2_92684.jpg

Figure 5.1: Anatomy of a Dwelling by Francois Dallegret

Source: http://socks-studio.com/img/blog/dallegret-06-b.jpg

Figure 5.2: Anatomy of HVAC. How Buildings Breathe

Source: Kevin Pu

Figure 5.3: Anatomy of Vehicles. How Vehicles Breathe

Source: Kevin Pu

Figure 5.4: Vehicular traffic on the Don Valley Parkway in Toronto

Source: https://upload.wikimedia.org/wikipedia/commons/1/16/ DVP_Congestion2.png

Figure 5.5: Diagram of the Gardiner Expressway dividing up the downtown core of Toronto

Source: Kevin Pu

Figure 5.6: Site analysis of urban pollution in Toronto according to the 2012 Toronto Public Health Report

Source: Kevin Pu 
Figure 5.7: Map of the G.T.A (Greater Toronto Area) with statistics

Source: Kevin Pu

Figure 5.7: Aerial Diagram of Toronto functioning as an AntiRespirator

Source: Kevin Pu

Figure 6.1: Interior Gulf Stream by Philippe Rahm

Source: http://www.philipperahm.com/data/projects/

interiorgulfstream/

Figure 6.2: Diagram of convection movement in the Interior Gulf Stream Research House

Source: http://www.philipperahm.com/data/projects/ interiorgulfstream/

Figure 6.3: City of Parauapebas, Brazil. Urbanization in one of Brazil's fastest growing cities leading to expansive deforestation into the Amazon rainforest

Source: http://curitibainenglish.com.br/wp-content/ uploads/2012/11/article-0-0D568CE6000005DC-993_468x286. jpg

Figure 6.4: Deforested area near Novo Progresso in Brazil's northern state of Para

Source: http://www.theguardian.com/environment/2013/nov/15/ amazon-deforestation-increased-one-third

Figure 6.5: Diagram of a Tree

Source: Kevin Pu

Figure 6.6: Stomata pore

Source: http://horticulture.tekura.school.nz/assets/horticultureimages/ht109-22.gif

Figure 6.7: Exploded Axonometric Design Study (Tree)

Source: Kevin Pu

Figure 6.8: Diagram of Design Study's (Tree) program

Source: Kevin Pu 
Figure 6.9: Elevations and Section of Design Study (Tree)

Source: Kevin Pu

Figure 6.10: Diagram of the Fly's Tracheal System

Source: http://www.asknature.org/strategy/

b1cc81440b1fda03d40c236b0b66ad6f

Figure 6.11: Design Study (Fly)

Source: Kevin Pu

Figure 6.12: Diagram of the Termite Mound

Source: http://www-tc.pbs.org/wnet/nature/files/2011/10/termite_ mound.jpg

Figure 6.13: Diagram of the Termite Mound continued

Source: http://inhabitat.com/building-modelled-on-termiteseastgate-centre-in-zimbabwe/

Figure 6.14: Section of the Eastgate building in Zimbabwe

Source: http://inhabitat.com/building-modelled-on-termiteseastgate-centre-in-zimbabwe/

Figure 6.15: Eastgate building by Mick Pearce. Atrium

Source: http://inhabitat.com/building-modelled-on-termiteseastgate-centre-in-zimbabwe/

Figure 6.16: Environment Bubble by Reyner Banham and Francois Dallegret

Source: https://studio4postindustrial.files.wordpress. com/2011/04/picture-8.png

Figure 6.17: Design Study (Critique of the Environment Bubble)

Source: Kevin Pu

Figure 6.18: Architecture as a Network of Circulation Spaces (Diagram) Design Study

Source: Kevin Pu

Figure 6.19: Architecture as a Network of Circulation Spaces (Open Network)

Source: Kevin Pu 
Figure 7.1: Picture of a snail shell

Source: http://thisisthefuture.org/wp-content/uploads/2011/02/bio.

jpg

Figure 7.2: Bell Tower staircases at the Sagrada Familia by Antio Gaudi. Gaudi took inspiration from the snail in his design of the $118 \mathrm{~m}$ tower staircase

Source: http://41.media.tumblr.com/tumblr_ log6vnJkfp1qlc7vyo1_1280.jpg

Figure 7.3: Systematic Breakdown of the Tree's Respiratory Process

Source: Kevin Pu

Figure 7.4: Inside the termite mound where termite workers are working to shift dirt around

Source: http://massdosage.co.za/galleries/africa/south_africa/ honeymoon/hi-res/p1030643.jpg

Figure 7.5: Close up of the fly

Source: http://viewpoints.iu.edu/science-at-work/files/2012/05/

flyheadsolo.jpg

Figure 7.6: Systematic Breakdown of the Fly's Respiratory Process

Source: Kevin Pu

Figure 7.7: Systematic Breakdown of the Termite Mound's Respiratory Process

Source: Kevin Pu

Figure 7.8: View up the solar chimney (central lung) of Aspiro

Source: Kevin Pu

Figure 8.1: Diagram of installation on site

Source: Kevin Pu

Figure 8.2: Photograph of Stomata taken by Remi Carrerio

Source: Remi Carrerio

Figure 8.3: Flow process of data from carbon dioxide input to oxygen output

Source: Kevin Pu 
Figure 8.4: Sectional Diagram through the "breathing" bag

Source: Kevin Pu

Figure 8.5: Diagram of Stomata's interaction with a breather and his microclimate

Source: Kevin Pu

Figure 8.6: Experiential section of Aspiro showing the flow of air and breathers simultaneously throughout the site

Source: Kevin Pu

Figure 8.7: Diagram of Aspiro's filtration process that mediates the macroclimate to provide a breathable micro-environment

Source: Kevin Pu

Figure 8.8: Winter render of the West Don Lands Centre

Source: Kevin Pu

Figure 8.9: Diagram of the West Don Lands development and the Gardiner Expressway

Source: Kevin Pu

Figure 8.10: Diagram of respiratory systems within the building

Source: Kevin Pu

Figure 8.11: Exploded Axonometric

Source: Kevin Pu

Figure 8.12: Interior renders of open concept spacing

Source: Kevin $\mathrm{Pu}$

Figure 8.13: Sectional Perspective

Source: Kevin Pu

Figure 8.14: 3D wall section detail of double skin façade with algae scrubber filters

Source: Kevin Pu

Figure 8.15: Sectional perspective of respiratory zones in Aspiro Source: Kevin Pu 
Figure 9.1: Initial sketches in response to anti respiration

Source: Kevin Pu

Figure 9.2: Aerial view of site adjacent to Gardiner Expressway off ramp on Queen Quay and York Street

Source: Kevin Pu

Figure 9.3: Air quality statistics in Toronto showing ultrafine particle concentrations around major highway sections

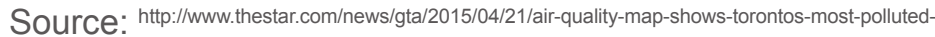
neighbourhoods.html

Figure 9.4: Responding to extreme urban conditions in Toronto

Source: Kevin Pu

Figure 9.5: View of York Street off ramp surrounding Aspiro on site

Source: Kevin Pu

Figure 9.6: Diagram of solar chimney on site as the lung of both site and building

Source: Kevin Pu

Figure 9.7: 1:5000 site plan of Aspiro

Source: Kevin Pu

Figure 9.8: Interior renders of different thermal experiences throughout Aspiro

Source: Kevin Pu

Figure 9.9: Diagram of formal design process of Aspiro in response to respiration on the constricting site of Queens Quay and York Street

Source: Kevin Pu

Figure 9.10: View of the green landscape within the micro landscape that Aspiro creates amongst the Gardiner off ramp

Source: Kevin Pu

Figure 9.11: Floor Plans

Source: Kevin Pu 
Figure 9.12: Views from under the Gardiner off ramp of Aspiro on site

Source: Kevin Pu

Figure 9.13: Elevations and Section

Source: Kevin Pu

Figure 9.14: Exploded axonometric drawing of Aspiro and its components

Source: Kevin Pu

Figure 9.15: Interior renders of the solar chimney as a central component to both program and function of the thermal bath

Source: Kevin Pu

Figure 9.16: Overall view of Aspiro

Source: Kevin Pu

Figure 9.17: Picture of a 1:1000 model of Queens Quay and York Street Gardiner Expressway off ramp

Source: Kevin Pu

Figure 10.1: Natural Fuse by Haque Design + Research. Diagram of the amount of plants needed to offset the daily breathing of humans

Source: Ai Hasegawa, Nitipak Samsen, Usman Haque. Structuring Participation for an Energy Commons. Sentient city: Ubiquitous computing, architecture, and the future of urban space. (New York: The MIT Press, 2011). 71.

Figure 10.2: Diagram breaking down the filtration rate of Aspiro's green wall lattice

Source: Kevin Pu 


\section{References}

Air pollution kills 7 million people every year globally, WHO finds. 2014 [cited 09/15 2014]. Available from http://www.cbc.ca/ news/health/air-pollution-kills-7-million-people-every-yearglobally-who-finds-1.2585505.

WOHA: Breathing architecture2012. , eds. Micaela Busenkell, Peter Cachola SchmalPrestel Publishing.

Arbona, Javier. 2010. It's in your nature: I'm lost in paris. Territory: Architecture Beyond Environment 80 (3): 46.

Armstrong, Rachel, and Simone Ferracina. 2013.

Unconventional computing: Design methods for adaptive architecture.

Banham, Reyner. 2007. A home is not a house. In Rethinking technology: A reader in architectural theory., eds. William W. Braham, Jonathan A. Hale and John Stanislav Sadar, 159.

- 1984. The architecture of the well-tempered environment. Second Edition ed. Chicago: University Of Chicago Press.

Barley, Nick. 2000. Breathing cities : The architecture of movement, ed. Nick Barley. Basel, Switzerland: Birkhäuser.

Benyus, Janine M. 1997. Biomimicry: Innovation inspired by nature.

Bhabha, Homi, Stefano Boeri, Chuck Hoberman, Rem Koolhaas, Sanford Kwinter, Bruno Latour, Nina-Marie Lister, et al. 2010. Ecological urbanism, eds. Moshen Mostafavi, Gareth Doherty. Baden, Switzerland: Lars Müller.

Busby, Peter, Max Richte, and Michael Driedger. 2011. Towards a new relationship with nature: Research and regenerative design in architecture. Experimental Green Strategies: Redefining Ecological Design Research 81 (6): 92.

Crandell, Gina. 2013. Tree gardens: Architecture and the forest.

Doan, Abigail. Biomimetic architecture: Green building in zimbabwe modeled after termite mounds. 2012 [cited 09/18 2014]. Available from http://inhabitat.com/building-modelledon-termites-eastgate-centre-in-zimbabwe/. 
Dollens, Dennis. 2005. Digital-botanic architecture.

El-Khoury, Rodolphe, Christos Marcopoulos, and Carol Moukheiber. 2012. The living, breathing, thinking, responsive buildings of the future. London: Thames \& Hudson.

Fortmeyer, Russell, and Charles Linn. 2014. Kinetic architecture: Design for active envelopes, ed. Driss Fatih. Victoria, Australia: The Images Publishing Group Pty Ltd.

Frichot, Hélène. 2008. Olafur eliasson and the circulation of affects and percepts: In conversation. Interior Atmospheres 78 (3): 30.

Gissen, David. 2010. The material transformations of AMID (CERO9) social oxygen balloons. Territory: Architecture Beyond Environment 80 (3): 40.

2010. Toxic territories. Territory: Architecture Beyond Environment 80 (3): 54.

2009. Subnature: Architecture's other environments, ed. Laurie Manfra. First Edition ed. New York: Princeton Architectural Press.

. 2003. Big \& green : Toward sustainable architecture in the 21st century, ed. David Gissen. New York: Princeton Architectural Press.

Holl, Steven, Juhani Pallasmaa, and Alberto Pérez-

Gómez. 2006. questions of perception : phenomenology of architecture. Second Edition ed. San Francisco, CA: William Stout Publishers.

Jones, Caroline. 2006. Sensorium : Embodied experience, technology, and contemporary art, ed. Caroline Jones. First Edition ed. Cambridge: The MIT Press.

Jürgen, Mayer, and Neeraj Bhatia. 2010. Arium: Weather + architecture, eds. Mayer Jürgen, Neeraj Bhatia. Ostfildern: Hatje Cantz.

Klassen, Filiz. 2009. Snow, rain, light, wind: Weathering architecture. Toronto: Ryerson University Faculty of Communication and Design. 
Le Corbusier. 1967. The radiant city: Elements of a doctrine of urbanism to be used as the basis of our machine-age civilization.

Manacorda, Francesco, Ariella Yedgar, and Barbican Art Gallery. 2009. Radical nature: Art and architecture for a changing planet, 1969-2009. London: Koenig Books Ltd.

Margonelli, Lisa. Collective mind in the mound: How do termites build their huge structures? 2014 [cited 09/20 2014]. Available from http://news.nationalgeographic. com/news/2014/07/140731-termites-mounds-insectsentomology-science/.

Mostafavi, Mohsen, and David Leatherbarrow. 1993. On weathering: The life of buildings in time. Cambridge: The MIT Press.

Oliveira, Ana Rosa, Alejandro Bahamon, and Sofia Cheviakof. 2000. Ecological architecture: Bioclimatic trends and landscape architecture in the year 2001. Trans. RichardLewis Rees, ed. Aurora Cuito. Barcelona, Spain: Paco Asensio.

Pawlyn, Michael. 2011. Biomimicry in architecture. London: Riba Publishing.

- 2011. Biomimicry in architecture. London: RIBA Publishing.

Peters, Terri. 2011. Ecology beyond buildings: Performancebased consumption and zero-energy research. Experimental Green Strategies: Redefining Ecological Design Research 81 (6): 124.

- 2011. Nature as measure: The biomimicry guild. Experimental Green Strategies: Redefining Ecological Design Research 81 (6): 44.

- 2010. ecoLogic studio. Territory: Architecture Beyond Environment 80 (3): 110.

Rahm, Philippe. 2009. Meteorological architecture. Architectural Design 79 (3): 30-41.

Rice, Charles. 2008. The atmosphere of interior urbanism: OMA at IIT. Interior Atmospheres 78 (3): 88.

Ripley, Colin, Geoffery Thün, and Kathy Velikov. 2012. The stratus project: Responsive interior atmospheres. Interiors: Design, Architecture, Culture 3 (1-2): 43. 
Roche, Francois, and R \& Sie (Architectural Firm). 2006. Fiction scripts. Beijing: AADCU Publication.

Ruby, Andreas, Benoi^t Durandin, and R \& Sie (Architectural Firm). 2004. Spoiled climate: R\&Sie, architects, ed. Andreas Ruby. Basel: Birkhauser.

Shepard, Mark. 2011. Sentient city: Ubiquitous computing, architecture, and the future of urban space, ed. Mark Shepard. New York: The Architectural League of New York, The MIT Press.

Spuybroek, Lars. 2008. The architecture of continuity. New York: Distributed Art Publishers.

- 2004. Nox: Machining architecture. New York: Thames \& Hudson.

Vitruvius Pollio, and Morris Hicky Morgan. 1960. Vitruvius: The ten books on architecture. New York: Dover Publications Inc.

Wagenfeld, Malte. 2008. The aesthetics of air: Experiments in visualising the invisible. Interior Atmospheres 78 (3): 20.

Yamanashi, Tomohiko, Tatsuya Hatori, Yoshito Ishihara, and Norihisa Kawashima. 2011. BIO SKIN: Urban cooling facade. Experimental Green Strategies: Redefining Ecological Design Research 81 (6): 100.

Yannas, Simos. 2011. Adaptive strategies for an ecological architecture. Experimental Green Strategies: Redefining Ecological Design Research 81 (6): 62.

Yeang, Ken. 2008. Biofuel from algae. Interior Atmospheres 78 (3): 118.

Zumthor, Peter. 2006. Atmospheres: Architectural environments surrounding objects. Basel, Switzerland: Birkhäuser. 
Appendix 


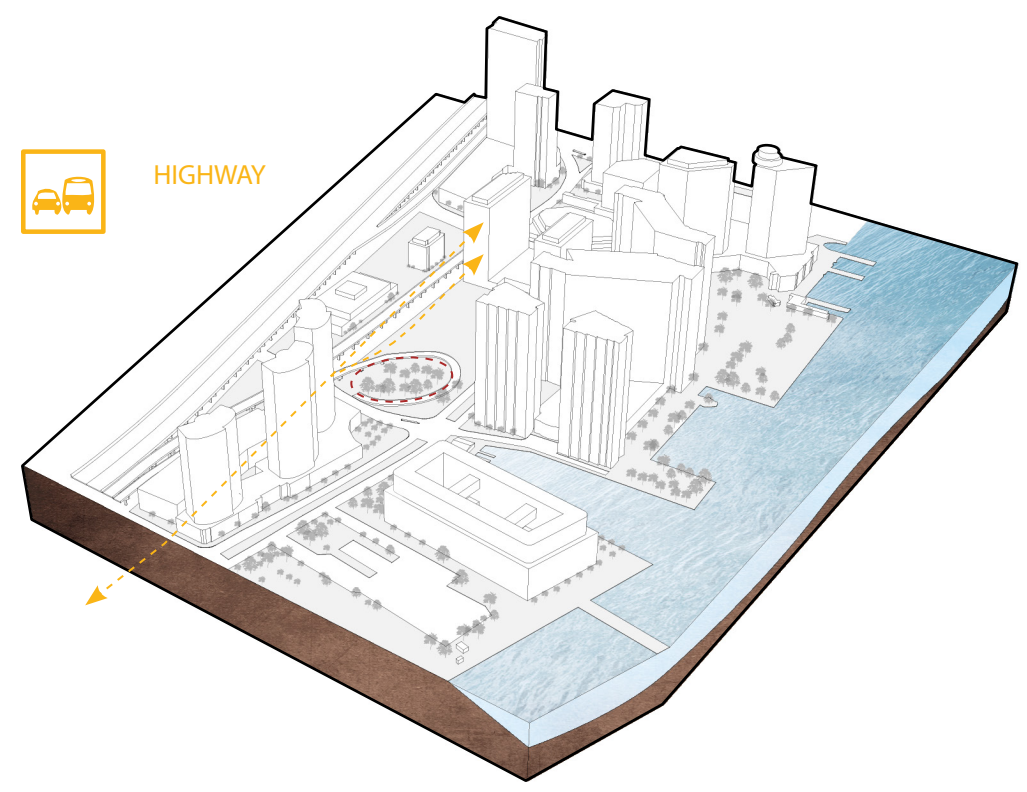

I SITE SURROUNDED BY GARDINER ON AND OFF RAMP

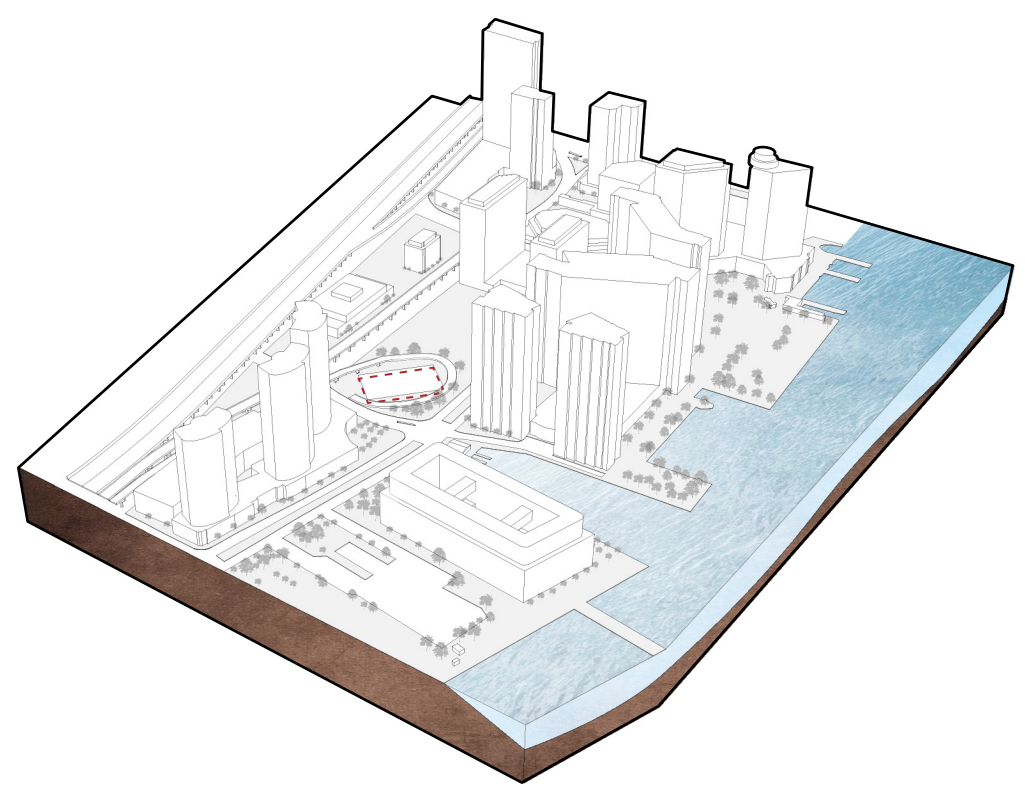

I ORIENT THE SITE TOWARDS THE SOUTH AND LOWER PART OF OFFRAMP

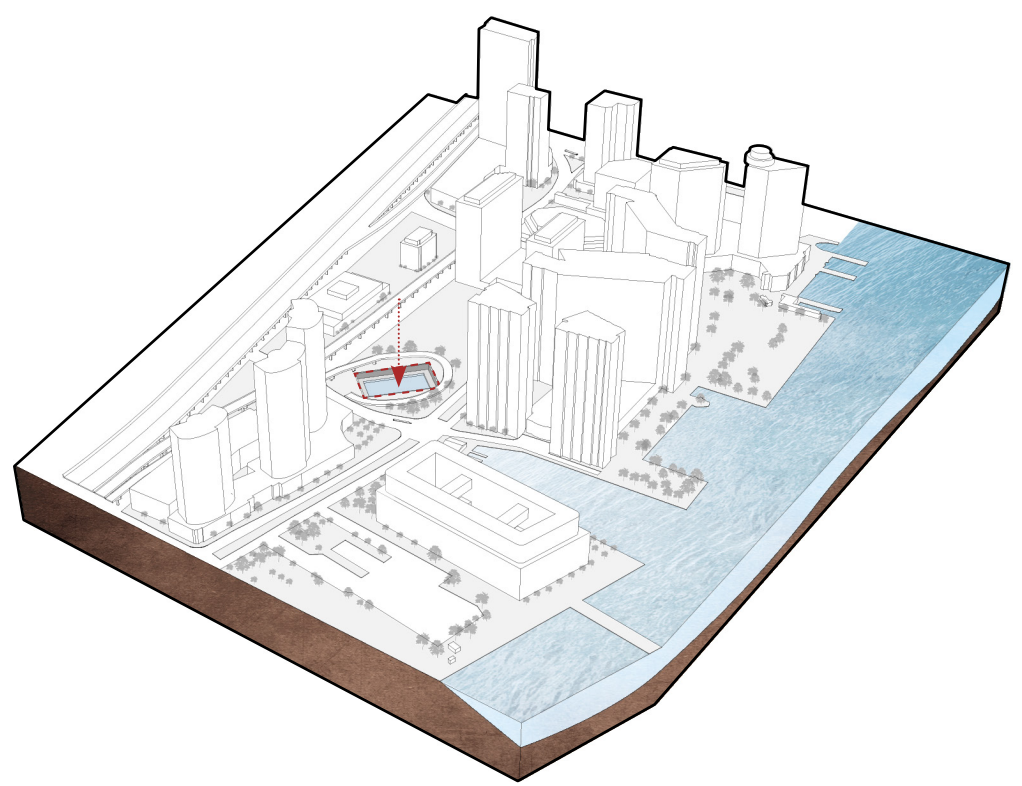




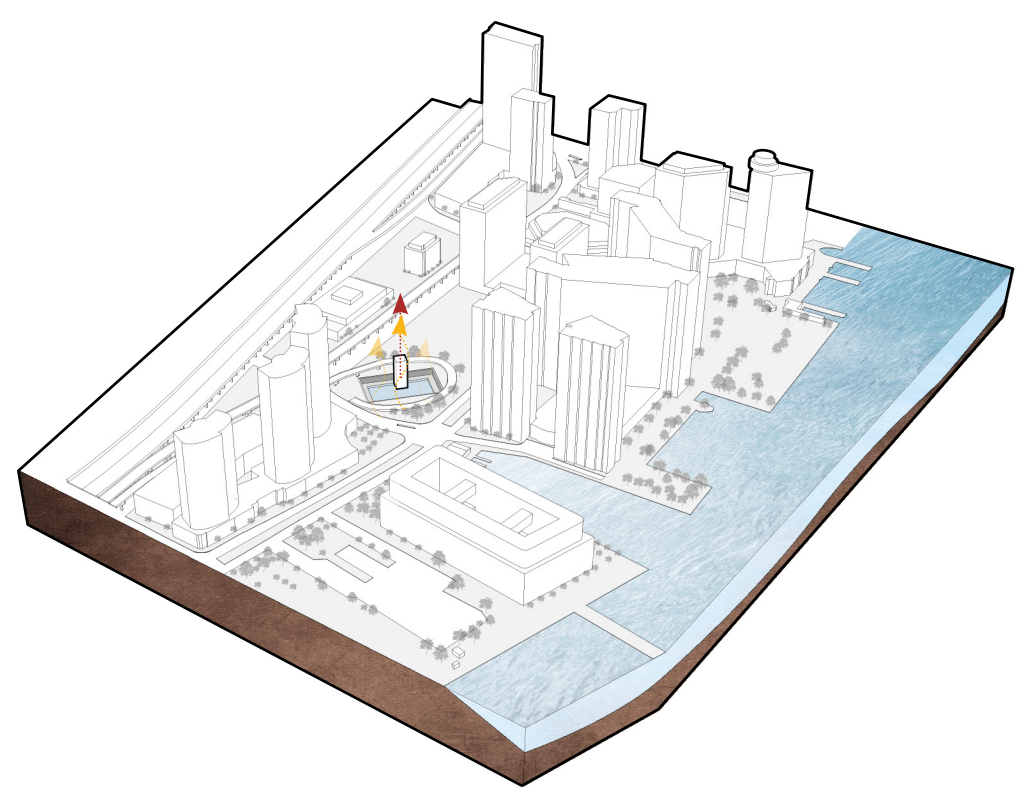

I CENTRAL SOLAR CHIMNEY TO EXHAUST STALE AIR OVER POOL

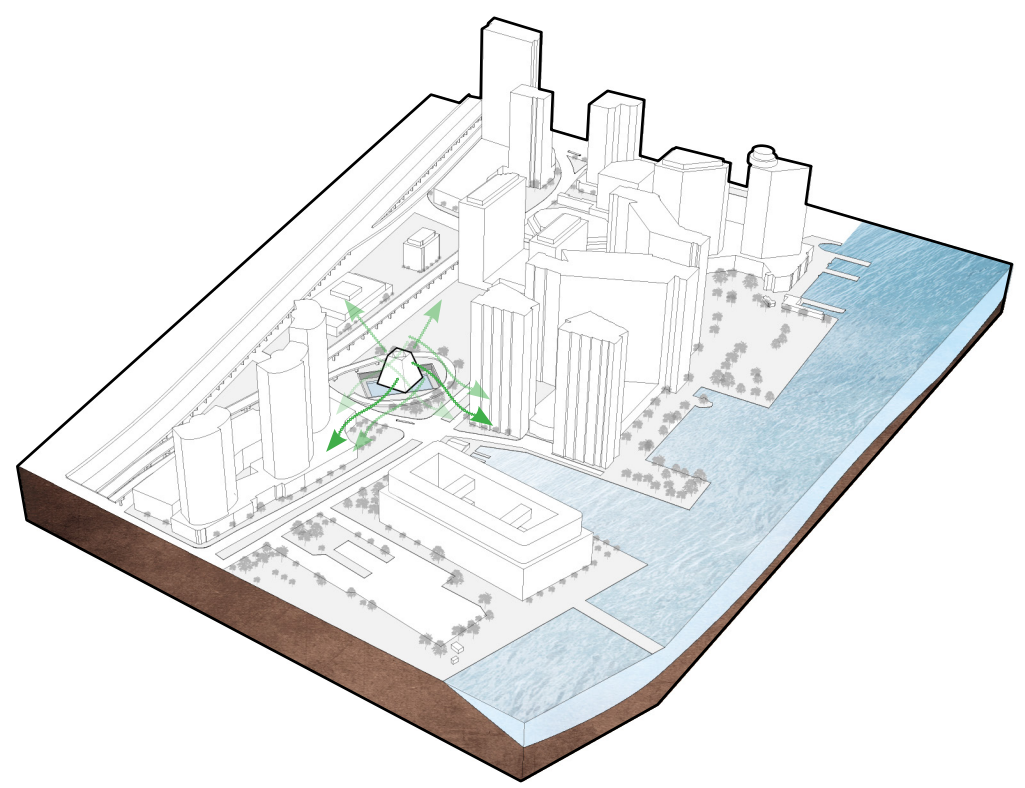

I INCREASED SURFACE AREA TO EXTERIOR FACADE TO FILTER SURROUNDING AIR

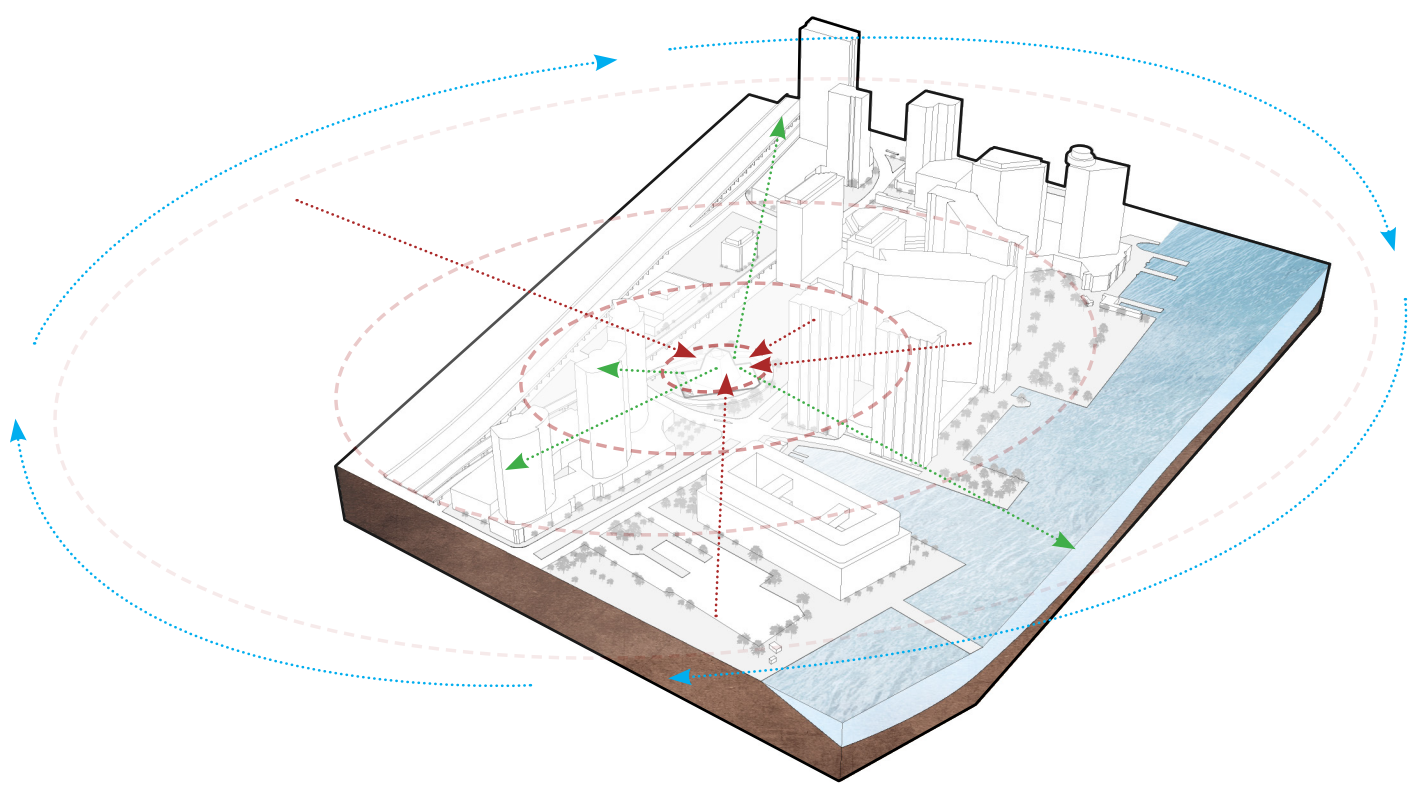

I GARDINER ON AND OFF RAMP AS CENTER OF CITY'S RESPIRATION SYSTEM 


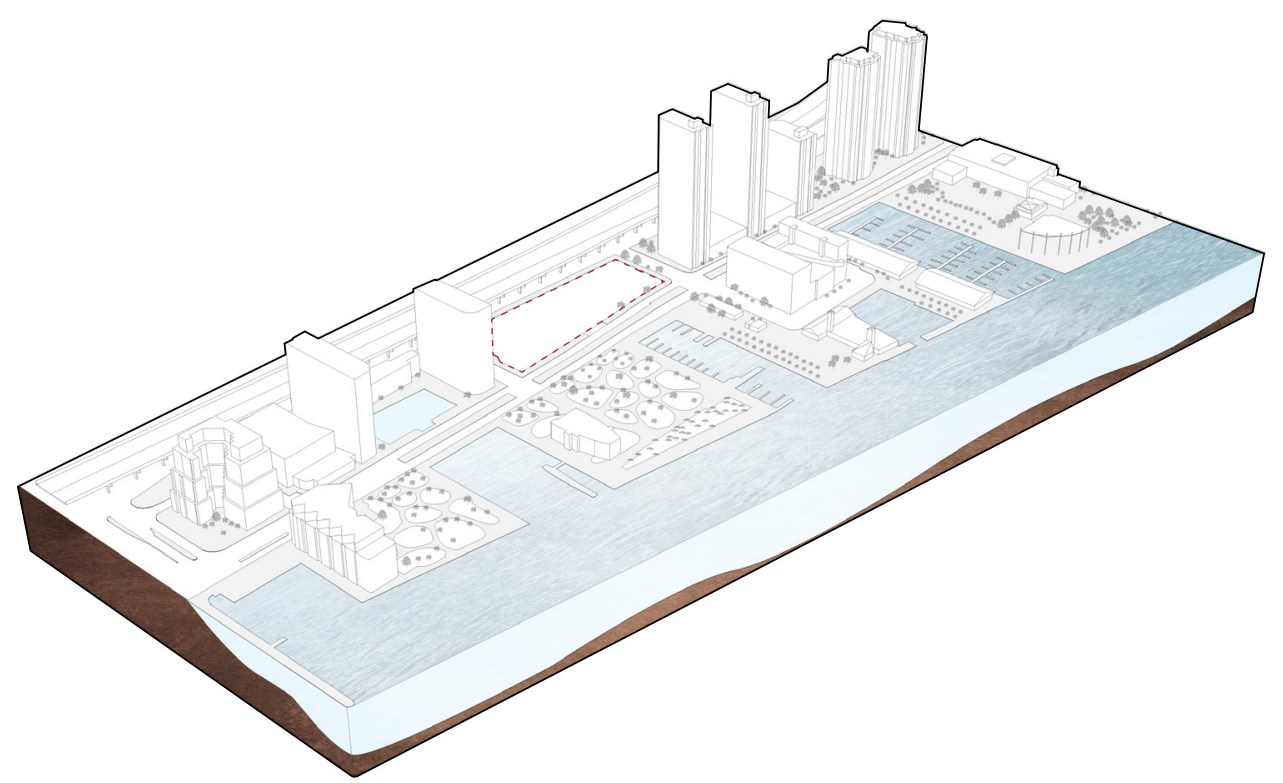

I SITE AMONGST A DENSE CONDOMINIUM DEVELOPMENT NEIGHBOURHOOD

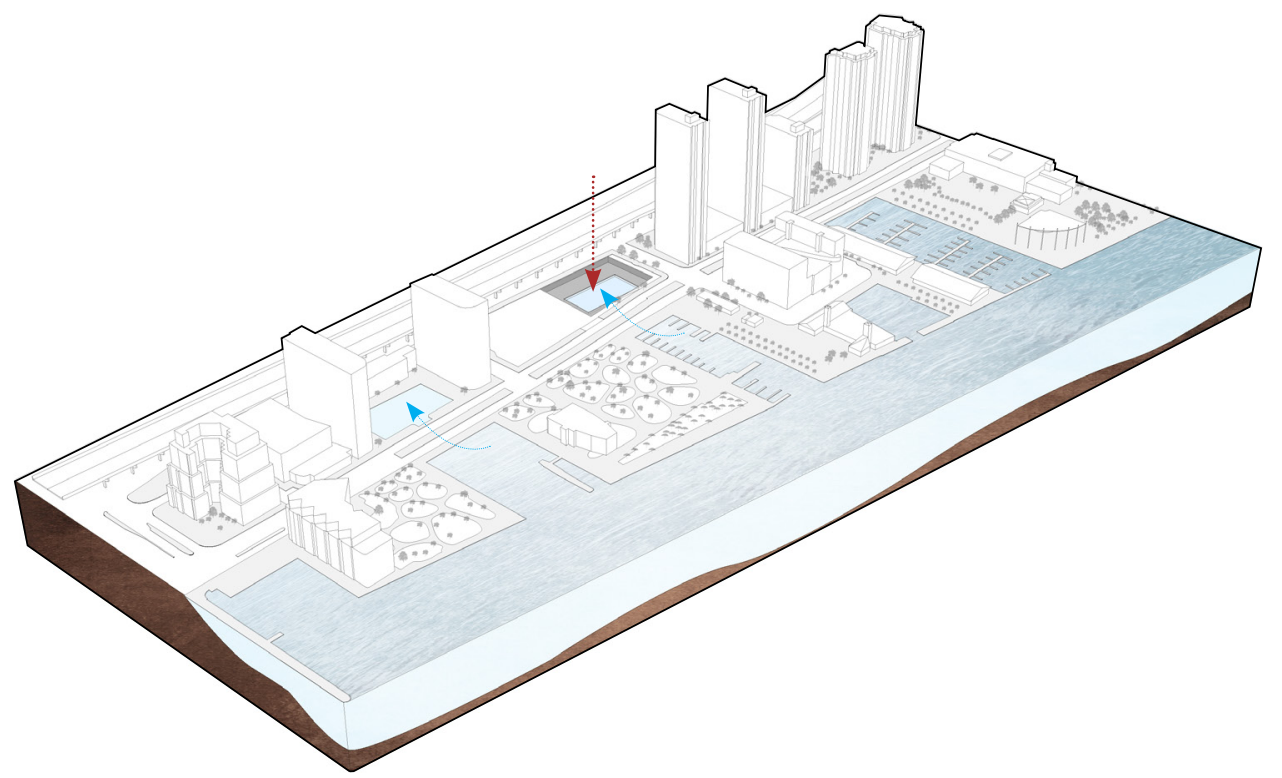

I SINKING THE SITE TO NATURALLY INSULATE INTERIOR AIR. POOL TO DRAW WATER FROM THE SHORELINE TO FILTER

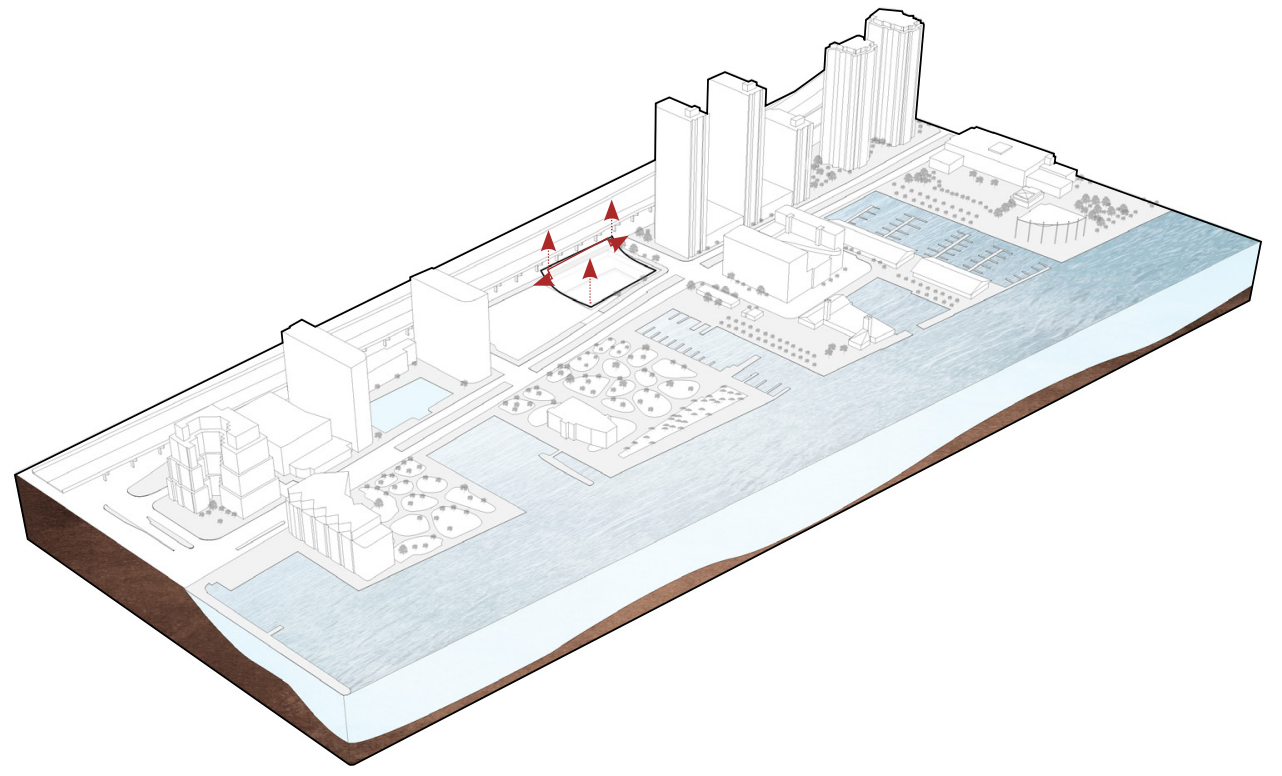

I SLOPING THE ROOF TO BACK AGAINST THE HIGHWAY TO ACT AS A BARRIER TO POLLUTED AIR FROM THE GARDINER 


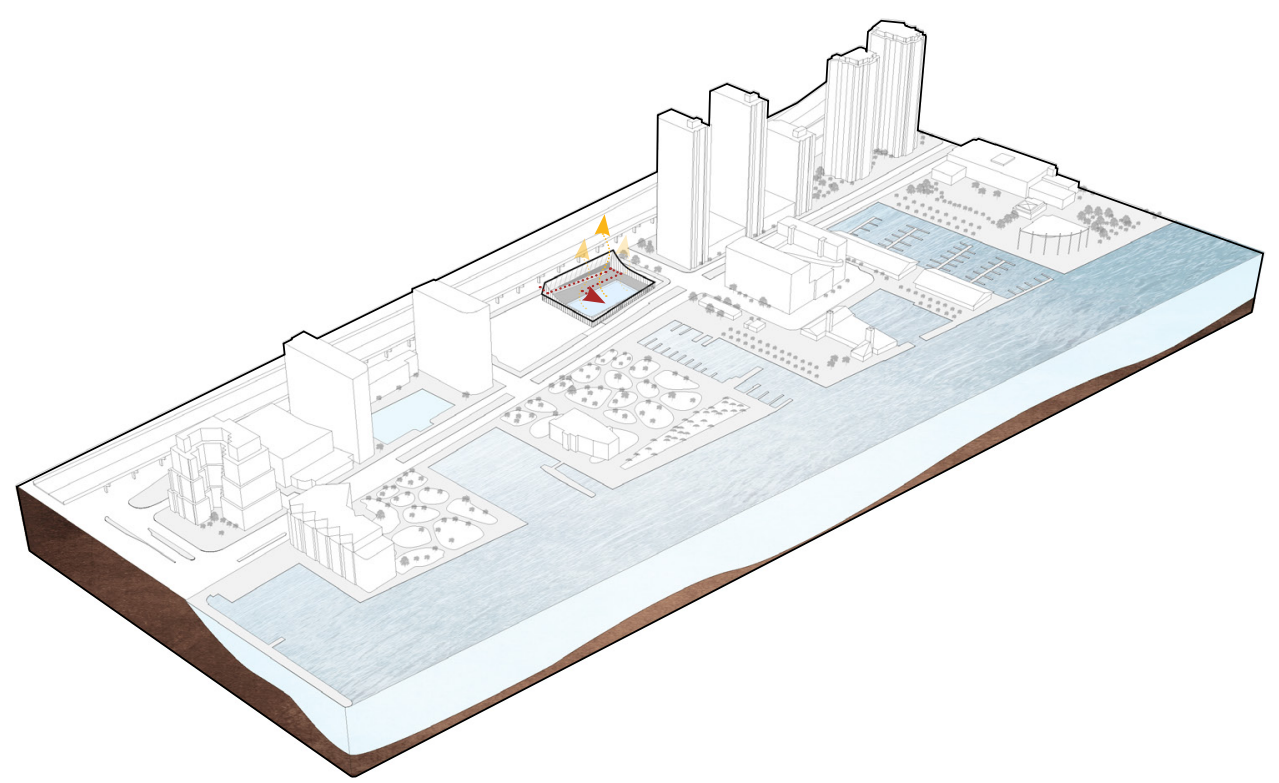

I USING THE POOL'S HUMIDITY TO FILTER THE GREEN ROOF

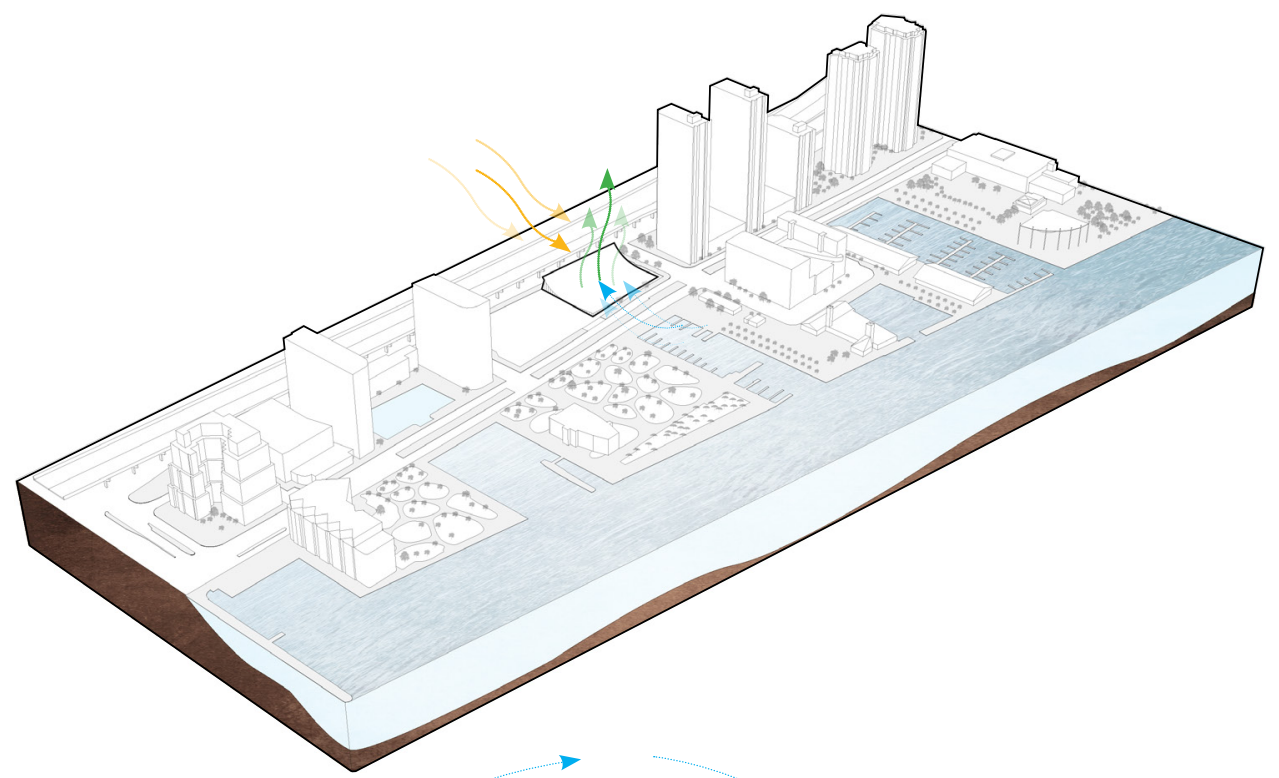

I BUILDING TO BLOCK OFF AND FILTER POLLUTED AIR AND CATCH PREVAILING WINDS FROM LAKE EFFECT

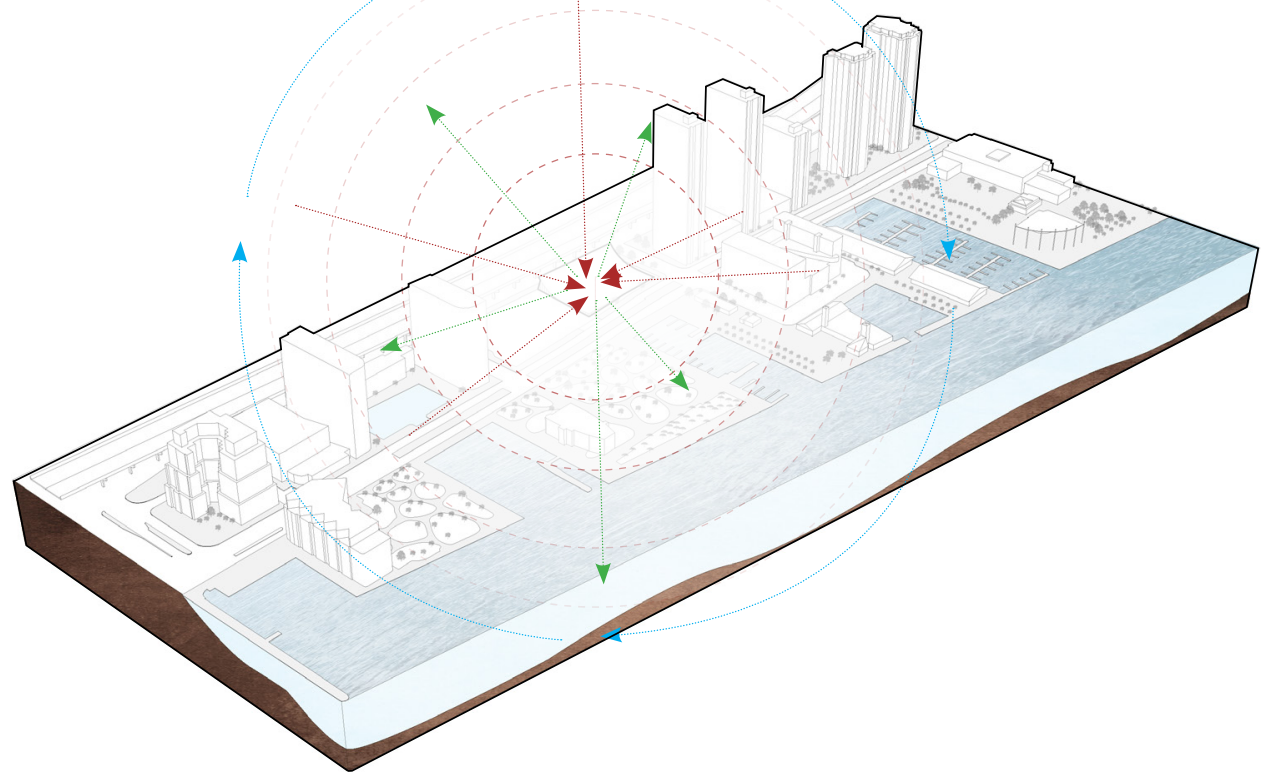

I AQUATIC CENTRE AS CENTER OF THE CONDOMINIUM DEVELOPMENT'S RESPIRATION SYSTEM 


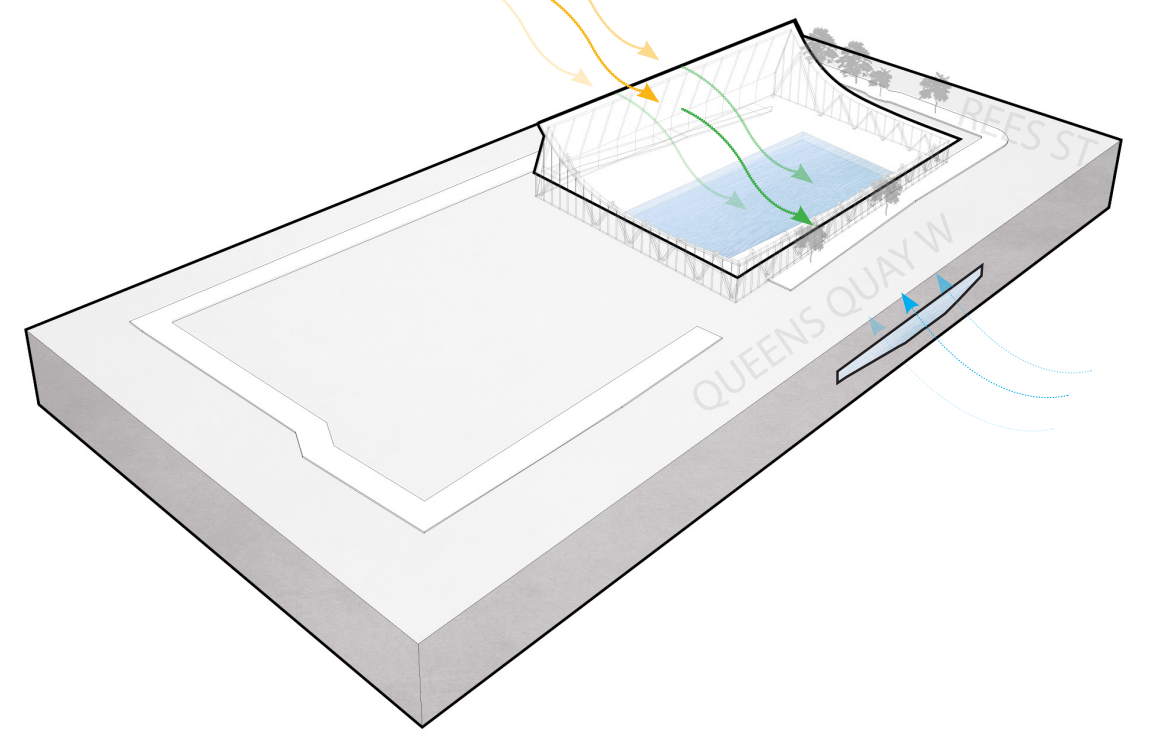

I BUILDING TO BE THE CENTRAL RESPIRATORY SYSTEM IN BOTH MICRO AND MACRO SCALE OF THE CITY
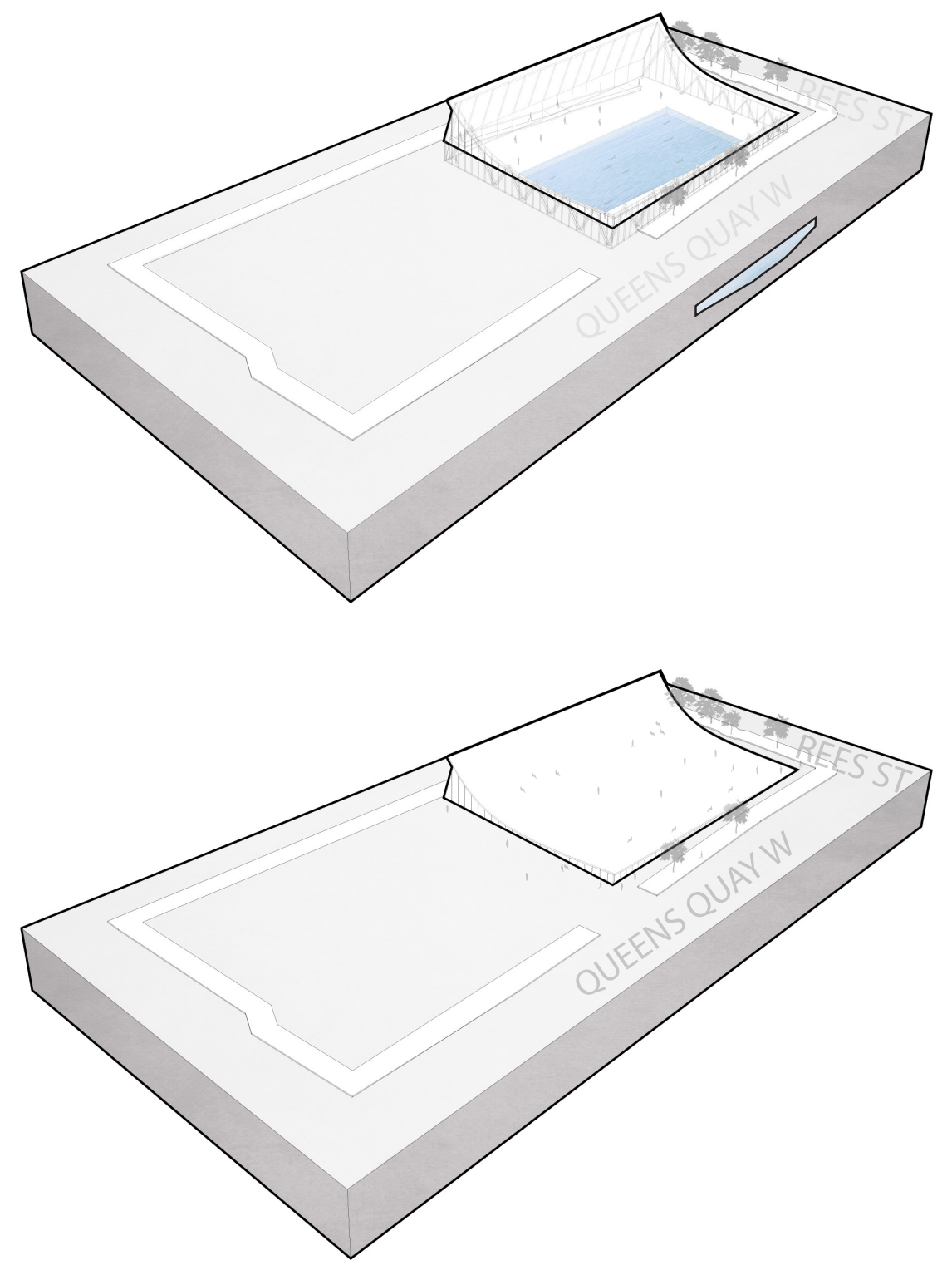

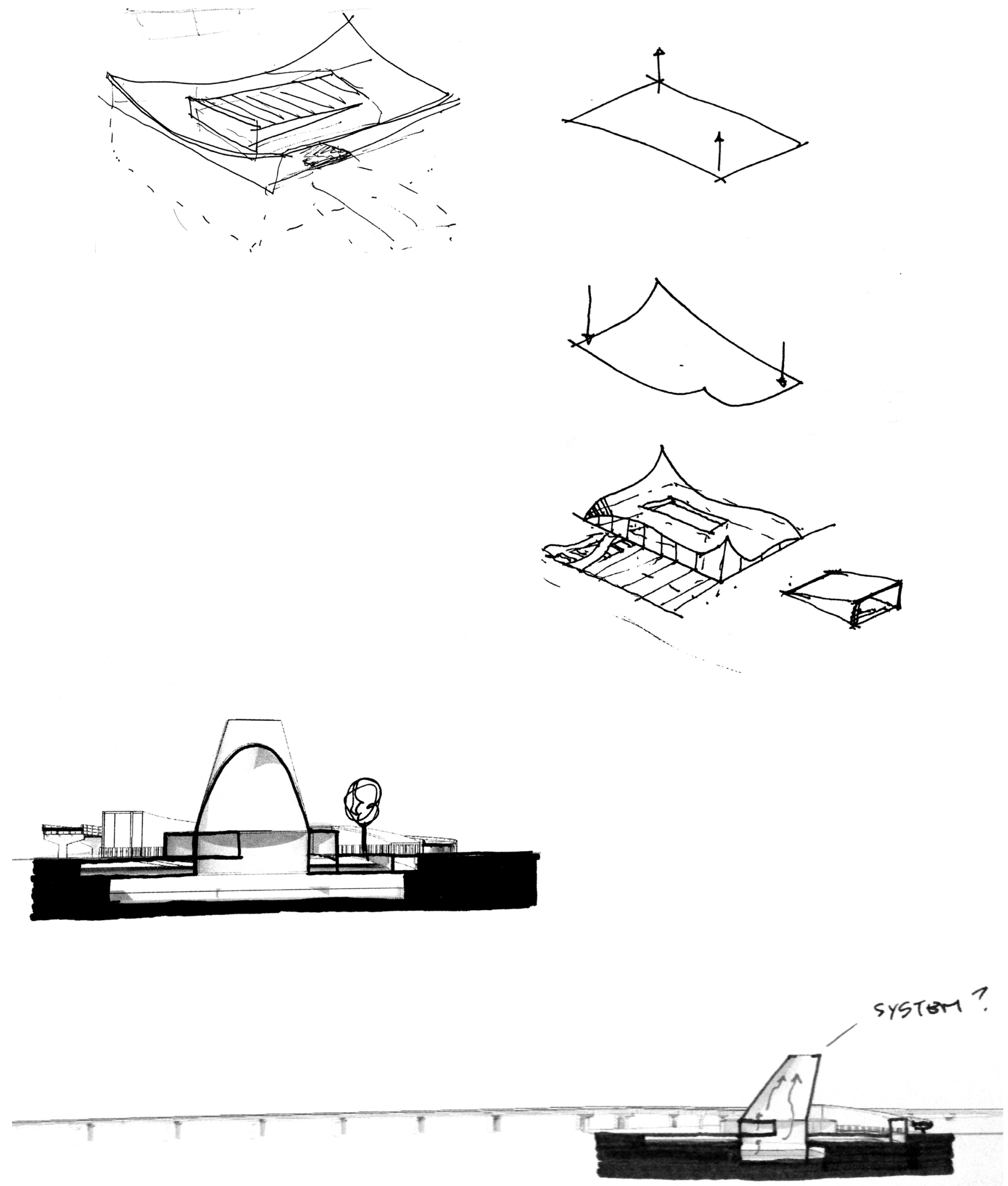


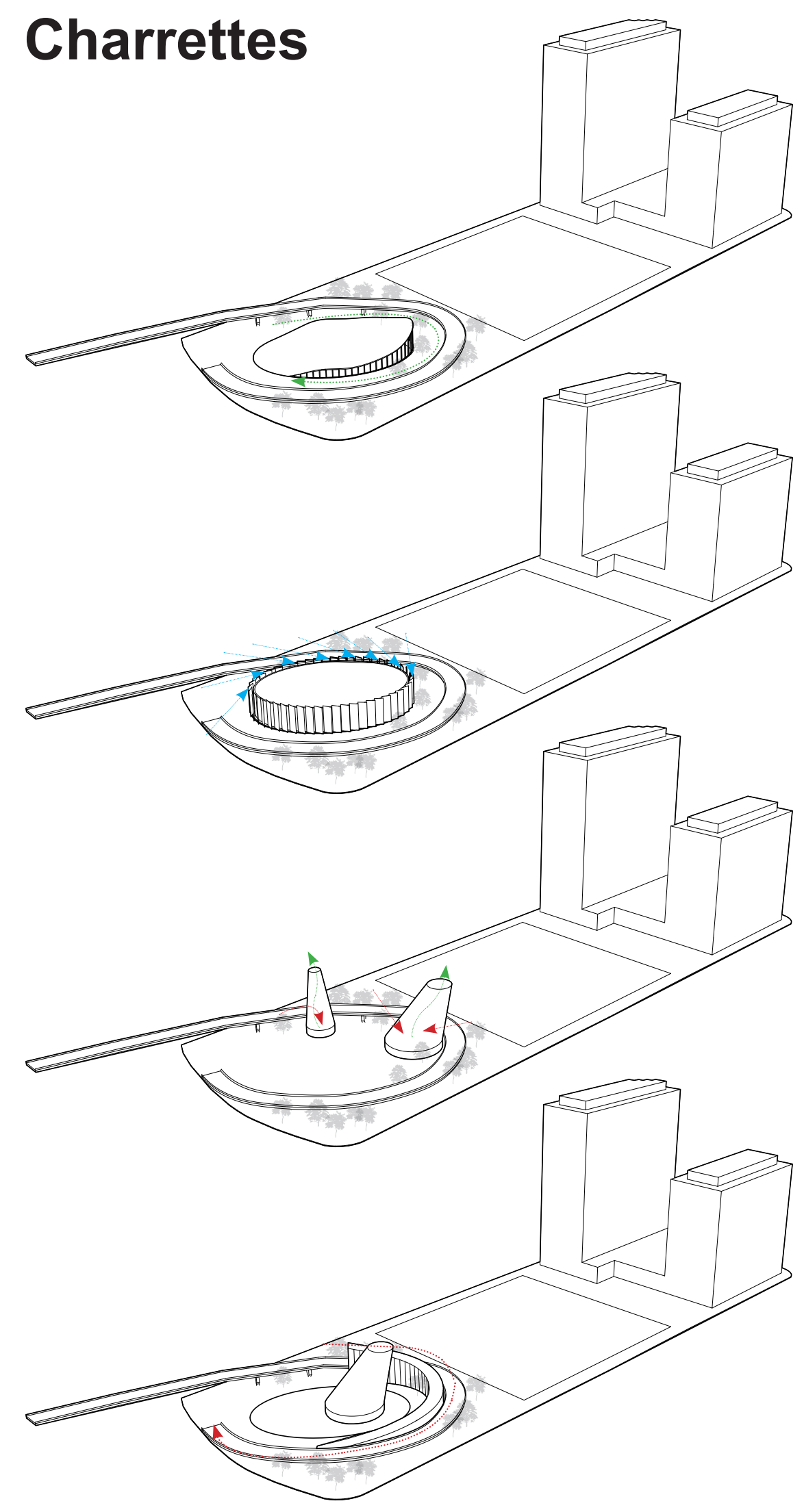




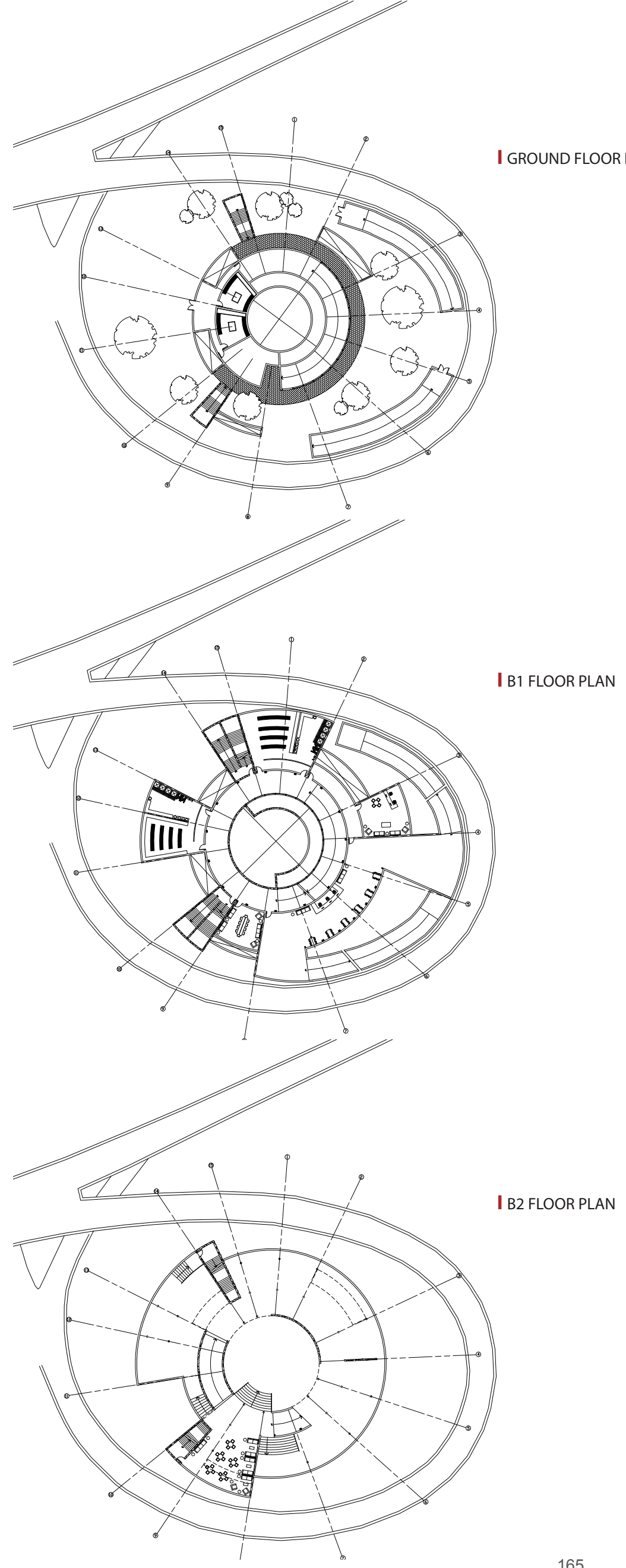



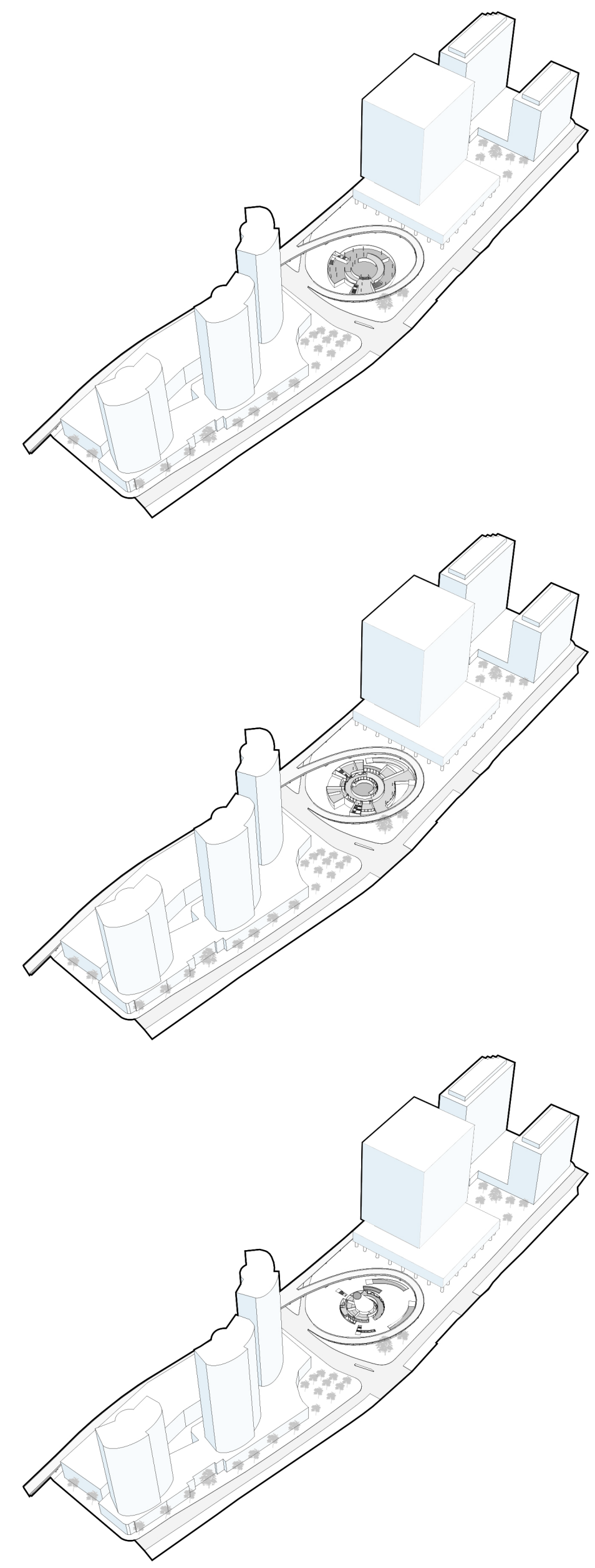

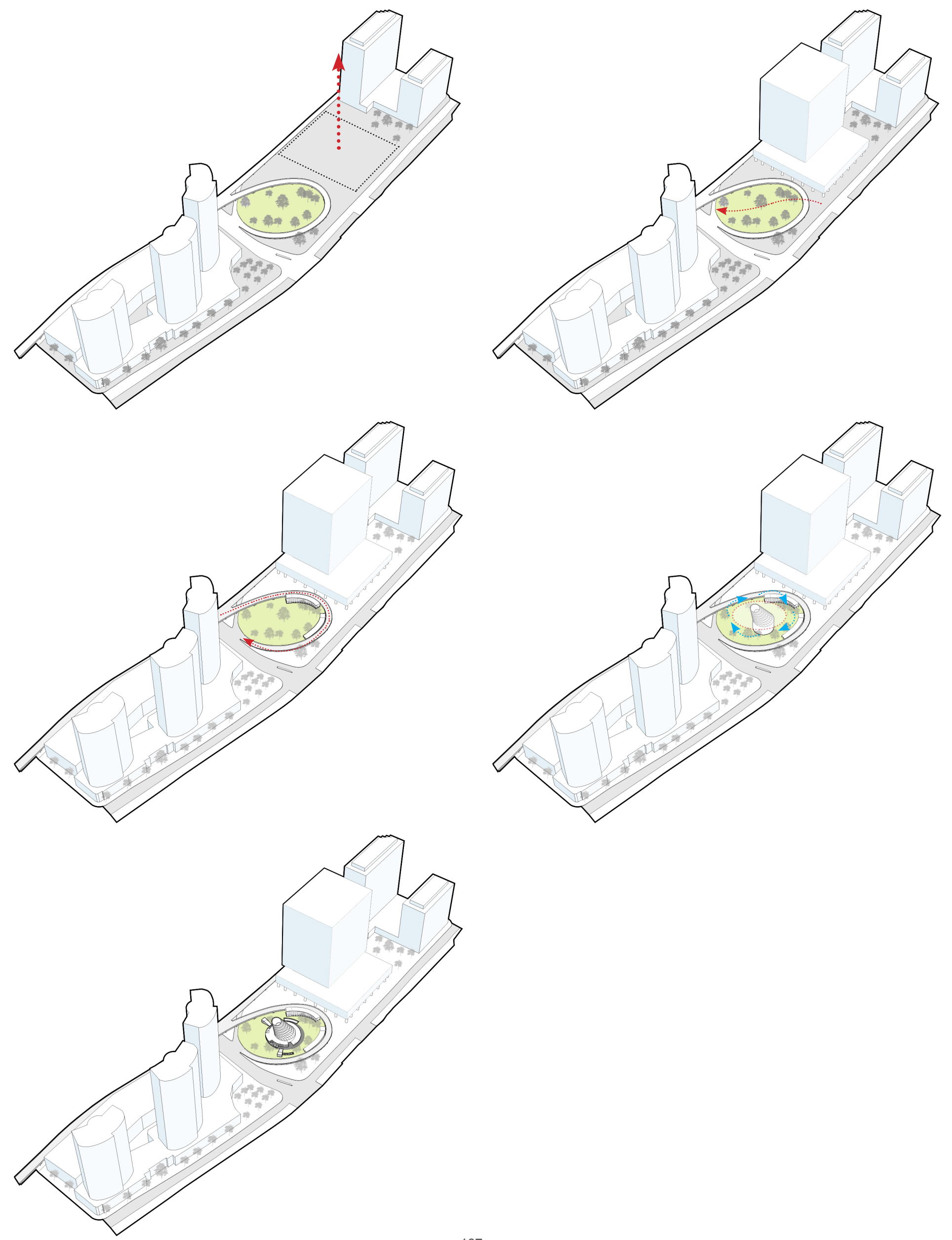

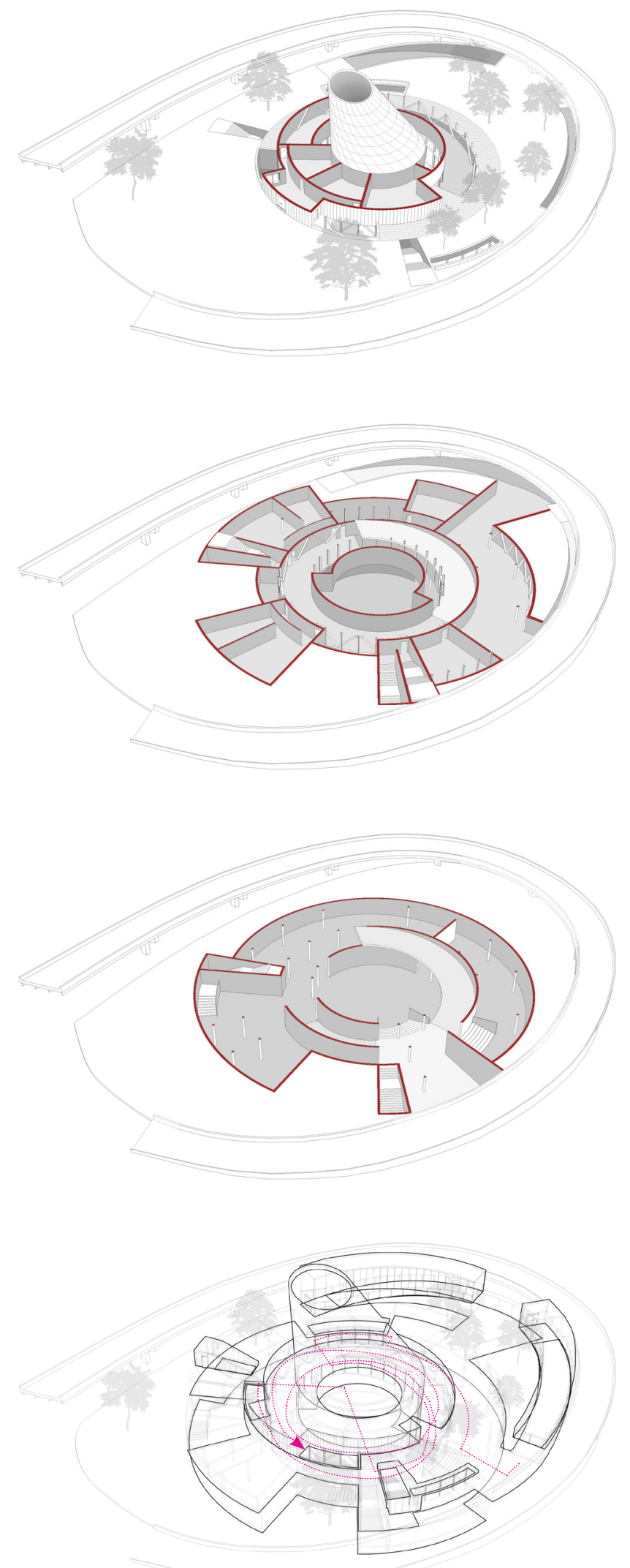
